\title{
Muscle wasting in COPD : a metabolic and functional perspective
}

Citation for published version (APA):

Engelen, M. P. K. J. (2000). Muscle wasting in COPD : a metabolic and functional perspective. [Doctoral Thesis, Maastricht University]. UM. https://doi.org/10.26481/dis.20001222me

Document status and date:

Published: 01/01/2000

DOI:

10.26481/dis.20001222me

Document Version:

Publisher's PDF, also known as Version of record

\section{Please check the document version of this publication:}

- A submitted manuscript is the version of the article upon submission and before peer-review. There can be important differences between the submitted version and the official published version of record.

People interested in the research are advised to contact the author for the final version of the publication, or visit the DOI to the publisher's website.

- The final author version and the galley proof are versions of the publication after peer review.

- The final published version features the final layout of the paper including the volume, issue and page numbers.

Link to publication

\footnotetext{
General rights rights.

- You may freely distribute the URL identifying the publication in the public portal. please follow below link for the End User Agreement:

www.umlib.nl/taverne-license

Take down policy

If you believe that this document breaches copyright please contact us at:

repository@maastrichtuniversity.nl

providing details and we will investigate your claim.
}

Copyright and moral rights for the publications made accessible in the public portal are retained by the authors and/or other copyright owners and it is a condition of accessing publications that users recognise and abide by the legal requirements associated with these

- Users may download and print one copy of any publication from the public portal for the purpose of private study or research.

- You may not further distribute the material or use it for any profit-making activity or commercial gain

If the publication is distributed under the terms of Article $25 \mathrm{fa}$ of the Dutch Copyright Act, indicated by the "Taverne" license above, 


\section{Muscle wasting in COPD:}

a metabolic and functional perspective

Mariëlle Engelen 
Cover design: Gabriëlla Cleuren, St. Niklaas, België Druk: Febodruk, Enschede

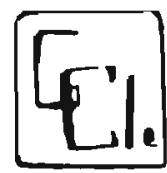

ISBN nr: $90-9014371-8$

The study presented in this thesis was performed at the Nutrition and Toxicology Research Institute Maastricht (NUTRIM), which participates in the Graduate School VLAG (Food Technology, Agrobiotechnology, Nutrition and Health Sciences), accredited by the Royal Netherlands Academy of Arts and Sciences (KNAW). 


\section{Muscle wasting in COPD:}

\section{a metabolic and functional perspective}

\section{Proefschrift}

ter verkrijging van de graad van doctor aan de Universiteit Maastricht, op gezag van de Rector Magnificus, Prof. Dr. A.C. Nieuwenhuijzen Kruseman volgens het besluit van het College van Decanen in het openbaar te verdedigen op vrijdag 22 december 2000 om 14.00 uur

door

Mariëlle Petra Karin Josee Engelen 
Table of contents 


\section{Promotor}

Prof. Dr. E.F.M. Wouters

\section{Co-promotor}

1)r. Ir. A.M.W.J. Schols

\section{Beoordelingscommissie}

Prof. Dr. W.H.M. Saris (voorzitter)

Prof. Dr. A. Bast

Prof. Dr. J.A. Romijn (Leids Universitair Medisch Centrum)

Prof. Dr. G.J. van der Vusse

Prof. Dr. K. Wasseman (Harbor U.C.L.A. Medical Center, U.S.A.)

The studies described in this thesis were supported by a research grant from the University Hospital Maastricht and a research fellowship from the European Society of Parenteral and Enteral Nutrition. The publication of this thesis was financially supported by: Stichting Hornerheide, Stichting Pulmonologie, Glaxo Wellcome Nederland BV, Dr. ir. J.H.J. van de Laar stichting, Nutricia Nederland BV, Zambon Nederland BV. 
Aan: mijn ouders

Opa Wilms (posthuum) 
Chapter 2 Dual-energy X-ray absorptiometry in the clinical evaluation of body composition and bone mineral density in patients with chronic obstructive pulmonary disease

Chapter 3 Different patterns of chronic tissue wasting among patients with chronic obstructive pulmonary disease

Chapter 4 Skeletal muscle weakness is associated with extremity fatfree mass wasting but not with airflow obstruction in patients with COPD

\section{PART 2: Protein metabolism}

Chapter 5 Enhanced whole body protein turnover at rest in patients with chronic obstructive pulmonary disease

Chapter 6 Suppressed response in whole body protein turnover to exercise in patients with emphysema

PART 3: Amino acid status of the peripheral skeletal muscle at rest and during exercise

Chapter 7 Factors contributing to alterations in skeletal muscle and plasma amino acid profiles in patients with chronic obstructive pulmonary disease

Chapter 8 Altered glutamate metabolism is associated with reduced muscle glutathione levels in patients with emphysema

Chapter 9 Exercise-induced lactate increase in relation to muscle substrates in patients with chronic obstructive pulmonary disease

Chapter 10 Effects of exercise on amino acid metabolism in patients with chronic obstructive pulmonary disease 
Chapter 11 General discussion

Summary / Samenvatting 179

Abbreviations

Dankwoord

Publicaties 195

Curriculum vitae 


\section{CHAPTER 1}

General introduction 


\section{INTRODUCTION}

\section{Chronic obstructive pulmonary disease}

Chronic obstructive pulmonary disease (COPD) represents an important health care problem. COPD is the fourth leading cause of death in the Netherlands and will be the third leading cause worldwide in 2020 , with an expected mortality of 4.7 million persons annually. Roughly 73 per 1000 persons are diagnosed as having COPD in the Netherlands. Clinical characteristics of COPD, namely a rapid decline in lung function or persistently decreased lung function, are observed in $20 \%$ of the general adult population in the Netherlands (1). Moreover, the total COPD-related medical costs are a major burden for the Dutch health care system. The direct costs of COPD represent $1.3 \%$ of the Dutch health care budget and are expected to increase by $60 \%$ in the near future, mostly due to aging of the population (2). Currently, long-term tobacco smoking is a causal factor in more than $90 \%$ of the patients in westemized societies.

The most important complaints of patients with COPD are exercise intolerance and dyspnea at exertion and in later stages also at rest. During the last decade, research has shown that primary lung failure is not the only factor contributing to these symptoms. Besides airflow obstruction and alveolar wall destruction, skeletal muscle dysfunction has been shown to be an important determinant of dyspnea and exercise intolerance (3). This indicates the importance of considering systemic impairment in the treatment of COPD. In order to optimize the effectiveness of COPD treatment and management, more insight is needed into the specific factors of local and systemic impairment which underlie skeletal muscle dysfunction, as well as its interrelationship.

\section{Local impairment in COPD}

COPD is a complex clinical situation having as a common factor smoking-related, fixed airtlow limitation, which does not change markedly over periods of several months of observation (4). COPD is characterized by reduced maximum expiratory flow, which is usually irreversible, and slow forced emptying of the lungs (5). Moreover, the airflow obstruction shows an abnormal rapid progressive deterioration with age. Although progression can be slowed by medication, reversal can only be (partially) achieved through surgical interventions and transplantation. The presence of airflow obstruction in COPD is due to emphysema and/or chronic bronchitis (4). It is clinically difficult to distinguish emphysema from chronic bronchitis because of the similar symptoms of shortness of breath, cough and wheezing. In a substantial proportion of patients, a combination of the characteristics ascribed to either chronic bronchitis or emphysema is present.

Chronic bronchitis is defined on clinical criteria as recurrent excessive mucus production in the bronchial tree occurring on most days for at least three months of 
the year for at least two successive years in a patient in whom other causes of cough have been excluded (6). The pathology of chronic bronchitis primarily includes large airway mucus gland hyperplasia and inflammation. Although not included in the definition of chronic bronchitis, chronic airflow obstruction is commonly present.

In contrast to chronic bronchitis, emphysema is a pathological entity defined by the American Thoracic Society as a condition of the lung characterized by abnormal permanent enlargement of airspaces distal to the terminal bronchioles accompanied by destruction of their walls and without obvious fibrosis (5). Destruction is defined as non-uniformity in the pattern of respiratory airspace enlargement. The mechanisms of airflow limitation in emphysema involve emphysematous destruction of parenchymal support of the peripheral airways and/or loss of elastic recoil force driving air out of the lung. In addition to the decreased expiratory airflow, chronic hyperinflation is present predominantly in patients with emphysema, which is a major determinant of the perception of dyspnea (7). Chronic hyperinflation is characterized by an abnormal increase in functional residual capacity, due to changes in the elastic properties of the lungs and chest wall (8). Chronic hyperinflation increases the rib cage contribution to chest wall motion, whilst it reduces the abdominal contribution. The diaphragm adapts to the chronically hyperinflated state of the lung by flattening. As a consequence, this reduces its force generating capacity leading to a reduction in the mechanical advantage of the diaphragm (9). Hyperinflation may worsen during exercise (dynamic hyperinflation), which is the result of the onset of inspiration before lung volume has fallen to the relaxation volume of the respiratory system (air trapping).

In addition. the structural changes of the lung parenchyma in emphysema result in a decreased diffusing capacity of the lung, and thereby an impaired gas exchange. The efficiency of gas exchange is dependent on the balance between alveolar ventilation and pulmonary blood flow (perfusion). Impaired oxygenation of the blood especially occurs in emphysema, due to destruction of gas exchange units, but is also present in chronic bronchitis, due to regions of appreciable ventilation to perfusion mismatch.

Airflow limitation on spirometry and disturbance of gas exchange, manifested by reduced single-breath carbon monoxide diffusing capacity $\left(\mathrm{Dl}_{\mathrm{co}}\right)$ have been proposed as the most accurate and specific pulmonary function tests for pulmonary emphysema (10). The impairment of $\mathrm{Dl}_{c o}$ present in emphysema may arise from breakdown of alveolo-capillary surface area, the concomitant loss of pulmonary arteries leading to impairment of diffusion in the enlarged airspaces and decreased diffusion of carbon monoxide into pulmonary blood. $\mathrm{Dl}_{\text {co }}$ gives a physiologic reflection of the integrity of the alveolo-capillary membrane, and is therefore considered to be an indirect marker of emphysema. A drawback of $\mathrm{Dl}_{\mathrm{co}}$ is that it provides only a very imprecise quantification of the grade of emphysema as in the upper zones of the lungs extensive destruction may occur before functional abnormalities become evident (11). Moreover, $\mathrm{Dl}_{\mathrm{co}}$ is decreased in a number of other pulmonary disorders (12). 
Recently, high-resolution computed tomography (HRCT) was introduced, which allows direct demonstration of the presence, extent and severity of macroscopic emphysema (12). HRCT is considered the most accurate imaging method for diagnosing emphysema in vivo $(13,14)$. Furthermore, the findings closely correlate with pathologic findings. There are two ways to quantify the extent of emphysema using HRCT; by visual inspection for areas of emphysematous destruction, and by quantitative analysis of the density of the lung.

\section{Systemic impairment in COPD}

\section{Reduced exercise capacity and muscle function}

Impaired exercise tolerance is a common manifestation of patients with COPD. Patients with COPD have derangements in respiratory mechanics that may cause them to stop exercise before the exercising limb muscles reach their functional limits. However, recently, the dominant symptoms limiting exercise tolerance during incremental cycle ergometry, in both health and disease were found to be sensation of leg fatigue and dyspnea (15). In line, Killian demonstrated that sensation of dyspnea and leg fatigue are the two dominant symptoms limiting exercise tolerance in COPD (16). The severity of airflow obstruction is only weakly associated with maximal oxygen uptake (17), indicating that other (ie, peripheral) factors are responsible for the decreased exercise capacity of COPD. In accordance with this, Gosselink (18) show'ed that peripheral skeletal muscle weakness, which is commonly present in COPD $(15,18)$, significantly contributes to the decreased exercise capacity in patients with COPD. In a recent study by Mador and colleagues (19), in which the femoral nerve was supramaximally stimulated, quadriceps twitch force fell significantly 10 minutes after high intensity exercise (at $60-70 \%$ of their predicted maximal work rate) until exhaustion. This indicates that contractile fatigue of the quadriceps femoris muscle occurs after a bout of high intensity exercise to the limits of tolerance. This suggests that fatigue of the muscles of locomotion should be considered as playing a role in the limitation of exercise tolerance in COPD.

In a large study, Hamilton et al. (15) found that approximately $70 \%$ of patients with chronic lung disease had lower quadriceps strength than the mean value obtained in normal subjects of similar age. The reduction in quadriceps strength averaged $20-30 \%$ in patients with severe to moderate disease $(15,18,20)$. Significant lower values have also been found in maximal muscle strength of the pectoralis major, latissimus dorsi, adductor pollicis and in handgrip strength in COPD patients compared with control subjects. However, in general, the upper limb strength of COPD patients was relatively preserved compared to that of the lower limbs $(18,21)$. The uneven distribution of muscle weakness between upper and lower limbs could be related to the fact that upper limb muscles are probably more normally involved in activities of daily living than lower limb muscles. The information on limb muscle endurance in patients with COPD is limited and conflicting. Endurance of the vastus lateralis muscle has been reported to be normal in hypoxemic patients with COPD (22), which is surprising when taking into account the morphologic and enzymatic deficiencies found in the 
vastus lateralis muscle of these patients (see below). In contrast, other investigators found a $50 \%$ reduction in dynamic endurance of the vastus lateralis muscle in 17 patients with COPD when compared with age-matched control normal subjects (23). Moreover, both normal static endurance of the elbow flexors (24) and reduced endurance of the adductor pollicis muscle (22) have been reported. Discrepant results between studies may be related in part to differences in methodology used to measure peripheral muscle endurance.

\section{Body' weight loss and muscle wasting}

The association between weight loss and severe COPD has long been recognized. Weight loss was generally considered a terminal progression in the disease process and therefore inevitable and irreversible. Furthermore, it was even suggested that weight loss is an adaptive mechanism to decrease oxygen consumption. However, in the last decade, several studies have challenged this attitude and showed that weight loss and a low body weight are associated with increased morbidity and mortality $(25,26)$. Little or no correlation was present with the degree of lung function impairment (26).

Since 1981 several studies have investigated the prevalence of nutritional depletion in COPD. Depending on the patient population analyzed, $25-48 \%$ of the clinically stable COPD patients eligible for pulmonary rehabilitation, and $20 \%$ of stable COPD out-patients were found to be underweight (27-32).

Body weight is a rather global measure of nutritional depletion and does not take into account differences in body composition among individuals. Whereas body weight consists of fat mass and fat-free mass (FFM), FFM reflects the quantity of actively metabolizing (liver, gut, immune system) and contracting (muscle) tissue.

Depletion of FFM commonly occurs in patients with COPD. FFM depletion is a significant problem in $35 \%$ of severe COPD patients eligible for pulmonary rehabilitation (32) but also in $20 \%$ of out-patients with moderate airflow obstruction (33). Furthermore, patients with COPD can suffer from a decreased FFM, even when body weight is normal (32). FFM depletion in COPD is considered to be a serious problem as it is associated with a reduced survival. It is also associated with a lower health status, as indicated by greater impairment in symptom, activity and overall scores, as measured by a disease specific questionnaire (34).

Besides negative effects on peripheral skeletal muscle strength, several studies have shown that patients with loss of body weight and FFM appear to have reduced exercise capacity as reflected by lower values for peak oxygen consumption and peak work rate $(35,36)$. Moreover, patients with FFM depletion were characterized by an earlier onset of lactic acid during exercise than non-depleted patients (35). These findings suggest that the functional consequences of nutritional depletion not only relate to muscle wasting per se, but also to alterations in muscle morphology and metabolism. 


\section{Alterations in muscle morphology and metabolism}

Adenosine triphosphate (ATP) is the common energetic currency of the cell and provides the energy for cross-bridge cycling. Several strategies are available to the muscle fiber for generating ATP. At the onset of contractile activity, muscle fibers initially draw on a small pool of existing ATP. However, ATP levels do not change significantly because phosphocreatine $(\mathrm{PCr})$ provides the substrate for rapid resynthesis catalyzed by creatine kinase. Inorganic phosphate and creatine $(\mathrm{Cr})$ are the net products of this overall reaction; both metabolites accumulate within the tissue during the early phase of exercise and can contribute to fatigue. The $\mathrm{PCr}$ stores in muscle can supply cellular needs for only a few seconds of strenuous contractions. During this time, glycogenolysis accelerates and the rate of glycolysis increases to provide a more sustainable energy source. Cytosolic pathways metabolize glucose to pyruvate, which is either reduced to lactate via lactate dehydrogenase, an anaerobic mechanism, or is transported into the mitochondrion. Within the inner mitochondrial matrix, pyruvate is converted to acetyl $\mathrm{CoA}$ and metabolized aerobically via the tricarboxylic acid (TCA) cycle to yield $\mathrm{CO}_{2}$ and water. Compared to anaerobic glycolysis, aerobic metabolism requires longer to activate. Aerobic metabolism has two important advantages to working fibers. It produces more energy, 38 ATP per mole of glucose versus 2 ATP from anaerobic glycolysis, and it enables the cell to utilize stored lipid as fuel via fatty acid metabolism. These properties are critical for muscle endurance. Mitochondrial respiration requires dehydrogenases within the mitochondrial matrix that metabolize pyruvate or free fatty acids to produce reducing equivalents, ie, reduced nicotinamide adenine dinucleotide (NADH). In the presence of molecular oxygen, $\mathrm{NADH}$ functions as a substrate for oxidative phosphorylation with the following overall reaction: $\mathrm{NADH}+\mathrm{H}^{+}+1 / 2 \mathrm{O}_{2}+3 \mathrm{ADP}+3 \mathrm{Pi} \rightarrow 3 \mathrm{ATP}+$ $\mathrm{NAD}^{+}+\mathrm{H}_{2} \mathrm{O}$.

Recent studies in severe COPD patients suggest that, in addition to and independent of the loss of muscle mass, intrinsic abnormalities in skeletal muscle metabolism are present $(37,38)$. In the peripheral skeletal muscle of stable severe COPD patients, a decrease in the proportion of the slow-twitch type 1 fibers and with a relative increase in fast-twitch type $2 \mathrm{~b} / \mathrm{x}$ fibers was seen, indicating a relative shift from oxidative to glycolytic capacity (39-41). In line with these morphological changes, in COPD reduced values were found for enzymes involved in the TCA cycle (citrate synthase) and in $\beta$-oxidation of fatty acids (hydroxyacyl CoA dehydrogenase) $(42,43)$. As mentioned above, glycolytic metabolism is less energy efficient because it produces less ATP per mole of glucose than oxidative metabolism. Alterations in substrate metabolism were found in skeletal muscle of COPD patients with mild hypoxemia, as indicated by a reduced glycogen and an increased lactate content (44).

The functional consequences of these changes were reflected in significant changes in skeletal muscle energy metabolism of patients with stable severe COPD at rest $(40,45)$. Alterations in adenine nucleotide metabolism were reflected in reduced values for ATP / adenosine diphosphate (ADP), $\mathrm{PCr} / \mathrm{Cr}$ ratio, and detectable levels of inosine monophosphate (IMP). Formation of IMP, a deamination product of adenosine monophosphate (AMP), is thought to reflect an imbalance 
between resynthesis and utilization of ATP. Several studies have shown early increases of blood lactate levels during submaximal exercise in patients with moderate to severe COPD $(42,46)$. Leg blood flow during submaximal exercise was preserved in these patients (47). The increased lactate production is responsible for the fall in muscle $\mathrm{pH}$, which in tum may play a role in determining exercise intolerance in these patients (47). Premature lactic acidosis has been associated with reduced oxidative enzyme concentrations in the lower limb muscles that can be at least partly reversed by physical training $(42,48)$. Moreover, a marked increase in muscle inorganic phosphate to phosphocreatine $(\mathrm{Pi} / \mathrm{PCr}$ ) ratio and intracellular acidosis at the end of forearm and calf exercise and a slow $\mathrm{PCr}$ resynthesis rate as assessed by ${ }^{31} \mathrm{P}$-Nuclear Magnetic Resonance techniques were found in stable severe COPD patients as compared with healthy controls $(37,38)$. Nutritional parameters were not different between the groups. The ratio of $\mathrm{PCr}$ to $\mathrm{Pi}$ is closely linked to that of ATP to ADP and is therefore a useful measure of mitochondrial phosphorylation potential. Recovery times for $\mathrm{PCr}$ are increasingly used to assess mitochondrial function.

These results suggest severely impaired oxidative phosphorylation during exercise, accompanied by increased and highly anaerobic metabolism, and that nutritional status is not the mechanism in these patients. Limited clinical data are available regarding the relative contribution of nutritional depletion on muscle enzyme capacities and energy rich substrates in COPD. The effects of nutritional depletion on type 2 fibers is suggested to be of greater magnitude than on type 1 fibers. In patients with anorexia nervosa, activities of glycolytic enzymes were $50 \%$ lower than those in sedentary control subjects, whereas the activities of the mitochondrial oxidative pathways were involved to a lesser extent (49).

A type 1 to type $2 \mathrm{~b} / \mathrm{x}$ shift accompanied by more glycolytic and less oxidative capacity in peripheral skeletal muscle implies loss of fatigue resistance. In contrast with that in peripheral skeletal muscle, a shift from type $2 \mathrm{~b} / \mathrm{x}$ to oxidative type 1 fibers has been reported in the diaphragm of COPD patients (50). This implies a shift toward a more fatigue-resistant but less strength-adapted muscle. Moreover, the observed alterations in enzyme activities confirm the morphological data in respiratory muscles, in that the oxidative enzymes are increased, whereas the glycolytic enzymes are reduced (51).

\section{Evidence for metabolic differences among patients with COPD}

Although COPD has been viewed as an uniform single entity $(52,53)$, more and more evidence exists that the presence of emphysema is specifically associated with metabolic changes.

\section{"Pink puffer and blue bloater" revisited}

The association between weight loss and emphysema was first described in the late $19^{\text {th }}$ century. A few decades ago, two contrasting types of patients with chronic airway obstruction were distinguished by purely clinical criteria: the 'pink puffer' and the 
'blue bloater'. The 'pink puffer' was characterized as being breathless with marked hyperinflation of the chest, and thin in appearance commonly with major weight loss. The 'blue bloater' had severe central cyanosis and was frequently obese with no marked weight loss, except occasionally in the terminal stages (54). As assessed by post-mortem analysis, there was somewhat more extensive emphysematous destruction of the lungs and much less evidence of active bronchial mucous gland hyperplasia in the 'pink puffer' than in the 'blue bloater'. Despite an equivalent degree of ventilatory impairment, the 'pink puffer' had larger lungs, and hyperventilated both at rest and during exercise. Based on this, the 'pink puffer' has often been considered as the emphysematous subtype of COPD, whereas the 'blue bloater' has often been considered as the chronic bronchitis subtype of COPD. Since only body weight was assessed in this study (54), no data were available regarding differences in body composition between these COPD subtypes.

In a previous study (33), we measured body composition in COPD out-patients and we observed that transfer coefficient $\left(\mathrm{K}_{\mathrm{co}}\right)$, which may discriminate between emphysema and bronchitis patients (55), was significantly lower in those with FFM depletion than in those without FFM depletion. Thirty eight percent of the patients with a $\mathrm{K}_{\mathrm{co}}<60 \%$ predicted (emphysematous type) compared with $5 \%$ of the patients with a $\mathrm{K}_{\mathrm{co}} \geq 80 \%$ (bronchitic type) were considered depleted. The significantly higher values for total lung capacity and residual volume in the group with lower $\mathrm{K}_{\text {co }}$ compared with the group with a $\mathrm{K}_{\mathrm{co}_{0}}=80 \%$ supports emphysematous changes in the depleted group, whereas airway obstruction and airway resistance were not different between the groups. This indicates that nutritional depletion is not confined to patients with severe airflow obstruction.

Thus, weight loss and nutritional depletion is a significant problem not only in patients with severe COPD, but also in out-patients with moderate airflow obstruction, especially in combination with an impaired diffusing capacity.

Besides differences in the amount of muscle mass between COPD subtypes, indirect evidence also exists that muscle morphology and metabolism may differ among COPD patients. These differences also appear to be related to the presence or absence of emphysema. As mentioned earlier, a relative shift has been observed from oxidative (type 1) to more glycolytic (type $2 \mathrm{~b} / \mathrm{x}$ ) fibers in the quadriceps femoris muscle of patients with COPD. Because the percentage of the glycolytic fibers was increased particularly in the muscle of COPD patients with a reduced diffusing capacity, decreased skeletal muscle oxidative metabolism is probably predominantly present in patients with emphysema (39). Also, functional consequences were found particularly in skeletal muscle of this COPD subtype. The COPD patients characterized by detectable IMP levels, reflecting a disturbed adenine nucleotide metabolism, differed from the IMP negative patients in that they had a significantly lower diffusing capacity (45).

These data suggest that there is a role of the integrity of the alveolocapillary membrane in the development of muscle wasting and metabolic alterations in skeletal muscle of patients with COPD. 


\section{OUTLINE OF THE THESIS}

The aim of the research reported in this thesis was to study muscle wasting in COPD and provide a metabolic and functional perspective. In order to characterize optimally the presence and severity of muscle wasting in COPD, accurate assessment of body composition, with special emphasis on fat-free mass is crucial. Moreover, precise determination of muscle wasting in COPD is of importance in achieving a better understanding of its consequences. In this way, the specific role of muscle wasting in the limited functional capacity (ie, skeletal muscle dysfunction) of these patients can be investigated. In order to provide a foundation for potential treatment strategies in which muscle wasting and its functional consequences can be ameliorated in COPD, knowledge of the specific causes of muscle wasting, the underlying metabolic alterations of protein and amino acid metabolism is necessary.

To gain insight into these aspects, three specific aims are defined in the thesis:

1. To characterize the changes in whole body and regional (extremity) composition in COPD patients and to evaluate the effect of fat-free mass depletion on peripheral skeletal muscle function (Part 1).

2. To analyze the alterations in whole body protein metabolism (synthesis and breakdown) in clinically and weight stable COPD patients in the postabsorptive state at rest and to study the effects of submaximal exercise (Part 2).

3. To investigate the specific disturbances in amino acid profile of the peripheral skeletal muscle at rest and during exercise (Part 3).

To study the contribution of underlying local impairment, the COPD patients were investigated as a group and stratified into subgroups according to the presence or absence of radiologically diagnosed emphysema. Each part of the thesis begins with an introduction section. The introduction sections corresponding to part 1,2 and 3 are presented on page 21,61 , and 89 , respectively. 


\section{References}

1. Van den Boom G, van Schayck CP, van Mollen MP, Tirimanna PR, den Otter JJ, van Grunsven PM, et al. Active detection of chronic obstructive pulmonary disease and asthma in the general population. Results and economic consequences of the DIMCA program. Am. J. Respir. Crit. Care Med. 1998;158:1730-8.

2. Rutten-van Molken MP, Postma MJ, Joore MA, Van Genugten ML, Leidl R, Jager JC. Current and future medical costs of asthma and chronic obstructive pulmonary disease in The Netherlands. Respir. Med. 1999;93:779-87.

3. Skeletal muscle dysfunction in chronic obstructive pulmonary disease. A statement of the American Thoracic Society and European Respiratory Society. Am. J. Respir. Crit. Care Med. 1999; 159:S1-40.

4. American Thoracic Society. Standards for the diagnosis and care of patients with chronic obstructive pulmonary disease (COPD) and asthma. Am. Rev. Respir. Dis. 1995;152:s77-s120.

5. Thurlbeck WM. Pathophysiology of chronic obstructive pulmonary disease. Clin. Chest Med. 1990;11:389-403.

6. American Thoracic Society. Chronic bronchitis, asthma, and pulmonary emphysema by the committee on diagnostic standards for nontuberculosis respiratory disease. Am. Rev. Respir. Dis. 1962;85:762-812.

7. O'Donnell DE, Webb KA. Exertional breathlessness in patients with chronic airflow limitation. The role of hyperinflation. Am. Rev. Respir. Dis. 1993;148:1351-1357.

8. Gibson GJ. Pulmonary hyperinflation a clinical overview. Eur. Respir. J. 1996;9:2640-2649.

9. Decramer M. Hyperinflation and respiratory muscle interaction. Eur. Respir. J. 1997;10:934941.

10. Gelb AF, Gold WM, Wright RR, Bruch HR, Nadel JA. Physiologic diagnosis of subclinical emphysema. Am. Rev. Respir. Dis. 1973;107:50-63.

11. Gurney JW, Jones KK, Robbins RA, Gossman GL, Nelson KJ, Daughton D, et al. Regional distribution of emphysema: correlation of high-resolution C.T with pulmonary function tests in unselected smokers. Radiology 1992;183:457-63.

12. Klein JS, Gamsu G, Webb WR, Golden JA, Muller NL. High-resolution CT diagnosis of emphysema in symptomatic patients with normal chest radiographs and isolated low diffusing capacity. Radiology 1992;182:817-821.

13. Stern EJ, Frank MS. CT of the lung in patients with pulmonary emphysema: diagnosis, quantification, and correlation with pathologic and physiologic findings. A.J.R. 1994;162:791798.

14. Thurlbeck WM, Muller NL. Emphysema: definition, imaging, and quantification. A.J.R. 1994:163:1017-1025.

15. Hamilton AL, Killian KJ, Summers E, Jones NL. Muscle strength, symptom intensity, and exercise capacity in patients with cardiorespiratory disorders. Am. J. Respir. Crit. Care Med. 1995;152:20212031.

16. Killian KJ, Leblanc P, Martin DH, Summers E, Jones NL, Campbell EJ. Exercise capacity and ventilatory, circulatory, and symptom limitation in patients with chronic airflow limitation. Am. Rev. Respir. Dis. 1992; 146:935-940.

17. Cotes $\mathrm{JE}$, Zejda J, King B. Lung function impairment as a guide to exercise limitation in work-related lung disorders. Am. Rev. Respir. Dis. 1988;137:1089-1093.

18. Gosselink R, Troosters T, Decramer M. Peripheral skeletal muscle weakness contributes to exercise limitation in COPD. Am. J. Respir. Crit. Care Med. 1996;153:976-980.

19. Mador MJ, Kufel TJ, Pineda L. Quadriceps fatique after cycle exercise in patients with chronic obstructive pulmonary disease. Am. J. Respir. Crit. Care Med 2000;161:447-453.

20. Decramer M, Lacquet LM, Fagard R, Rogiers P. Corticosteroids contribute to muscle weakness in chronic airflow obstruction. Am. J. Rev. Respir. Dis. 1994;150:1 1-16. 
21. Bernard S, Leblanc P, Whittom F, Carrier G, Jobin J, Belleau R, Maltais F. Peripheral muscle weakness in patients with chronic obstructive pulmonary disease Am. J. Respir. Crit. Care Med. 1998;158:629-634.

22. Zattara-Hartmann MC, Badier M, Guillot C, Tomei C, Jammes Y. Maximal force and endurance to fatigue of respiratory and skeletal muscles in chronic hypoxemic patients: the effects of oxygen breathing. Muscle Nerve 1995;18:495-502.

23. Serres I, Gautier V, Varray AL, Prefault CG. Impaired skeletal muscle endurance related to physical inactivity and altered lung function in COPD patients. Chest 1998;113:900-905

24. Newell SZ, McKenzie DK, Gandevia SC. Inspiratory and skeletal muscle strength and endurance and diaphragmatic activation in patients with chronic airflow limitation. Thorax 1989;44:903-912.

25. Schols AMWJ, Slangen J, Volovics L, Wouters EFM. Weight loss is a reversible factor in the prognosis of chronic obstructive pulmonary disease. Am. J. Respir. Crit. Care Med. 1998;157:1791-1797.

26. Wilson DO, Rogers RM, Wright EC, Anthonisen NR. Body weight in chronic obstructive pulmonary disease. Am. Rev. Respir. Dis. 1989;139:1435-1438.

27. Driver AG, McAlevy MT, Smith JL. Nutritional assessment of patients with chronic obstructive pulmonary disease and acute respiratory failure. Chest 1982;82:568-571.

28. Braun SR, Keim NL, Dixon RM, Clagnaz P, Anderegg A, Shrago ES. The prevalence and determinants of nutritional change in chronic obstructive pulmonary disease. Chest 1984;86:558-563.

29. Openbrier DR, Irwin MM, Rogers RM, Gottleib GP, Dauber JH, Vanheil OH. Nutritional status and lung function in patients with emphysema and chronic bronchitis. Chest 1983;83:7-22.

30. Fiaccadori E, Del Canale S, Coffrini E, Vitali P. Antonucci C, Cacciani G, et al. Hypercapnichypoxemic chronic obstructive pulmonary disease (COPD): influence of severity of COPD on nutritional status. Am. J. Clin. Nutr. 1988;48:680-685

31. Gray-Donald K, Gibbons L, Shapiro SH, Martin JG. Effect of nutritional status on excreise performance in patients with chronic obstructive pulmonary disease. Am. Rev. Respir. Dis. 1989; 140:1544-1548.

32. Schols AMWJ, Soeters PB, Dingemans AMC, Mostert R, Frantzen PJ, Wouters EFM. Prevalence and characteristics of nutritional depletion in patients with stable COPD eligible for pulmonary rehabilitation. Am. Rev. Respir. Dis. 1993;147:1151-1156.

33. Engelen MPKJ, Schols AMWJ, Baken WC, Wesseling GJ, Wouters EFM. Nutritional depletion in relation to respiratory and peripheral skeletal muscle function in oul-patients with COPD. Eur. Respir. J. 1994;7:1793-1797.

34. Shoup R, Dalsky G, Wamer S, Davies M, Connors M, Khan M, et al. Body composition and health-related quality of life in patients with obstructive airways disease. Eur. Respir. I. 1997; 10:1576-1580.

35. Baarends EM, Schols AMWJ, Mostert R, Wouters EFM. Peak exercise response in relation to tissue depletion in patients with chronic obstructive pulmonary disease. Eur. Respir. J 1997; 10:2807-2813.

36. Palange P, Forte S, Felli A, Galassetti P, Serra P, Carlone S. Nutritional state and exercise tolerance in patients with COPD. Chest 1995;107:1206-12.

37. Tada H, Kato H, Misawa T, Sasaki S, Hayashi S, Takahashi H, et al. 3 IP-Nuclear magnetic resonance evidence of abnormal skeletal muscle metabolism in patients with chronic lung disease and congestive heart failure. Eur. Respir. J. 1992;5:163-169.

38. Wuyam B, Payen JF, Levy P, Bensaidane H, Reutenauer H, Le Bas JF, et al. Metabolism and aerobic capacity of skeletal muscle in chronic respiratory failure related to chronic obstructive pulmonary disease. Eur. Respir. J. 1992;5:157-162.

39. Satta A, Migliori GB, Spanevello A, Neri M, Bottinelli R, Canepari M, et al. Fibre types in skeletal muscles of chronic obstructive pulmonary disease patients related to respiratory function and exercise tolerance. Eur. Respir. J. 1997; 10:2853-2860.

40. Jakobsson P, Jorfeldt L, Brundin A. Skeletal muscle metabolites and fiber types in patients with advanced chronic obstructive pulmonary disease (COPD), with and without chronic respiratory failure. Eur. Respir. J. 1990;3:192-196. 
41. Whittom F, Jobin J, Simard PM, Leblanc P, Simard C, Bernard S, et al. Histochemical and morphological characteristics of the vastus lateralis muscle in patients with chronic obstructive pulmonary disease. Med. Sci. Sports Exerc. 1998;30:1467-1474.

42. Maltais F, Simard AA, Simard C, Jobin J, Desgagnes P, LeBlanc P. Oxidative capacity of the skeletal muscle and lactic acid kinetics during exercise in normal subjects and in patients with COPD. Am. J. Respir. Crit. Care Med. 1996;153:288-293.

43. Jakobsson P, Jorfeldt L, Henriksson J. Metabolic enzyme activity in the quadriceps femoris muscle in patients with severe chronic obstructive pulmonary disease. Am. J. Respir. Crit. Care Med. 1995; 151:374-377.

44. Jakobsson P, Jorfeldt L. Long-term oxygen therapy may improve skeletal muscle metabolism in advanced chronic obstructive pulmonary disease patients with chronic hypoxaemia. Respir. Med. 1995;89:471-476.

45. Pouw EM, Schols AMWJ, Van der Vusse GJ, Wouters EFM. Elevated inosine monophosphate levels in resting muscle of patients with stable COPD. Am. J. Respir. Crit. Care Med. 1998;157:453-457.

46. Casaburi R, Patessio A, Ioli F, Zanaboni S, Donner CF, Wasserman K. Reductions in exercise lactic acidosis and ventilation as a result of exercise training in patients with obstructive lung disease. Am. Rev. Respir. Dis. 1991;143:9-18.

47. Maltais F, Jobin J, Sullivan MJ, Bernard S, Whittom F, Killian KJ, Desmeules M, Belanger M, LeBlanc P. J. Appl. Physiol. 1998;84:1573-1580.

48. Maltais F, LeBlanc P, Simard C, Jobin J, Berube C, Bruneau J, Carrier L, Belleau R. Skeletal muscle adaptation to endurance training in patients with chronic obstructive pulmonary disease. Am. J. Respir. Crit. Care Med. 1996;154:442-447.

49. Essen B, Fohlin L, Thoren C, Saltin B. Skeletal muscle fibre types and sizes in anorexia nervosa patients. Clin. Physiol. 1981;1:395-403.

50. Hughes RL, Katz H, Sahgal V, Campbell JA, Hartz R, Shields TW. Fiber size and energy metabolites in five separate muscles from patients with chronic obstructive lung disease. Respiration 1983;44:321-328.

51. Sanchez J, Brunet A, Medrano G, Debesse B, Derenne JP. Metabolic enzymatic activities in the intercostal and serratus muscles and in the latissimus dorsi of middle-aged normal men and patients with moderate obstructive pulmonary disease. Eur. Respir. J. 1988;1:376-383.

52. American Thoracic Society. Definitions, epidemiology, pathophysiology, diagnosis, and staging. Am. J. Respir. Crit. Care Med. 1995;152:S78-S121.

53. European Respiratory Society. Optimal assessment and management of chronic obstructive pulmonary disease (COPD). Eur. Respir. J. 1995;8:1398-1420.

54. Filley GF, Beckwitt HJ, Reever JT, Mitchelli RS. Chronic obstructive bronchopulmonary disease. 2. oxygen transport in two clinical types. Am. J. Med. 1968;44:26-38.

55. Gelb AF, Schein M, Kuei J, Tashkin DP, Muller NL, Hogg JC, et al. Limited contribution of emphysema in advanced chronic obstructive pulmonary disease. Am. Rev. Respir. Dis. $1993 ; 147: 1157-1161$. 


\section{PART 1}

Muscle wasting in relation to skeletal muscle function 


\section{INTRODUCTION}

Several studies indicate that physical capacity is impaired in patients with COPD $(1,2)$. The severity of airflow obstruction is only weakly associated with physical capacity, indicating that other factors must be responsible for the physical impairment in COPD. Depletion of fat-free mass commonly occurs in COPD and is a useful measure of muscle mass in the absence of shift between body water compartments. Depletion of fat-free mass negatively influences the physical capacity of COPD patients by reducing their (respiratory and peripheral skeletal) muscle function and exercise capacity and by enhancing symptom intensity (fatigue and dyspnea) $(1,2)$, independent of the degree of airflow obstruction. Moreover, muscle weakness and a reduced exercise capacity in COPD patients have been shown to increase the utilization of health care resources (3).

Earlier, COPD in-patients suffered from physical impairment, assessed by respiratory muscle strength and exercise performance, even to a greater degree than underweight patients with a relative preservation of fat-free mass, indicating that fat-free mass is a better predictor of respiratory and peripheral skeletal muscle strength than body weight (4). Because fat-free mass depletion negatively influences physical capacity, it is of particular importance to assess body composition in COPD patients with special emphasis on fat-frec mass. Currently, several established and validated methods are available for the assessment of body composition. Most of these methods rely on a simple 2-compartimental model that separates the body into 2 chemically distinct parts: fat-free mass and fat mass. Deuterium dilution and bioelectrical impedance spectroscopy are relatively easy, non-invasive methods to assess fat-free mass, and have been used and validated extensively in $\operatorname{COPD}(5,6)$. The novel body composition technique dual-energy X-ray absorptiometry (DXA) goes a step further and allows for the differentiation of the body into 3 compartments bone mineral content, fat and lean tissue not only at the whole body level, but also at various regions (leg, arm, trunk) (7). In addition, DXA is able to evaluate bone mineral density in the body. DXA is a convenient and non-invasive method less demanding for the patients, relatively easy for the practitioner and thus well applicable in clinical practice and well as in the elderly.

\section{OUTLINE OF THE CHAPTERS IN PART 1}

In chapter 2, we determined whether DXA is an applicable method in the clinical evaluation of body composition in COPD. In this chapter, we compared fat-free mass and fat mass by DXA with those obtained from deuterium dilution in a group of stable severe COPD patients, who were recruited cross-sectionally from a pulmonary rehabilitation center, and in healthy, age-matched volunteers. In addition, we examined whether the additional application of bone mineral density measurement is of value in COPD patients by comparing the extent of bone mineral loss in COPD patients with that of the healthy volunteers. In chapter 3 , we determined whether patterns of tissue depletion were different between COPD patients with and without 
macroscopic emphysema. Besides assessing fat-free mass and fat mass, DXA makes it possible to measure lean mass (bone-free fat-free mass) (14). Body composition was measured by DXA and the stratification of the COPD group into patients with and without macroscopic emphysema was done by the novel technique highresolution computed tomography, which gives a more direct insight in the presence and extent of alveolar wall destruction (the hall-mark of emphysema) in patients with COPD. In addition to estimating bone mineral density, fat mass, and bone-free, fatfree mass, DXA provides regional assessment of the 3 compartments. Until yet, no data are available on whether depletion of whole body fat-free mass in COPD patients is the result of a general process affecting multiple body compartments or whether it preferentially influences specific body subregions (ie, extremities, trunk). This information may be important in the diagnosis of skeletal muscle weakness because extremity fat-free mass gives a more detailed reflection of physically active muscle mass during daily life activities. In chapter 4, we examined whether extremity fat-free mass assessment is of more value than whole body fat-free mass measurement in the evaluation of peripheral skeletal muscle function in COPD patients with and without macroscopic emphysema. Moreover, we examined whether possible differences in skeletal muscle function between the COPD subtypes were related to differences in the severity of airflow obstruction.

\section{References}

1. Hamilton AL, Killian KJ, Summers E, Jones NL. Muscle strength, symptom intensity, and exercise capacity in patients with cardiorespiratory disorders. Am. J. Respir. Crit. Care Med. 1995;152:20212031

2. Gosselink R, Troosters T, Decramer M. Peripheral skeletal muscle weakness contributes to exercise limitation in COPD. Am. J. Respir. Crit. Care Med. 1996;153:976-980.

3. Decramer M, Gosselink R, Troosters T, Verschueren M, Evers G. Muscle weakness is related to utilization of health care resources in COPD patients. Eur. Respir. J. 1997; 10:417-423.

4. Schols AMWJ, Soeters PB, Dingemans AMC, Mostert R, Frantzen PJ, Wouters EFM. Prevalence and characteristics of nutritional depletion in patients with stable COPD eligible for pulmonary rehabilitation. Am. Rev. Respir. Dis. 1993;147:1151-1156.

5. Schols AMWJ, Wouters EF, Soeters PB, Westerterp KR. Body composition by bioelectricalimpedance analysis compared with deuterium dilution and skinfold anthropometry in patients with chronic obstructive pulmonary disease. Am. J. Clin. Nutr. 1991;53:421-4.

6. Baarends EM, Schols AMWJ, Van Marken Lichtenbeld WD, Wouters EFM. Analysis of body water compartments in relation to tissue depletion in clinically stable patients with chronic obstructive disease. Am. J. Clin. Nutr. 1997;65:88-94.

7. Mazess RB, Barden H, Bisek JP, Hanson J. Dual-energy X-ray absorptiometry for total-body and regional bone- mineral and soft-tissue composition. Am. J. Clin. Nutr. 1990;51:1106-1112. 


\section{CHAPTER 2}

Dual - energy X-ray absorptiometry in the clinical evaluation of body composition and bone mineral density in patients with chronic obstructive pulmonary disease

Mariëlle P.K.J. Engelen, Annemie M.W.J.

Schols, Guido A.K. Heidendal' and Emiel F.M. Wouters

Depts. of Pulmonology and 'Nuclear Medicine, University Hospital Maastricht, Maastricht, The Netherlands 


\section{ABSTRACT}

Background: Depletion of fat-free mass (FFM) occurs in a considerable number of patients with chronic obstructive pulmonary disease (COPD).

Objective: The goal of the study was to determine whether dual-energy X-ray absorptiometry (DXA) is an applicable method in the clinical evaluation of body composition in COPD.

Design: In a cross-sectional study in 79 COPD patients participating in a pulmonary inpatient program and in 23 healthy volunteers, DXA was compared to deuterium dilution (Deu) in the estimation of FFM. Bone mineral density (BMD), DXA measurement, was also compared between the 2 groups.

Results: $\mathrm{FFM}_{\mathrm{DXA}}$ was highly related to $\mathrm{FFM}_{\text {Deu }}$ in men $\left(\mathrm{R}^{2}=0.93, \mathrm{P}<0.001\right)$ and women $\left(\mathrm{R}^{2}=0.96, \mathrm{P}<0.001\right)$. On average, $\mathrm{DXA}$ resulted in higher $F F M$ values than did Deu in COPD patients $(3.4 \mathrm{~kg} ; \mathrm{P}<0.001)$ and in healthy volunteers $(2.1 \mathrm{~kg} ; \mathrm{P}<0.001)$. Furthermore, the intramethod difference in FFM was higher in men than in women in the COPD group $(\mathrm{p}<0.05)$ and in healthy volunteers $(\mathrm{p}<0.001)$. BMD was lower in the COPD group than in the healthy, age-matched volunteers $(p<0.001)$. In $56 \%$ of the COPD patients, there were indications of bone mineral loss, defined as a BMD below $1 \mathrm{SD}$ of a matched reference population provided by the software. BMD was less than $2 \mathrm{SD}$ in $36 \%$ of the COPD patients.

Conclusions: DXA appears a suitable alternative method to Deu for assessing body composition and for identifying bone mineral loss in COPD patients, and is therefore applicable in the clinical evaluation of these patients.

\section{INTRODUCTION}

Depletion of fat-free mass (FFM) commonly occurs in patients with chronic obstructive pulmonary disease (COPD) and negatively influences physical capacity, independent of the degree of airflow obstruction $(1,2,3)$. It is therefore particularly important to assess body composition in COPD patients with special emphasis on FFM. Currently, several established and validated methods are available for the assessment of body composition. Most of these methods rely on a two-compartment model that separates the body into two chemically distinct parts: FFM and fat mass. When relating body composition to physical capacity in COPD application of a twocompartment model appears to be appropriate (4). The most commonly used wellvalidated methods based on this two-compartment model are hydrodensitometry and deuterium dilution (Deu). However, these methods are laborious and not easily applicable in clinical practice.

Recontly, duil-energy $x$-ray absorptiometry (DXA) was introduced to differentiate body composition into 3 compartments. DXA directly assesses bone mineral content (5) and the soft tissue surrounding the bone $(5,6)$ by measuring the amount of fat and lean tissue. For that purpose, it is commonly used for accurate estimation of fat, bone and bone-free lean mass $(5,7,8)$. Also, bone mineral density (BMD; bone mineral 
content normalized for bone size) of the whole body and subregional compartments can be assessed. Because DXA is accepted as a safe, convenient, and noninvasive method, it is well applicable in clinical practice as well as in the elderly, especially because the results are immediately available. However, the validity of this method in specific patient populations (i.e. COPD) still has to be addressed.

Therefore, we compared FFM by DXA with that measured by Deu in 79 patients with stable severe COPD, recruited cross-sectionally and in 23 healthy age-matched volunteers. In addition, BMD of the whole body and subregional compartments of the COPD group was compared with that of the healthy volunteers and with reference values provided by the DXA software in order to determine the percentage of COPD patients with indications of bone mineral loss.

\section{METHODS}

\section{Study population}

During an 8-months period, 99 patients were consecutively admitted to a pulmonary rehabilitation center for inpatient rehabilitation. From this group, 79 patients [ $64 \mathrm{men}$, 15 women aged $65.0 \pm 8.1 \mathrm{y}$, with body mass indices (BMIs: in $\mathrm{kg} / \mathrm{m}^{2}$ ) of $23.5 \pm$ $\left.4.4 \mathrm{~kg} / \mathrm{m}^{2}\right]$ were studied. These patients had irreversible COPD, according to American Thoracic Society guidelines (9) with a forced expiratory volume in one second $\left(\mathrm{FEV}_{1}\right)$ less than $70 \%$ of the predicted value and with a reversibility after inhalation of a bronchodilating agonist less than $10 \%$ of predicted. The patients were clinical stable. not suffering from a respiratory tract infection or other concomitant confounding diseases (ie malignancics and gastrointestinal or endocrine disorders) and were without clinically demonstrable abnormalities in fluid balance (as manifested by clinically visible signs of edema or regular use of diuretics). Maintenance corticosteroid medication in this patient population consisted of oral corticosteroids (prednisone dose $<10 \mathrm{mg} /$ day) $(44 \%)$ and inhaled corticosteroids (85\%). Also, 23 healthy age-matched volunteers free from acute or chronic diseases and not taking medication influencing bone metabolism participated in the study. The medical ethical committee of the University Hospital Maastricht approved the study.

\section{Assessment of body weight and composition}

Body weight was measured by using an electronic bean scale with a digital readout to the nearest $0.1 \mathrm{~kg}$ (model 708; Seca, Hamburg, Germany) with patients and healthy volunteers standing barefoot and wearing light indoor clothing. Body height was measured to the nearest $0.1 \mathrm{~cm}$ (model 220, Seca).

Whole body FFM, consisting of lean tissue mass and bone mineral mass, and fat mass were determined by scanning each subject on a DPX-L Bone Densitometer (Lunar Radiation Corporation, Madison, WI)(voltage: $76.0 \mathrm{kVp}$; current: $150 \mu \mathrm{A}$; collimation: $1.68 \mathrm{~mm}$ ). For that purpose, the subject lay in supine position on a scan 
table for approximately 15 minutes while the DXA scanner performed multiple fast speed transverse scans from head to toes with $1 \mathrm{~cm}$ intervals, with a scan area of 576 * $1968 \mathrm{~mm}$ and a sample interval of $1 / 32$. The instrument used a rectilinear scanner to detect density differences as the two levels of photon energy were projected through the subject. The DPX-L scanner used a constant potential x-ray source at $78 \mathrm{kV}$ and a $\mathrm{K}$-edge filter to achieve a congruent beam of stable dual-energy radiation with effective energies of 38 and $70 \mathrm{keV}$ (5). Data were collected in maximal 205 scan lines * 120 sample points (pixel size: $4.8 * 9.6 \mathrm{~mm}$ ). Entrance radiation dose was minimal $(<0.02 \mathrm{mSv} / \mathrm{scan})$. Total tissue mass, bone mineral mass, fat mass and lean tissue mass were derived according to computer algorithms (Lunar software version 1.3) provided by the manufacturer $(5,10,11)$. Percentage body fat was calculated as fat mass relative to total tissue mass. FFM DXA $_{\text {a }}$ was computed as the sum of lean tissue mass and bone mineral mass.

BMD is the bone mineral mass normalized for bone size. BMDs of the patients and healthy volunteers were expressed as $\mathrm{g} / \mathrm{cm}^{2}$ and as a percentage of a healthy age-, sex-, weight- and ethnicity matched reference population data provided by the manufacturer. The healthy volunteers as well as the reference population provided by the software of the manufacturer, were free from chronic diseases affecting bone and were not taking medications that influence bone (ie, corticosteroids, anticonvulsants, and thyroxine).

Quality assurance tests were run daily. Three times a week DXA software validation phantoms provided by the manufacturer, and closely reflecting the attenuation characteristics of the major constituents of the body (lean mass, fat mass and bone), were scanned.

Total body water (TBW) was estimated from deuterium dilution space (6). In the late evening, each subject consumed a preweighted oral dose of deuterium labeled water $\left({ }^{2} \mathrm{H}_{2} \mathrm{O}\right)(12)$ (99.84 atom percent excess) of $1 \mathrm{~g} / \mathrm{L}$ predicted TBW (based on height, weight, age and sex). This dose was mixed into $70 \mathrm{~mL}$ deionized water. Just before and approximately ten hours later a urine sample was collected; the latter sample was obtained after complete voiding the bladder.

An isotope ratio mass spectrometer was used to analyze ${ }^{2} \mathrm{H}_{2} \mathrm{O}$ concentration in the urine according to the standard Maastricht protocol (13). After complete equilibration, deuterium dilution space was calculated from the quantity of ${ }^{2} \mathrm{H}_{2} \mathrm{O}$ administered and the urinary ${ }^{2} \mathrm{H}_{2} \mathrm{O}$ concentrations (14). In calculating $\mathrm{TBW}$, it was assumed that deuterium dilution space was a factor of 1.04 times greater than TBW, owing to the estimated $4 \%$ nonaqueous hydrogen exchange and isotope fractionation (15). TBW was used to estimate deuterium based FFM with the assumption that water represents a fixed proportion of the FFM (hydration factor of 0.73 ) and that fat is anhydrous. A two-compartment model was used to derive FFM. FFM $\mathrm{DEU}_{\mathrm{DU}}=\mathrm{TBW} /(1.04 * 0.73)$.

Fat mass was calculated by subtracting FFM from body weight and expressed as a percentage of body weight. 


\section{Pulmonary function tests}

All subjects underwent spirometry with determination of $F E V_{1}$ and forced vital capacity (FVC) with the highest value from at least three technically acceptable assessments being used. Static and dynamic lung volumes (total lung capacity, residual volume and airway resistance) were assessed by whole-body plethysmography (Masterlab; Jaeger, Wurzburg, Germany). Diffusing capacity for carbon monoxide was measured by using the single-breath method (Masterlab). All values obtained were related to a predicted reference value (16).

\section{Statistical analysis}

Results are expressed as means \pm SDs. The paired $t$-test was used for pairwise comparisons between measures of FFM and linear regression analysis was performed to determine the relationship between estimates of FFM for the 2 methods. The limits of agreement between the different methods were calculated as the mean intermethod difference $\pm 2 \mathrm{SD}$, according to the method described by Bland and Altman (17). Intermethod FFM and BMD differences between men and women or between COPD patients and healthy age-matched volunteers were assessed using independent samples t-test. Significance of difference was assessed at $p<0.05$.

\section{RESULTS}

In 79 patients with moderate to severe airflow obstruction and 23 healthy volunteers (16 men and 7 women) body composition was measured by DXA and Deu. Age and height did not differ significantly between the COPD and healthy volunteer groups (table 1). COPD patients had significantly lower values for FFM $\mathrm{DXA}_{\mathrm{A}}, \mathrm{FFM}_{\mathrm{Dew}}, \mathrm{FEV}_{1}$, diffusing capacity for carbon monoxide, and FVC, and higher values for total lung capacity and airway resistance.

There was a strong relation between mean FFM ${ }_{D X A}$ and $F F M_{D e u}$ in all subjects combined $\left(\mathrm{R}^{2}=0.94, \mathrm{P}<0.001\right)$ and when the study group was divided into men (Figure 1) and women (Figure 2). A Bland-Altman plot of the intermethod difference in FFM against the mean value of FFM by DXA and Deu (FFM DXA-Deu $_{\text {versus }}$ $\mathrm{FFM}_{\mathrm{DXA}+\mathrm{Dev}} / 2$ ) showed a high degree of agreement for men (Figure 1) and women (Figure 2). There was no relation between the two measures in the two sexes or in the COPD or healthy volunteer group. Mean $\mathrm{FFM}_{\mathrm{DXA}}$ in men was $3.6 \mathrm{~kg}$ above mean FFM $_{\text {Deu, }}$, the difference in FFM values being between -0.5 and $7.8 \mathrm{~kg}$ of the mean of the 2 values. Mean FFM ${ }_{\text {DXA-Deu }}$ in women was $1.4 \mathrm{~kg}$ and the limits of agreement were -2.6 to $5.3 \mathrm{~kg}$.FFM $\mathrm{DXA}_{\mathrm{A}}$ was significantly higher than $\mathrm{FFM}_{\mathrm{Dcu}}$ in the COPD group (mean difference: $3.4 \pm 2.2 \mathrm{~kg} ; \mathrm{P}<0.001$ ) as well as in the healthy volunteer group (mean difference: $2.1 \pm 2.1 \mathrm{~kg} ; \mathrm{P}<0.001$ ). Moreover, this intermethod difference of FFM was significantly higher in the COPD group compared the healthy volunteers $(\mathrm{p}<0.05)$. 
Table 1. General characteristics of patients with COPD and healthy, age-matched volunteers

\begin{tabular}{|c|c|c|c|c|c|c|c|}
\hline & & \multicolumn{3}{|c|}{$\begin{array}{l}\text { Healthy volunteers } \\
(\mathrm{n}=15 \mathrm{M}, 7 \mathrm{~W})\end{array}$} & \multicolumn{3}{|c|}{$\begin{array}{c}\text { COPD patients } \\
(\mathrm{n}=64 \mathrm{M}, 15 \mathrm{~W})\end{array}$} \\
\hline & & mean & $\pm:$ & $\mathrm{SD}$ & mean & \pm & $\mathrm{SD}$ \\
\hline Age & $\overline{\mathrm{Y}}$ & 65.0 & \pm & 3.3 & 65.0 & \pm & 8.1 \\
\hline Weight & $\mathrm{Kg}$ & 72.2 & \pm & 11.4 & 69.0 & \pm & 13.7 \\
\hline TBW & $\mathrm{L}$ & 37.8 & \pm & 6.4 & 34.2 & \pm & $6.2^{*}$ \\
\hline $\mathrm{FFM}_{\mathrm{DXA}}$ & $\mathrm{Kg}$ & 53.9 & \pm & 10.5 & 50.2 & \pm & $8.7^{*}$ \\
\hline $\mathrm{FFM}_{\mathrm{DEU}}$ & $\mathrm{Kg}$ & 51.8 & \pm & 8.8 & 46.8 & \pm & $8.5^{*}$ \\
\hline Height & $\mathrm{Cm}$ & 168.9 & \pm & 8.2 & 168.0 & \pm & 9.3 \\
\hline $\mathrm{FEV}_{1}$ & \%pred. & 109.9 & \pm & 17.1 & 39.7 & \pm & $14.1 * * *$ \\
\hline $\mathrm{Dl}_{\mathrm{co}}$ & \%pred. & 116.7 & \pm & 21.4 & 61.1 & \pm & $21.7^{* * *}$ \\
\hline FVC & \%pred. & 119.7 & \pm & 15.0 & 86.0 & \pm & $18.8 * * *$ \\
\hline TLC & \%pred. & 115.2 & \pm & 10.2 & 121.2 & \pm & $18.0^{*}$ \\
\hline RV & $\%$ pred. & 113.2 & \pm & 15.4 & 185.9 & \pm & $55.9^{* * *}$ \\
\hline $\mathrm{R}_{\mathrm{aw}}$ & $\%$ pred. & 92.7 & \pm & 42.8 & 242.4 & \pm & $96.3^{* * *}$ \\
\hline
\end{tabular}

Values are mean $\pm \mathrm{SD}$; TBW: total body water; $\mathrm{FI}$ M: fat-free mass; $\mathrm{FEV}_{1}$ : forced expiratory volume in one second; $\mathrm{Dl}_{\text {co }}$ : diffusing capacity for carbon monoxide; FVC: forced vital capacity; TLC: total lung capacity; $\mathrm{RV}$ : residual volume; $\mathrm{R}_{\mathrm{aw}}$; airway resistance; significance of difference compared to the controls: *:p $<0.05 * * *$ p $<0.001$

Stratification by sex showed that there were higher values for FFM $M_{D X A}$ than $F F M_{D E U}$ in men in particular. In men, there was a higher intermethod difference in FFM was present in the COPD group $(\mathrm{p}<0.05)$ and in the healthy volunteer group $(\mathrm{p}<0.001)$ (fig. 3) than in women. The intermethod difference of FFM correlated significantly with $\operatorname{sex}(\mathrm{r}: 0.40 ; \mathrm{p}<0.001)$, health status $(0=$ no COPD; $\mathrm{l}=\mathrm{COPD})$ $(r: 0.24 ; p<0.05)$, height $(r: 0.35 ; p<0.001)$, and FFM of the trunk $(r: 0.29 ; p<0.01)$.

Table 2. Total body and subregional bone mineral density (BMD) of patients with COPD and healthy, age-matched volunteers

Whole-body BMD

$\left(\mathrm{g} / \mathrm{cm}^{2}\right)$

(\% of predicted)

$$
1.16 \pm 0.11
$$$$
103 \pm 9
$$

Subregional BMD $\left(\mathrm{g} / \mathrm{cm}^{2}\right)$

\begin{tabular}{lll} 
Arms & $0.93 \pm 0.12$ & $0.86 \pm 0.20^{*}$ \\
Legs & $1.24 \pm 0.16$ & $1.11 \pm 0.16^{* *}$ \\
Trunk & $0.96 \pm 0.01$ & $0.88 \pm 0.16^{* *}$ \\
\hline
\end{tabular}

Values are mean \pm SD; BMD: bone mineral density in $\mathrm{g} / \mathrm{cm}^{2}$ and expressed as percentage of an age-, weight-, sex-, and ethnicity-matched healthy reference population provided by the apparatus manufacturer; significance of difference compared to the controls: ${ }^{*}: p<0.05 ;{ }^{* *}: p<0.01 ;{ }^{* * *}: p<0.001$ 

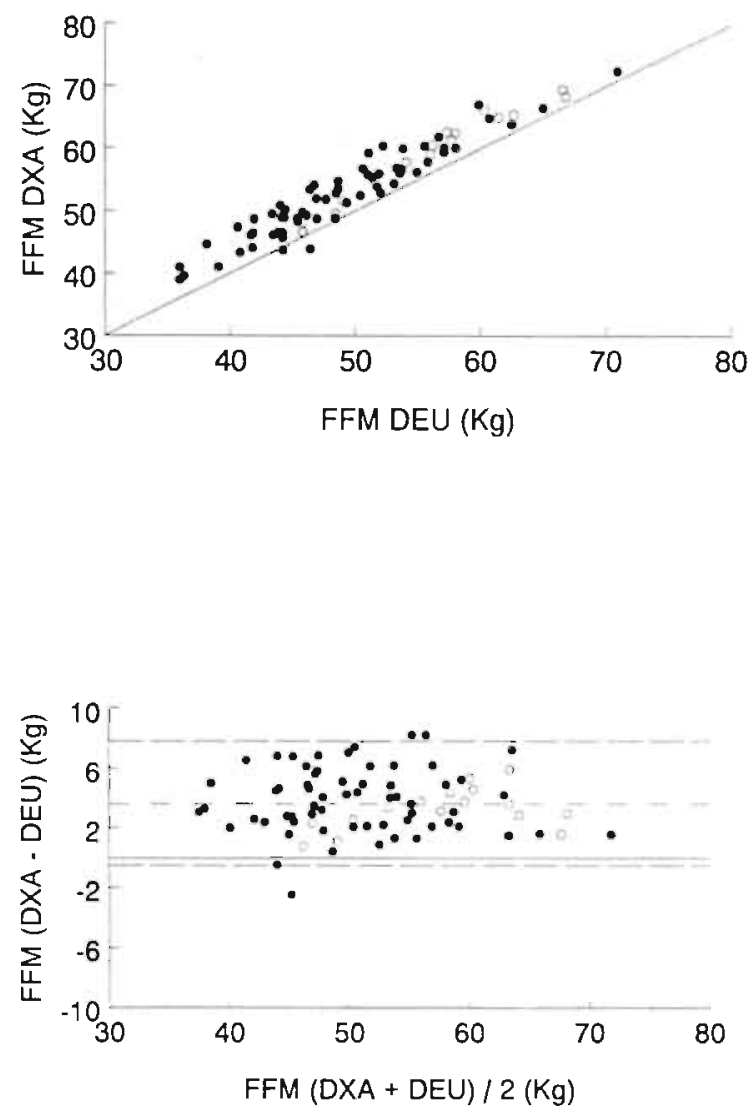

Figure 1. Estimates of fat-free mass (FFM) by dual-energy X-ray absorptiometry (DXA) and deuterium dilution (DEU) in 64 male patients with COPD and in 16 healthy male volunteers (top panel). $\mathrm{R}^{2}: 0.93(\mathrm{p}<0.001) ; \mathrm{FFM}_{\mathrm{DXA}}=\left(0.97{ }^{*} \mathrm{FFM}_{\mathrm{DEU}}\right)+5.34$; SEE: $2.11 \mathrm{~kg}$. Line of identity is included. Closed circles represent COPD patients $(n=64)$; open circles represent healthy volunteers $(n=16)$.

Difference in FFM between DXA and DEU for the 80 men studied versus the mean FFM between the 2 methods. $\mathrm{R}^{2}<0.001$ (bottom panel). The intermethod difference in FFM (dotted line) is $3.6 \mathrm{~kg}$; the limits of agreement (dashed lines) are -0.5 to $7.8 \mathrm{~kg}$. Closed circles represent COPD patients $(n=64)$; open circles represent healthy volunteers $(n=16)$. 


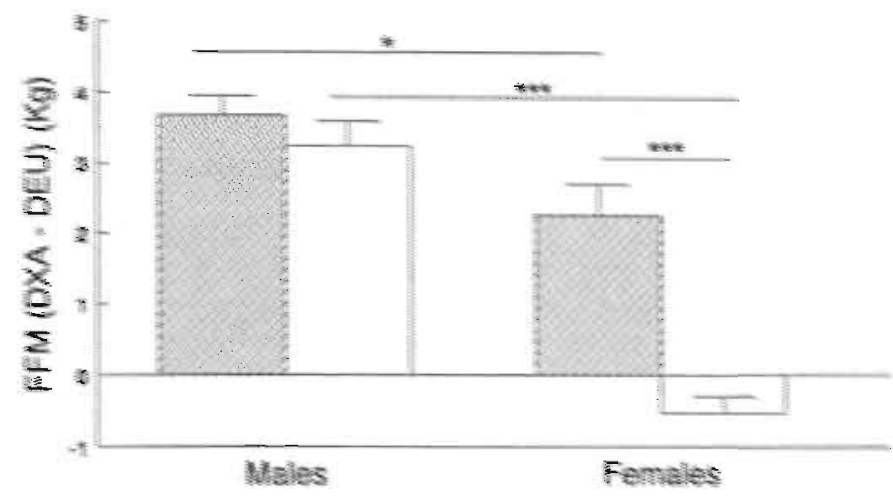

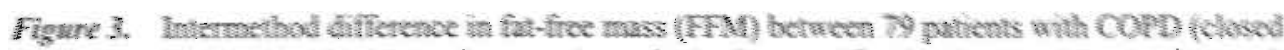

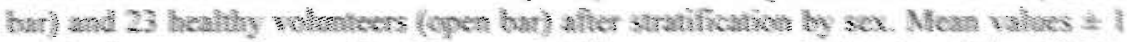

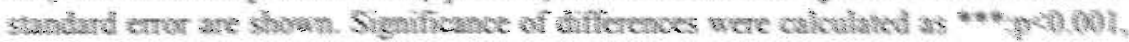
s.patis

In linear regression analysis, only sex, COPD and height remained as significant predictors and explained $24 \%$ of the variance in FFM (in $\mathrm{g} / \mathrm{cm}^{2}$ ) was significantly lower in COPD patients than in the healthy volunteers $(\mathrm{p}<0.001)$ (table 2).

In the COPD group, significantly lower values were also found for BMD of the arms $(P<0.05)$, legs $(P<0.01)$ and trunk $(P<0.01)$. Compared with age-, sex-, weight- and ethnicity-matched reference population data provided by Lunar software, $56 \%$ of the COPD patients studied had indications of bone mineral loss ( $\mathrm{z}$-score $<-1) 9 \%$ of the healthy volunteer group had these indications. In $36 \%$ of the total COPD group BMD was more than two standard deviations below that of the reference population ( $\mathrm{z}$-score $<-2$ ); $19 \%$ of the COPD patients had a BMD between one and two SDs below that of the reference population $(-2<\mathrm{z}$-score $<-1)$. Mean BMDs of the latter two groups were $0.94 \pm 0.07 \mathrm{~g} / \mathrm{cm}^{2}$ vs. $0.99 \pm 0.07 \mathrm{~g} / \mathrm{cm}^{2}$ (NS), respectively, which corresponds to $88 \pm$ $3 \%$ and $83 \pm 4 \%$ predicted $\mathrm{BMD}(\mathrm{P}<0.01)$. The $\mathrm{BMD}$ of the COPD group with no indications of bone mineral loss (z-score > $>$; BMD: $1.12 \pm 0.08 \mathrm{~g} / \mathrm{cm}^{2} ; 99 \pm 5 \%$ of predicted) was significantly higher than that of the 2 COPD groups with bone mineral loss $(\mathrm{P}<0.001)$.

The percentage of patients using corticosteroids was not significantly different between the COPD groups with and without bone mineral loss (inhaled corticosteroids: $84 \%$ compared with $85 \%$; oral corticosteroids: $49 \%$ compared with $36 \%)$. 


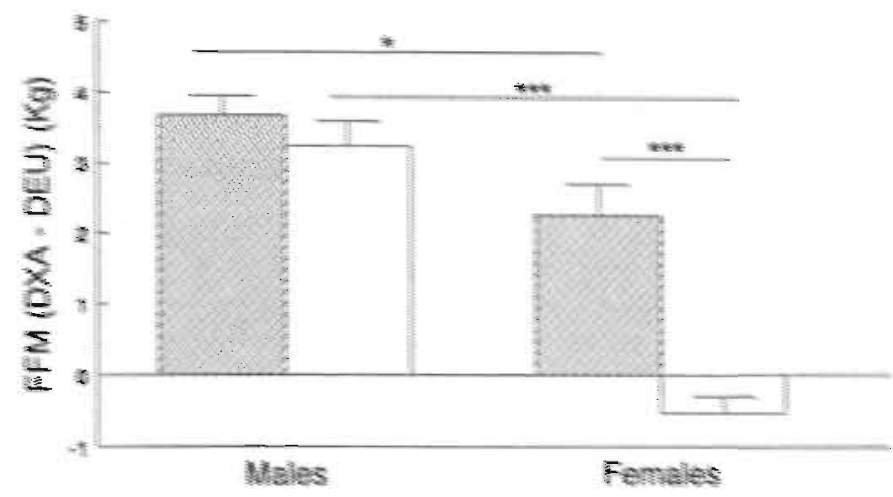

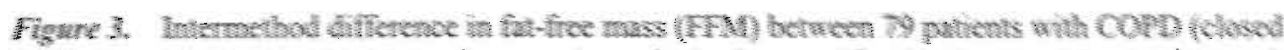

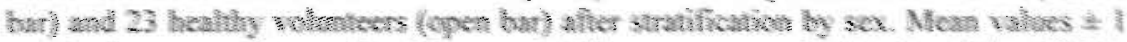

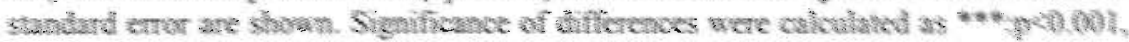
s.patis

In linear regression analysis, only sex, COPD and height remained as significant predictors and explained $24 \%$ of the variance in FFM (in $\mathrm{g} / \mathrm{cm}^{2}$ ) was significantly lower in COPD patients than in the healthy volunteers $(\mathrm{p}<0.001)$ (table 2).

In the COPD group, significantly lower values were also found for BMD of the arms $(P<0.05)$, legs $(P<0.01)$ and trunk $(P<0.01)$. Compared with age-, sex-, weight- and ethnicity-matched reference population data provided by Lunar software, $56 \%$ of the COPD patients studied had indications of bone mineral loss ( $\mathrm{z}$-score $<-1) 9 \%$ of the healthy volunteer group had these indications. In $36 \%$ of the total COPD group BMD was more than two standard deviations below that of the reference population ( $\mathrm{z}$-score $<-2$ ); $19 \%$ of the COPD patients had a BMD between one and two SDs below that of the reference population $(-2<\mathrm{z}$-score $<-1)$. Mean BMDs of the latter two groups were $0.94 \pm 0.07 \mathrm{~g} / \mathrm{cm}^{2}$ vs. $0.99 \pm 0.07 \mathrm{~g} / \mathrm{cm}^{2}$ (NS), respectively, which corresponds to $88 \pm$ $3 \%$ and $83 \pm 4 \%$ predicted $\mathrm{BMD}(\mathrm{P}<0.01)$. The $\mathrm{BMD}$ of the COPD group with no indications of bone mineral loss (z-score > $>$; BMD: $1.12 \pm 0.08 \mathrm{~g} / \mathrm{cm}^{2} ; 99 \pm 5 \%$ of predicted) was significantly higher than that of the 2 COPD groups with bone mineral loss $(\mathrm{P}<0.001)$.

The percentage of patients using corticosteroids was not significantly different between the COPD groups with and without bone mineral loss (inhaled corticosteroids: $84 \%$ compared with $85 \%$; oral corticosteroids: $49 \%$ compared with $36 \%)$. 


\section{DISCUSSION}

This study showed a high level of agreement between DXA and Deu in the estimation of FFM although systematically higher values for FFM were given by DXA, particularly in men, regardless of health status. Furthermore, DXA provided BMD values that were lower in COPD patients than standardized reference values.

We found highly significant correlation coefficients in COPD patients and in healthy volunteers when we compared FFM $\mathrm{DXA}_{\mathrm{DA}}$ and $\mathrm{FFM}_{\mathrm{Dcu}}$ and these estimates were as good as those reported in healthy volunteers $(r: 0.74-0.92 ; p<0.001)(7,18-20)$. Intermethod differences in FFM in male and female COPD patients and healthy volunteers were randomly distributed in relation to the means of the two estimates for FFM, according to Bland-Altman type analyses. SEEs from comparisons of FFM were lower than or similar to SEEs reported by Pierson et al (21) and Wellens et al (22) in healthy adults. Therefore, we suggest that DXA and Deu are interchangeable when assessing FFM in healthy persons and those with COPD.

In the present study, mean $F_{F M}$ was significantly higher than $F F M_{D e u}$ in COPD patients and in healthy volunteers. In the past, contradictory results were observed for FFM - higher $(19,22)$ as well as lower (7) estimates of FFM were found by DXA than by Deu. FFM ${ }_{\text {DXA }}$ was lower than FFM determined by skinfold thickness measurements (23) and hydrodensitometry $(20,22)$, although most of these studies were carried out in healthy research volunteers. Intermethod differences in FFM were noted in all COPD patients and in healthy male volunteers but not in healthy female volunteers. This observation contrasts with the findings of an earlier study in FFM DXA was significantly higher than $F_{F} M_{D E U}$ in healthy men and women (22). The discrepancy may have been due to the small number of healthy female subjects participating in the current study $(n=7)$. Furthermore, a higher intermethod difference in FFM was measured in the COPD group than in the healthy volunteers, suggesting a COPD related effect. This intermethod difference was entirely sex-specific because it was higher in female COPD patients than in female volunteers, but was not different between male COPD patients and male volunteers $(p=0.26)$. More studies are needed to evaluate whether there actually is a COPD related effect on intermethod differences in FFM.

In both COPD patients and healthy volunteers, the overestimation of FFM by DXA compared with FFM by Deu was significantly greater in men than in women, confirming a sex-related intermethod difference in FFM as reported earlier in healthy adults. The systemic overestimation of FFM by DXA compared with Deu might be related to systematic errors in the DXA or Deu method used. To avoid adjustment for potential overestimation of TBW, Deu uses a correction factor of $4 \%$ for potential error due to the exchange of nonaqueous protein hydrogen. However, when the extremes of isotopic exchange factors of $2 \%$ and $5 \%$ (24) were used in the current study, the intermethod difference in FFM did not change significantly. Furthermore, the Deu method assumes uniform hydration of FFM (TBW=0.73*FFM ${ }_{D E U}$ ), although 
extensive interindividual variation exists $(67-78 \%)(25)$. Particularly in hospitalized patients and very old people this hydration coefficient $(0.73 \mathrm{~L} / \mathrm{kg})$ might not be accurate (26). The attenuation coefficient of FFM used in DXA assumes constant hydration but in practice, physiologic changes in hydration have a minimal effect on the measured FFM. Earlier studies found that DXA accurately assesses small manipulations in hydration in vivo as changes in lean tissue mass (27-29). In the present study, the hydration coefficient calculated as the ratio of TBW to FFM lower in the COPD group than in the healthy volunteers $(0.68 \pm 0.03$ compared with $0.71 \pm 0.03 \mathrm{~L} / \mathrm{kg} ; \mathrm{P}<0.001$ ). These values were lower than the hydration coefficient of $0.73 \mathrm{~L} / \mathrm{kg}$ reported by others (30). If DXA indeed measures FFM hydration more accurately than the constant of $0.73 \mathrm{~L} / \mathrm{kg}$, then body composition in this study population may not be estimated accurately by Deu. However, it is still uncertain whether this analysis was confounded by the potential influence of hydration itself on DXA.

What might the clinical consequences be of this systematic difference in FFM between Deu and DXA in measuring FFM? In general, when a systematic difference is found between two indirect measures of body composition, and neither method is gold standard, it is difficult to determine which of the methods is responsible for the difference and which is providing an accurate assessment. Comparison of DXA with more sophisticated body-composition measures might shed light on this conundrum. In clinical longitudinal studies in COPD patients the consequences of a systematic difference are not important because the evaluation of the effect of time related interventions on body composition is not influenced by a systematic difference. Differences between methods might only be a problem when absolute values of FFM are compared among different studies in COPD patients. However, the intermethod difference in the present study was relatively small and therefore no real problems are expected when studies are compared. Patients with moderate to severe COPD participated in the present study, and although our study group did not represent COPD patients in general, it represented the population of interest in most metabolic studies of COPD. Because FFM ${ }_{D X A}$ and FFM deu values were nearly equal in COPD patients and in healthy control subjects, we think that DXA can also be used in patients with mild COPD.

BMD, as assessed by DXA is the key clinical indicator of the patient's skeletal status and varies with age, gender, menopausal state, ethnicity, and physical activity. BMD values below the age-matched $\mathrm{SD}$ indicate that additional factors may be affecting the patient's BMD (secondary factors, ie, those not age-related or osteoporosis). In the present study, whole-body and subregional BMD were lower in the COPD group than in the healthy volunteers. When compared with matched reference population dati provided by the LUNAR software, $36 \%$ of the studied COPD patients had a BMD below two SDs of the reference population and 19\% had a BMD between one and two SDs. The exact cause of this high prevalence of bone mineral loss in COPD is still open for discussion. 
Although the percentage of corticosteroid users was not different between the COPD groups with and without bone mineral loss, no information was available about the history of duration and dose of corticosteroid intake.

In the present study, highly significant correlations in the estimate of FFM were found between DXA and Deu, suggesting that DXA is an alternative method to Deu for assessing body composition. However, DXA gives systematically higher values for FFM than does Deu, particularly in men, regardless of health status. DXA makes it possible to identify the relatively high percentage of COPD patients with indications of bone mineral loss. We therefore conclude that DXA is an informative, well-suited and easily applicable method for clinically evaluating body composition and BMD in patients with COPD.

\section{References}

1. Wilson DO, Rogers RM, Wright EC, Anthonisen NR. Body weight in chronic obstructive pulmonary disease. Am. Rev. Respir. Dis. 1989;139:1435-1438.

2. Schols AMWJ, Soeters PB, Dingemans AMC, Mostert R, Frantzen PJ, Wouters EFM. Prevalence and characteristics of nutritional depletion in patients with stable COPD eligible for pulmonary rehabilitation. Am. Rev. Respir. Dis. 1993;147:1151-1156.

3. Engelen MPKJ, Schols AMWJ, Baken WC, Wesseling GJ, Wouters EFM. Nutritional depletion in relation to respiratory and peripheral skeletal muscle function in out-patients with COPD. Eur. Respir. J. 1994;7:1793-1797.

4. Schols AMWJ, Mostert R, Soeters PB, Wouters EFM. Body composition and exercise performance in patients with chronic obstructive lung disease. Thorax 1991;46:695-699.

5. Mazess RB, Barden H, Bisek JP, Hanson J. Dual-energy X-ray absorptiometry for total-body and regional bone- mineral and soft-tissue composition. Am. J. Clin. Nutr. 1990;51:1106-1112.

6. Lukaski HC. Methods for the assessment of human body composition: traditional and new. Am. J. Clin. Nutr. 1987;46:537-556.

7. Jensen MD, Kanaley JA, Roust LR, et al. Assessment of body composition with use of dualenergy X-ray absorptiometry: evaluation and comparison with other methods. Mayo. Clin. Proc. 1993;68:867-873.

8. Haarbo J, Gotfredsen A, Hassager C, Christiansen C. Validation of body composition by dual energy X-ray absorptiometry (DEXA). Clin. Physiol. 1991;11:331-341.

9. American Thoracic Society. Standards for the diagnosis and care of patients with chronic obstructive pulmonary disease (COPD) and asthma. Am. Rev. Respir. Dis. 1987;137:225-228.

10. Peppler WW, Mazess RB. Total body bone mineral and lean body mass by dual-photon absorptiometry. 1. Theory and measurement procedure. Calcif. Tissue Int. 1981;33:353-359.

11. Gotfredsen A, Jensen J, Borg J, Christiansen C. Measurement of lean body mass and total body fat using dual photon absorptiometry. Metabolism 1986;35:88-93.

12. Deurenberg $P$, Westrate JA, Seidell JC. Body mass index as a measure of body fatness: age and sex specific prediction formulas. Br. J. Nutr. 1991:65:105-114.

13. Westerterp KR, Wouters L, Van Marken Lichtenbeld WD. The Mastricht protocol for the measurement of body composition and energy expenditure with labeled water. Obesity research 1995;3:49-57.

14. Schoeller DA. Isotope dilution methods. In: Bjontorp $\mathrm{P}$, Brodorf $\mathrm{BN}$, eds. Obesity. Philadelphia: J.B. Lippencott Company, 1992:80-88.

15. Coward WA, Parkinson SA, Murgatroyd PR. Body composition measurements for nutrition research. Nutr. Res. Rev. 1988;1:115-124.

16. Quanjer P, Tammeling GJ, Cotes JE, Pedersen OF, Peslin R, Yemault JC. Standardized lung function testing. Eur. Respir. J. 1993;6:5-40. 
17. Bland JM, Altman DG. Statistical methods for assessing sgreement between two methods of clinical assessment. ancet 1986;1:307-310.

18. Pritchard IE, Nowson CA, Strauss, BV, Carlson J5, Kaymakci B, Wark. DD. Evaluation of dual energy X-ray absorptiometry as a method of measurement of body fati. Eur. 3. Clin. Nutr. $1993 ; 47 ; 216-228$.

19. Whithers RT, Smith DA, chattertos BE, Schultz CG, Gaftney RD. A comparison of four methods of estimating the body composision of male endurance athletes. Eur. J. Clin. Nutr. 1992;46:773-784.

20. Van Loan MD, Mayclin PL. Body composition assessment: dual-energy X-ray absorptiometry (DEXA) compared to reference methods. Eur. 3. Clin. Wutr. 1992:46:125-130.

21. Pierson RM, Heymsfield SB, Russell-Aulet M, Mazariegos M, Tiemey M. Measuring body fat: calibrating the ralers; intermethod comparisons in 389 normal caucasion subjects. Ams. I.

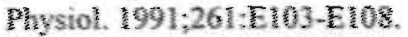

22. Wellens R, Chumlea WC, Guo \$, hoche AF, Reo MV, Siervogel RM. Body composition in white adults by dual-energy $\mathrm{X}$-ray absorptiometry, densitometry, and total body water. Am. J. Clin. Nutr. 1994;59:547-555.

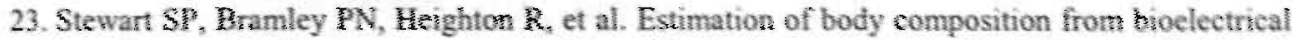
impedance of body segments: comparison with dual-energy X-ray absorptiometry. British $J$. Natr. 1993;69:645-655.

24. Johansson AG, Forstund A, Sjodin A, Mallmin $\mathrm{H}$, Wambraeus L, 羙junghall S. Determination of body composition - a comparison of dual-energy X-ray absorptiometry and fydrodensitometry. Am. J. Clin. Nutr. 1993;57:323-326.

25. Mansfield R, Evarns S, Brodowics G, MeClung M. Comparison of dual-energy X-ray absorptiometry and underwater weighing in older and younger subjects. Med. Sci. Sports Exerc. 1991;23:S72.

26. Garrow JS. New approaches to body composition. Am. J. Clin. Nutr. 1982;35:1152-1158.

27. Culebras JM, Moore FD. TBW and the exchangeable hydrogen. Am. J. Physiol. 1977;232:R54R59.

28. Elia M. Body composition analysis: an evaluation of two component models, multicomponent models and bedside techniques. Clin. Nutr. 1992;11:114-127.

29. Forbes GL. Human body composition: growth, aging, nutrition, and activity. New York: Springer-Verlag, 1987:

30. Formica C, Atkinson MG, Nyulasi I, McKay J, Heale W, Seeman E. Body composition following hemodialysis: studies using dual-energy $\mathrm{X}$-ray absorptiometry and bioelectrical impedance analysis. Osteoporos. Int. 1993;3:192-197.

31. Going SB. Massett MP, Hall MC, et al. Detection of small changes in body composition by dual-energy X-ray absorptiometry. Am. J. Clin. Nutr. 1993;57:845-850.

32. Horber FF, Thomi F, Casez JP, Fonteille J, Jaeger P. Impact of hydration status on body composition as measured by dual-energy X-ray absorptiometry in normal voluntecrs and patients on haemodialysis. Br. J. Radiology 1992;65:895-900.

33. Heymstield SB, Waki M. Body composition in humans: advances in the development of multicompartiment chemical models. Nutrition reviews 1991;49:97-108. 



\section{CHAPTER 3}

Different patterns of chronic tissue wasting among patients with chronic obstructive pulmonary disease

Mariëlle P.K.J. Engelen, Annemie M.W.J.

Schols, Rob J.S. Lamers' and Emiel F.M.

Wouters

Depts. of Pulmonology and 'Radiology,

University Hospital Maastricht, Maastricht, The Netherlands 


\section{ABSTRACT}

Background \& Aims: Nutritional depletion is frequently present in patients with chronic obstructive pulmonary disease, but it is unknown whether a difference exists between the two subtypes. The aim of this study was to determine whether patterns of tissue depletion were different between COPD patients with and without radiologic emphysema (EMPH+, EMPH-, respectively) and whether these were related to pulmonary function.

Methods: In 99 severe COPD patients and 28 healthy volunteers, body weight and composition were assessed by dual-energy X-ray absorptiometry. Patients were stratified into EMPH- $(n=50)$ and EMPH $+(n=49)$ by high-resolution computed tomography.

Results: Lean mass depletion was found in $37 \%$ of the EMPH+ patients and in $12 \%$ of the EMPH- patients. The EMPH+ patients had lower values for body mass index than the other groups $(p<0.01)$, mainly due to a lower lean mass $(p<0.01)$ and bone mineral content $(p<0.01)$. Fat mass was also lower in the EMPH+ group compared to the EMPH- group $(p<0.001)$. The EMPH- patients had a higher fat mass $(p<0.05)$ and a lower bone mineral content $(\mathrm{p}<0.01)$ than the healthy volunteers.

Conclusions: Substantial differences in body composition were found not only between chronic obstructive pulmonary disease patients and healthy volunteers, but also between COPD patients with and without emphysema.

\section{INTRODUCTION}

Weight loss and tissue depletion commonly occur in Chronic Obstructive Pulmonary Disease (COPD). Patients with tissue depletion, as indicated by a low body mass index, appear to have poor survival rates $(1,2)$. Although COPD is viewed as an uniform single entity $(3,4)$, recently more evidence came available that diffusing limitation (the hallmark of emphysema) is associated with metabolic changes (5). This suggests that differences in body composition are present between COPD patients with and without emphysema.

Already in the past, anthropometric characteristics were used to differentiate COPD subtypes. The "pink puffer" (emphysematous type) was characterized as being thin in appearance with frequent major weight loss, whereas the "blue bloater" (chronic bronchitic type) was frequently obese with no marked weight loss, except occasionally in terminal stages (6). Despite an equal extent of ventilatory impairment, the pink puffers showed more emphysematous destruction of the lungs as assessed by post-mortem analysis (6). Since only body weight was assessed in this study, no data are available regarding differences in body composition (i.e. fat mass, and the metabolically active FFM). 
The importance of measuring FFM is emphasized by the fact that depletion of fat-free mass, indicating loss of muscle mass, appears to significantly contribute to peripheral skeletal muscle weakness and impaired exercise capacity in COPD (7-10). In previous studies, we showed that FFM depletion is a significant problem in severe COPD inpatients (11) and outpatients with moderate airflow obstruction (10). Depletion of FFM was poorly related to the degree of airflow obstruction but a stronger relationship was found with diffusing capacity $(1,10)$. This suggests that FFM depletion is mainly present in patients suffering from emphysema.

Single breath diffusing capacity for carbon monoxide is an indirect reflection of the integrity of the alveolo-capillary membrane, and is therefore considered to be a marker of emphysema. Recently, high-resolution computed tomography (HRCT) was introduced, which allows direct demonstration of the presence, extent and severity of emphysema (12). Besides assessing FFM and FM, dual-energy X-ray absorpiometry (DXA) makes it possible to measure lean mass (bone-free FFM) and bone mineral mass (13). Recently, body composition by DXA was evaluated by comparison with bioelectrical impedance and deuterium dilution in patients with chronic respiratory disease $(14,15)$. These studies reported a high level of agreement, indicating that DXA is a well-suited method for assessing body composition in this patient population.

The purpose of this study was to investigate possible differences in body composition between COPD patients with and without emphysema, as defined by HRCT, adjusted for pulmonary function. In addition, the body composition ' of the COPD subgroups were compared to a group of healthy age-matched volunteers.

\section{METHODS}

\section{Study population}

A group of 99 patients with moderate to severe COPD (22 women, 77 men; FEV $38.5 \pm 13.3 \%$ pred.), who were consecutively admitted to a pulmonary rehabilitation center, were studied. These patients fulfilled the following criteria: (1) COPD according to American Thoracic Society guidelines (16) and chronic airflow limitation defined as measured forced expiratory volume in one second $\left(\mathrm{FEV}_{1}\right)$ less than $70 \%$ of the predicted value (2) irreversible obstructive airway disease $(<10 \%$ improvement of $\mathrm{FEV}_{1}$ predicted baseline after inhalation of a $\beta_{2}$-agonist); (3) clinically stable and not suffering from respiratory tract infection; (4) no concomitant confounding diseases like malignancies, gastrointestinal disorders, severe endocrine disorders or recent surgery. Twenty-eight healthy, age-matched volunteers free from acute and chronic diseases also participated in the study. $80 \%$ of the COPD patients and $71 \%$ of the healthy volunteers were (ex)smokers. The maintenance treatment of COPD patients consisted of inhaled $\beta_{2}$-agonists, inhaled anticholinergics, inhaled corticosteroids and/or oral theophylline. $44 \%$ of the 
patients were treated with oral corticosteroids. None of the healthy volunteers did use any of these maintenance medications. The study was approved by the medical ethical committee of the University Hospital Maastricht.

\section{Assessment of emphysema}

In all patients, evaluation of the presence and severity of parenchymal destruction, the hallmark of emphysema (17), was performed by high-resolution computed tomography (HRCT) using a commercial scanner (Somatom Plus; Siemens, Erlangen, Germany) (voltage: $137 \mathrm{kVp}$, current:220 mA, collimation: $1.0 \mathrm{~mm} ; 1.0$ sec. scanning time). Five HRCT scans were obtained in supine position during breath holding at end-expiration: two scans of the upper and two scans of the lower lung zones at three and six cm above and below the carina, respectively and one scan at the carina. Images were made at a level of -800 Hounsfield Units (HU) and a window width of 1,600 HU, which is appropriate for lung detail. The severity and extent of emphysema in each scan were visually scored on a four-point scale by two independent observers according to the direct observational method developed by Sakai (18). The detection and quantification of emphysema by visual inspection and grading was quick and easy to perform. For each of the 10 lung sections, the score for scverity was multiplied by the score for the extent and the resultant scores were subsequently summed to give the total HRCT score. Visual HRCT scores ranged from 0 (no emphysema) to 120 (severe emphysema).

\section{Assessment of body weight and composition}

Body weight was measured by using an electronic beam scale with a digital readout to the nearest $0.1 \mathrm{~kg}$ (model 708: Seca, Hamburg, Germany) with patients and healthy volunteers standing barefoot and wearing light indoor clothing. Body height was measured to the nearest $0.1 \mathrm{~cm}$ (model 220; Seca). Whole body FFM, consisting of lean mass and bone mineral content (BMC), and fat mass were determined by scanning all patients and healthy volunteers on a DPX-L Bone Densitometer (Lunar Radiation Corporation, Madison, WI)(voltage: $76.0 \mathrm{kVp}$; current: $150 \mu \mathrm{A}$ : collimation: $1.68 \mathrm{~mm}$ ). For that purpose, the subject lay in supine position on a scan table for approximately 15 minutes while the DXA scanner performed multiple fast speed transverse scans from head to toes with $1 \mathrm{~cm}$ intervals, with a scan area of 576 by $1968 \mathrm{~mm}$ and a sample interval of $1 / 32$. The instrument used a rectilinear scanner to detect density differences as the two levels of photon energy were projected through the subject. The DPX-L DXA scanner used a constant potential x-ray source at $78 \mathrm{kV}$ and a K-edge filter to achieve a congruent beam of stable dual-energy radiation with effective energies of 38 and $70 \mathrm{keV}$ (13). Data were collected in a maximum of 205 scan lines by 120 sample points (pixel size: $4.8 * 9.6 \mathrm{~mm}$ ). Entrance radiation dose was minimal ( $<0.02 \mathrm{mSv} / \mathrm{scan})$. BMC, FM and lean mass were derived according to computer algorithms (Lunar software version 1.3) provided by the manufacturer $(13,19,20)$. Body weight was obtained by adding lean mass, BMC 
and FM. Percentage body fat was calculated as FM relative to body weight. FFM was computed as the sum of lean mass and BMC.

Bone mineral density (BMD) is the BMC normalized for bone size. Bone mineral densities of the subjects were expressed as grams per centimeter squared.

Quality assurance tests were run daily. Three times a week, DXA software validation phantoms provided by the manufacturer, and closely reflecting the attenuation characteristics of the major constituents of the body (lean mass, fat mass and bone) were scanned.

Between-group comparison was performed by adjusting weight, FFM, FM, lean mass and BMC for body surface. For this purpose, these parameters were divided by squared height $\left(\mathrm{kg} / \mathrm{m}^{2}\right)$, as suggested by VanItallie (21). Body mass index (BMI), FFM index, FM index, lean mass index and BMC index were used for statistical analysis.

\section{Pulmonary function tests}

All patients and healthy volunteers underwent spirometry with detemination of forced expiratory volume in one second $\left(\mathrm{FEV}_{1}\right)$ and forced vital capacity $(\mathrm{FVC})$ with the highest value from at least 3 technically acceptable assessments being used. Static and dynamic lung volumes (total lung capacity (TLC), intrathoracic gas volume (ITGV) and airway resistance $\left(\mathrm{R}_{\mathrm{u}}\right)$ ) were assessed by whole-body plethysmography (Masterlab, Jaeger, Wurzburg, Germany). Diffusing capacity for carbon monoxide $\left(\mathrm{Dl}_{\mathrm{co}}\right)$ was measured by using the single-breath method (Masterlab, Jaeger, Wurzburg, Germany). Subtracting estimated dead space from inspiratory volume gives an estimate of alveolar volume (VA) and the $\mathrm{DL}_{\mathrm{co}}$ was then corrected for alveolar volume (transfer factor $\mathrm{K}_{\mathrm{co}}$ ). All values obtained were related to a reference value and expressed as percentage of the predicted value (22).

\section{Statistical analysis}

Results are expressed as means \pm SDs. Patients were stratified by HRCT score into three groups: HRCT score $<30$ (no or trivial emphysema), $30 \leq$ HRCT score $<60$ : moderate emphysema; HRCT score $\geq 60$ : severe emphysema. The group with no or trivial emphysema was defined as the EMPH- group, the group with moderate to severe emphysema was defined as the EMPH+ group.

A second classification was performed according to body composition. Stratification by lean mass index $\left(12.9 \mathrm{~kg} / \mathrm{m}^{2}\right.$ (females) $/ 16.3 \mathrm{~kg} / \mathrm{m}^{2}$ (males)) resulted in a lean mass depleted group and a non-depleted group, as defined by Shoup (23). Differences in body composition and pulmonary function between the total COPD group, the COPD patients with and without emphysema and the healthy volunteers were assessed by analysis of covariance (ANCOVA), taking into account possible variation in $\mathrm{FEV}_{\mathrm{l}}$ and sex. Tukey's pairwise multiple comparison procedure was used to analyze the differences between the EMPH+, EMPH- and the control group. 
Scheffe test was used to analyze the differences between the COPD group and control group. A two-tailed probability value of less than 0.05 was considered as statistically significant.

\section{RESULTS}

Ninety-nine COPD patients (50 EMPH- patients, 49 EMPH+ patients) and 28 healthy voluntecrs participated in the study (Table 1). Mean age was $64 \mathrm{y}$.

\section{Body weight and composition in COPD patients and healthy volunteers}

Despite a comparable body weight and BMI in the COPD group and the healthy voluntecrs, marked differences were present in body composition. The COPD group had lower values for FFM index $(p<0.001)$, due to a lower lean mass index $(p<0.01)$ and BMC index $(p<0.001)$. Also, BMD was lower in the COPD group $(p<0.001)$. No significant differences were found in FM index and percentage body fat.

Table 1. General characteristics, bodj weight and composition of the healthy volunteers, the total COPD population, and the COPD subtypes

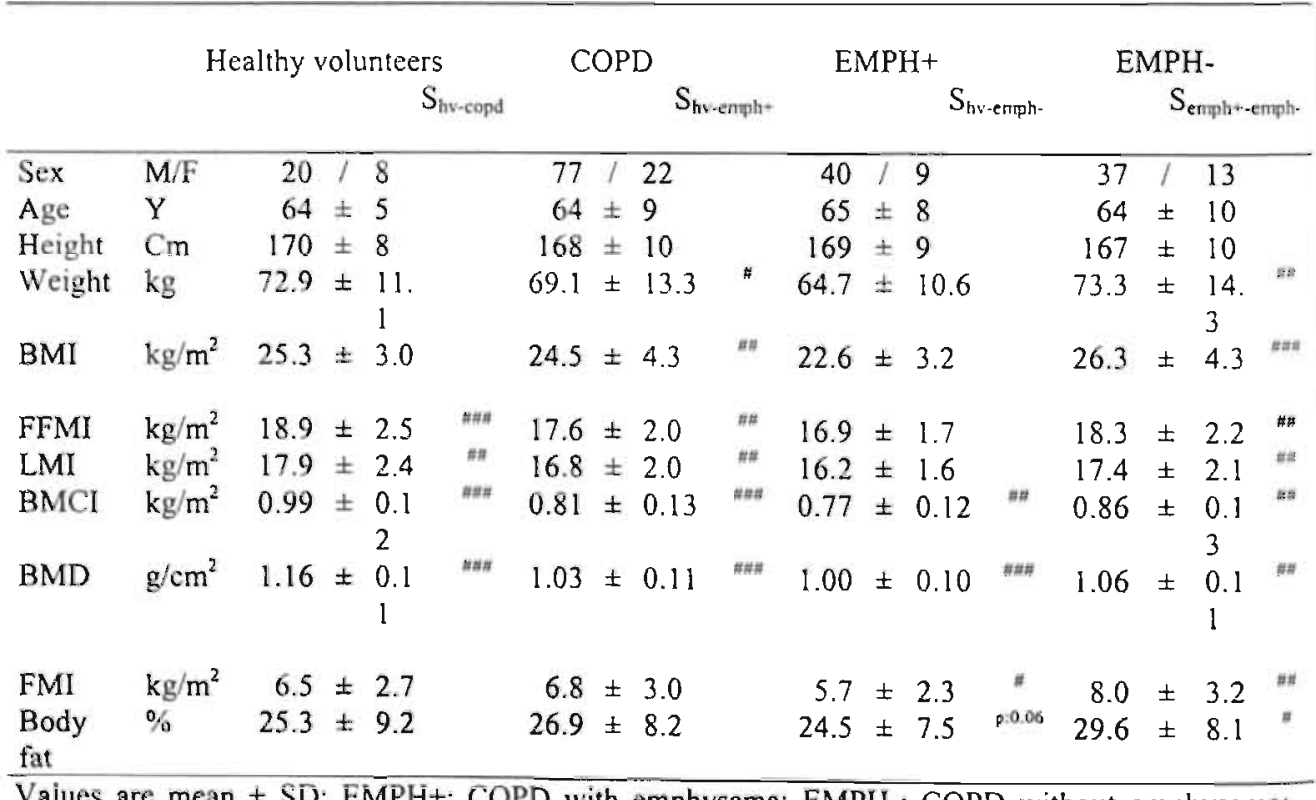

Values are mean \pm SD; EMPH+: COPD with emphysema; EMPH-: COPD without emphysema; BMI: body mass index; FFMI: fat-free mass/height ${ }^{2}$; LMI: lean mass/height ${ }^{2}$; BMCI: bone mineral contentheight ${ }^{2}$; BMD: bone mineral density; FMI: fat mass/height ${ }^{2} ; \mathrm{S}_{\mathrm{lv}-\text { copd }}$ : significance between the healthy volunteers and the total copd group; $\mathrm{S}_{\mathrm{hv} \text {-emph+ }}$ significance between the healthy volunteers and the EMPH+ group; $S_{\mathrm{hv} \text {-empt }}$ : significance between the healthy volunteers and the EMPH- group; $\mathrm{S}_{\text {empht-emph }}$ : significance between the EMPH+ and EMPH- patients; ${ }^{n} \mathrm{P}<0.05 ;{ }^{n t} \mathrm{P}<0.01 ;{ }^{* a s} \mathrm{P}<0.001$ 


\section{Body weight and composition in EMPH- patients, EMPH+ patients and healthy volunteers}

Recent involuntary weight loss was found in $49 \%$ of the EMPH+ patients and in $22 \%$ of the EMPH- patients ( $\mathrm{p}<0.05$ ). Lean mass depletion, as defined by Shoup (23), was found in $37 \%$ of the EMPH+ patients, $12 \%$ of the EMPH- patients and in $4 \%$ of the healthy controls. In $16 \%$ of the EMPH+ patients and in $8 . n$ of the EMPHpatients, lean mass depletion was found despite a normal body wcight (BMI $>21$ $\left.\mathrm{kg} / \mathrm{m}^{2}\right)$.

Body weight and BMI were lower in the EMPH+ group than in the healthy controls (Table 1). This lower body weight was the result of a lower lean mass index $(\mathrm{p}<0.01)$ and BMC index $(\mathrm{p}<0.001)$. Also, BMD was lower in the EMPH+ group $(\mathrm{p}<0.001)$. No significant difference was found in $F M$ index or in percentage body fat between the two groups.

Body weight, BMI, lean mass index and FFM index were not different between the EMPH- and the healthy control group. However, the EMPH- group had lower values for BMC index $(p<0.01)$ and BMD $(p<0.001)$ and higher values for FM index $(p<0.05)$ and percentage body fat $(p=0.06)$.

Body weight and composition were significantly different between the EMPH- and the EMPH+ group. The EMPH+ patients had lower values for BMI, FFM index and FM index than the EMPH- group. The lower FFM index in the EMPH+ group was the result of a lower lean mass index $(\mathrm{p}<0.01)$ and BMC index $(\mathrm{p}<0.01)$. Also, BMD was lower in the EMPH+ group $(p<0.01)$. Significance of differences in body composition between the COPD subtypes remained after adjustment for variation in $\mathrm{FEV}_{1}$. Values for body weight and all measures of body composition were comparable in the group with moderate emphysema $(30 \leq$ HRCT-score $<60)$ and severe emphysema (HRCT-score $\geq 60$ ).

The EMPH- and EMPH+ patients had higher values for $\mathrm{RV}$ and $\mathrm{R}_{\mathrm{aw}}$, and lower values for $\mathrm{FEV}_{1}, \mathrm{FVC}$, diffusing capacity $\left(\mathrm{DL}_{\mathrm{co}}, \mathrm{K}_{\mathrm{co}}\right)$ and arterial $\mathrm{pO}_{2}$ than the healthy volunteers (Table 2). Moreover, the EMPH+ patients had also higher valucs for TLC than the healthy volunteers. Comparison of the two COPD subtypes revealed that the EMPH+ patients had lower values for $\mathrm{FEV}_{1}, \mathrm{Dl}_{\mathrm{co}}$ and $\mathrm{K}_{\mathrm{co}}$, and had more severe hyperinflation (reflected by higher values for TLC and RV). No differences were found in arterial $\mathrm{pO}_{2}$ and $\mathrm{pCO}_{2}$ between the COPD subtypes.

In the COPD group, FFM index as well as lean mass index were significantly correlated with $\mathrm{DL}_{\mathrm{co}}$ (FFM index: $\mathrm{r}: 0.34 ; \mathrm{p}<0.05$; lean mass index: $\mathrm{r}: 0.36 ; \mathrm{p}-0.05$ ) and with $\mathrm{K}_{\mathrm{co}}$ (FFM index: $\mathrm{r}: 0.26 ; \mathrm{p}<0.05$; lean mass index: $\mathrm{r}: 0.27 ; \mathrm{p}<0.05$ ). Fat mass index was significantly correlated with $\mathrm{R}_{\mathrm{aw}}(\mathrm{r}:-0.27 ; \mathrm{p}<0.05)$, and with the static lung volumes RV $(r:-0.26 ; p<0.05)$ and ITGV $(r:-0.35 ; p<0.01)$. No significant relationship was found between BMD and any of the lung function data. 
Table 2. Pulmonary characteristics of the COPD patients with and without emphysema and the healthy volunteers

\begin{tabular}{|c|c|c|c|c|c|c|c|c|c|c|c|}
\hline \multirow{3}{*}{$\begin{array}{l}\mathrm{FEV}_{1} \\
\text { HRCT-score }\end{array}$} & \multirow[b]{2}{*}{ \%pred. } & \multicolumn{3}{|c|}{ EMPH $^{+}{ }_{\mathrm{S}_{\mathrm{emph}+-\mathrm{emph}}}$} & \multicolumn{3}{|c|}{$\begin{array}{l}\text { EMPH- } \\
\qquad S_{\text {hvermph- }}\end{array}$} & \multicolumn{4}{|c|}{$\begin{array}{l}\text { Healthy volunteers } \\
\qquad S_{\mathrm{lw}-\mathrm{emph}}\end{array}$} \\
\hline & & 33.4 & \pm 10.8 & 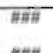 & 43.6 & \pm 13.7 & pHAI- & 108.0 & \pm 1 & 17.2 & $y=$ \\
\hline & & 61.4 & \pm 23.8 & Hil & 7.3 & \pm 7.8 & & & & & \\
\hline $\mathrm{Dl}_{\mathrm{co}}$ & $\%$ pred. & 43.6 & \pm 15.8 & sin & 73.7 & \pm 17.0 & \#\#\# & 117.0 & \pm 1 & 19.6 & Fint \\
\hline $\mathbf{K}_{\mathrm{co}}$ & \%pred. & 49.8 & \pm 15.8 & "s\#\# & 88.7 & \pm 39.6 & Ht & 113.3 & \pm 2 & 20.3 & F\#\#\# \\
\hline FVC & \%pred. & 85.2 & \pm 19.3 & & 86.1 & \pm 16.3 & H\# & 118.0 & \pm 1 & 15.1 & HAH \\
\hline $\mathrm{R}_{\mathrm{aw}}$ & $\%$ pred. & 240.3 & \pm 79.6 & & 252.4 & \pm 100.6 & $m z$ & 96.1 & \pm 4 & 44.4 & 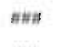 \\
\hline TLC & $\%$ pred. & 128.4 & \pm 16.0 & $n \pi$ & 118.2 & \pm 19.6 & & 115.0 & \pm 1 & 11.8 & $\#$ \\
\hline RV & $\%$ pred. & 209.1 & \pm 58.8 & $m$ & 175.4 & \pm 50.5 & $m$ & 115.1 & \pm 1 & 19.1 & F*\# \\
\hline $\mathrm{pO}_{2}$ & $\mathrm{kPa}$ & 9.1 & \pm 1.2 & & 9.7 & \pm 1.5 & \#\#" & 11.8 & \pm 1 & 1.6 & An" \\
\hline $\mathrm{pCO}_{2}$ & $\mathrm{kPa}$ & 5.7 & \pm 0.9 & & 5.7 & \pm 0.7 & & 5.5 & \pm 0 & 0.4 & \\
\hline
\end{tabular}

Values are mean \pm SD; EMPH+: COPD with emphysema; EMPH-: COPD without emphysema; $\mathrm{FEV}_{1}$ : forced expiratory volume in 1 second; $\mathrm{Dl}_{\mathrm{co}}$ : diffusing capacity for carbon monoxide; $\mathrm{K}_{\mathrm{co}}$ : diffusing capacity corrected for alveolar volume; FVC: forced vital capacity; $\mathrm{R}_{\mathrm{aw}}$ : airway resistance; TLC: total lung capacity; RV: residual volume; $\mathrm{S}_{\text {emph+-enph-: }}$ significance between the EMPH+ and EMPH- patients; $S_{\mathrm{hv}-\text { emplr. }}$ : significance between the healthy volunteers and the EMPH- group; $S_{\mathrm{hv} \text { - }}$ emph+: significance between the healthy volunteers and the EMPH+ group; ${ }^{* t h} \mathrm{P}<0.01 ;{ }^{* \# n} \mathrm{P}<0.001$

\section{DISCUSSION}

The present study showed differences in body composition between COPD patients and healthy volunteers despite comparable values for body mass index. Body composition was also different between the COPD subtypes EMPH+ and EMPH-, stratified by high resolution computed tomography. The EMPH+ patients had lower values for body mass index than the EMPH- patients, due to a lower fat mass, lean mass and bone mineral mass. However, a reduced lean mass and bone mineral mass was also found in EMPH- patients when compared to healthy volunteers, despite a relatively elevated fat mass. Different patterns of chronic tissue wasting between patients with EMPH- and EMPH+ can thus be distinguished. This might indicate the involvement of different regulatory mechanisms for disturbances in intermediary metabolism in COPD.

In the present study, a relatively high proportion of EMPH+ patients expressed weight loss and was underweight. In general, loss of fat mass is the normal metabolic response to a negative energy balance, which is the net result of diminished energy intake relative to energy expenditure. In COPD, it is unlikely that a diminished energy intake, in absolute terms, is the most important determinant of weight loss. Earlier studies revealed normal or even high dietary energy intake when compared to predicted energy requirements (24-26). On the other hand, multiple studies found elevated values for energy expenditure in the resting state (REE) of COPD patients $(24,26-28)$. REE does not account for differences in total daily 
energy expenditure (TDE), although this is often assumed particularly in sedentary people and patients. In a recent study by our group, free living TDE in severe COPD patients was significantly higher compared with healthy subjects (29). In a subsequent study, an elevated TDE was even observed in COPD patients, independently of their REE (30). Thus, depending upon the underlying cause of the metabolic derangement, a dissociation may be present between REE and TDE, the latter being the most important determinant of energy balance.

In general, TDE can be influenced by the level of physical activity as well as the efficiency of energy expenditure for a given activity. The above cited study by Baarends et al. shows an increased TDE in severe COPD patients despite comparable daily activity patterns between these patients and healthy controls (29). This finding suggests a decreased efficiency for a given activity in COPD patienrs. The presence of mechanical inefficiency during submaximal exercise was demonstrated in a later study (31). Patients with a decreased mechanical efficiency were characterized by an increased oxygen cost of breathing as reflected by increased values for oxygen consumption $\left(\mathrm{VO}_{2}\right)$ per liter ventilation and an increased $\mathrm{VO}_{2}$ /work load relationship. In COPD, the presence of dynamic hyperinflation might be an important contributor to this increased oxygen cost of breathing during exercise. As observed in the present study, marked hyperinflation at rest (based on high values for RV and TLC) was found particularly in EMPH+ patients. Based on this, we expect that EMPH+ patients will express a relatively high oxygen cost of breathing during activities, due to more air trapping. As a result, a high amount of dynamic hyperinflation occurs. This high oxygen cost of breathing might contribute to an increased total daily energy expenditure, in particular, in the EMPH+ group. Therefore, EMPH+ patients might be more prone to weight loss based on an increased energy requirement unbalanced by dietary intake.

Besides a lower fat mass, the EMPH+ patients were also characterized by a significantly lower FFM than the healthy volunteers. It is expected that weight loss in the EMPH+ group is not only the result of FM loss, but also to small losses of FFM (32). FFM depletion was present in EMPH+ patients as well as in EMPHpatients, suggesting that additional factors besides a negative energy balance may negatively influence FFM in COPD. A sedentary lifestyle, often observed in COPD, may contribute to a decreased FFM in EMPH- and EMPH+ patients, since it is known to negatively affect muscle mass (33), independent of the amount of fat mass. COPD is also characterized by a systemic inflammatory response based on elevated levels of acute phase proteins and cytokines in peripheral blood. The inflammatory status of COPD patients was associated with an increased resting energy expenditure (34) and a decreased dietary intake (35). Moreover, a relation was found between inflammation and alterations in amino acid metabolism (36).

A remarkable observation in the present study was the significantly higher fat mass in the EMPH- group than in the healthy volunteers. Although the specific cause is 
unknown, inactivity as well as disturbances in intermediary metabolism could play a role in this. More research is needed to get insight in the mechanisms which underlie the increased levels of fat mass in EMPH- patients. This is of importance in order to improve intervention strategies in this group. Nutritional supplementation is of crucial importance in EMPH+ patients. However, it might be less beneficial in weight stable EMPH- patients since the risk of overfeeding is present, thereby further increasing their metabolically inactive fat mass. In this group, physical training may be beneficial to increase FFM.

Dual-energy X-ray absorptiometry allowed us to find a reduced bone mineral mass in the COPD group compared to the healthy volunteer group. Bone mineral loss in COPD patients might be the result of a decreased mechanical loading due to their sedentary lifestyle and/or to the use of specific medication (i.e. glucocorticosteroids). The observation that $\mathrm{EMPH}+$ patients had significantly lower values for bone mineral mass than EMPH- patients is more difficult to explain. The percentage of patients using inhaled and/or oral corticosteroids was not significantly higher in the EMPH+ group compared to the EMPH- group (oral corticosteroids: $54 \%$ vs. $50 \%$ resp.; inhaled corticosteroids: $76 \%$ vs. $91 \%$ resp.). Also, the activity level is not expected to be different between the COPD subtypes. However, it is well possible that loss of bone mineral mass in the EMPH+ patients is inevitable in the course of cachexia $(37,38)$.

In the present study, HRCT was used for assessment of emphysema since it is considered the most accurate imaging method for diagnosing emphysema in vivo $(39,40)$ and the findings correlate closely to pathologic findings. However, a drawback of the used visual scoring technique is that they depend on the experience of the observer and an 10\% intraobserver and interobserver variability has been reported (41). Moreover, HRCT is not sensitive in detecting the earliest lesions of emphysema (42).

The present study shows substantial differences not only in body composition between COPD patients and healthy volunteers but also between the COPD subtypes EMPH- and EMPH+, stratified by HRCT. These differences in wasting patterns need to be considered when initiating specific nutritional and exercise intervention strategies to enhance functional performance in COPD.

\section{References}

1. Wilson DO, Rogers RM, Wright EC, Anthonisen NR. Body weight in chronic obstructive pulmonary disease. Am. Rev. Respir. Dis. 1989; 139: 1435-1438.

2. Schols AMWJ, Slangen J, Volovics L, Wouters EFM. Weight loss is a reversible factor in the prognosis of chronic obstructive pulmonary disease. Am. J. Respir. Crit. Care Med. 1998; 157: 1791-1797.

3. American Thoracic Society. Definitions, epidemiology, pathophysiology, diagnosis, and staging. Am. J. Respir. Crit. Care Med. 1995; 152: S78-S121. 
4. European Respiratory Society. Optimal assessment and management of chronic obstructive pulmonary disease (COPD). Eur. Respir. J. 1995; \&: 1398-1420.

5. Donahoe $M$. Nutritional support in advanced lung disease. The pumonary cachexia syndrome. Clin. Chest Med. 1997; 18:547-561.

6. Filley GF, Beckwitt HJ, Reever IT, Mitchell RS. Chronic obstructive bronchopulmonary disease. 2. oxygen transport in two clinical types. Am. J. Med. 1968; 44: 26-38.

7. Bemard S, LeBlane P, Whittom F, Camier G, Jobin J, Belleau R, Maltais F. Peripheral muscle weakness in patients with chronic obstructive pulmonary disease. Am. J. Respir. Crit. Care Med. 1998; 158: 629-634.

8. Baarends EM, Schols AMWJ, Mostert R, Wouters EFM. Peak exercise response in relation to tissue depletion in patients with chronic obstructive pulmonary disease. Eur. Respir. J. 1997; 10: $2807-2813$.

9. Schols AMWJ, Mostert R, Soeters PB, Wouters EFM. Body composition and exercise performance in patients with chronic obstructive lung disease. Thorax 1991; 46: 695-699.

10. Engelen MPKJ, Schols AMWJ, Baken WC, Wesseling GJ, Wouters EFM. Nutritional depletion in relation to respiratory and peripheral skeletal muscie function in out-patients with COPD. Eur. Respir. J. 1994; 7: 1793-1797.

11. Schols AMWJ, Soeters PB, Dingemans AMC, Mostert R, Frantzen PJ, Wouters EFM. Prevalence and characteristics of nutritional depletion in patients with stable COPD eligible for pulmonary rehabilitation. Am. Rev. Respir. Dis. 1993; 147: 1151-1156.

12. Klein JS, Gamsu G, Webb WR, Golden JA, Muller NL. High-resolution CT diagnosis of emphysema in symptomatic patients with normal chest radiographs and isolated low diffusing capacity. Radiology 1992; 182: 817-821.

13. Mazess RB, Barden H, Bisek JP, Hanson J. Dual-energy X-ray absorptiometry for total-body and regional bone- mineral and soft-tissue composition. Am. J. Clin. Nutr. 1990; 51: 1106-1112.

14. Kyle UG, Rochat T, Slosman DO, Fitting J-W. Thiebaud D. New bioelectrical impedance formula for patients with respiratory insufficiency: comparison to dual-energy X-ray absorptiometry. Eur. Respir. J. 1998; 12: 960-966.

15. Engelen MPKJ, Schols AMWJ, Heidendal GAK, Wouters EFM. Dual-energy X-ray absorptiometry in the clinical evaluation of body composition and bone mineral density in patients with chronic obstructive pulmonary disease. Am. J. Clin. Nutr. 1998; 68: 1298-1303.

16. American Thoracic Society. Standards for the diagnosis and care of patients with chronic obstructive pulmonary disease (COPD) and asthma. Am. Rev. Respir. Dis. 1987; 137: 225-228.

17. American Thoracic Society. Chronic bronchitis, asthma, and pulmonary emphyserna by the committee on diagnostic standards for nontubercolosis respiratory disease. Am. Rev. Respir: Dis. $1962 ; 85: 762-812$.

18. Sakai F, Gamu G, Im JG, Ray CS. Pulmonary function abnormalities in patients with CTdetermined emphysema. J. Comput. Assist. Tomogr. 1987; 11:963-968.

19. Peppler WW, Mazess RB. Total body bone mineral and lean body mass by dual-photon absorptiometry. 1. Theory and measurement procedure. Calcif. Tissue Int. 1981; 33:353-359.

20. Gotfredsen A, Jensen J, Borg J, Christiansen C. Measurement of lean body mass and total body fat using dual photon absorptiometry. Metabolism 1986; 35: 88-93.

21. VanItallie TB, Yan M, Heymsfield SB, Funk RC, Boileau RA. Height-normalized indices of body's fat-free mass and fat mass: potentially useful indicators of nutritional status. Am. J. Clin. Nutr. 1990; 52: 953-959.

22. Quanjer P, Tammeling GJ, Cotes JE, Pedersen OF, Peslin R, Yernault JC. Standardized lung function testing. Eur. Respir. J. 1993; 6: 5-40.

23. Shoup R, Dalsky G, Warner S, Davies M, Connors M, Khan M, Khan F, ZuWallack R. Body composition and health-related quality of life in patients with obstructive airways disease. Eur. Respir. J. 1997; 10: 1576-1580.

24. Hunter AMB, Carey MA, Larsh HW. The nutritional status of patients with chronic obstructive pulmonary disease. Am. Rev. Respir. Dis. 1981; 124: 376-381. 
25. Braun SR, Keim NL, Dixon RM, Clagnaz P, Anderegg A, Shrago ES. The prevalence and determinants of nutritional change in chronic obstructive pulmonary disease. Chest $1984 ; 86$ : 558-563.

26. Schols AMWJ, Mostert R, Soeters PB, Saris WHM, Wouters E F M. Energy balance in patients with chronic obstructive pulmonary disease. Am. Rev. Respir. Dis. 1991; 143: 1248-1252.

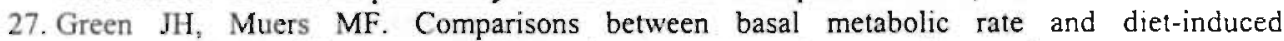
thermogenesis in different types of chronic obstructive pulmonary disease. Clin. Sci. 1992; 83: 109-116.

28. Openbrier DR, Irwin MM, Rogers RM, Gottleib GP, Dauber JH, Vanheil OH. Nutritional status and lung function in patients with emphysema and chronic bronchitis. Chest 1983; 83: 7-22.

29. Baarends EM, Schols AMWJ, Pannemans DLE, Westerterp KR, Wouters EFM. Total free living energy expenditure in patients with severe chronic obstructive pulmonary disease. Am. J. Respir. Crit. Care Med. 1997; 155: 549-554.

30. Baarends EM, Schols AMWJ, Westerterp KR, Wouters EFM. Total daily energy expenditure relative to resting energy expenditure in clinically stable patients with chronic obstructive pulmonary disease. Thorax 1997; 52: 780-785.

31. Baarends EM, Schols AMWJ, Akkermans MA, Wouters EFM. Decreased mechanical efficiency in clinically stable patients with chronic obstructive pulmonary disease. Thorax 1997; 52: 981 . 986.

32. Westerterp KR, Donkers JHHLM, Fredrix EWHM, Boekhoudt P. Energy intake, physical activity and body weight: a simulation model. Br. J. Nutr. 1995; 73: 337-347.

33. Sargeant AJ, Davies CTM, Edwards RHT, Maunder C, Young A. Functional and structural changes after disuse of human muscle. Clin. Sci. Mol. Med. 1977; 52: 337-342.

34. Schols AMWJ, Buurman WA, Staal-van den Brekel AJ, Dentener MA, Wouters EFM. Evidence for a relation between metabolic derangements and increased levels of inflammatory mediators in a subgroup of patients with chronic obstructive pulmonary disease. Thorax 1996; 51 : 819 824.

35. Schols AMWI, Creutzberg EC, Campfield A, Buurman WA, Saris WHM, Wouters EFM. A role for leptin in emphysema related tissue wasting? Am. J. Respir. Crit. Care Med. 1997; 155: A 901.

36. Pouw EM, Schols AMWJ, Deutz NEP, Wouters EFM. Arterial and muscle amino-acid levels in relation to resting energy expenditure and inflammation in stable COPD. Am. Rev. Respir. Crit. Care Med. 1998; 158: 1-5.

37. Mazess RB, Barden HS, Ohlrich ES. Skelctal and body-compositional effects of anorexia nervosa. Am. J. Clin. Nutr. 1990; 52: 438-441.

38. Van Marken-Lichtenbeld WD, Heidendal GAK, Westerterp KR. Energy expenditure and physical activity in relation to bone mineral density in women with anorexia nervosa. Eur. J. Clin. Nutr. 1997; 51: 826-830.

39. Stern EJ, Frank MS. CT of the lung in paticnts with emphysema: diagnosis, quantification, and correlation with pathologic and physiologic findings. A. J. R. 1994; 162: 791-798.

40. Thurlbeck WM, Muller NL. Emphysema: definition, imaging, and quantification. A. J. R. 1994; 163: 1017-1025,

41. Morgan MDL. Detection and quantification of pulmonary emphysema by computed tomography: a window of opportunity. Thorax 1992; 47: 1001-1004.

42. Miller RR, Muller NL, Vedal S, Morrison NJ, Staples CA. Limitations of computed tomography in the assessment of emphysema. Am. Rev. Respir. Dis. 1989; 139: 980-983. 


\section{CHAPTER 4}

Skeletal muscle weakness is associated with wasting of extremity fat-free mass but not with airflow obstruction in patients with chronic obstructive pulmonary disease

Mariëlle P.K.J. Engelen, Annemie M.W.J. Schols, Joan D. Does' and Emiel F.M. Wouters

Dept. of Pulmonology, University Hospital Maastricht, Maastricht, and 'Asthma Center Hornerheide, Horn, The Netherlands 


\section{ABSTRACT}

Background: Skeletal muscle weakness is a prominent problem in many patients with chronic obstructive pulmonary disease (COPD).

(Objcctive: The aim of the study was to determine the relationship between skeletal muscle function, body composition, and lung function in COPD patients with and without radiologic emphysema (EMPH+ and EMPH-, respectively) and healthy volunteers.

Design: In 50 patients with EMPH-, 49 patients with EMPH+, and 28 healthy volunteers skeletal muscle function was assessed by handgrip and linear isokinetic dynamometry. Whole-body and sub-regional fat-free mass (FFM) were assessed by dual-energy X-ray absorptiometry.

Results: Whole-body and extremity FFM were significantly lower in $\mathrm{EMPH}+$ patients $(\mathrm{P}<0.001)$ and EMPH- $(\mathrm{P}<0.05)$ than in healthy volunteers, but trunk FFM was significantly lower only in patients with EMPH+ $(\mathrm{P}<0.001)$. Extremity FFM was not significantly different between the COPD subtype groups, despite significantly lower values for whole-body and trunk FFM $(\mathrm{P}<0.05)$ in patients with EMPH+. Absolute skeletal muscle function $(P<0.001)$ and muscle function per kilogram of whole-body FFM were significantly lower in both COPD subtype groups than in healthy volunteers $(\mathrm{P}<0.05)$, but no significant difference was found between EMPH- and EMPH+ patients. Muscle function per kilogram of extremity FFM was not significantly different between the three groups and was not associated with forced expiratory volume in one second.

Conclusions: Skeletal muscle weakness is associated with wasting of extremity FFM in COPD patients, independent of airflow obstruction and COPD subtype.

\section{INTRODUCTION}

Skeletal muscle weakness is observed in many patients with chronic obstructive pulmonary disease (COPD) $(1,2)$. This muscle weakness is recognized as an important factor in COPD patients, because it affects their physical capacity by reducing peak exercise performance and enhancing symptom intensity $(1,3)$. Furthermore, muscle weakness and a reduced exercise capacity in COPD patients have been shown to increase utilization of health care resources (4).

Muscle wasting is one of the factors that can be considered in the pathogenesis of skeletal muscle weakness in COPD. In earlier studies, depletion of whole-body fatfree mass (FFM), mainly consisting of muscle mass, has been observed in both COPD inpatients (5) and outpatients (6). No data are available on whether depletion of whole- body FFM in COPD patients is the result of a general process affecting multiple body compartments or whether it preferentially influences specific body subregions (ie, extremities). This information seems important, because in a recent study by Bemard et al (7), skeletal muscle weakness in COPD patients was related to 
peripheral muscle atrophy, as assessed by thigh muscle cross-sectional area (CSA). Absolute quadriceps strength was significantly lower in these COPD patients than in a healthy control group, whereas the ratio of quadriceps strength to muscle CSA was not significantly different between the two groups. Furthermore, quadriceps strength and muscle CSA were positively correlated with the severity of airflow obstruction.

However, assessment of muscle CSA is not easily applicable in clinical practice. Recently, we showed that dual-energy X-ray absorptiometry (DXA) is a clinically valid method for the assessment of whole-body composition and bone mineral loss in COPD patients (8). Moreover, DXA makes it possible to assess FFM and lean mass (ie, bone-free FFM) in several body subregions. This information might be important in the diagnosis of skeletal muscle weakness, because extremity FFM gives a more detailed reflection of physically active muscle mass during daily life activities.

Two previous studies reported FFM depletion in the COPD patients with and without emphysema $(6,9)$, but FFM depletion was present to a greater extent in those with emphysema. In addition, the emphysema patients had lower values for forced expiratory volume in one second $\left(\mathrm{FEV}_{1}\right)$ than those without emphysema. These two findings suggest that COPD patients with emphysema are more prone to peripheral skeletal muscle wasting and weakness than are patients without emphysema.

The purpose of the present study was to examine whether assessment of whole-body FFM gives a reflection of extremity FFM in COPD patients with and without emphysema and in healthy volunteers, as assessed by DXA. The second aim wais to compare skeletal muscle function between the three study groups, and to find out whether possible differences are related to differences in whole-body and subregional FFM, the severity of airflow obstruction, or both.

\section{SUBJECTS AND METHODS}

\section{Study population}

All studied COPD patients were consecutively admitted to a pulmonary rehabilitation center for inpatient rehabilitation. Patients were selected on the basis of the presence of chronic airflow limitation (10) $\left(\mathrm{FEV}_{1}<70 \%\right.$ of the predicted value) and irreversible

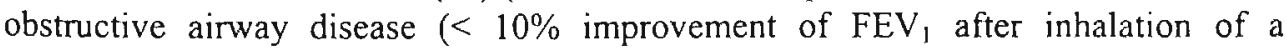
bronchodilating agonist). All patients were clinically stable and without a respiratory tract infection. Patients with malignancies, gastrointestinal disorders, or severe endocrine disorders or who had undergone surgery recently were excluded from the study. As a result, a group of 99 patients ( 77 men, 22 women) (Table 1) remained for further analysis. This group was further stratified into those with emphysema $(\mathrm{EMPH}+)(\mathrm{n}=40)$ and those without emphysema (EMPH-) $(\mathrm{n}=50)$ by high-resolution computed tomography (HRCT). Twenty-eight healthy, age-matched voluntcers free of disease participated as the control group. The study was approved by the Medical Ethical Committee of the University Hospital Maastricht 


\section{Assessment of skeletal muscle function of the upper and lower extremities}

Isometric handgrip strength was assessed in all subjects by using a Harpenden handgrip dynamometer (Yamar, Preston, Jackson, MI). The isometric grasp of the right hand was determined by measuring the maximally developed strength of the flexors of the fingers. The highest value of three maneuvers was used for statistical analysis.

Linear isokinetic muscle function of the lower limbs was assessed by a multijoint dynamometer device (Aristokin; LODE, Groningen, Netherlands). While seated with knees bent at a $90^{\circ}$ angle, the subjects' feet were attached to a fixed support, leaving the ankles free to rotate. The subjects performed maximal isokinetic extension of the legs against an applied resistance of $250 \mathrm{~N}$. The rate at which the seat shifted backwards was set at $20 \mathrm{~cm} / \mathrm{s}$ (preload: $150 \mathrm{~N}$; duration preload: $0.3 \mathrm{sec}$ ). Thus, the force generated by the subject increased with increasing voluntary effort, but the velocity of the contraction remained constant at $20 \mathrm{~cm} / \mathrm{s}$. At this isokinetic rate, the maximal energy generated by the legs mainly determined the outcome of performance. The highest power value (in W) from five technically well-performed repetitions was used in the statistical analysis. Before testing, each subject was familiarized in a standardized way with the equipment and the requested movement.

\section{Assessment of whole-body and subregional fat-free mass and lean mass}

Whole-body FFM, which consists of lean mass and bone mineral mass, was determined by scanning each subject on a DPX bone densitometer (Lunar Radiation Corporation, Madison, WI). For more technical details, see reference (8). FFM and lean mass were assessed in the whole body and in several body subregions (eg, trunk, arms and legs); the latter were obtained by positioning cuts with Lunar software. Extremity FFM was obtained by summing the FFM of the arms and legs. Precision of subregional measurements is known to be poorer than that of the whole body $(11,12)$. The same operator performed the positioning of the cuts for all images scanned to avoid inter-operator variability. Quality-assurance tests were run daily.

\section{Assessment of emphysema}

In the COPD group, evaluation of the presence and severity of parenchymal destruction, which is a hallmark of emphysema (13), was performed by HRCT with use of a commercial scanner (Somatom Plus; Siemens, Erlangen, Germany) at a voltage of $137 \mathrm{kVp}$, a current of $220 \mathrm{~mA}$, a collimation of $1.0 \mathrm{~mm}$, and a scanning time of $1 \mathrm{~s}$. Five HRCT scans were obtained while the patients were in a supine position and held their breath at end expiration: two scans of the upper and two scans of the lower lung zones at three and six $\mathrm{cm}$ above and below the carina, and one scan at the carina. Images were made at a level of -800 Hounsfield units (HU) and a window width of $1600 \mathrm{HU}$, appropriate for lung detail. The severity and extent of emphysema in each scan were visually scored on a four-point scale by two 
independent observers according to the direct observational method developed by Sakai et al (14). For each of the ten lung sections, the score for the severity of emphysema was multiplied by the extent; the resulting scores were subsequently summed to give a total HRCT score. Visual HRCT scores ranged from 0 (no emphysema) to 120 (severe emphysema). Stratification of the patients by HRCT score resulted in two groups: those with an HRCT score $<30$ (no or trivial emphysema) and those with an HRCT score $\geq 30$ (mild-to-severe emphysema). The group with no or trivial emphysema was defined as the EMPH-group; the group with mild-to-moderate emphysema was defined as the $\mathrm{EMPH}+$ group.

\section{Pulmonary function tests}

All subjects underwent spirometry. The highest value from at least three technically acceptable assessments was used. The FEV 1 obtained was related to a reference value and expressed as a percentage of the predicted value (15).

\section{Statistical analysis}

Results are expressed as means \pm SDs. The SPSS 7.5 for Windows (SPSS Inc, Chicago) computer software program was used for statistical analysis. Analysis of covariance (ANCOVA), with sex as covariate, followed by Tukey's pairwise multiple comparison procedure were used to determine possible differences in skeletal muscle function and subregional FFM and lean mass between the patients with EMPH- and EMPH+ and the healthy volunteers. In all groups, linear regression analysis was used to calculate the slope and the intercept coefficients from the relation between wholebody FFM (dependent variable) and extremity or trunk FFM (independent variable).

Furthermore, in each group, the slope and intercept coefficients of the 2 lines were statistically compared by using a t-test as described by Kleinbaum et al (16). ANOVA with Bonferroni correction was used to compare the slopes and intercept coefficients among the groups. Linear regression analysis was also performed to determine the relation between muscle function per kilogram of extremity FFM (dependent variable) and $\mathrm{FEV}_{1}$ (independent variable) for the entire study population. The signilicance level was set at $\mathrm{P}<0.05$.

\section{RESULTS}

Ninety-nine patients with moderate-to-severe airflow obstruction $\left(\mathrm{FEV}_{1}: 38.5 \pm 13.3\right.$ $\%$ predicted), and 28 healthy volunteers were studied. Forty-nine COPD patients were defined as having EMPH+ and 50 as having EMPH-. Airflow obstruction was significantly $(\mathrm{P}<0.001)$ more severe in the EMPH+ patients $\left(\mathrm{FEV}_{1}: 33.4 \pm 10.8 \%\right.$ of predicted) than in the EMPH- patients (43.6 $\pm 13.7 \%$ of predicted). The use of maintenance corticosteroid medication, which is suggested to influence muscle performance, was not significantly different between the EMPH- and I.MPH+ 
patients (oral corticosteroid use: $54 \%$ compared with $50 \%$, respectively; prednisone dose $<10 \mathrm{mg} / \mathrm{d})$.

Whole-body FFM was significantly lower in the EMPH+ patients than in the EMPHpatients $(\mathrm{P}<0.05)$ and the healthy volunteers $(\mathrm{P}<0.001)$, partly because the EMPH+ patients had a significantly lower trunk FFM than the other two groups $(\mathrm{P}<0.01)$ (Table 1). Whole-body FFM was significantly lower in the EMPH- patients than in the healthy volunteers, whereas no significant difference was found in trunk FFM between these two groups. Extremity FFM was significantly lower in the two COPD subtype groups than in the healthy volunteers $(\mathrm{P}<0.001)$, but no significant difference was found in extremity FFM between the two COPD subtype groups. In all comparisons, the findings for lean mass were the same as those for FFM.

Extremity FFM expressed as a percentage of whole-body FFM was significantly lower $(\mathrm{P}<0.001)$ in both the EMPH- $(39.7 \pm 2.9 \%)$ and the EMPH+ $(40.9 \pm 2.7 \%)$ patients than in the healthy volunteers $(46.2 \pm 1.6 \%)$ and tended to be lower in the EMPH- group than in the EMPH+ group $(\mathrm{P}=0.054)$.

Table 1. Whole body and sub-regional fat-free mass and lean mass, and skeletal muscle function of COPD patients with and without emphysema, and healthy volunteers

$\begin{array}{ccc}\text { EMPH+ } & \text { EMPH- } & \text { Healthy volunteers } \\ \mathrm{n}=49 & \mathrm{n}=50 & \mathrm{n}=28\end{array}$

\section{Fat-free mass}

Whole body

Trunk

Extremities

Lean mass

Whole body

Trunk

Extremities

$\begin{array}{ll}\mathrm{Kg} & 48.6^{\mathrm{a}} \pm 7.5 \\ \mathrm{Kg} & 23.2^{\mathrm{a}} \pm 3.9 \\ \mathrm{Kg} & 19.9^{\mathrm{a}} \pm 3.6\end{array}$

$46.3^{2} \pm 7.2$

$23.3^{2} \pm 3.8$

$18.6^{\circ} \pm 3.4$

\section{$51.1^{\circ} \pm 9.3$ \\ $25.3^{\circ} \pm 4.8$ \\ $20.4^{2} \pm 4.6$}

$48.7^{b} \pm 8.9$

$24.6^{\mathrm{b}} \pm 4.5$

$19.0^{3} \pm 4.4$ $54.4^{\mathrm{c}} \pm 10.3$

$25.3^{b} \pm 4.7$

$25.2^{b} \pm 5.2$

$51.6^{\mathrm{b}} \pm 9.8$

$24.6^{\mathrm{b}} \pm 4.7$

$23.7^{\mathrm{b}} \pm 4.9$

Muscle function

Upper extremities

Handgrip strength

$\mathrm{Kg} \quad 33.3^{\circ} \pm 9.7$

$0.7^{2} \pm 0.2$

$34.6^{a} \pm 9.9$

$0.7^{2} \pm 0.1$

$42.0^{b} \pm 11.1$

$1.7^{3} \pm 0.4$

$1.7^{2} \pm 0.3$

$0.8^{\mathrm{b}} \pm 0.1$

$1.7^{2} \pm 0.3$

\section{Lower extremities}

Power $20 \mathrm{~cm} / \mathrm{s}$

W

/ whole body FFM W/kg

/ extremity FFM W/kg $193.9^{\circ} \pm 568$

$3.9^{3} \pm 1.2$

$9.3^{2} \pm 3.0$ $193.0^{\circ} \pm 55.2$

$241.8^{b} \pm 67.1$

$4.4^{b} \pm 0.8$

$9.5^{2} \pm 1.8$

Values are mean \pm SD; EMPH+: COPD with emphysema, EMPH-: COPD without emphysema; data were analyzed by ANCOVA with sex as the covariate. Means not sharing a common superscript are significantly different at $\mathrm{P}<0.05$ 

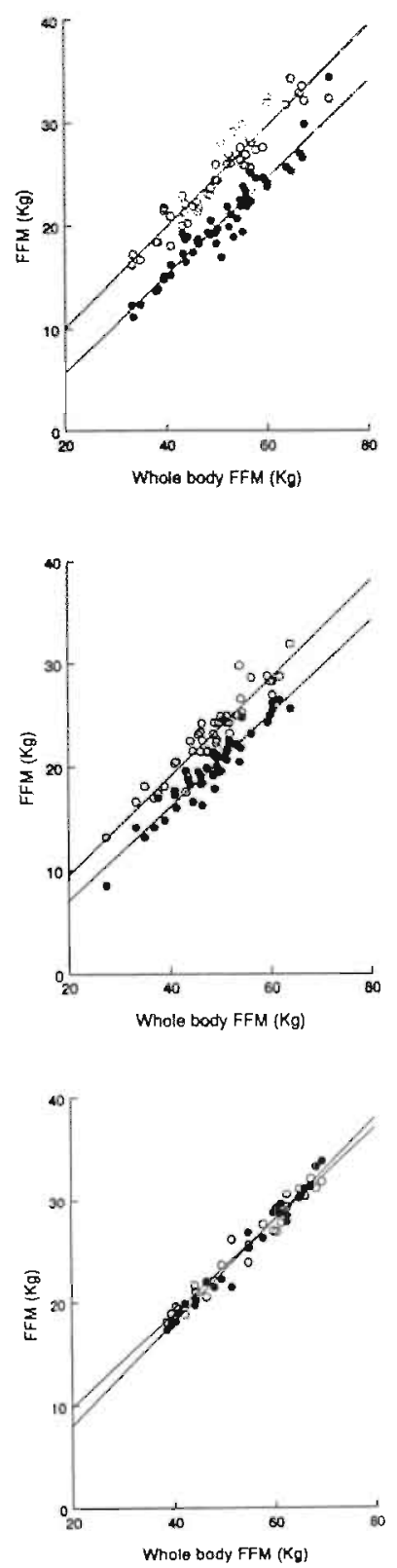

Figure 1. Scatter plot of trunk FFM (open circles) and extremity FFM (closed circles) vs. total body FFM in 50 EMPH- patients (top panel), $49 \mathrm{EMPH}+$ patients (middle panel) and 28 healthy volunteers (bottom panel). Regression lines are included:

EMPH-: $\quad$ FFM $_{\text {extrenity }}=\left(0.47 * \mathrm{FFM}_{\text {whole bedy }}\right)-3.85 ; \mathrm{FFM}_{\text {trukk }}=\left(0.49 * \mathrm{FFM}_{\text {whole body }}\right)+0.16$

EMPH+: $\quad$ FFM $_{\text {extrenity }}=\left(0.45 * \mathrm{FFM}_{\text {whole bxdy }}\right)-2.12 ; \mathrm{FFM}_{\text {ounk }}=\left(0.48 * \mathrm{FFM}_{\text {whole body }}\right)-0.19$

$\mathrm{HV}: \quad \mathrm{FFM}_{\text {extrentity }}=\left(0.71 * \mathrm{FFM}_{\text {whote body }}\right)-2.03 ; \mathrm{FFM}_{\text {trmk }}=\left(0.45 * \mathrm{FFM}_{\text {whole body }}\right)+0.50$ 
In Figure 1, whole-body FFM is plotted against subregional FFM (extremity compared with trunk) for the patients with EMPH- or EMPH+ and the healthy volunteers. In all groups, whole-body FFM was highly significantly correlated with extremity FFM as well as trunk FFM ( $r>0.94$ : data not shown).
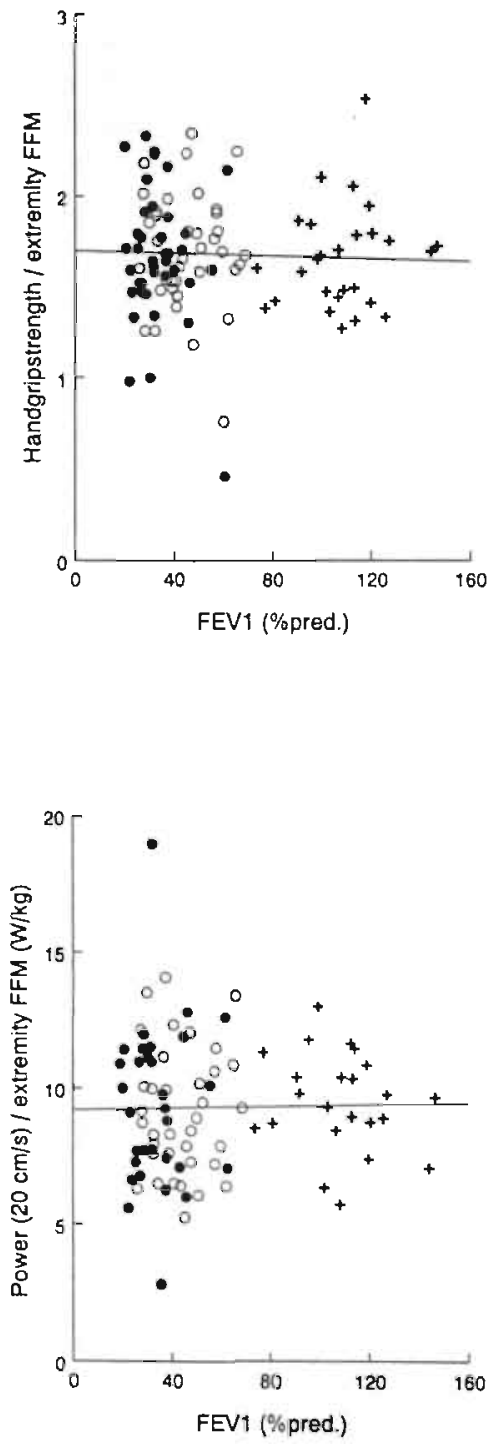

Figure 2. Scatter plot of ratio handgrip strength to extremity FFM vs. FEV (top pancl) and ratio power to extremity FFM vs. FEV 1 (bottom panel) in EMPH- patients (open circles), EMPH+ patients (closed circles) and healthy volunteers (cross signs). Regression lines of the whole study population are included:

Top panel: Handgrip strength : extremity FFM $=\left(-0.0004 * \mathrm{FEV}_{1}\right)+1.20$

Bottom panel: Power / extremity FFM $=\left(0.002 * \mathrm{FEV}_{\mathrm{l}}\right)+9.19$ 
To assess whether there was a significant difference in the relation between wholebody FFM and extremity FFM compared with trunk FFM for each group, the slopes and intercept coefficients of the two regression lines were compared. The slopes of the two lines were not significantly different between the three groups.

However, the intercept of the regression line for extremity FFM was lower than that for trunk FFM in the EMPH- group (estimated vertical distance: $4.9 \mathrm{~kg} ; 95 \% \mathrm{CI}$ : $4.3,5.5 \mathrm{~kg}$ ) and the EMPH+ group (estimated vertical distance: $3.2 \mathrm{~kg} ; 95 \%$ CI: 2.7 , $3.7 \mathrm{~kg}$ ) than in the healthy volunteers. Values for the intercept of trunk FFM and extremity FFM were not significantly different from those of the healthy volunteers.

Isometric muscle strength of the upper extremities as well as isokinetic muscle function of the lower extremities (Table 1) were significantly lower in the two COPD subtype groups than in the healthy volunteers $(\mathrm{P}<0.001)$, but were not significantly different between the two COPD subtype groups. Expressed as a percentage of the mean value for healthy volunteers, handgrip strength was $82 \pm 24 \%$ in the EMPHgroup and $79 \pm 23 \%$ in the EMPH + group; the power of the lower extremities was 80 $\pm 23 \%$ in the EMPH- group and $80 \pm 24 \%$ in the EMPH+ group. Additionally, muscle function expressed per kilogram of whole-body FFM (Table 1) was significantly lower in the two COPD subtype groups than in the healthy volunteers. However, when handgrip strength and the power of the lower extremities were expressed per kilogram of extremity FFM, no significant differences were found between the three groups. Moreover, the ratio of handgrip strength to extremity FFM as well as the ratio of the power of the lower extremities to extremity FFM were not associated with $\mathrm{FEV}_{1}(\mathrm{r}=$ $-0.03, r=0.04$, resp.) (Figure 2).

\section{DISCUSSION}

The present study showed that skeletal muscle function in absolute terms and per kilogram of whole-body FFM was significantly lower in the two COPD subtype groups than in the healthy volunteers, but was not significantly different between the two COPD subtype groups. Muscle function expressed per kilogram of extremity FFM was not significantly different among the three groups and was not associated with airflow obstruction.

Skeletal muscle weakness has been reported to be a serious problem in many patients with COPD $(1,3)$. However, these studies were limited by the absence of a healthy control group, by the fact that body weight but not body composition, was assessed, or by both. Until recently, it was unclear whether skeletal muscle weakness in COPD patients is actually related to a disturbed body composition or to alterations in the contractile properties of the peripheral skeletal muscles. Bernard et al. (7) showed that absolute quadriceps strength was lower in COPD patients than in healthy subjects, but the ratio of quadriceps strength to muscle CSA was not significantly different between the two groups. Our results agree with their findings that muscle function of the upper 
and lower extremities was lower in COPD patients than in a healthy control group, but that the ratio of muscle function to extremity FFM was comparable in the two groups. The findings were independent of the underlying disease (EMPH- or EMPH+), suggesting that the contractile properties of the peripheral skeletal muscles are preserved in both COPD subtype groups. Despite the fact that the EMPH+ group had more severe airflow obstruction (as reflected by lower $\mathrm{FEV}_{\mathrm{I}}$ values) than the EMPHgroup, no association was found between muscle function expressed per kilogram extremity FFM and $\mathrm{FEV}_{1}$.

This observation is in contrast with the finding of Bernard et al. (7), who found that quadriceps strength and muscle CSA were positively correlated with FEV 1 in COPD patients. On the basis of the findings of their study, muscle function is lower in patients with EMPH- and EMPH+ than in healthy subjects, being lowest in those with EMPH+. The present study showed that skeletal muscle weakness in EMPH- patients as well as in EMPH+ patients was due to loss of extremity FFM, but was not related to airflow obstruction.

In the present study, muscle function per kilogram of whole-body FFM was significantly lower in the two COPD subtype groups than in the healthy volunteers, whereas no significant difference was found in muscle function per kilogram of extremity FFM between the three groups. This suggests that whole-body FFM is not a good reflection of extremity FFM in the COPD groups. Both COPD subtype groups had significantly lower whole-body and extremity FFM than the healthy volunteers. A strong relation was found between the two measures in all groups, suggesting that whole-body FFM is a good reflection of extremity FFM, independent of the underlying lung disease. Assessment of lean mass (ie. bone-free FFM) did not further improve this relation. However, extremity FFM expressed as a percentage of wholebody FFM was significantly lower in the two COPD subtype groups than in the healthy volunteers and tended to be even lower in the EMPH-group. The lower extremity FFM values in both COPD subtype groups was not reflected in whole-body FFM. This dissociation needs to be considered when peripheral skeletal muscle function is evaluated in these patient populations. This is also particularly important when traditionally and more commonly applied body-composition techniques are used, which can only assess whole-body FFM. When this dissociation is not taken into account, normal whole-body FFM values may partly mask the loss of extremity FFM loss in EMPH+ patients and particularly in EMPH- patients.

Deconditioning, because of chronic inactivity, may be an important factor contributing to the loss of extremity FFM in COPD patients. In healthy subjects, disuse results in muscle fiber atrophy (17) and when the duration of disuse increases, there is progressive muscle mass (18). In the studied COPD groups, handgrip strength was $81 \%$ of the control value and the power of the lower extremities was $80 \%$ of the control value. This suggests that skeletal muscle weakness in COPD affects the upper and lower extremities to the same extent. This is in contrast with the findings $(3,19)$ that reported a more pronounced decrease in muscle strength of the lower extremities. 
Our finding is quite remarkable because on the basis of the results of these other studies, one would expect the physical activity level of the lower extremities of COPD patients to be lower than that of the upper extremities. However, our finding also implies that besides muscle disuse, other factors likely negatively influence muscle strength in COPD patients. Prolonged administration of oral corticosteroids (particularly high doses of fluorinated steroids) is known to cause muscle weakness and myopathic changes $(20,21)$. In patients with severe COPD (22). steroid-induced myopathy (after prolonged prednisone use at a dose $>10 \mathrm{mg} / \mathrm{d}$ ) was characterized by fiber atrophy. In the present study, half of the COPD patients were using oral corticosteroids (prednisone dose: $<10 \mathrm{mg} / \mathrm{d}$ ) as maintenance medication. The percentage of patients using oral corticosteroids was not significantly different between the COPD subtype groups.

FFM has been shown to be lower in the COPD patients exhibiting an acute phase response (23) than in patients without an acute phase response. Furthermore, an elevated concentration of lipopolysaccharide binding protein, which is a positive acute phase protein, has been related to decreased plasma amino acid concentrations in patients with severe COPD (24). We hypothesized that to enhance acute phase protein synthesis, a redistribution of amino acids from the skeletal muscle to the liver takes place. Enhanced amino acid fluxes in the skeletal muscle will increase local protein degradation. When this situation is not balanced by adequate protein synthesis, a catabolic state may induce extremity muscle loss in COPD patients. If this hypothesis is correct, it may also explain the comparable values for extremity FFM found in the EMPH+ and EMPH- groups, because no significant differences in systemic inflammatory mediators were found (25).

In the present study, we showed that DXA effectively determined skeletal muscle weakness in COPD patients via regional (extremity) FFM assessment. To further expand the value of DXA in the clinical evaluation of body composition in COPD patients, it is necessary to evaluate the effects of intervention strategies on subregional body composition. In FFM-depleted COPD patients, FFM can be increased by nutritional supplementation, which enhances protein synthesis. Furthermore, physical training benefits this group, because it can act as an important anabolic stimulus. In non-FFM-depleted COPD patients, strength training of the peripheral skeletal muscles alone may be sufficient to increase skeletal muscle mass and function. In these ways, enhanced limb skeletal muscle mass and function may increase exercise capacity and eventually result in an improved quality of life in COPD patients.

\section{References}

1. Hamilton AL, Killian KJ, Summers E, Jones NL. Muscle strength, symptom intensity, and exercise capacity in patients with cardiorespiratory disorders. Am. J. Respir. Crit. Care Med. 1995;152:2021-2031.

2. Nishimura Y, Tsutsumi M, Nakata H, Tsunenari T, Maeda H, Yokoyama M. Relationship between respiratory muscle strength and lean body mass in men with COPD. Chest 1995; 107:1232-1236. 
3. Gosselink R, Troosters T, Decramer M. Peripheral skeletal muscle weakness contributes to exercise limitation in COPD. Am. J. Respir. Crit. Care Med. 1996;153:976-980.

4. Decramer M, Gosselink R, Troosters T, Verschueren M, Evers G. Muscle weakness is related to utilization of health care resources in COPD patients. Eur. Respir. J. 1997;10:417-423.

5. Schols AMWJ, Soeters PB, Dingemans AMC, Mostert R, Frantzen PJ, Wouters EFM. Prevalence and characteristics of nutritional depletion in patients with stable COPD eligible for pulmonary rehabilitation. Am. Rev. Respir. Dis. 1993;147:1151-1156.

6. Engelen MPKJ, Schols AMWJ, Baken WC, Wesseling GJ, Wouters EFM. Nutritional depletion in relation to respiratory and peripheral skeletal muscle function in out-patients with COPD. Eur. Respir. J. 1994;7:1793-1797.

7. Bernard S, LeBlanc P, Whittom F, Carrier G, Jobin J, Belleau R, Maltais F. Peripheral muscle weakness in patients with chronic obstructive pulmonary disease. Am. J. Respir. Crit. Care Med. 1998:158:629-634.

8. Engelen MPKJ, Schols AMWJ, Heidendal GAK, Wouters EFM. Dual-energy X-ray absorptiometry in the clinical evaluation of body composition and bone mineral density in patients with chronic obstructive pulmonary disease. Am. J. Clin. Nutr. 1998;68:1298-1303.

9. Engelen MPKJ, Schols AMWJ, Lamers RJS, Wouters EFM. Different patterns of chronic tissue wasting among patients with chronic obstructive pulmonary disease. Clin. Nutr. 1999;18:275-280.

10. American Thoracic Society. Standards for the diagnosis and care of patients with chronic obstructive pulmonary disease (COPD) and asthma. Am. Rev. Respir. Dis. 1987;137:225-228.

11. Mazess RB, Barden H, Bisek JP, Hanson J. Dual-energy X-ray absorptiometry for total-body and regional bone- mineral and soft-tissue composition. Am. J. Clin. Nutr. 1990;51:1106-1112.

12. Jensen MB, Hermann AP, Hessov I, Mosekilde L. Components of variance when assessing the reproducibility of body composition measurements using bio-impedance and the Hologic QDR2000 DXA scanner. Clin. Nutr. 1997;16:61-65.

13. American Thoracic Society. Chronic bronchitis, asthma, and pulmonary emphysema by the committce on diagnostic standards for nontubercolosis respiratory disease. Am. Rev. Respir. Dis. 1962;85:762-812.

14. Sakai F, Gamu G, Im JG, Ray CS. Pulmonary function abnormalities in patients with CTdetermined emphysema. J. Comput. Assist. Tomogr. 1987;11:963-968.

15. Quanjer P. Tammeling GJ, Cotes JE, Pedersen OF, Peslin R, Yernault JC. Standardized lung lunction testing. Eur. Respir. J. 1993;6:5-40.

16. Kleinbaum DG, Kupper LL, Muller KE. Applied regression analysis and other multivariate methods. Boston: PWS-Kent Publishing Company, 1988.

17. Appell HJ. Muscular atrophy following immobilisation. Sports Med. 1990;10:42-58.

18. Bloomfield SA. Changes in musculoskeletal structure and function with prolonged bed rest. Med. Sci. Sports Exerc. 1997;29:197-206.

19. Bernard S, Leblanc P, Whittom G, Carrier G, Jobin J, Maltais F. Peripheral muscle function and exercise capacity in COPD and in normal subjects. Am. J. Respir. Crit. Care Med. 1997;155:A598.

20. Afifi AK, Bergman RA, Harvey JC. Steroid myopathy. Clinical, histologic and cytologic observations. John Hopkins Med. J. 1968;123:158-174.

21. Golding DN, Murray SM, Pearch GW, Thompson M. Corticosteroid myopathy. Ann. Phys. Med. 1961;5:171-176.

22. Decramer $M$, deBock V, Dom R. Functional and histologic picture of steroid-induced myopathy in chronic obstructive pulmonary disease. Am. J. Respir. Crit. Care Med. 1996;153:1958-1964.

23. Schols AMWJ, Buurman WA, Staal-van den Brekel AJ, Dentener MA, Wouters EFM. Evidence for a relation between metabolic derangements and increased levels of inflammatory mediators in a subgroup of patients with chronic obstructive pulmonary disease. Thorax 1996;51:819-824.

24. Pouw EM, Schols AMWJ, Deutz NEP, Wouters EFM. Arterial and muscle amino-acid levels in relation to resting energy expenditure and inflammation in stable COPD. Am. Rev. Respir. Crit. Care Med. 1998;158:1-5.

25. Dentener MA, Schols AMWJ, Wouters EFM. No difference in systemic inflammatory profile of chronic bronchitis-versus emphysema patients. Am. Rev. Respir. Crit. Care Med. 1998;157:A796. 


\section{PART 2}

\section{Protein metabolism}




\section{INTRODUCTION}

In a substantial number of COPD patients fat-free mass wasting occurs despite relative preservation of fat mass. This suggests that disturbances in protein balance may be present without associated body weight loss. Fat-free mass wasting can result from depressed protein synthesis, enhanced protein breakdown, or both, and will lead to a negative nitrogen balance. Mechanistic studies are needed to elucidate whether muscle wasting in COPD is mediated by specific alterations in protein turnover. Protein turnover refers to a continuous and dynamic flux in protein metabolism whereby proteins are constantly being synthesized and degraded. The negative nitrogen balance observed in severely depleted COPD paticnts has been shown to be the consequence of decreased protein synthesis, whereas protein breakdown was not affected (1). In COPD patients who maintain their fat-free mass, it is of importance to elucidate whether alterations are present in protein turnover during daily life conditions ie. overnight fasting, physical exercise. A variety of indirect and direct measures are employed in man to evaluate aspects of protein turnover, including urinary creatinine excretion, urinary 3 -methylhistidine measurement, amino acid balance studies, and estimates of protein turnover using infusion of stable isotopes of amino acids. With the use of stable isotope methodology, more insight can be obtained in both the rate of protein synthesis and breakdown.

\section{OUTLINE OF THE CHAPTERS IN PART 2}

In chapter 5, whole body protein metabolism was evaluated in clinically and weight stable severe COPD patients with and without radiological emphysema. The novel technique of stable isotope infusion was employed. By measuring whole body protein synthesis and breakdown, using the combined infusion of the stable isotopes of phenylalanine and tyrosine, protein catabolism was studied in a selected group of COPD patients in the postabsorptive state. Moreover, a comparison was performed between protein breakdown measured by the combined infusion of phenylalanine and tyrosine, and by leucine labeled tracer. Exercise is known to influence protein metabolism. In chapter 6, we assessed the effect of 20 minutes of constant low intensity exercise on whole body protein synthesis and breakdown during exercise and recovery in stable severe COPD patients and healthy age-matched controls. Furthermore, we examined whether differences occur in whole body protein turnover between COPD subtypes, before, during and after exercise .

\section{References}

1. Morrison WL, Gibson JNA, Scrimgeour C, Rennie MJ. Muscle wasting in emphysema. Clin. Sci. $1988 ; 75: 415-420$. 


\section{CHAPTER 5}

\section{Enhanced levels of whole-body protein turnover in patients with chronic obstructive pulmonary disease}

Mariëlle P.K.J. Engelen, Nicolaas E.P. Deutz', Emiel F.M. Wouters and Annemie M.W.J. Schols

Depts. of Pulmonology and 'Surgery, University Hospital Maastricht, Maastricht, The Netherlands 


\section{ABSTRACT}

A substantial number of patients with chronic obstructive pulmonary disease (COPD) are characterized by fat-free mass wasting and altered muscle and plasma amino acid levels, suggesting changes in protein metabolism. In the present study, we examined whether whole-body protein breakdown (PB) and synthesis (PS) differ between 14 stable patients with COPD and 8 healthy controls. Whole-body PB, PS and net PB (=PB-PS) were measured by the combined infusion of the stable isotopes L-[ring$\left.{ }^{2} \mathrm{H}_{5}\right]$-Phenylalanine (PHE) and L- $\left[\right.$ ring- $\left.{ }^{2} \mathrm{H}_{2}\right]$-Tyrosine. Because there is evidence for specific disturbances in leucine ( $\mathrm{LEU}$ ) metabolism, the $\mathrm{PB}$ values were compared with those obtained when infusing $\mathrm{L}-\left[1-{ }^{13} \mathrm{C}\right]$-LEU tracer. In arterialized-venous plasma and in vastus lateralis muscle, the isotope enrichment values and amino acid concentrations were measured. Whole-body PS and PB, assessed by PHE and TYR tracer, were higher in the COPD group than in the control group $(\mathrm{p}<0.05)$, indicating an elevated protein turnover. Net PB was increased in both groups, indicating a comparable degree of protein catabolism in the postabsorptive state. In contrast, whole-body PB determined by LEU tracer, was not different between the groups. As a consequence, the ratio of LEU to PHE breakdown was reduced in the COPD group $(\mathrm{p}<0.001)$. Moreover, in the COPD group a higher muscle-to-plasma gradient was found for LEU $(p<0.001)$ but not for PHE. The present study reveals elevated levels for protein turnover in patients with COPD, and indicates that infusion of the LEU tracer gives a reflection of LEU metabolism but not of whole-body protein metabolism in these patients.

\section{INTRODUCTION}

Weight loss and depletion of fat-free mass (FFM) is a serious problem in many patients with chronic obstructive pulmonary discase (COPD), negatively affecting their exercise capacity, muscle strength, and survival rates (I-3). Recently, we observed alterations in the amino acid levels of two peripheral skeletal muscles in patients with COPD as compared with healthy control subjects $(4,5)$. Moreover, striking differences were found in muscle amino acid profile between patients with COPD with and without radiological diagnosed macroscopic emphysema (EMPH+ and EMPH-, respectively) (5). Because amino acids are the basics of proteins, changes in protein metabolism are likely to be present in patients with COPD.

Mechanistic studies are needed to elucidate whether specific processes in protein metabolism are responsible for the observed decrease in FFM in patients with COPD. With the use of stable isotope methodology, more insight can be obtained in wholebody protein metabolism as the rate of whole-body protein synthesis (PS) and protein breakdown (PB) can be assessed. At present, only one study investigated whole-body protein metabolism in patients with COPD (6). In that study, the $1{ }^{13} \mathrm{C}$ stable isotope of leucine (LEU) was used to measure whole-body PS and PB in severely FFM 
depleted patients with emphysema. Based on this protocol, it was concluded that a reduced whole-body PS was present in emphysema patients, but that whole-body PB did not differ as compared with age-matched controls.

Under normal conditions, metabolism of LEU (one of the branched-chain amino acids besides isoleucine and valine) is considered to accurately reflect metabolism of all amino acids. Therefore, the $1-{ }^{13} \mathrm{C}$ stable isotope of LEU is often used for measurement of whole-body PS and PB. However, in several studies in stable severe COPD patients, consistently lower levels were found for LEU, whereas the levels of the other branched-chain amino acids isoleucine and valine, and most of the other plasma amino acids were within the normal range or only slightly changed (5-8). If this low plasma LEU is an indicator of altered LEU metabolism in COPD, the measurement of wholebody LEU metabolism using the $1-{ }^{13} \mathrm{C}$ tracer of LEU probably is not a good estimation for whole-body protein metabolism. Today, besides tracers of LEU, the combined infusion of L- $\left[\right.$ ring- $\left.{ }^{2} \mathrm{H}_{5}\right]$-Phenylalanine (PHE) and L- $\left[\right.$ ring $\left.{ }_{-}^{2} \mathrm{H}_{2}\right]-$ Tyrosine (TYR) tracer is often used to investigate the rate of whole-body PS and $\mathrm{PB}$ in humans.

The purpose of the present study was to investigate whether differences in the rates of whole-body PS and $\mathrm{PB}$ are present in the postabsorptive state between patients with stable severe COPD as a group or stratified into the COPD subtypes, and age-matched controls, using the combined infusion of PHE- and TYR- labeled tracers. In addition, a comparison was performed between the PB values obtained by PHE- and TYRlabeled tracers and by the LEU- labeled tracer.

\section{METHODS}

\section{Study population}

A group of 14 patients with moderate to severe airflow obstruction $\left(\mathrm{FEV}_{1}: 37 \pm 12\right.$ \%pred.) and 8 healthy age-matched volunteers were studied. The COPD group was carefully selected in order to obtain 7 patients with macroscopic emphysema $(\mathrm{EMPH}+)$ and 7 without macroscopic emphysema (EMPH-), based on high-resolution computed tomography (9). All patients and controls were men. The patients had COPD according to American Thoracic Society guidelines (10) and chronic airflow limitation, defined as measured forced cxpiratory volume in one second $\left(\mathrm{FEV}_{1}\right)$ less than $70 \%$ of reference $\mathrm{FEV}_{1}$. Furthermore, the patients had irreversible obstructive airway disease $\left(<10 \%\right.$ improvement of $\mathrm{FEV}_{1}$ predicted baseline after inhalation of $\beta_{2}$-agonist) and were in clinically stable condition and not suffering from respiratory tract infection or exacerbation of their disease at least four weeks prior to the study. Exclusion criteria were malignancy, cardiac failure, distal arteriopathy, recent surgery, severe endocrine, hepatic or renal disorder, and use of anticoagulant medication. Also, subjects who were using systemic corticosteroids within three months before the beginning of the study were excluded. The maintenance treatment of the studied 
COPD patients consisted of inhaled $\beta_{2}$-agonists, inhaled anticholinergics, inhaled corticosteroids and/or oral theophylline. Written informed consent was obtained from all subjects and the study was approved by the medical ethical committee of the University Hospital Maastricht.

\section{Study protocol}

After an overnight fast, all subjects were in supine position for three hours. A catheter was placed in an antecubital vein of the arm for infusion of the tracers. Each subject was given a priming dose, followed by continuous infusion until the end of the experiment. The following isotope infusion rates (IR) and priming doses (PD) were used: L- $\left[\right.$ ring $-{ }^{2} \mathrm{H}_{5}$ ]-Phenylalanine: $\mathrm{IR}=0.054 \mu \mathrm{mol} / \mathrm{kg} \mathrm{FFM} / \mathrm{min}, \mathrm{PD}=3.68 \mu \mathrm{mol} / \mathrm{kg}$ FFM; L- $\left[\right.$ ring $\left.{ }^{2} \mathrm{H}_{2}\right]$-Tyrosine: $\mathrm{IR}=0.014 \mu \mathrm{mol} / \mathrm{kg} \mathrm{FFM} / \mathrm{min}, \mathrm{PD}=0.95 \mu \mathrm{mol} / \mathrm{kg}$; and $\mathrm{L}-\left[1-{ }^{13} \mathrm{C}\right]$-Leucine $(\mathrm{LEU}): \mathrm{IR}=0.065 \mu \mathrm{mol} / \mathrm{kg} \mathrm{FFM} / \mathrm{min}, \mathrm{PD}=4.43 \mu \mathrm{mol} / \mathrm{kg} \mathrm{FFM}$. Moreover, a bolus dose of $\mathrm{L}-\left[\right.$ ring $\left.-{ }^{2} \mathrm{H}_{4}\right]$-Tyrosine was also administered to prime the phenylalanine-derived plasma tyrosine pool ( $\mathrm{PD}=0.3 \mu \mathrm{mol} / \mathrm{kg}$ ). The tracers were obtained from Cambridge Isotopic Laboratories (Woburn, MA, USA).

A second catheter was placed in a superficial dorsal vein of the hand of the contralateral arm, which was placed in a thermostatically controlled hot box (internal temperature: $60^{\circ} \mathrm{C}$ ), a technique to mimic direct arterial sampling (11). Arterialized venous blood samples were taken at 2,2.5 and 3 hours into infusion. At the end of the 3 -hours period, a muscle biopsy of the lateral part of the quadriceps femoris muscle was obtained under local anesthesia using the needle biopsy technique (12).

\section{Analysis of peripheral skeletal muscle and arterialized venous blood}

Arterialized venous blood was put in a heparinized syringe, immediately put on ice and subsequently centrifuged at $4{ }^{\circ} \mathrm{C}$ for 10 minutes to obtain plasma. Plasma was deproteinized with sulfosalicylic acid (5\%). Both muscle tissue and plasma were immediately frozen in liquid nitrogen and stored at $-80^{\circ} \mathrm{C}$ until analysis. After adding glass beads $(1 \mathrm{~mm}$ ), muscle tissue was homogenized using a Mini-beater (Biospec Products, Bartlesville, OK). Homogenized muscle tissue was deproteinized with sulfosalicylic acid (5\%).

The concentrations and the enrichments of the amino acids PHE, TYR and LEU in arterial plasma and the concentrations in muscle tissue were analyzed by a liquid chromatography mass spectrometry system (13).

\section{Calculations}

We used a simplified model in which the whole-body amino acid pool is assumed to be homogeneous, with a constant exchange of amino acids enter and exit from a metabolic pool of amino acids, because all proteins are constantly being synthesized and simultaneously degraded. The flux or protein turnover is defined, under steady state conditions, as the total flux into or out of the active metabolic amino acid pool. In 
our case, the influx into the metabolic pool is from the PB. The efflux from the metabolic pool includes the amino acids used for PS and for oxidation (in case of PHE this is hydroxylation which takes place in the liver and kidney). All other metabolic pathways are considered minor. Thus, in the postabsorptive state: protein turnover $=$ $\mathrm{PB}=\mathrm{PS}+$ hydroxylation (14-16).

The following equations were used:

Whole-body rate of appearance $\left(\mathrm{R}_{\mathrm{a}}\right)=$ infusion rate / tracer-tracee ratio in plasma Hydroxylation of PHE into TYR = whole-body $\mathrm{R}_{\mathrm{a}} \mathrm{TYR}$ * (tracer-tracee ratio TYR4 / tracer-tracee ratio PHE5).

Tracer-tracee ratio TYR4 / tracer-tracee ratio PHE5 is the enrichment of the label in tyrosine $\left({ }^{2} \mathrm{H}_{4}\right.$-Tyr $)$ coming from phenylalanine $\left({ }^{2} \mathrm{H}_{5}\right.$-PHE). PHE hydroxylation reflects net whole-body protein breakdown.

Whole-body $\mathrm{PB}=$ whole-body $\mathrm{R}_{\mathrm{aPHE}}$

Whole-body PS = whole-body $\mathrm{R}_{\mathbf{a}} \mathrm{PHE}-\mathrm{PHE}$ hydroxylation

Whole-body LEU breakdown = whole-body $\mathrm{R}_{\mathrm{aLEU}}$

Unfortunately, we were not able to measure whole-body LEU synthesis because LEU oxidation was not measured. To get a reflection of LEU oxidation, the patients had to breathe through a mouthpiece for a certain period of time to obtain breath samples. Several patients were unable to do this and therefore we eliminated this part from the protocol.

Because the amount of FFM is an important determinant for protein tumover, PB, PS, PHE hydroxylation, and whole-body $\mathrm{R}_{\mathrm{aLEU}}$ were expressed per kilogram FFM afterward to take into account possible differences in FFM between the COPD and the control group. Whole-body FFM was measured by bioelectrical impedance analyses (BIA 101, RJL Systems Detroit, USA) in the supine position at the right site. FFM of the COPD patients was calculated using a patient's specific regression equation (17), whereas FFM of the healthy controls was calculated using a specific regression equation for elderly men as described by Lukaski and coworkers (18).

\section{Pulmonary function tests}

All patients and healthy volunteers underwent spirometry with determination of forced expiratory volume in 1 second $\left(\mathrm{FEV}_{1}\right)$ and forced vital capacity (FVC) with the highest value from at least three technically acceptable maneuvers being used. Static and dynamic lung volumes (total lung capacity (TLC), intrathoracic gas volume (ITGV), and airway resistance $\left(\mathrm{R}_{\mathrm{aw}}\right)$ ) were assessed by whole-body plethysmography (Masterlab, Jaeger, Wurzburg, Germany). Diffusing capacity for carbon monoxide $\left(\mathrm{DL}_{\mathrm{co}}\right)$ was measured using the single-breath method (Masterlab, Jaeger, Wurzburg, Germany). Subtracting estimated dead space from inspiratory volume gives an estimate of alveolar volume and the $\mathrm{Dl}_{c o}$ was then corrected for alveolar volume (transfer factor $\mathrm{K}_{\mathrm{co}}$ ). All values obtained were related to a reference value and expressed as percentages of the predicted value (19). 


\section{Statistical analysis}

Results are expressed as mean \pm standard error (SE) for muscle and arterial venous plasma determinations and mean \pm standard deviation (SD) for other characteristics for the total COPD and control group, and after stratification of the COPD group into EMPH+ and EMPH-. The mean value of PB, PS, PHE hydroxylation, and whole-body $\mathrm{R}_{\mathrm{aLEU}}$ at the time points 2, 2.5 and 3 hours was used as the resting value. The nonparametric Mann-Whitney $U$ test was used to test whether the changes in time were significantly different from zero, and whether differences in pulmonary function, muscle, and arterial plasma determinations were present between the study groups.

\section{RESULTS}

Fourteen male COPD patients and 8 male healthy volunteers participated in the study (table 1). Age, height, and body weight did not significantly differ between the groups, but a tendency toward a lower FFM was found in the COPD group ( $p=0.1$; ns). The COPD patients had moderate to severe airflow obstruction, a mildly reduced diffusing capacity, and moderately increased airways resistance. Absolute FVC was $3.6 \pm 0.6 \mathrm{~L}$ in the COPD group and $4.3 \pm 0.5 \mathrm{~L}$ in the control subjects $(p<0.05)$. Arterial $\mathrm{pO}_{2}$ was lower in the COPD group than in the control group $(\mathrm{p}<0.05)$. In the control group, all lung function values were within the normal range.

Table 1. General characteristics of the COPD patients and healthy controls

\section{Controls COPD}

\begin{tabular}{|c|c|c|c|c|c|c|}
\hline Age & $\mathrm{Y}$ & 66 & \pm 5 & 62 & \pm & 7 \\
\hline Height & $\mathrm{Cm}$ & 172.4 & $\pm \quad 5.9$ & 172.5 & \pm & 7.4 \\
\hline Weight & $\mathrm{Kg}$ & 76.6 & $\pm \quad 11.9$ & 76.1 & 土: & 12.4 \\
\hline FFM & $\mathrm{Kg}$ & 55.9 & $\pm \quad 5.4$ & 52.9 & \pm & 7.3 \\
\hline $\mathrm{FEV}_{1}$ & \%pred. & 102 & 19 & 37 & \pm & $12^{* * *}$ \\
\hline $\mathrm{DL}_{\infty}$ & \%pred. & 112 & 20 & 71 & \pm & $25^{* *}$ \\
\hline $\mathrm{K}_{\mathrm{-o}}$ & \%pred. & 107 & 22 & 65 & \pm & $19 * *$ \\
\hline RV & \%pred & 119 & 25 & 189 & \pm & $45^{* * *}$ \\
\hline $\mathrm{R}_{\mathrm{ww}}$ & $\%$ pred & 99 & 29 & 244 & \pm & $91^{* * *}$ \\
\hline $\mathrm{PaO}_{2}{ }^{\prime \prime}$ & $\mathrm{kPa}$ & 11.3 & 1.0 & 10.0 & \pm & $1.6^{*}$ \\
\hline
\end{tabular}

Values are means $\pm \mathrm{SD}$; FFM: fat-free mass; $\mathrm{FEV}_{1}$ : forced expiratory volume in $\mathrm{Is} ; \mathrm{DL}_{\mathrm{oc}}$ : diffusing capacity for carbon monoxide; $\mathrm{K}_{\infty}$ : transfer factor; $\mathrm{RV}$ : residual volume; $\mathrm{R}_{\mathrm{aw}}$ : airways resistance; $\mathrm{PaO}_{2}$ : arterial oxygen pressure. ${ }^{*} 1 \mathrm{kPa}=7.5 \mathrm{mmHg}$. Significance of difference compared to the controls: ${ }^{*} p<0.05 ;{ }^{* *} p<0.01 ;{ }^{* * *}$ p $<0.001$. 

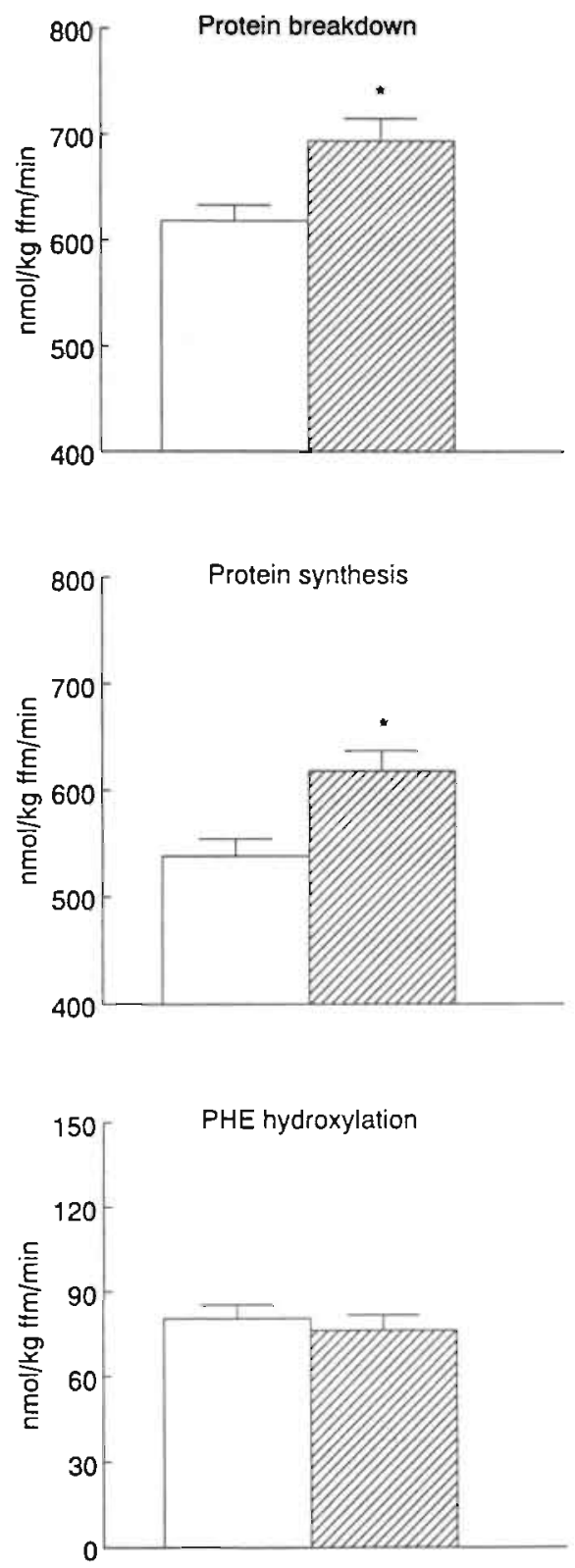

Figure 1. Bar diagram of protein breakdown (top panel), protein synthesis (middle panel) and PHE hydroxylation (reflecting net balance; bottom panel) of 8 healthy volunteers (control, open bar) and 14 patients with COPD (closed bar). Mean values $\pm 1 \mathrm{SE}$ are shown. Significance of differences between the 2 groups was calculated as $* P<0.05$. 
Tracer-tracee ratio of PHE and LEU reached an isotopic steady state within three hours (difference among the time points 2, 2.5 and 3 hours were $<5 \%$ and nonsignificant from zero) in both groups. PB (Fig 1, top panel) as well as PS (Fig 1, middle panel) were significantly higher in the COPD group than in the control group $(p<0.05)$. Hydroxylation of PHE was significantly different from zero in both groups $(p<0.05)$, indicating net PB in the postabsorptive state (Fig 1, lower panel). However, net PB was not different between COPD and the control group. Stratification of the COPD group into patients with EMPH- and EMPH+ by HRCT did not result in any differences in PS or PB between the COPD subtypes.

Whole-body $\mathrm{R}_{\mathrm{aLEU}}$ was not significantly different between the COPD and the control group (1464 $\pm 53 \mathrm{nmol} / \mathrm{kg} \mathrm{ffm} / \mathrm{min}$ vs. $1545 \pm 19 \mathrm{nmol} / \mathrm{kg} \mathrm{ffm} / \mathrm{min}$, respectively). However, the ratio of whole-body $R_{a L E U}$ to $R_{a P H E}$ was significantly lower in the COPD group ( $2.1 \pm 0.1$ vs. $2.5 \pm 0.2, \mathrm{p}<0.001$ ).

Stratification of the COPD group into EMPH- and EMPH+ resulted in lower values for whole-body $\mathrm{R}_{\mathrm{aLEU}}$ in the EMPH- as compared with the control group ( $\left.\mathrm{p}<0.05\right)$, whereas no significant difference was found between the EMPH+ and the control group (EMPH-: 1404 $\pm 65 \mathrm{nmol} / \mathrm{kg} \mathrm{ffm} / \mathrm{min} ; \mathrm{EMPH}+: 1550 \pm 80 \mathrm{nmol} / \mathrm{kg} \mathrm{ffm} / \mathrm{min}$ ). Although ratio whole-body $\mathrm{R}_{\text {aLEU }}$ to $\mathrm{R}_{\mathrm{aPHE}}$ was reduced in both COPD subtypes as compared with the control group, the lowest values were found in the EMPH- group (EMPH-: $2.0 \pm 0.1, \mathrm{p}<0.001, \mathrm{EMPH}+: 2.2 \pm$ $0.1, \mathrm{p} 0.05)$.

Muscle-to-plasma concentration gradient for LEU was higher in the COPD than in the control group ( $3.7 \pm 0.3$ vs. $1.8 \pm 0.1 ; \mathrm{p}<0.001$ ), whereas comparable levels were found for PHF: $(2.3 \pm 0.2$ vs. $1.9 \pm 0.1)$.

\section{DISCUSSION}

In the present study, enhanced levels of whole-body PS and PB were found in the postabsorptive state in patients with stable severe COPD, indicating an increased whole-body protein turnover.

The ability to maintain homeostatic regulation of metabolic processes is an important key to the survival of living organisms. A small difference between PS and PB rates determines protein accretion or loss. In the studied COPD and control groups, whole-body PB was higher than PS, indicating net protein catabolism in the postabsorptive state. However, comparable values were found for net $\mathrm{PB}$ in both groups, indicating that net protein catabolism was not elevated in patients with severe COPD. It has to be emphasized that the elevated values for whole-body PB and PS were observed in patients with severe COPD, who were clinically stable at the time of measurement. Moreover, the patients were weight stable and had only slightly lower values for FFM than the control subjects. It is unknown yet whether chronic or acute unstable conditions like an acute exacerbation of COPD symptoms or progressive weight loss, which commonly occur in COPD, enhance the alterations in whole-body PB and PS, and induce net protein catabolism in these patients. 
Elevated values for PS and PB, as observed in the COPD group, have previously been reported in other chronic diseases (20-22). In the metabolic stress-related diseases human immunodeficiency virus infection and liver cirrhosis an enhanced production of acute phase proteins may possibly account for the observed increase in protein turnover, suggesting an association between increased protein turnover and the presence of inflammation. In the studied COPD patients, the elevated protein turnover may also be mediated by an activation of the cytokine network. Although the patients with COPD were clinically stable and not suffering from exacerbations of symptoms for at least three months, an increased systemic inflammatory response has been described in these patients. Evidence for this is given by several studies, reporting elevated circulating concentrations of cytokines and acute phase proteins in peripheral blood of stable severe COPD patients $(4,23)$. Recently, increased levels of plasma lipopolysaccharide binding protein were associated with decreased total amino acid concentrations in COPD (4), confirming a relation between inflammation and alterations in protein metabolism. Whether the presence of systemic inflammation is the only mechanism responsible for the increased protein turnover in the studied COPD group deserves further investigation.

Protein turnover is assumed to contribute to $20 \%$ of resting energy expenditure in normal adults (24). When protein turnover is elevated, increased energy is needed for formation of peptide bindings, amino acid transport, RNA turnover and PB. This suggests that the elevated protein turnover, among other factors like systemic inflammation, medication, metabolic and mechanical inefficiency of the respiratory muscles may increase resting energy expenditure levels in COPD. The exact contribution of an elevated protein tumover to the hypermetabolic state in a substantial proportion of COPD patients needs to be determined (25-28). In our study, the $10 \%$ whole-body protein tumover increase in the COPD patients presumably causes a $2 \%$ increase in their REE.

The present study was not able to identify to what extent the skeletal muscle protein pool contributes to the increased whole-body PB and PS levels in patients with COPD. At rest, skeletal muscle contributes approximately $25 \%$ to whole-body protein turnover in man (29). It is unclear yet, whether this value remains the same during pathophysiological conditions such as COPD. COPD patients are often characterized by low-grade systemic inflammation without evidence of an acute infection. Therefore, the contribution of the splanchnic area could be increased due to enhanced acute phase protein synthesis. In addition, recently, low concentrations of tumor necrosis factor-alpha were found to induce skeletal muscle protein loss in vitro (30). We recently observed increased skeletal muscle wasting in patients with COPD (31). Therefore, a combination of the enhanced net splanchnic protein synthesis and an increased net skeletal muscle protein breakdown will result in increased whole-body protein turnover without enhanced net whole-body protein breakdown. More research is necessary to elucidate the relative contribution of skeletal muscle and splanchnic area to the elevated whole-body PB and PS levels in patients with COPD.

Today, the stable isotopes of PHE and LEU are often used independent of each other to measure whole-body PB and PS. In the present study, whole-body $\mathrm{R}_{\mathrm{aPHE}}$ value was higher in the COPD group than in the control group. However, no difference was found in whole- 
body $\mathrm{R}_{\mathrm{aLEU}}$ level between the total COPD group and control group, which is in line with the data obtained by Morrison (6) in FFM depleted patients with emphysema .

However, ratio whole-body $R_{\text {aLEU }}$ to $R_{\text {aPHE }}$ was significantly lower in the studied COPD group than in the controls, indicating a discrepancy between whole-body $R_{a L E U}$ and $R_{a P H E}$. This is remarkable as under normal conditions release into plasma of any essential amino acid should be proportional to its average content in body proteins. The average content of LEU in body proteins is about $8 \%$ opposed to $3-4 \%$ of PHE (32). Therefore, the ratio of whole-body $\mathrm{R}_{\mathrm{aLEU}}$ to $\mathrm{R}_{\mathrm{aPHE}}$ should be approximately $2.0-2.7$. In the present study, this ratio was 2.5 and 2.1 in the control group and COPD group, respectively, indicating a slightly reduced ratio in the latter group.

The discrepancy in the release of LEU and PHE into plasma may be explained by an abnormal equilibration of the amino acid tracers between the intracellular and extracellular pools. Although LEU and PHE share a common transmembrane transport system, a possible selective abnormality in the subsequent transport of individual amino acids across the cell membrane would result in a disequilibration between intra- and extracellular amino acid enrichments, and therefore in plasma $R_{a}$ of the amino acids. In the present study, the muscleto-plasma gradient was higher for LEU in the COPD group than in the control group, whereas comparable levels were found for PHE, suggesting a specific defect in the membrane transport of LEU in COPD. Recently, we reported increased plasma insulin levels in patients with COPD (33), which were associated with increased values for muscle-toplasma LEU gradient. This suggests that hyperinsulinemia negatively affects LEU transmembrane transport and thus LEU metabolism in COPD. Therefore, it is very possible that the elevated insulin levels in the COPD group suppress the endogenous release of LEU but not that of PHE.

In conclusion, the present study shows that whole-body PS and PB are elevated in patients with stable severe COPD in the postabsorptive state, indicating an increased whole-body protein tumover. Furthemore, use of the isotopically labeled tracer of LEU gives insight in the disturbance in whole-body LEU metabolism but does not well reflect whole-body protein metabolism in patients with COPD.

\section{References}

1. Bemard S, LeBlanc P, Whittom F, Carrier G, Jobin J, Belleau R, et al. Peripheral muscle weakness in patients with chronic obstructive pulmonary disease. Am. J. Respir. Crit. Care Med. 1998;158:629-634.

2. Baarends EM, Schols AMWJ, Mostert R, Wouters EFM. Peak exercise response in relation to tissue depletion in patients with chronic obstructive pulmonary disease. Eur. Respir..J. 1997; 10:2807-2813.

3. Schols AMWJ, Slangen J, Volovics L, Wouters EFM. Weight loss is a reversible factor in the prognosis of chronic obstructive pulmonary disease. Am. J. Respir. Crit. Care Med. 1998;157:1791-1797.

4. Pouw EM, Schols AMWJ, Deutz NEP, Wouters EFM. Plasma and muscle amino-acid levels in relation to resting energy expenditure and inflammation in stable COPD. Am. J. Respir. Crit. Care Med. 1998:158:797-801.

5. Engelen MPKJ, Schols AMWJ, Does JD, Deutz NEP, Wouters EFM. Differences in amino acid profile of peripheral skeletal muscle between patients with emphysema and chronic bronchitis. Am. J. Respir. Crit. Care Med. 1999; 159:A475.

6. Momison WL, Gibson JNA, Scrimgeour C, Rennie MJ. Muscle wasting in emphysema. Clin. Sci. $1988 ; 75: 415-420$. 
7. Schols AMWJ, Deutz NEP, Mostert R, Wouters EFM. Plasma amino acid levels in patients with chronic obstructive pulmonary disease. Monaldi Arch. Chest Med. 1993;48:546-548.

8. Hofford JM, Milakofsky L, Vogel WH, Sacher RS, Savage GJ, Pell S. The nutritional status in advanced emphysema associated with chronic bronchitis. A study of amino acid and catecholamine levels. Am. Rev. Respir. Dis. 1990;141:902-908.

9. Engelen MPKJ, Schols AMWJ, Lamers RJS, Wouters EFM. Different patterns of chronic tissue wasting among patients with chronic obstructive pulmonary disease. Clin. Nutr. 1999;18:275-280.

10. American Thoracic Society. Standards for the diagnosis and care of patients with chronic obstructive pulmonary disease (COPD) and asthma. Am. Rev. Respir. Dis. 1995;152:s77-s120.

11. Abumrad NN, Rabin D, Diamond MP, Lacy WW. Use of a heated superficial hand vein as an altemative site for the measurement of amino acid concentrations and for the study of glucose and alanine kinetics in man. Metabolism 1981;30:936-40.

12. Betgstrom L. Muscle electrolytes in man. Determination by neutron activation analysis on needle biopsy specimens. A study of normal subjects, kidney patients, and patients with chronic diarrhea. Scand. J. Clin. Lab. Invest. 1962;68:7-110.

13. Van Ejjk HM, Rooyakkers DR, Soeters PB, Deutz NEP. Determination of amino acid isotope enrichment using liquid chromatography-mass spectrometry. Anal. Biochem. 1999;271:8-17.

14. Barazzoni R, Zanetti M, Vettore $M$, Tessari P. Relationships between phenylalanine hydroxylation and plasma aromatic amino acid concentrations in humans. Metabolism 1998;47:669-74.

15. Tessari P, Barazzoni R, Zanetti M, Vettore M, Normand S, Bruttomesso D, et al. Protein degradation and synthesis measured with multiple amino acid tracers in vivo. Am. J. Physiol. 1996;271:E733-41.

16. Thompson GN, Pacy PJ, Merritt H, Ford GC, Read MA, Cheng KN, et al. Rapid measurement of wholebody and forearm protein tumover using a $\left[{ }^{2} \mathrm{H}_{5}\right]$ phenylalanine model. Am. J. Physiol. 1989;256:E631-9.

17. Schols AMWJ, Wouters EF, Soeters PB, Westerterp KR. Body composition by bioelectrical-impedance analysis compared with deuterium dilution and skinfold anthropometry in patients with chronic obstructive pulmonary disease. Am. J. Clin. Nutr. 1991;53:421-4.

18. Lukaski HC, Bolonchuk WW, Hall CB, Siders WA. Validation of tetrapolar bioelectrical impedance method to assess human body composition. J. Appl. Physiol. 1986;60:1327-32.

19. Quanjer P, Tammeling GJ, Cotes JE, Pedersen OF, Peslin R, Yemault JC. Standardized lung function testing. Eur. Respir. J. 1993;6:5-40.

20. Macallan DC, McNurlan MA, Milne E, Calder AG, Garlick PJ, Griftin GE. Whole-body protein turnover from leucine kinetics and the response to nutrition in human immunodeficiency virus infection. Am. J. Clin. Nutr. 1995;61:818-26.

21. Jeevanandam M, Horowitz GD, Lowry SF, Brennan MF. Cancer cachexia and protein metabolism. Lancet $1984 ; 1: 1423-6$.

22. Melville S, McNurlan MA, Calder AG, Garlick PJ. Increased protein turnover despite normal energy metabolism and responses to feeding in patients with lung cancer. Caricer Res. 1990;50:1125-31.

23. Schols AMWJ, Buurman WA, Staal-van den Brekel AJ, Dentener MA, Wouters EFM. Evidence for a relation between metabolic derangements and increased levels of inflammatory mediators in a subgroup of patients with chronic obstructive pulmonary disease. Thorax 1996;51:819-824.

24. Waterlow JC. Whole-body protein turnover in humans-past, present, and future. Annu. Rev. Nutr. 1995; 15:57-92.

25. Hunter AMB, Carey MA, Larsh HW. The nutritional status of patients with chronic obstructive pulmonary disease. Am. Rev. Respir. Dis. 1981;124:376-381.

26. Schols AMWJ, Mostert R, Soeters PB, Saris WHM, Wouters EFM. Energy balance in patients with chronic obstructive pulmonary disease. Am. Rev. Respir. Dis. 1991;143:1248-1252.

27. Green JH, Muets MF. Comparisons between basal metabolic rate and diet-induced thermogenesis in different types of chronic obstructive pulmonary disease. Clin..Sci. 1992;83:109-116.

28. Openbrier DR, Irwin MM, Rogers RM, Gottleib GP, Dauber JH, Vanheil OH. Nutritional status and lung function in patients with emphysema and chronic bronchitis. Chest 1983:83:7-22.

29. Deutz NEP, Wagenmakers AJ, Soeters PB. Discrepancy between muscle and whole-body protein tumover. Curr. Opin. Clin. Nutr. Metab. Care 1999;2:29-32. 
30. Li YP, Schwartz RJ, Waddell ID, Holloway BR, Reid MB. Skeletal muscle myocytes undergo protein loss and reactive oxygen- mediated NF-kB activation in response to tumor necrosis factor alpha. Faseb J. 1998;12:871-80.

31. Engelen MPKJ, Schols AMWJ, Does JD, Wouters EFM. Skeletal muscle weakness is associated with wasting of extremity fat-free mass loss but not with airflow obstruction in patients with chronic obstructive pulmonary disease. Am. J. Clin. Nutr. 2000;71:733-738.

32. McCullough AJ, Glamour T. Differences in amino acid kinetics in cirrhosis. Gastroenterology 1993;104:1858-65.

33. Engelen MPKJ, Deutz NEP, Menheere PPCA, Wouters EFM, Schols AMWJ. Altered leucine metabolism is associated with hyperinsulinemia in patients with COPD. Eur. Repir. J. 2000;16:P535. 


\section{CHAPTER 6}

\section{Suppressed response in whole body protein turnover to exercise in patients with emphysema}

Mariëlle P.K.J. Engelen, Nicolaas E.P. Deutz', Rob Mostert ${ }^{2}$, Emiel F.M. Wouters, and Annemie M.W.J. Schols

Depts. of Pulmonology and 'Surgery, University Hospital Maastricht, Maastricht, and ${ }^{2}$ Asthma Center Hornerheide, Horn, The Netherlands 


\section{ABSTRACT}

Recently, pronounced alterations were found in whole body protein metabolism at rest in weight stable patients with chronic obstructive pulmonary disease (COPD) in the post-absorptive state. To investigate whether physical activity in daily life affects whole body protein metabolism differently in COPD compared with control subjects, whole body protein synthesis (PS) and breakdown (PB) were measured in 14 clinically and weight stable severe COPD patients and 8 healthy age-matched controls during and after 20 minutes of constant work rate cycle exercise, using the combined infusion of the isotopically labeled amino acids of $\mathrm{L}-\left[\mathrm{ring}-{ }^{2} \mathrm{H}_{5}\right]-$ Phenylalanine (PHE) and L- $\left[\right.$ ring- $\left.{ }_{-} \mathrm{H}_{2}\right]$-Tyrosine (TYR). Arterialized-venous blood was sampled during the exercise period and until 1 hour of recovery for measurement of the amino acid concentrations and the isotopic enrichment values. After an initial increase in whole body PS and PB in both study groups during exercise $(p<0.05)$, whole body $\mathrm{PS}$ as well as $\mathrm{PB}$ returned to baseline values at the end of exercise in the COPD group but remained elevated in the control subjects. In recovery from exercise, PS and PB immediately normalized in the control group but reached lower values in the COPD group compared with baseline values $(\mathrm{p}<0.05)$. Stratification of the COPD group into patients with and without macroscopic emphysema (EMPH+ $(n=7)$, EMPH- $(n=7)$, respectively) revealed a different pattern of whole body protein metabolism between the subtypes. In the EMPH+ group, PS as well as PB did not change at all during exercise, and even fell below baseline values in recovery $(\mathrm{p}<0.05)$. This reduction in protein tumover remained until at least 1 hour in recovery. In contrast, the changes in the patterns of PS and PB were comparable in the EMPH- and the control group throughout the entire study period. Net PB (=PBPS) was not increased during exercise or recovery in any of the study groups. The present study indicates that constant work exercise in daily life does not induce net protein catabolism in clinically and weight stable patients with COPD but it suppresses whole body protein turnover specifically in those with emphysema.

\section{INTRODUCTION}

Recently, pronounced alterations were found in whole body protein metabolism at rest in weight stable patients with chronic obstructive pulmonary disease (COPD) in the post-absorptive state and at rest, as indicated by elevated levels for whole body protein synthesis and breakdown. Besides ovemight fasting, also other naturally occurring conditions like daily life physical exercise may possibly influence whole body protein metabolism in these patients. It is of importance to get more insight in this because physical exercise is an important element in the pulmonary rehabilitation of patients with COPD.

It is unclear to what extent daily life physical exercise alters the specific processes of whole body protein metabolism (protein synthesis and breakdown) in weight and FFM stable patients with COPD and whether this leads to net anabolism or maybe 
even catabolism. A single exercise session in severe COPD patients generally lasts a relatively short time (on average 20 minutes). It can be argued that besides the actual exercise period, the post-exercise (recovery) response may be as important to the overall state of protein metabolism in COPD. Moreover, data about the effects of exercise on whole body protein metabolism in patients with COPD may be relevant because it indirectly provides information on the metabolic (protein) costs and needs of these patients in daily life, and during pulmonary rehabilitation.

Therefore, the purpose of the study was to investigate the effects of 20 minutes of constant work rate cycle exercise on whole body PB and PS during exercise and 1 hour of recovery in patients with stable severe COPD as compared with healthy agematched control subjects. Furthermore, it was examined whether and to what extent exercise induces differences in whole body PS and PB among COPD subtypes.

\section{METHODS}

\section{Study population}

A group of 14 patients with moderate to severe airflow obstruction (FEV $1: 37 \pm 12 \%$ pred.) and 8 healthy age-matched volunteers were studied. The COPD group was carefully selected in order to obtain 7 patients with macroscopic emphysema (EMPH+) and 7 without macroscopic emphysema (EMPH-), based on highresolution computed tomography (1). All subjects were men. All patients had COPD according to ATS guidelines (2) and chronic airflow limitation, defined as measured forced expiratory volume in one second (FEV:) less than $70 \%$ of reference $\mathrm{FEV}_{1}$. Furthermore, the patients had irreversible obstructive airway disease $(<10 \%$ improvement of $\mathrm{FEV}_{1}$ predicted baseline after inhalation of $\mathrm{B}_{2}$-agonist) and were in clinically stable condition and not suffering from respiratory tract infection or exacerbation of their disease at least 4 weeks prior to the study. Exclusion criteria were malignancy, cardiac failure, distal arteriopathy, recent surgery, severe endocrine, hepatic or renal disorder, and use of anticoagulant medication. Also, subjects who were using oral corticosteroids within three months before the beginning of the study were excluded. The maintenance treatment of the studied COPD patients consisted of inhaled $\beta_{2}$-agonists, inhaled anticholinergics, inhaled corticosteroids and/or oral theophylline. Written informed consent was obtained from ail subjects and the study was approved by the medical ethical committee of the University Hospital Maastricht.

\section{Study protocol}

Rest

After an overnight fast, all subjects were in supine position for thiee hours. A catheter was placed in an antecubital vein of the arm for infusion of the tracers. Each 
subject was given a priming dose, followed by continuous infusion until the end of the experiment.

The following isotope infusion rates (IR) and priming doses (PD) were used: $\mathrm{L}-\left[\right.$ ring $\left.{ }^{2} \mathrm{H}_{5}\right]$-Phenylalanine: $\mathrm{IR}=0.054 \mu \mathrm{mol} / \mathrm{kg} \mathrm{FFM} / \mathrm{min}, \mathrm{PD}=3.68 \mu \mathrm{mol} / \mathrm{kg} \mathrm{FFM}$; $\mathrm{L}-\left[\right.$ ring $\left.{ }^{2} \mathrm{H}_{2}\right]$-Tyrosine: $\mathrm{IR}=0.014 \mu \mathrm{mol} / \mathrm{kg} \quad \mathrm{FFM} / \mathrm{min}, \quad \mathrm{PD}=0.95 \mu \mathrm{mol} / \mathrm{kg}$; $\mathrm{L}-\left[\right.$ ring $\left.-{ }^{2} \mathrm{H}_{4}\right]$-Tyrosine: $\mathrm{PD}=0.3 \mu \mathrm{mol} / \mathrm{kg}$. The tracers were obtained from Cambridge Isotopic Laboratories (Woburn,MA,USA).

A second catheter was placed in a superficial dorsal vein of the hand of the contralateral arm, which was placed in a thermostatically controlled hot box (internal temperature: $60^{\circ} \mathrm{C}$ ), a technique to mimic direct arterial sampling (3). Arterialized venous blood samples were taken at 2, 2.5 and 3 hours into infusion to assure an isotopic steady state.

\section{Exercise}

After the resting period, all subjects performed a submaximal exercise test on an electronically braked cycle ergometer (Comival 400, Lode, Groningen, The Netherlands) for 20 minutes. Work rate for each subject was calculated as $20 \%$ of the predicted workload, according to the equations of Jones (4). Pedaling frequency was selected by the subjects between 60 and $70 \mathrm{rpm}$ and held constant throughout the test. An infrared electrode was placed on a finger to measure oxygen saturation (Fasttrac, Sensor Medics Co., Anaheim, California). Heart rate was measured throughout the test using a sport tester (PE3000, Polar Electro cy, Kempele, Finland). Arterialized-venous blood was sampled at 10,15 and 20 minutes of exercise.

\section{Recovery}

Arterialized venous blood was taken $15,30,45$ and 60 minutes in recovery.

\section{Analysis of arterialized venous blood}

Arterialized venous blood was put in a heparinized syringe, immediately put on ice and subsequently centrifuged at $4{ }^{\circ} \mathrm{C}$ for 10 minutes to obtain plasma. Plasma was immediately frozen in liquid nitrogen and stored at $-80^{\circ} \mathrm{C}$ until analysis.

The concentrations and the enrichments of the amino acids were analyzed by LC-MS system (5).

\section{Calculations}

We used a single pool model in which the whole body amino acid pool is assumed to be homogeneous, with a constant exchange of amino acids enter and exit from a metabolic pool of amino acids, because all proteins are constantly being synthesized and simultaneously degraded. The flux or protein turnover is defined, under steady state conditions, as the total flux into or out of the active metabolic amino acid pool. 
In our case, the influx into the metabolic pool is from the breakdown of body protein (PB). The efflux from the metabolic pool includes the amino acids used for synthesis of protein (PS) and for hydroxylation (or oxidation). All other metabolic pathways are considered minor. Thus, in the post-absorptive state: protein turnover $=\mathrm{PB}=$ PS + hydroxylation.

The following equations were used:

1. Whole body rate of appearance $\left(\mathrm{Wb}_{\mathrm{a}}\right)=$ infusion rate / tracer-tracee ratio in plasma

2. Hydroxylation of PHE into TYR (PHEhyd) $=W_{b R}$ TYR $^{*}$ (tracer-tracee ratio of TYR4 / tracer-tracee ratio of PHE5).

Hydroxylation of PHE is reflecting net whole body protein breakdown (= net $\mathrm{PB}$ )

3. Whole body Protein breakdown $(P B)=$ whole body $R_{a P H E}$

4. Whole body Protein synthesis (PS) = whole body $\mathrm{R}_{\mathrm{a}} \mathrm{PHE}$ - hydroxylation of PHE

In order to account for possible differences in FFM between the study populations, whole body FFM was measured by bioelectrical impedance analyses (BIA 101, RJL Systems Detroit, USA) in the supine position at the right site. FFM of the COPD patients was calculated using a patient specific regression equation (6), whereas FFM of the healthy controls was calculated using a specific regression equation for elderly men (7). Fat mass (FM) was calculated by subtracting FFM from body weight, the latter was measured using an electronic beam scale with a digital readout to the nearest $0.1 \mathrm{~kg}$ (model 708: Seca, Hamburg, Germany). PB, PS, and net PB were expressed in $\mathrm{nmol} / \mathrm{kg} \mathrm{ffm} / \mathrm{min}$.

\section{Pulmonary function tests}

All patients and healthy volunteers underwent spirometry with determination of forced expiratory volume in one second $\left(\mathrm{FEV}_{\mathrm{l}}\right)$ with the highest value from at least three technically acceptable maneuvers being used. Diffusing capacity for carbon monoxide $\left(\mathrm{DL}_{\mathrm{co}}\right)$ was measured using the single-breath method (Masterlab, Jaeger, Wurzburg, Germany). All values obtained were related to a reference value and expressed as percentages of the predicted value (8).

\section{Statistical analysis}

Results are expressed as mean \pm standard error (SE) for arterial venous plasma determinations and mean \pm standard deviation (SD) for other characteristics. The mean value of $\mathrm{PB}, \mathrm{PS}$, net $\mathrm{PB}$ at the time points $2,2.5$ and 3 hours was used as the resting value. The Mann-Whitney $U$ test was used to test whether the changes in time in PB, PS and net PB were significant different from zero, and to determine differences in pulmonary function, exercise capacity, and arterial plasma determinations between the control and the COPD (sub)group(s). 


\section{RESULTS}

Fourteen male COPD patients (7 EMPH+, 7 EMPH-) and 8 male healthy volunteers participated in the study (table 1).

Table 1. General characteristics of the study population

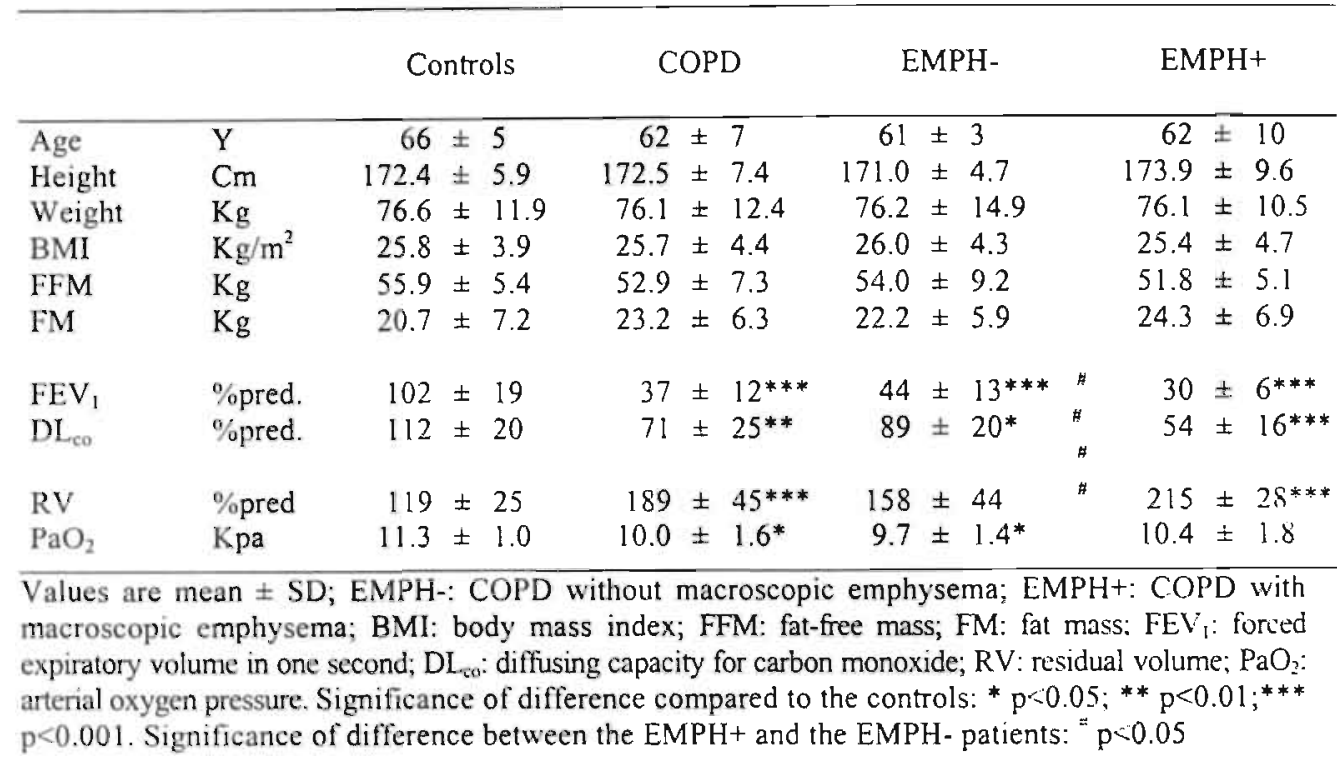

Table 2. Exi'rcise characteristics of the study population

Controls COPD EMPH- EMPH+

\begin{tabular}{|c|c|c|c|c|c|c|c|c|c|}
\hline WR & Watt & $33.5 \pm 2.8$ & 35.1 & \pm & 6.3 & 34.2 & \pm 6.5 & 35.8 & \pm 6.5 \\
\hline$\% \mathrm{WR}_{\operatorname{nax}}$ & $\%$ & $16.9 \pm 2.4$ & 44.0 & \pm & $15.0^{* * *}$ & 32.9 & $\pm 8.5^{* *}$ & 51.5 & $\pm 14.0^{* *}$ \\
\hline $\mathrm{O}_{2}$ saturation & $\%$ & & & & & & & & \\
\hline Rest & & $95.6 \pm 0.7$ & 93.5 & \pm & $1.3 * * *$ & 93.9 & $\pm 1.2^{*}$ & 93.1 & $\pm 1.5^{* *}$ \\
\hline End-exercise & & $95.1 \pm 0.7$ & 92.1 & \pm & $1.8 * * *$ & 93.1 & $\pm 1.1^{* *}$ & 91.0 & $\pm 1.7^{* *}$ \\
\hline Heart rate & $\mathrm{B} / \mathrm{min}$ & & & & & & & & \\
\hline Rest & & $73.2 \pm 5.9$ & 83.1 & \pm & $12.9^{*}$ & 79.9 & \pm 12.2 & 86.6 & \pm 13.7 \\
\hline End-exercise & & $91.6 \pm 3.1$ & 111.6 & \pm & $20.6^{* *}$ & 107.3 & \pm 19.2 & 116.7 & $\pm 22.8^{p-0.08}$ \\
\hline
\end{tabular}

Values are mean \pm SD; EMPH-: COPD without macroscopic emphysema; EMPH+: COPD with macroscopic emphysema; WR: work rate; Significance of difference compared to the controls: * $p<0.05 ; *^{* *} p<0.01 ;{ }^{* * *} p<0.001$. Significance of difference between the EMPH+ and the EMPHpatients: $" \mathrm{p}<0.05$ 
Age, height, body weight, FFM and FM did not significantly differ between the groups. No recent involuntary weight loss was present in any patient or control subject. The COPD patients had moderate to severe airflow obstruction, mild to moderate reduced diffusing capacity and arterial $\mathrm{pO}_{2}$, and increased hyperinflation. The EMPH+ had more severe airflow obstruction and air trapping than the EMPHpatients $(\mathrm{p}<0.05)$, but no diffcrence was found in arterial $\mathrm{pO}_{2}$ between the COPD subtypes. In the control group, all lung function values were within the normal range.

Absolute work rate used in the cycle test was not different between the study groups (table 2), but when expressed as a percentage of a previously performed incremental exercise test, the work rate was higher in both COPD subtypes than in the controls $(p<0.01)$. Moreover, the relative work rate was even higher in the EMPH+ than in the EMPH- group $(\mathrm{p}<0.05)$.

Transcutaneous $\mathrm{O}_{2}$ saturation at rest and at end-exercise was lower in all COPD patients than in the controls. Moreover, a lower $\mathrm{O}_{2}$ saturation was found at endexercise in the EMPH+ than in the EMPH- patients $(p<0.05)$. Heart rate was not significantly different between the 3 groups at rest or end-exercise.

\section{Protein metabolism in the total COPD group vs. age-matched controls}

As observed earlier (9), resting data for protein metabolism were increased at rest in patients with COPD. Whole body PB (Fig 1, upper panel) as well as PS (Fig 1, middle panel) significantly increased immediately after start of exercise and to a similar degree in the COPD as well as in the control group. This elevation in PS and PB remained during 15 minutes of exercise.

However, at minute 20 of exercise, the increase in PS as well as in PB was not significantly different from zero anymore in the COPD group. In recovery, PS and $\mathrm{PB}$ immediately normalized in the control group, but decreased to significantly lower values in the COPD group as compared to baseline resting values. Net PB (Fig 1, lower panel) did not change during exercise or recovery in the COPD and control group.

\section{Protein metabolism in the EMPH- patients vs. EMPH+ patients}

In the EMPH- group, like in the control group, $\mathrm{PB}$ increased during exercise $(p<0.05)$ and immediately returned to baseline values in recovery (Fig 2, upper panel). In contrast, PB did not change at all during exercise in the EMPH patients, and decreased in recovery when compared to baseline values $(\mathrm{p}<0.05)$. Comparable findings were present for PS (Fig 2, middle panel). In the EMPH-group, like in the control group, PS increased during exercise $(p<0.05)$ and immediately returned to baseline values in recovery. In the EMPH+ group, PS did not change during exercise but decreased in recovery. This decrease remained statistically significant from zero until at least one hour in recovery. Net PB (Fig 2, lower panel) did not change significantly during exercise or recovery as compared to baseline values in both COPD subtype groups. 

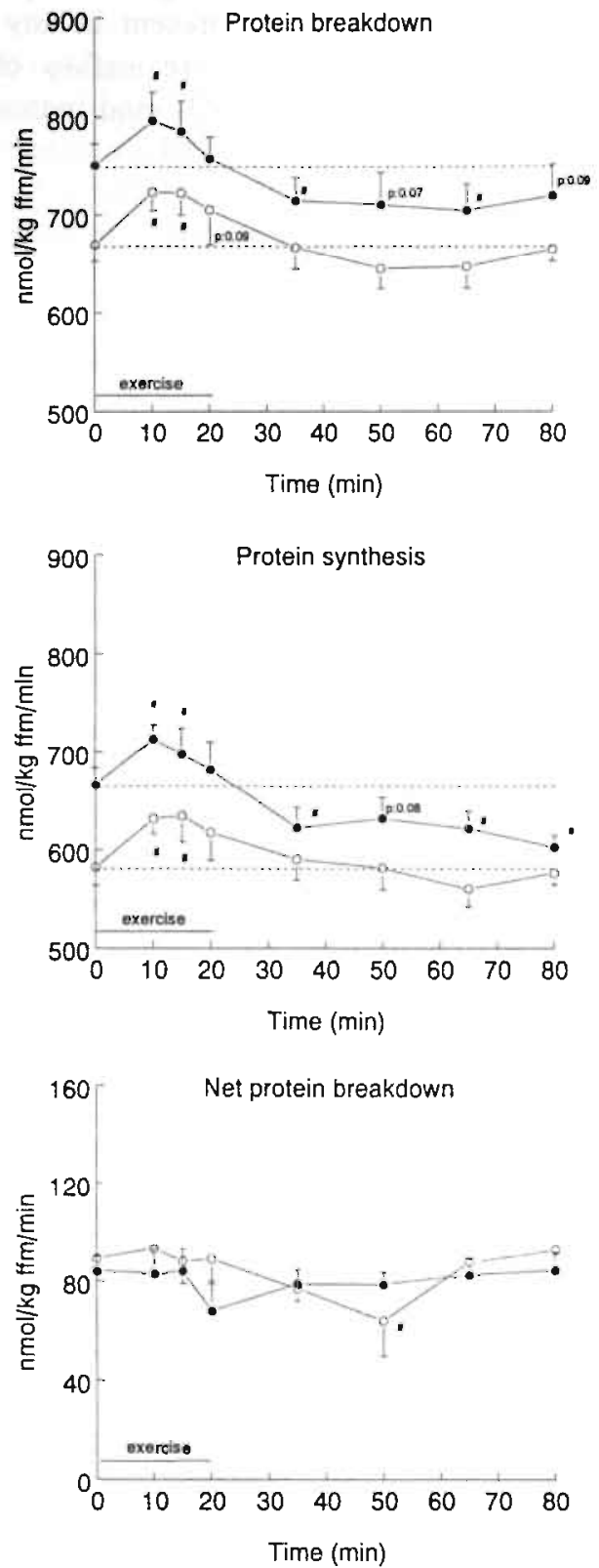

Figure 1. Changes in whole body protein breakdown (top panel), protein synthesis (middle panel) and net protein breakdown (bottom panel) of the healthy volunteers (open circle) and the total COPD group (closed circle) during 20 minutes of exercise and 1 hour of recovery. Mean values \pm 1 SE are shown. Significance of differences compared to baseline values were calculated as ${ }^{\sharp} \mathrm{P}<0.05$. 

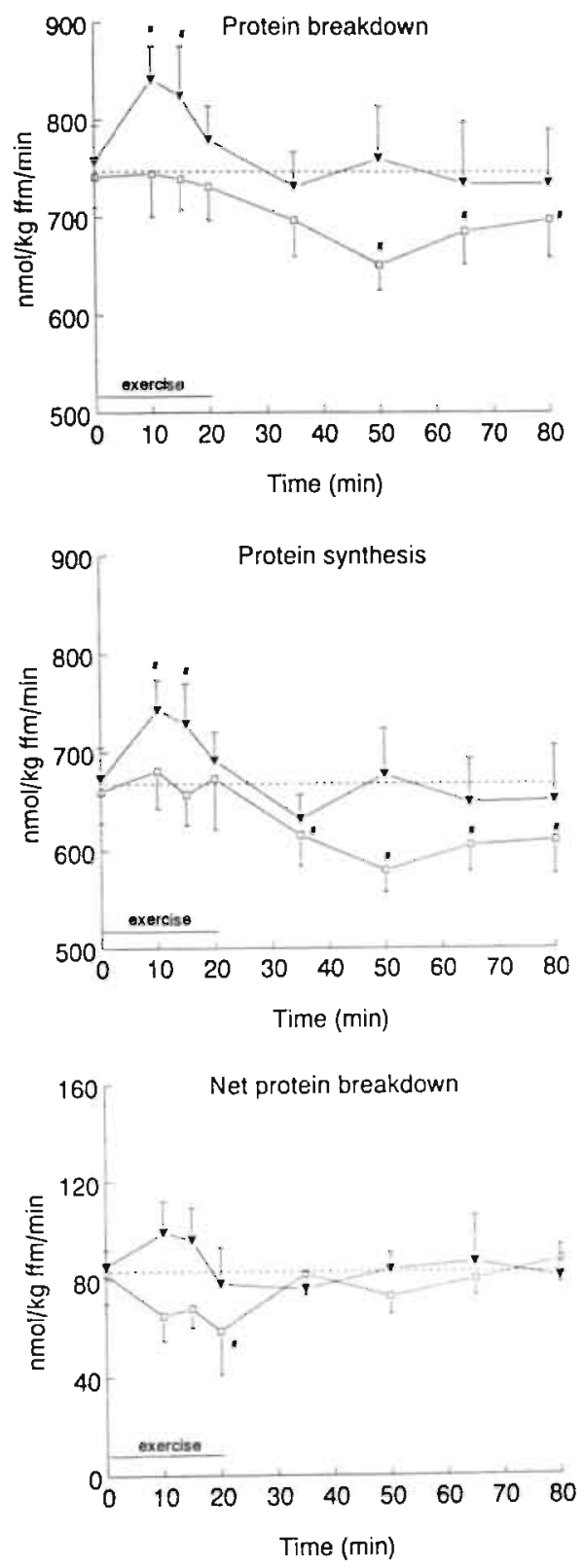

Figure 2. Changes in whole body protein breakdown (top panel), protein synthesis (middle panel) and net protein breakdown (bottom panel) of the EMPH- patients (closed triangle) and EMPH+ patients (open square) during 20 minutes of exercise and 1 hour of recovery. Mean values $\pm 1 \mathrm{SE}$ are shown. Significance of differences compared to baseline values were calculated as " $\mathrm{P}<0.05$. 


\section{DISCUSSION}

In the present study, a different response was present in whole body protein tumover to constant cycle exercise in COPD. After an initial increase in whole body PS and $\mathrm{PB}$ during exercise, whole body $\mathrm{PS}$ as well as $\mathrm{PB}$ returned to baseline values at the end of exercise in the COPD group but remained elevated in the controls. In recovery from exercise, a normalization of PB and PS was immediately present in the control group, whereas a further decrease was found in PS and PB in the total COPD group compared with baseline values.

Specifically in the emphysematous patients, PB and PS did not change at all during exercise but even fell to significantly lower values in recovery.

Until yet, only limited studies are available studying the acute effects of cycle exercise on whole body protein metabolism. The (initial) increase in whole body PB during low-intensity exercise in the total COPD and control group is in line with some previous studies in healthy subjects (10-12), whereas other studies did not find a change in whole body PB (13). Moreover, conflicting results were reported regarding whole body $P S$ during endurance exercise as decreased $(10,14)$ as well as unchanged values $(11,13)$ were observed.

The varying findings in exercise related protein metabolism between the yet limited studies may possibly be related to the different exercise protocols (intensities and durations) and study populations (mostly young physically active controls) used. Moreover, steady state measurements were generally difficult to obtain in particular during high-intensity exercise. In the present study, after an initial increase, whole body PS as well as PB reached a plateau between 10 and 15 minutes of exercise in the studied COPD and control groups, suggesting that an isotopic (tracer) steady state and thus a physiologic steady state was obtained. In this case, the subsequent decrease in PB and PS in these groups suggests an adaptive physiologic response to exercise.

In the present study, net PB was not increased in any of the study groups during exercise or recovery, indicating that cycle exercise at this low intensity does not induce net protein catabolism in the COPD patients or in the healthy controls. It has to be emphasized that the studied severe COPD patients were clinically- and weight stable. It is unknown whether a similar response of net $\mathrm{PB}$ to exercise is present in COPD patients who are in an unstable condition like during weight loss and acute exacerbations.

Whole body levels of PS and PB during exercise do not necessarily reflect PS and $\mathrm{PB}$ in different body subregions (ie skeletal muscle, splanchnic area). Earlier, splanchnic leucine (LEU) $R_{a}$ was shown to contribute for $73 \%$ to the exercise induced release of whole body LEU $\mathrm{R}_{\mathrm{a}}(15)$. Williams (15) showed that the increased LEU release during exercise in dogs is coming from the gut, indicating that the gut is the primary source of the increased $R_{3}$ in the splanchnic area (15). This is probably 
related to the fact that the gut is richly innervated and subject to changes in sympathetic and parasympathetic output, cytokines and hormones.

However, there is also evidence that a moderate increase in nitrogen efflux from muscle occurs during low intensity exercise (16). The observed increase in skeletal muscle PB during exercise (reflected by an elevated TYR release) was the main consequence of an elevated non-contractile protein degradation as decreased values for contractile protein degradation (reflected by reduced 3-methylhistidine excretion values) were found (17). Thus, the enhanced availability of amino acids to the intramuscular amino acid pool during exercise occurs via PB within the active muscles (18) and via an increased branched-chain amino acid delivery from the gut to the active muscle (19). Consequently, the elevation in intracellular appearance of amino acids increases muscle PS $(20,21)$. Therefore, it can be hypothesized that the gut and to a smaller extent the active muscle are likely responsible for the observed increase in whole body PB during exercise in the studied EMPH- patients and controls. The active skeletal muscle, as the most important consumer of amino acids during exercise, is probably responsible for the observed increase in whole body PS. This hypothesis has to be tested in COPD by performing regional arterio-venous measurements across a muscle compartment (ie legs).

Remarkably, the EMPH+ group was not able to increase their whole body protein turnover during exercise.

In a previous study, reduced intracellular muscle amino acid concentrations were found in emphysema patients at rest (22), suggesting a decreased amino acid availability in muscle. In general, amino acid availability is negatively influenced by a reduction in blood flow. It is therefore well possible that an impaired blood flow may play a role in the reduced amino acid levels observed in these patients at rest. In addition, via a reduction in AA availability, a reduced blood flow may contribute to the observed reduction in whole body PS during exercise as observed in the emphysema patients $(20,23)$. To confirm this hypothesis, studies are needed which actually measure blood flow at rest and during exercise in patients with emphysema. Furthermore, a significantly lower transcutaneous $\mathrm{O}_{2}$ saturation was found during exercise in the EMPH+ as compared to the EMPH- group. When hypoxic conditions are actually present in the EMPH+ patients during exercise, whole body PS rate is expected to decrease since cellular hypoxia may result in the development of the "sick cell" syndrome with an increased passive permeability of muscle membranes to sodium and reduced sodium pump activity. Consequently, influx of sodium would increase and sodium-dependent efflux of amino acids would be promoted. Moreover, elevation of whole body protein turnover is generally known to be an energy consuming process. Recently, activity-related energy expenditure was found to be elevated in COPD patients with emphysema (24). Therefore, it can be hypothesized that emphysema patients preferentially use their energy sources for enhanced work of breathing and inefficient muscle contraction during exercise, at the cost of elevating their whole body protein turnover. 
In recovery, whole body $\mathrm{PS}$ and $\mathrm{PB}$ immediately returned to baseline values in the EMPH- and control groups but significantly decreased in the EMPH+ patients as compared to baseline values. In the past, several studies which have actually examined the response in whole body protein turnover after endurance exercise in healthy subjects did not achieve a general agreement as unchanged $(25,26)$ as well as increased $(10,26)$ values were found for whole body PB and PS. The increased PS in muscle after exercise was explained by the elevated total free intracellular amino acid pool which is due to an increased transport of several amino acids into skeletal muscle $(20)$ and to skeletal muscle proteolysis $(20,27)$ immediately after exercise.

It is remarkable that whole body protein turnover in the EMPH+ patients remained at lower values until at least one hour in recovery although there is no energy need for muscle contraction anymore. In general, a reduction in whole body protein turnover is less beneficial in a situation in which nutrition is provided. In this situation, nutrition will get less well metabolized, inducing a lower anabolic response than when there is no reduction in protein turnover. Further studies are necessary to demonstrate the exact cause of this suppressed response in whole body protein turnover to exercise in emphysema.

In conclusion, exercise suppresses whole body PB and PS specifically in COPD patients with emphysema. Quantification of the rate of PB and PS in skeletal muscle of these paticnts will be an important step forward in the understanding of their altered protein metabolic response to exercise. Furthermore, the close relationship between whole body PS and PB values during and after exercise in all study groups suggests a mechanistic link between the two processes.

\section{References}

1. Engelen MPKJ, Schols AMWJ, Lamers RJS, Wouters EFM. Different patterns of chronic tissue wasting among patients with chronic obstructive pulmonary disease. Clin. Nutr. 1999;18:275280.

2. American Thoracic Society. Standards for the diagnosis and care of patients with chronic obstructive pulmonary disease (COPD) and asthma. Am. Rev. Respir. Dis. 1995; 152:s77-s120.

3. Abumrad NN, Rabin D, Diamond MP, Lacy WW. Use of a heated superficial hand vein as an altemative site for the measurement of amino acid concentrations and for the study of glucose and alanine kinctics in man. Metabolism 1981;30:936-40.

4. Jones NI.. Clinical exercise testing. 3rd ed. ed. Philadelphia: Saunders; 1988.

5. Van Eijk HMH, Rooyakkers DR, Soeters PB, Deutz NEP. Determination of amino acid isotope enrichment using liquid chromatography-mass spectrometry. Anal. Biochem. 1999;271:8-17.

6. Sihols AMWJ, Wouters EF, Soeters PB, Westerterp KR. Body composition by bioelectricalimpedance analysis compared with deuterium dilution and skinfold anthropometry in patients with chronic obstructive pulmonary disease. Am. J. Clin. Nutr. 1991;53:421-4.

7. Lukaski HC, Bolonchuk WW, Hall CB, Siders WA. Validation of tetrapolar bioelectrical impedance method to assess human body composition. J. Appl. Physiol. 1986;60:1327-32.

8. Quanjer P. Tammeling GJ, Cotes JE, Pedersen OF, Peslin R, Yemault JC. Standardized lung function testing. Eur. Respir. J. 1993;6:5-40.

9. Engelen MPKJ, Deutz NEP, Wouters EFM, Schols AMWJ. Enhanced levels of whole body protein tumover in patients with chronic obstructive pulmonary disease. Am. J. Respir. Crit. Care Med. 2000; In press. 
10. Rennie MJ, Edwards RH, Krywawych S, Davies CT, Halliday D, Waterlow JC, et al. Effect of exercise on protein turnover in man. Clin. Sci. 1981;61:627-39.

11. Phillips SM, Atkinson SA, Tamopolsky MA, MacDougall JD. Gender differences in leucine kinetics and nitrogen balance in endurance athletes. J. Appl. Physiol. 1993;75(5):2134-41.

12. Carraro $F$, Naldini $A$, Weber J-M, Wolfe RR. Alanine kinetics in humans during low-intensity exercise. Med. Sci. Sports Exerc. 1994;26:348-353.

13. Carraro F, Hart WH, Stuart CA, Layman DK, Jahoor F, Wolfe RR. Whole body and plasma protein synthesis in exercise and recovery in human subjects. Am. J. Physiol. 1990;258:E821E831.

14. Wolfe RR, Goodenough RD, Wolfe MH, Royle GT, Nadel ER. Isotopic analysis of leucine and urea metabolism in exercising humans. J. Appl. Physiol. 1982;52:458-466.

15. Williams BD, Wolfe RR, Bracy DP, Wasserman DH. Gut proteolysis contributes essential amino acids during exercise. Am. J. Physiol. 1996;270:E85-E90.

16. Wolfe RR, Wolfe MH, Nadel ER, Shaw JH. Isotopic determination of amino acid-urea interactions in exercise in humans. J. Appl. Physiol. 1984;56:221-9.

17. Dohm GL, Israel RG, Breedlove RL, Williams RT, Askew EW. Biphasic changes in 3methylhistidine excretion in humans after exercise. Am. J. Physiol. 1985;248:E588-92.

18. Dohm GL, Tapscott E, Kasperek GJ. Protein degradation during endurance exercise and recovery. Med. Sci. Sports Exerc. 1987;19:S166-S171.

19. Ahlborg G, Felig P, Hagenfeldt L, Hendler R, Wahren J. Substrate turnover during prolonged exercise in man. Splanchnic and leg metabolism of glucose, free fatty acids, and amino acids. J. Clin. Invest. 1974;53:1080-90.

20. Biolo G, Maggi SP, Williams BD, Tipton KD, Wolfe RR. Increased rates of muscle protein turnover and amino acid transport after resistance exercise in human. Am. J. Physiol. 1995:268:E514-E520.

21. Biolo G, Tipton KD, Klein S, Wolfe RR. An abundant supply of amino acids enhances the metabolic effect of exercise on muscle protein. Am. J. Physiol. 1997;273:E122-E129.

22. Engelen MPKJ, Schols AMWJ, Does JD, Deutz NEP, Wouters EFM. Differences in amino acid profile of peripheral skeletal muscle between patients with emphysema and chronic bronchitis. Am. J. Respir. Crit. Care Med. 1999;159:A475.

23. Biolo G, Fleming RY, Maggi SP, Wolfe RR. Transmembrane transport and intracellular kinetics of amino acids in human skeletal muscle. Am. J. Physiol. 1995;268:E75-84.

24. Baarends EM, Schols AMWJ, Westerterp KR, Wouters EFM. Total daily energy expenditure relative to resting energy expenditure in clinically stable patients with chronic obstructive pulmonary disease. Thorax 1997;52:780-785.

25. Tipton KD, Ferrando AA, Williams BD, Wolfe RR. Muscle protein metabolism in female swimmers after a combination of resistance and endurance exercise. J. Appl. Physiol. 1996;81:2034-2038.

26. Devlin JT, Brodsky I, Scrimgeour A, Fuller S, Bier DM. Amino acid metabolism after intense exercise. Am. J. Physiol. 1990;258:E249-55.

27. Phillips SM, Tipton KD, Aarsland A, Wolf SE, Wolfe RR. Mixed muscle protein synthesis and breakdown after resistance exercise in humans. Am. J. Physiol. 1997;273:E99-E107. 



\section{PART 3}

\section{Amino acid status of the peripheral skeletal muscle at rest and during exercise}




\section{INTRODUCTION}

Amino acids, the building blocks of proteins, play a pivotal role in intermediary metabolism. Skeletal muscle comprises approximately $60 \%$ of the body cell mass and serves as an important reserve system which in conditions of shortage maintains supplies of amino acids for protein synthesis and metabolism. Several studies in the past have reported pronounced disturbances in the plasma amino acid profile of patients with severe COPD (1). Consistently reduced values were found for the branched-chain amino acids.

Plasma amino acid levels do not directly reflect muscle amino acid metabolism. In acute diseases and conditions associated with muscle wasting, a specific skeletal muscle amino acid profile was found. However, little is known about the amino acid profile of chronic diseases associated with muscle wasting such as COPD. Not only at rest but also during exercise, skeletal muscle is known to participate actively in metabolism of amino acids. A specific amino acid profile has been found after exercise in healthy subjects but no information is available on the amino acid response during exercise in COPD.

Decreased resting muscle glutamate levels have been observed in metabolic stress induced cachexia, a catabolic condition which is characterized by a relative shift from oxidative to glycolytic capacity in peripheral skeletal muscle (2). A relative shift from oxidative to glycolytic capacity is found in COPD, as reduced values have been found for enzymes involved in the tricarboxylic acid cycle and in $\beta$-oxidation of fatty acids $(3,4)$. This suggests that COPD patients may be particularly prone to intracellular glutamate depletion. Glutamate is one of the most important nonessential amino acids. Glutamate is active in many metabolic pathways at rest e.g. as precursor in the synthesis of the amino acid glutamine and the antioxidant glutathione. During exercise, glutamate is important since it preserves high-energy phosphates in muscle through different metabolic mechanisms. Further studies need to be conducted in these areas in COPD.

\section{OUTLINE OF THE CHAPTERS IN PART 3}

In this part, the focus changes to intrinsic alterations in the amino acid profile of peripheral skeletal muscle of patients with COPD. In chapter 7 , factors possibly contributing to the alterations in plasma branched-chain amino acid profile ie. hyperinsulinemia, lung function impairment were studied. Moreover, further characterization of the peripheral skeletal muscle amino acid status was performed in patients with COPD with stratification of the group into patients with and without radiologically diagnosed emphysema. In chapters 8 and $\mathbf{9}$, particular attention was paid to the amino acid glutamate, because under normal conditions it is present in a high content in muscle. Moreover, glutamate is an important precursor for other substrates and it is metabolically active at rest and during exercise. In chapter 8 , 
alterations in the concentration of glutamate as substrate for glutamine and glutathione synthesis was studied in the peripheral skeletal muscle of COPD patients with radiologic emphysema at rest. In chapter 9, we studied the relationship between venous lactate response to incremental exercise and muscle glutamate levels. In chapter 10, the response of the amino acid profile in skeletal muscle and plasma during submaximal cycle exercise was examined in COPD patients and compared to that of healthy age-matched controls.

\section{References}

1. Schols AMWJ, Deutz NEP, Mostert R, Wouters EFM. Plasma amino acid levels in patients with chronic obstructive pulmonary disease. Monaldi Arch. Chest Med. 1993;48:546-548.

2. Tayek JA. A review of cancer cachexia and abnormal glucose metabolism in humans with cancer. J. Am. Coll. Nutr. 1992;11:445-56.

3. Maltais F, Simard AA, Simard C, Jobin J, Desgagnes P, LeBlanc P. Oxidative capacity of the skeletal muscle and lactic acid kinetics during exercise in normal subjects and in patients with severe chronic obstructive pulmonary disease. Am. J. Respir. Crit. Care Med. 1995;151:374-377. 



\section{CHAPTER 7}

Factors contributing to alterations in skeletal muscle and plasma amino acid profiles in patients with chronic obstructive pulmonary disease

Mariëlle P.K.J. Engelen, Emiel F.M. Wouters, Nicolaas E.P. Deutz ${ }^{1}$, Paul P.C.A. Menheere ${ }^{2}$ and Annemie M.W.J. Schols

Depts. of Pulmonology, 'Surgery and ${ }^{2}$ Clinical Chemistry, University Hospital Maastricht, Maastricht, The Netherlands 


\section{ABSTRACT}

Background: There is increasing evidence of abnormal protein metabolism in patients with chronic obstructive pulmonary disease (COPD) as reflected by lower plasma branched-chain amino acids (BCAA) concentrations and different muscle amino acid (AA) patterns than in age-matched control subjects.

Objective: We examined whether the low plasma BCAA concentrations in COPD reflect an imbalance between anabolic and catabolic processes as evidenced by a low fat-free mass (FFM) and alterations in the anabolic hormone insulin and whether discrepancies in muscle AA concentrations between studies are related to different patient characteristics.

Design: AA profile in arterial plasma and quadriceps femoris muscle and insulin concentrations in venous plasma were analyzed in 28 postabsorptive COPD patients (14 with and 14 without macroscopic emphysema) and 28 control subjects. FFM was measured by dual-energy X-ray absorptiometry.

Results: The lower sum of plasma BCAAs in the COPD group than in the control subjects than in the control subjects was the result of a lower leucine concentration $(p<0.001)$; no significant difference was found in valine and isoleucine was found between the groups. In the COPD group, the lower leucine concentrations were associated with low FFM $(p<0.01)$. Compared with those in the control group, the muscle-to-plasma gradient was higher in the COPD group $(p<0.001)$ and was associated with a higher insulin concentration $(p<0.01)$. Several muscle AA concentrations were higher or tended to be higher in the group without emphysema than in the control group, whereas nearly all AA concentrations were lower in the group with emphysema.

Conclusions: Leucine metabolism is altered in COPD patients and is associated with low FFM and high insulin concentrations. There were striking differences in the skeletal muscle AA profile between the COPD subtypes.

\section{INTRODUCTION}

Weight loss and low body weight are common in patients with chronic obstructive pulmonary disease (COPD) and occur predominantly in those with macroscopic emphysema (EMPH+) (1). Lower body weights in EMPH+ patients than in COPD patients without macroscopic emphysema (EMPH-) was mainly the consequence of lower fat mass value in the EMPH+ patients, whereas both COPD subtypes, purticularly I:MPH+ patients, have fat-free mass (FFM) values that are lower than those of age-matched control subjects. Despite these differences in whole body FFM between the COPD subtypes, comparable low values are found for extremity FFM (2).

These low FFM values suggest that intermediary metabolic abnormalities exist in COPD patients. Indeed, several studies reported pronounced disturbances in the plasma amino acid (AA) profile of patients with stable, severe COPD (3-6). In 
addition, abnomal AA concentrations were found in the tibialis anterior muscle of COPD patients (6). In that study, muscle glutamine concentrations were elevated; however, low glutamine concentrations were recently found in the quadriceps femoris muscle of COPD patients of the subtype EMPH+ (7). It is unknown whether this discrepancy in muscle glutamine concentrations also exists for the other amino acids and can be attributed to differences in the characteristics of the COPD population or muscle studied.

Consistently lower plasma branched-chain amino acid (BCAA) concentrations are found in the plasma of COPD patients than in plasma of age-matched control subjects $(8-10)$. One explanation could be that changes in insulin level, a hormone that has a strong anabolic action, influence AA metabolism, particularly that of the BCAAs. Elevated insulin concentrations are found in several other chronic wasting diseases, such as heart and liver failure, and are related to insulin resistance to glucose $(11,12)$. Moreover, increased fasting plasma insulin concentrations are observed in COPD patients with severe hypoxemia than in healthy control subjects (13), but it is unknown whether hyperinsulinemia is also present in normoxemic COPD patients.

The main purpose of the present study was to examine whether the low plasma BCAA concentrations in normoxemic patients with severe COPD reflect an imbalance between anabolic and catabolic processes, as evidenced by low FFM values, and whether they are associated with increased insulin concentrations. The second aim of the study was to examine whether EMPH+ and EMPH- patients have AA profile (including glutamine) in the quadriceps femoris muscle that are different from those of healthy, age-matched control subjects.

\section{SUBJECTS AND METHODS}

\section{Study population}

A group of 28 COPD patients ( 21 men and 6 women) and 28 healthy, age-matched control subjects ( 20 men and 8 women) was studied. The patients were in clinically stable condition and consecutively recruited on admission to a pulmonary rehabilitation center. All patients were participants in an in-patient pulmonary rehabilitation program on weekdays over $8-13$ weeks. The study was performed in the second week of admission, before the rehabilitation program actually started. The control group was recruited from an advertisement in a local newspaper.

All patients had chronic airflow limitation, defined as a measured forced expiratory volume in one second $\left(\mathrm{FEV}_{1}\right)$ less than $70 \%$ of the predicted value. Furthermore, the patients had irreversible obstructive airway disease ( $<10 \%$ improvement in the FEV, predicted after inhalation of $\beta_{2}$-agonist), were in clinically stable condition, and had no respiratory tract infection or exacerbation of their disease at least four weeks 
before the study. An exacerbation was defined as a recent increase in dyspnea, cough, and sputum production of sufficient severity to warrant a change in medication (mild to moderate) or admission to the hospital (severe). Moreover, none of the patients had a fever or a bacterial infection on the basis of a sputum culture. Exclusion criteria were malignancy, cardiac failure, distal arteriopathy, recent surgery, infection, use of anticoagulant medication, or severe endocrine, hepatic, gastrointestinal, and renal disorders. Written, informed consent was obtained from all subjects and the study was approved by the Medical Ethical Committee of the University Hospital Maastricht, Netherlands.

\section{Assessment of emphysema}

In all patients, the presence and severity of parenchymal destruction, the hallmark of emphysema (14), was evaluated by high-resolution computed tomography (HRCT) using a commercial scanner (Somatom Plus; Siemens, Erlangen, Germany) at the following settings: voltage: $137 \mathrm{kVp}$, current:220 mA, collimation: $1.0 \mathrm{~mm} ; 1.0 \mathrm{sec}$. scanning time. Five HRCT scans were obtained while the subjects were in supine position and held their breath at end-expiration: two scans of the upper and two scans of the lower lung zones three and six $\mathrm{cm}$ above and below the carina, respectively, and one scan at the carina. Images were made at a level of -800 Hounsfield Units (HU) and a window width of $1600 \mathrm{HU}$, which is appropriate for lung detail. The : $e^{2}$ verity and cxtent of emphysema in each scan were visually scored on a four-point scale by two independent observers according to the direct observational method dereloped by Sakai (15). The detection and quantification of emphysema by visual inspection and grading was quick and easy to perform (16). For each of the ten lung sections, the score for severity was multiplied by the score for the extent of emphysema, and the resultant scores were subsequently summed to give the total HRCT score. Visual HRCT scores ranged from 0 (no macroscopic emphysema) to 120 (severe macroscopic emphysema). Stratification of the patients by HRCT score resulted into two groups: the EMPH- group (those with an HRCT score $<30$; no or trivial macroscopic emphysema) and the EMPH+ group (those with an HRCT score $\geq 30$; mild-to-severe macroscopic emphysema) (17).

\section{Arterial and venous blood sample collection and analysis}

Postaborptive arterial blood was obtained by puncturing the artery radialis while the subjects breathed room air. One sample was used to determine blood gases $\left(\mathrm{pO}_{2}\right.$, $\mathrm{pCO}_{2}$ ), $\mathrm{pH}$, and oxygen saturation (ABL 330; Radiometer, Copenhagen, Denmark). A second sample was collected into a heparin-containing syringe, immediately put on ice, and subsequently centrifuged at $3120 * \mathrm{~g}$ for 10 minutes at $4{ }^{\circ} \mathrm{C}$ to obtain plasma. Plasma was deproteinized with $5 \%$ sulfosalicylic acid to determine AA profiles. Samples were frozen in liquid nitrogen and stored at $-80^{\circ} \mathrm{C}$ until analyzed.

An evacuated tube containing EDTA (Sherwood Medical, St Louis, Missouri, USA) was used to collect venous blood. Plasma was separated from blood cells by centrifugation at $3120^{*} \mathrm{~g}$ for 10 minutes at $4{ }^{\circ} \mathrm{C}$ within two hours after collection. 
Immediately after the first separation, the separated plasma was again centrifuged at $3120^{*} \mathrm{~g}$ for 10 minutes at $4^{\circ} \mathrm{C}$. Plasma samples were stored at $-80^{\circ} \mathrm{C}$ until analyzed. Insulin was analyzed using a commercially available immunofluorometric assay (IFMA) by using an AutoDelfia automatic analyzer (Perkin-Elmer, Turku, Finland). There was no measurable cross-reactivity with autoantibodies against insulin.

\section{Peripheral skeletal muscle biopsy collection and analysis}

Postabsorptive muscle biopsies were obtained from the lateral part of the quadriceps femoris muscle by using the needle-biopsy technique after administration of a local anesthetic while the subjects were in supine position and at rest (18). All biopsies were immediately frozen in liquid nitrogen and stored at $-80^{\circ} \mathrm{C}$ until analyzed. After $1-\mathrm{mm}$ glass beads were added, the muscle tissue was homogenized with a Mini-beater (Biospec Products, Bartlesville, OK), and deproteinized with $5 \%$ sulfosalicylic acid for AA determination.

The AA profiles in muscle and arterial plasma were analyzed in the same batch run by fully automated high-performance liquid chromatography (HPLC) $(19,20)$. The following AAs were measured: glutamine (GLN), alanine (ALA), valine (VAL), isoleucine (ILE), leucine (LEL), phenylalanine (PHE), tyrosine (TYR), arginine (ARG), histidine (HIS), lysine (LYS), methionine (MET), threonine (THR), tryptophan (TRP), $\alpha$-amino-butyric acid ( $\alpha-A B)$, asparagine (ASN), citrulline (CIT), glutamate (GLU), ornithine (ORN), serine (SER) and tyrosine (TYR). The sum of BCAAs included LEU + ILE + VAL, the sum of aromatic amino acids included PHE + TYR + TRP, and the sum of total AAs included all measured AAs.

\section{Metabolic measures}

\section{Body weight and composition}

Body weight was measured with an electronic beam scale with a digital read-out to the nearest $0.1 \mathrm{~kg}$ (Seca, model 708, Hamburg. Germany), while the subjects were standing barefoot and wearing light indoor clothing. Weight loss was defined as involuntary weight loss $>5 \%$ of body weight during the last three months. Body height was measured to the nearest $0.1 \mathrm{~cm}$ (Seca, model 220, Hamburg, Germany). FFM was determined by scanning all patients and control subjects with a DPX-L Bone Densitometer (Lunar Radiation Corporation, Madison, WI) (21).

\section{Resting energy' expenditure en dietary energy intake}

REE was measured in all the patients after an overnight fast under standardized conditions (22) by open-circuit indirect calorimetry with a ventilated-hood system (Oxycon- $\beta$; Mijnhardt, Bunnik, Netherlands). $\mathrm{O}_{2}$ consumption and $\mathrm{CO}_{2}$ production were calculated from the airflow and the differences in the concentration of $\mathrm{O}_{2}$ and $\mathrm{CO}_{2}$ between incoming and outgoing air. Energy expenditure was calculated by using the abbreviated Weir formula (23). REE was expressed per kilogram of FFM, 
and as a percentage of the REE of an age- and FFM matched control group (24). The dietary energy intake of the COPD group was ascertained retrospectively before admission to the hospital, during the first week of rehabilitation, by using the dietary history method with a cross check. The information was coded for computer nutrient analysis by the same trained dietician. The nutrient database was derived from the Dutch food-composition tables (25).

\section{Pulmonary function tests}

$\mathrm{FEV}_{1}$ was determined in all patients and control subjects by spirometry; the highest value from at least three technically acceptable procedures was used. The diffusing capacity of the lungs for carbon monoxide $\left(\mathrm{DL}_{\mathrm{co}}\right)$ was measured by using the single-breath method (Masterlab, Jaeger, Wurzburg, Germany). All values obtained were related to a reference value and expressed as a percentage of the predicted value (26).

\section{Statistical analysis}

Results are expressed as mean \pm standard error (SE) for muscle and plasma determinations, and mean \pm standard deviation (SD) for other characteristics. SPSS 7.5 for WINDOWS (SPSS Inc, Chicago) was used for statistical analysis. Oneway analysis of variance was used to determine differences in general characteristics, plasma and muscle AAs, and insulin between the total COPD population, the EMPH+ and EMPH- subtypes, and the control group. Subsequently, Tukey's multiple (pairwise) comparisons procedures were used to analyze the differences between the EMPH+, EMPH- and control groups. Scheffe's test was used to analyze the differences between the control and the COPD groups to control for type 1 error. Linear regression analysis was performed to determine the relation between insulin, the ratio of glucose to insulin, and the individual BCAAs. A p-value $<0.05$ was considered significant.

\section{RESULTS}

The clinical characteristics of the study groups are shown in Table 1. The subjects' mean age was 64 years. The EMPH+ group had significantly greater airflow obstruction and significantly lower body weights than did the EMPH- group.

FFM was significantly lower in the total COPD and EMPH+ groups than in the control subjects and tended to be lower, but not significantly so, in the EMPHgroup. More subjects in the EMPH+ group than in the EMPH- group lost weight ( $43^{\circ}$; compared with $21 \%$; NS). C-reactive protein was not significantly higher in the two COPD subtypes than in the control subjects, although it was highly variable in the EMPH- group. Absolute REE, REE expressed per kilogram FFM, and REE expressed as a percentage of that predicted was significantly higher in the EMPH- 
than in the EMPH+ group, but there was no significant difference in dietary energy intake between groups.

Table 1. General characteristics of the healthy control subjects, the total COPD populaiion, and the COPD subtypes with (EMPH+) and without (EMPH-) emplysema

\begin{tabular}{|c|c|c|c|c|c|c|c|c|}
\hline \multirow[b]{2}{*}{ Sex } & \multirow[b]{2}{*}{$\mathrm{M} / \mathrm{F}$} & $\begin{array}{l}\text { Controls } \\
(n=28)\end{array}$ & \multicolumn{2}{|c|}{$\begin{array}{l}\text { COPD } \\
(n=28)\end{array}$} & \multicolumn{2}{|c|}{$\begin{array}{l}\text { EMPH- } \\
(n=14)\end{array}$} & \multicolumn{2}{|r|}{$\begin{array}{l}\text { EMPH+ } \\
(n=14)\end{array}$} \\
\hline & & $20 / 8$ & 20 & 18 & 9 & 75 & & $11 / 3$ \\
\hline Age & $y$ & $64 \pm 5$ & 64 & \pm 9 & 64 & \pm 11 & & $65 \pm 8$ \\
\hline $\mathrm{FEV}_{1}$ & $\%$ pred. & $108 \pm 17$ & 41 & $\pm 15^{* * *}$ & 49 & $\pm 16^{* * *}$ & $"$ & $33 \pm 10^{* * *}$ \\
\hline $\mathrm{Dl}_{\mathrm{co}}$ & $\%$ pred. & $117 \pm 17$ & 67 & $\pm 26^{* * *}$ & 85 & $\pm 20^{* * *}$ & $m n$ & $41 \pm 6^{* * *}$ \\
\hline Weight loss & $Y / N$ & $1 / 27$ & 9 & $/ 19$ & 3 & 111 & & $6 / 8$ \\
\hline Body weight & $\mathrm{kg}$ & $74.4 \pm 11.0$ & 71.3 & \pm 14.6 & 74.6 & $=13.0$ & " & $67.3 \pm 15.8^{*}$ \\
\hline FFM & $\mathrm{kg}$ & $54.4 \pm 10.3$ & 48.6 & $\pm 8.2^{*}$ & 49.4 & \pm 7.2 & & $47.6 \pm 3.4^{*}$ \\
\hline FM & $\mathrm{kg}$ & $18.5 \pm 6.9$ & 20.1 & \pm 10.2 & 23.3 & \pm 11.1 & & $16.1 \pm 7.5$ \\
\hline Albumin & $\mathrm{G} / \mathrm{L}$ & $39.1 \pm 2.5$ & 36.0 & $\pm 2.7^{* * *}$ & 36.1 & $\pm 2.4^{* *}$ & & $35.9 \pm 3.2^{* *}$ \\
\hline CRP & $\mu \mathrm{g} / \mathrm{mL}$ & $1.5 \pm 6.5$ & 2.6 & \pm 8.7 & 5.1 & \pm 12.9 & & $0.7 \pm 1.9$ \\
\hline Energy intake & $\mathrm{MJ} / 24 \mathrm{~h}$ & & 7.1 & \pm 2.2 & 7.3 & \pm 1.9 & & $6.9 \pm 2.6$ \\
\hline REE & $\mathrm{MJ} / 24 \mathrm{~h}$ & & 6.2 & \pm 1.3 & 6.7 & \pm 1.2 & $"$ & $5.6 \pm 1.2$ \\
\hline $\mathrm{REE} / \mathrm{FFM}$ & $\mathrm{MJ} / 24 \mathrm{~h} / \mathrm{kg}$ & & 0.13 & \pm 0.02 & 0.14 & \pm 0.02 & " & $0.11 \pm 0.02$ \\
\hline REE & $\%$ pred. & & 100 & \pm 21 & 109 & \pm 20 & $"$ & $88 \pm 15$ \\
\hline
\end{tabular}

Values are mean $\pm \mathrm{SD}$; EMPH+, EMPH-: COPD with and without emphysema, respectively; $\mathrm{FEV}_{1}$ : forced expiratory volume in one second; $\mathrm{Dl}_{\mathrm{co}}$ : diffusing capacity for carbon monoxide; FFM: fatfree mass; FM: fat mass; CRP: C-reactive protein; REE: resting energy expenditure. Significant different from the control group: *** $p<0.001 ; * * p<0.01 ;{ }^{*} p<0.05$; significance of difference between the EMPH- and the EMPH+ group: "

\section{BCAA profile in plasma}

The individual plasma BCAAs (and remaining AAs) of the control, the total COPD group, and the COPD subtypes EMPH- and EMPH+ are shown in table 2. The total COPD group and the EMPH- and EMPH+ subtypes had significantly lower plasma Leucine concentrations than did the control group. Moreover, plasma leucine was significantly lower in the EMPH+ group than in the EMPH- group. No significant differences were found in plasma isoleucine or valine between the COPD subtypes and the control subjects.

\section{AA profile in skeletal muscle}

In muscle (table 3), we were specifically interested in the AAs glutamine, glutamate and alanine; the aromatic AAs (phenylalanine, tyrosine, and tryptophan); and the individual muscle BCAAs leucine, isoleucine and valine because these AAs play a 
prominent role in overall protein metabolism. Muscle glutamate was significantly lower in the COPD than in the control group but glutamine, alanine, all aromatic Aas, and BCAAs were not significantly different between these two groups.

Table 2. Plasma amino acid profile in the healthy control subjects, the total COPD population, and the COPD subtypes with (EMPH+) and without (EMPH-) emphysema

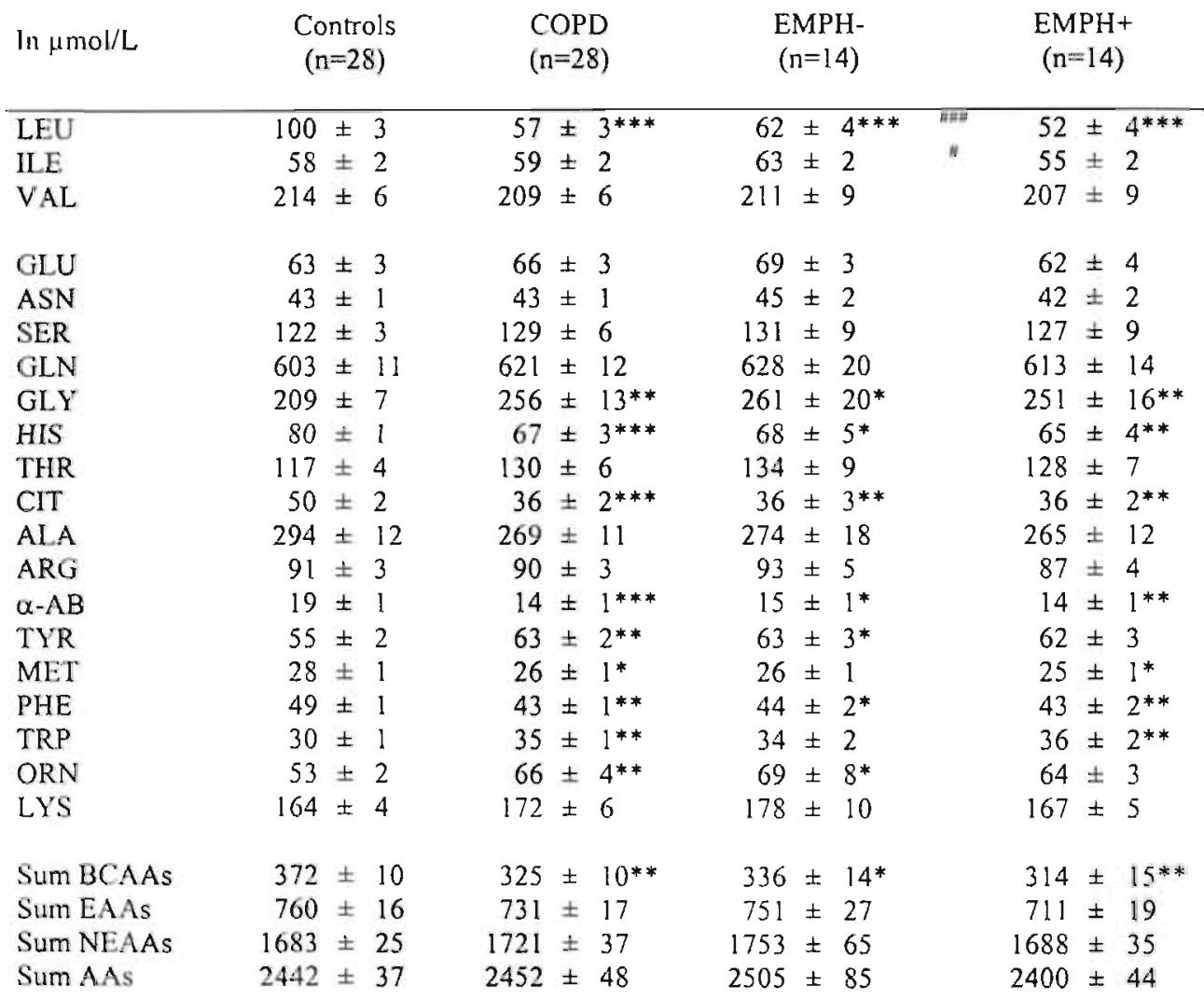

Values are mean \pm SE; EMPH-: COPD without macroscopic emphysema; EMPH+: COPD with macroscopic emphysema; LEU: leucine; ILE: isoleucine; VAL: valine; GLU: glutamate; ASN: asparagine; SER: serine; GLN: glutamine; GLY: glycine; HIS: histidine; THR: threonine; CIT: citrulline; ALA: alanine, ARG: arginine; $\alpha A B: \alpha$-amino-butyric acid; TYR: tyrosine, MET: methionine; PHE: phenylalanine; TRP: Typtophan; ORN: omithine; LYS: lysine; BCAA: branchedchain amino acids; EAA; essential amino acids; NEAA: non-essential amino acids: AA: amino acids. Significant different from the control group: *** $p<0.001 ;{ }^{* *} p<0.01 ;{ }^{*} p<0.05$; significance of difference between the EMPH- and the EMPH+ group: ${ }^{n z} p<0.001 ;{ }^{*} p<0.05$ 
Table 3. Amino acid profile in skeletal muscle of healthy control subjects, the total COPD population, and the COPD subgroups with (EMPH+) and without (EMPH-) emplysema

$\begin{array}{lcccc}\text { In } \mu \mathrm{mol} / \mathrm{kg}_{\mathrm{ww}} & \begin{array}{c}\text { Controls } \\ (\mathrm{n}=28)\end{array} & \begin{array}{c}\text { COPD } \\ (\mathrm{n}=28)\end{array} & \begin{array}{c}\text { EMPH- } \\ (\mathrm{n}=14)\end{array} & \begin{array}{c}\text { EMPH+ } \\ (\mathrm{n}=14)\end{array}\end{array}$

\begin{tabular}{|c|c|c|c|c|c|c|c|c|c|}
\hline GLN & 13255 & \pm 125 & 13443 & \pm 262 & $14503 \pm$ & $256^{* * *}$ & ज्ञात & $12382 \pm$ & $181^{* *}$ \\
\hline GLU & $1985=$ & \pm 73 & 1472 & $\pm 79^{* * *}$ & $1682 \pm$ & 121 & $"$ & $1262 \pm$ & $64^{* * *}$ \\
\hline ALA & $1840=$ & \pm 85 & 1915 & \pm 120 & $2359 \pm$ & 230 & " & $1640 \pm$ & 137 \\
\hline PHE & $70=$ & \pm 2 & 78 & \pm 6 & $93 \pm$ & 9 & mi! & $63 \pm$ & $6^{* *}$ \\
\hline TYR & $89=$ & \pm 4 & 92 & \pm 7 & $112 \pm$ & $11^{*}$ & " & $75 \star$ & $5^{*}$ \\
\hline TRP & 25 & \pm 2 & 23 & \pm 3 & $26 \pm$ & 5 & & $20 \pm$ & $3^{*}$ \\
\hline LEU & $153=$ & \pm 6 & 156 & \pm 12 & $187 \pm$ & 18 & "in & $127 \pm$ & $12 * *$ \\
\hline ILE & 72 & \pm 3 & 81 & \pm 8 & $96 \pm$ & $12^{*}$ & $m$ & $64 \pm$ & $6^{*}$ \\
\hline VAL & 262 & \pm 11 & 260 & \pm 21 & $300 \pm$ & 32 & " & $218 \pm$ & $24^{* *}$ \\
\hline ASN & $229=$ & \pm 22 & 261 & \pm 18 & $300 \pm$ & $27^{*}$ & $"$ & $223 \pm$ & 20 \\
\hline SER & 446 & \pm 23 & 526 & $\pm 28^{*}$ & $617 \pm$ & $41^{* *}$ & " & $457 \pm$ & 20 \\
\hline GLY & 981 & \pm 40 & 1306 & $\pm 60^{* * *}$ & $1418 \pm$ & $89 * * *$ & $n$ & $1194 \pm$ & $69^{*}$ \\
\hline HIS & 355 & \pm 12 & 304 & $\pm 18^{*}$ & $354 \pm$ & 22 & "n & $252 \pm$ & $20^{* * *}$ \\
\hline THR & 604 & \pm 25 & 589 & \pm 27 & $662 \pm$ & 35 & \#\# & $515 \pm$ & $37^{*}$ \\
\hline $\mathrm{CIT}$ & 121 & \pm 12 & 130 & \pm 14 & $141 \pm$ & 24 & & $118 \pm$ & 14 \\
\hline $\mathrm{ARG}$ & 485 & \pm 30 & 436 & \pm 23 & $501 \pm$ & 24 & $m$ & $370 \pm$ & $30^{*}$ \\
\hline$\alpha-A B$ & 63 & \pm 3 & 60 & \pm 3 & $67 \pm$ & 3 & $"$ & $53 \pm$ & $5^{*}$ \\
\hline MET & 34 & \pm 2 & 25 & $\pm 4^{*}$ & $32 \pm$ & 6 & $"$ & $16 \pm$ & $3^{* *}$ \\
\hline ORN & 187 & \pm 15 & 204 & \pm 20 & $230 \pm$ & 33 & & $178 \pm$ & 20 \\
\hline LYS & 694 & \pm 40 & 628 & \pm 34 & $727 \pm$ & 47 & "* & $529 \pm$ & $32^{*}$ \\
\hline Sum BCAAs & 487 & \pm 18 & 497 & \pm 40 & $583 \pm$ & 60 & 成 & $410 \pm$ & $42^{* *}$ \\
\hline Sum EAAs & 1914 & \pm 57 & 1840 & \pm 87 & $2124 \pm$ & 107 & Hen & $1556 \pm$ & $81^{* *}$ \\
\hline Sum NEAAs & 20036 & \pm 90 & 20151 & \pm 400 & $22108 \pm$ & $134^{* * *}$ & "n\# & $18194 \pm$ & $96^{* * *}$ \\
\hline Sum AAs & 21949 & $\pm \quad 170$ & 21991 & \pm 464 & $24231 \pm$ & $182^{* * *}$ & mat & $19750 \pm$ & $164 * * *$ \\
\hline
\end{tabular}

Values are mean \pm SE; EMPH-: COPD without macroscopic emphysema; EMPH+: COPD with macroscopic emphysema; GLN: glutamine; GLU: glutamate; ALA: alanine, PHE: phenylalanine; TYR: tyrosine, LEU: leucine; ILE: isoleucine; VAL: valine; ASN: asparagine; SER: serine; GLY: glycine; HIS: histidine; THR: threonine; CIT: citrulline; ARG, arginine; $\alpha A B, \alpha$-amino-butyric acid; MET, methionine; TRP, tryptophan; ORN: ornithine; LYS: lysine; BCAA: branched-chain amino acids; EAA: essential amino acids; NEAA: non-essential amino acids. Significant different from the control group: ${ }^{* * *} p<0.001 ;{ }^{* *} p<0.01 ;{ }^{*} p<0.05$; significance of difference between the EMPH- and the EMPH+ group: ${ }^{\text {\#kt }} \mathrm{p}<0.001 ;{ }^{* \prime \prime} \mathrm{p}<0.01 ;{ }^{\prime \prime} \mathrm{p}<0.05$ 
Stratification of the COPD group into the subtypes EMPH- and EMPH+ resulted in remarkable differences. The EMPH+ group had lower glutamine, glutamate, phenylalanine, tyrosine, and individual BCAA concentrations than did the EMPHand control groups. The EMPH- group had significantly higher glutamine, tyrosine, and isoleucine concentrations than did the control subjects. As a result, the sum of AAs in muscle was significantly lower in the EMPH+ than in the EMPH- and control groups but was significantly higher in the EMPH- group than in the control group.

The ratio of muscle to plasma leucine was significantly higher in EMPH$(4.4 \pm 0.5)$ and EMPH+ $(3.1 \pm 0.2)$ groups than in the control group $(2.0 \pm 0.1$; $\mathrm{p}<0.001)$. Moreover, the ratio was significantly higher in the EMPH- than in the $\mathrm{EMPH}+$ group.

Insulin concentrations (Fig 1a) were significantly higher and the ratio of glucose to insulin (Fig 1b) was significantly lower in the total COPD, EMPH+, and EMPHgroups than in the control group, but no significant differences were found between the EMPH+ and EMPH- subtypes. The insulin concentration correlated with the ratio of muscle to plasma leucine $(\mathrm{r}: 0.53 ; \mathrm{p}<0.01)$ in the COPD group. Whole-body FFM correlated with plasma leucine $(r: 0.56 ; p<0.01)$, isoleucine $(r: 0.43 ; p<0.05)$, and valine (r:0.40;p<0.05).

Stratification of the COPD group into oral corticosteroid users $(\mathrm{n}=11)$ and nonusers showed that the oral corticosteroid users had lower plasma leucine $(p<0.01)$, valine $(p<0.05)$ and muscle glutamate $(p<0.05)$ concentrations. The number of oral corticosteroid users in the EMPH- and EMPH+ group was comparable (5 compared with 6 , respectively).

\section{DISCUSSION}

In the present study, there were significant differences in plasma AA concentrations between the COPD patients and the control subjects. Changes in plasma AA concentrations are difficult to interpret unless there is some consistency in findings among studies.

In the past, several studies examined plasma AA levels in COPD patients and all of them observed lower BCAA concentrations than in control subjects (8-10). The lower sum of BCAA concentrations in the COPD group than in the control subjects in the present study was due to lower concentrations of leucine but not of isoleucine or valine, which confirms previous findings by Hofford et al. (27). Moreover, higher postabsorptive concentrations were found in both COPD subtypes than in the control group. Hyperinsulinemia is known to reduce plasma BCAA concentrations in cirrhotic patients by increasing BCAA uptake in muscle and additionally in adipose tissue (12). Although fat mass was lower in the EMPH+ group than in the EMPHgroup, and thus less BCAAs were taken up via this pathway, BCAA concentrations were lower in the EMPH+ group. Systemic inflammation, often reported in COPD 
(28), is known to negatively affect plasma BCAA concentrations. In vivo studies showed that interleukin 1 and tumor necrosis factor $\alpha$ can stimulate muscle BCAA catabolism and AA uptake by hepatocytes (29), and, additionally, increase the activity of muscular branched-chain keto acid dehydrogenase (30). To our knowledge, no studies on the interactive effect of cytokines and hormones on leucine metabolism in skeletal tissue have been conducted.
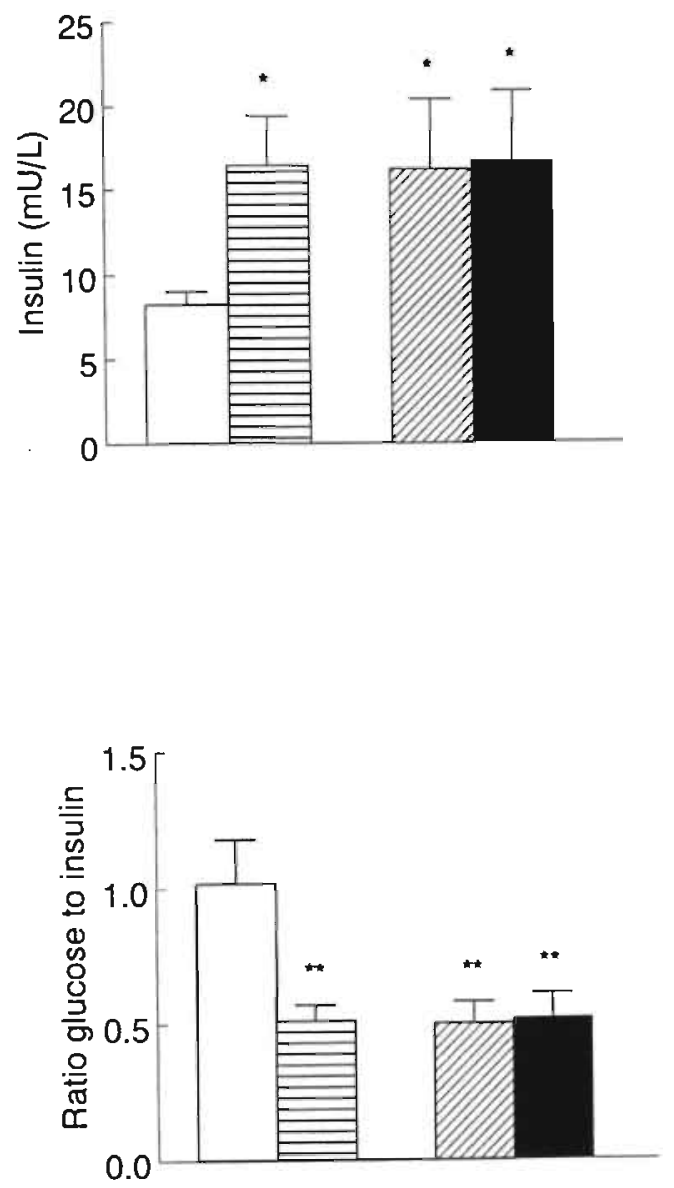

Figure 1. Bar diagram of fasting venous insulin level (top panel) and ratio glucose to insulin (bottom panel) of 28 healthy controls (open bar), 28 COPD (horizontal-striped bar). 14 EMPH(cross-striped bar) and $14 \mathrm{EMPH}+$ patients (closed bar). Mean values $\pm 1 \mathrm{SE}$ are shown. Significance of differences were calculated as ** $\mathrm{P}<0.01 ; * \mathrm{P}<0.05$. 
Besides an increased leucine uptake, a suppressed release of leucine may also contribute to low plasma leucine concentrations in COPD. Insulin is known to inhibit endogenous proteolysis, indicating that hyperinsulinemia may reduce the rate of appearance of leucine into plasma because of the suppression of endogenous protein breakdown. Furthermore, the increased insulin concentrations in the COPD group were associated with an elevated muscle-to-plasma leucine gradient, suggesting possible abnormalities in the transmembrane leucine transport system. Moreover, a lower ratio of glucose to insulin was found in the COPD group than in the control group, possibly indicating insulin resistance for glucose. More research is needed to assess the relation between insulin resistance and leucine metabolism in COPD to elucidate whether hyperinsulinemia induces a comparable suppression in leucine flux in COPD patients and healthy persons.

Additionally, a significant correlation was found between plasma leucine concentrations and whole-body FFM, suggesting that a poor nutritional state may have further contributed to the lower plasma leucine concentrations in the COPD group than in the control group, possibly by increasing leucine oxidation in skeletal muscle to a noncarbohydrate energy substrate. This observation agrees with the finding of low plasma BCAA concentrations reported in subjects with anorexia nervosa (31) and protein-calorie malnutrition (32). We conclude that the lower plasma leucine concentration in COPD patients than in the control subjects was due to specific alterations in leucine metabolism. More research is needed in which advanced metabolic techniques (eg, flux measurements and the use of stable-isotopelabeled tracers) are used to elucidate to what extent hyperinsulinemia, as well as the other factors mentioned above, contributes to the explanation for the lower plasma leucine concentrations observed in patients with COPD than in control subjects.

In the total COPD group, only a few muscle AA concentrations were significantly different from those of the control group. However, stratification of the group showed striking differences in the muscle AA profile between the EMPH- and EMPH+ subtypes. Extensive studies were carried out previously in acute catabolic diseases and conditions associated with muscle wasting (Table 4). Acute metabolic stress as well as nonmetabolic stress-related diseases and conditions resulted in a similar pattern of change in AA concentrations (eg, a decrease in glutamine and increases in aromatic Aas and BCAAs) $(33-37,38,39-41)$, although the gradation of responses was different.

Little is known about the muscle amino acid profile of chronic diseases associated with muscle wasting. The available literature (Table 4$)(0,42-44)$ indicates relatively small differences in the muscle AA profile of patients with metabolic stress-related chronic diseases; however, each of the chronic diseases is associated with an unique AA pattern.

The total COPD group had quadriceps femoris muscle glutamate concentrations that were lower than but aromatic AA and BCAA concentrations that were comparable 
with those of the control group. This agrees with previous data suggesting that there were no muscle-specific AA differences in the tibialis anterior muscle of stable, severe COPD patients (6). However, the COPD group with no or mild emphysema as determined by the diffusing capacity of the lungs (6) had higher concentrations of muscle glutamine and alanine than did age-matched control subjects. Elevated glutamine concentrations were also found in the EMPH- group in the present study. Moreover, the EMPH- patients had higher concentrations of nearly all muscle AAs than did the control group. In addition, these patients werc hypermetabolic (reflected by increased REE levels) and had low FFM. Although protein catabolism can not be excluded as a potential cause of this AA profile, we hypothesize that the increase in most of the AA concentrations toward a higher set point in FMPH- patients is a consequence of an increased muscle protein turnover. This, in addition to systemic inflammation (28), may possibly contribute to these patients' increased REEs.

A remarkable finding is the increased muscle glutamine concentration in the EMPHgroup. Elevated glutamine concentrations were not associated with any of the other chronic or acute diseases studied, except for acute liver failure (Table 4) (.37), in which glutamine synthesis increased because of the presence of hyperammonemia. Ammonia concentrations in the muscle or plasma of the EMPH- group were not significantly higher than those of the control group (muscle: $155 \pm 138 \mu \mathrm{mol} / \mathrm{kg}_{\mathrm{ww}}$ and $148 \pm 113 \mu \mathrm{mol} / \mathrm{kg}_{w w}$, respectively; plasma: $62 \pm 7 \mu \mathrm{mol} / \mathrm{L}$ and $63 \pm 8 \mu \mathrm{mol} / \mathrm{L}$, respectively). Further research is needed to elucidate the cause of the elevated GLN levels in the EMPH- group.

In contrast, nearly all the muscle Aas were lower in the EMPH+ group than in the control subjects. Previously, reduced muscle AA concentrations were also found after stress hormone infusion (45) and within twelve hours after surgery (36) (Table 4), probably because of elevated catabolic hormone concentrations. Although elevated concentrations of norepinephrine were found in patients with emphysema $(10)$, it is unlikely that increased catabolic hormone levels were responsible for the decreased muscle AA concentrations in the EMPH+ group because lower (absolute and relative) REE values were found in this group than in the control group, which suggests mild hypometabolism. Despite reduced REE levels and normal dietary energy intakes, periods of negative energy balance may still occur in these patients during the day.

Recently, it has been shown that the skeletal muscles of emphysema patients were less mechanically efficient than were those of a healthy control group, which suggests that emphysema patients require higher energy levels for a given activity (46). When the increased free-living total daily energy expenditure in these patients is not adequately matched by their dietary intake, chronic starvation may occur. In this situation, enhanced levels of AAs are transported from the skeletal muscle to the splanchnic area to increase the rate of gluconeogenesis to supply glucose for energy. This means that a drain is placed on the plasma AA pool and when the demand of AAs continues to rise, a fall in the muscle AA concentrations is the consequence. 
No studies have examined muscle AA concentration in other chronic nonmetabolic stress-related conditions (ie, anorexia nervosa), which could confirm this hypothesis.

Table 4. Intracellular free amino acid pattern in chronic and acute diseases and condition. associated with muscle wasting: an overview of studies

Aromatic

$\mathrm{BCAAs}$

Refs.

AAs

GLN GLU ALA PHE TYR LEU ILE VAL

Acute disease or condition

A. Metabolic stress related:

Sepsis

Injury

Surgical trauma:

After 12 hours

After 24 hours and more

Fulminant hepatic failure*

Acute pancreatitis

Stress hormone infusion

B. Nonmetabolic stress-related:

Partial starvation

Bedrest

Bedrest and partial starvation

Malnutrition

\section{Chronic disease}

Metabolic stress related:

Diabetes (Type 1)

Liver cirrhosis

Chronic renal failure:

Hemodialysis

Uremia

COPD**

COPD***

\section{EMPH-*** \\ $\mathrm{EMPH}+* * *$}

GLN: glutamine; GLU: glutamate; ALA: alanine; PHE: phenylalanine; TYR: tyrosine; LEU: leucine; ILE: isoleucine; VAL: valine; BCAA: branched-chain amino acids. *: Significance was not provided: **: tibialis anterior muscle; ***: present study: EMPH-: COPD patients without macroscopiv emphysema, EMPH+: COPD patients with macroscopic emphysema. $\uparrow$ : significantly higher than in control subjects, $\downarrow$ : significantly lower than in control subjects, $\approx$ : not significantly different from control subjects.

We conclude that the striking differences in skeletal muscle AA profiles between the EMPH + and EMPH- groups imply that careful stratification and characterization of patients with COPD and other chronic diseases are important in studies of differences in muscle amino acid concentrations. 


\section{References}

1. Engelen MPKJ, Schols AMWJ, Lamers RJS, Wouters EFM. Different patterns of chronic tissue wasting among patients with chronic obstructive pulmonary disease. Clin. Nutr. 1999;18:275280.

2. Engelen MPKJ, Schols AMWJ, Does JD, Wouters EFM. Skeletal muscle weakness is associated with wasting of extremity fat-free mass loss but not with airflow obstruction in patients with chronic obstructive pulmonary disease. Am. J. Clin. Nutr. 2000;71:733-738.

3. Hunter AMB, Carey MA. Larsh HW. The nutritional status of patients with chronic obstructive pulmonary disease. Am. Rev. Respir. Dis. 1981;124:376-381.

4. Schols AMWJ, Mostert R, Soeters PB, Saris WHM, Wouters EFM. Energy balance in patients with chronic obstructive pulmonary disease. Am. Rev. Respir. Dis. 1991;143:1248-1252.

5. Green JH, Muers MF. Comparisons between basal metabolic rate and diet-induced thermogenesis in different types of chronic obstructive pulmonary disease. Clin. Sci. 1992;83:109-116.

6. Pouv EM, Schols AMWJ, Deutz NEP, Wouters EFM. Plasma and muscle amino-acid levels in relation to resting energy expenditure and inflammation in stable COPD. Am. Rev. Respir. Crit. Care Med. 1998;158:797-801.

7. Engelen MPKJ, Schols AMWJ, Does JD, Deutz NEP, Wouters EFM. Altered glutamate metabolism is associated with reduced muscle glutathione levels in patients with emphysema. Am. J. Respir. Crit. Care Med. 2000;161:98-103.

8. Morrison WL, Gibson JNA, Scrimgeour C, Rennie MJ. Muscle wasting in emphysema. Clin. Sci. $1988 ; 75: 415-420$.

9. Schols AMWJ, Deutz NEP, Mostert R, Wouters EFM. Plasma amino acid levels in patients with chronic obstructive pulmonary disease. Monaldi Arch. Chest Dis. 1993;48:546-548.

10. Hofford JM, Milakofsky L, Vogel WH, Sacher RS, Savage GJ, Pell S. The nutritional status in advanced emphysema associated with chronic bronchitis. A study of amino acid and catecholamine levels. Am. Rev. Respir. Dis. 1990;141:902-908.

11. Swan JW, Anker SD, Walton C, et al. Insulin resistance in chronic heart failure: relation to severity and etiology of heart failure. J. Am. Coll. Cardiol. 1997:30:527-32.

12. Munro HN, Femstrom JD, Wurtman RJ. Insulin, plasma amino acid imbalance, and hepatic coma. Lancet $1975 ; 1: 722-4$.

13. Jakobsson $\mathrm{P}$, Jorfeldt $\mathrm{L}$, von Schenck $\mathrm{H}$. Insulin resistance is not exhibited by advanced chronic obstructive pulmonary disease patients. Clin. Physiol. 1995;15:547-55.

14. American Thoracic Society. Chronic bronchitis, asthma, and pulmonary emphysema by the committee on diagnostic standards for nontuberculosis respiratory disease. Am. Rev. Respir. Dis. 1962;85:762-812.

15. Sakai F, Gamu G, Im JG, Ray CS. Pulmonary function abnormalities in patients with CTdetermined emphysema. J. Comput. Assist. Tomogr. 1987;11:963-968.

16. Morgan MDL. Detection and quantification of pulmonary emphysema by computed tomography: a window of opportunity. Thorax 1992;47:1001-1004.

17. Lamers RJS, Wouters EFM, Kemerink GJ, Van Engclshoven GJ. Emphysema and airflow limitation in patients with advanced chronic obstructive pulmonary disease: a CT study Quantitative CT of the lungs: technical aspects and clinical studies. PhD thesis. Maastricht University, Maastricht, The Netherlands. 1998:93-109.

18. Bergstrom L. Muscle electrolytes in man. Determination by neutron activation analysis on needle biopsy specimens. A study on normal subjects, kidney patients, and patients with chronic diarrhea. Scand. J. Clin Lab. Invest. 1962;68:7-110.

19. Van Eijk HMH, van der Heijden MA, van Berlo $\mathrm{CL}$, Soeters PB. Fully automated liquidchromatographic determination of amino acids. Clin. Chem. 1988;34:2510-3.

20. Van Eijk HMH, Rooyakkers DR, Deutz NEP. Rapid routine determination of amino acids in plasma by high-performance liquid chromatography with a 2-3 um Sperisorb ODS 2 column. J. Chromatogr. 1993;620:143-148. 
21. Engelen MPKJ, Schols AMWJ, Heidendal GAK, Wouters EFM. Dual-energy X-ray absorptiometry in the clinical evaluation of body composition and bone mineral density in patients with chronic obstructive pulmonary disease. Am. J. Clin. Nutr. 1998;68:1298-1303.

22. Schols AMWJ, Schoffelen PFM, Ceulemans J, Wouters EFM, Saris WHM. Measurement of resting energy expenditure in patients with chronic obstructive pulmonary disease in a clinical setting. JPEN J. Parent. Ent. Nutr. 1992;16:364-368.

23. Weir JB. New methods for calculating metabolic rate with special reference to protein metabolism. J. Physiol. 1949;109:1-9.

24. Creutzberg EC, Schols AMWJ, Bothmer-Quaedvlieg FC, Wouters EFM. Prevalence of an elevated resting energy expenditure in patients with chronic obstructive pulmonary disease in relation to body composition and lung function. Eur. J. Clin. Nutr. 1998;52:396-401.

25. Voorlichtingsbureau voor de voeding. Stichting Nederlands Voedingsstoffen Bestand. Nevo tabel. 's Gravenhage: 1986.

26. Quanjer P, Tammeling GJ, Cotes JE, Pedersen OF, Peslin R, Yernault JC. Standardized lung function testing. Eur. Respir. J. 1993;6:5-40.

27. Hofford JM, Milakofsky L, Vogel WH, Sacher RS, Savage GJ, Pell S. The nutritional status in advanced emphysema associated with chronic bronchitis. A study of amino acid and catecholamine levels. Am. Rev. Respir. Dis. 1990;141:902-8.

28. Schols AMWJ, Buurman WA, Staal-van den Brekel AJ, Dentener MA, Wouters EFM. Evidence for a relation between metabolic derangements and increased levels of inflammatory mediators in a subgroup of patients with chronic obstructive pulmonary disease. Thorax 1996;51:819-824.

29. Andus T, Bauer J, Gerok W. Effects of cytokines on the liver. Hepatology 1991;13:364-75.

30. Nawabi MD, Block KP, Chakrabarti MC, Buse MG. Administration of endotoxin, tumor necrosis factor, or interleukin 1 to rats activares skeletal muscle branched-chain alpha-keto acid dehydrogenase. J. Clin. Invest. 1990;85:256-63.

31. Halmi KA, Struss AL, Owen WP, Stegink LD. Plasma and erythrocyte amino acid concentrations in anorexia nervosa. JPEN J. Parent. Enteral Nutr. 1987;11:458-64.

32. Saunders SJ, Truswell AS, Barbezat GO, Wittman W, Hansen JD. Plasma free amino acid pattem in protein-calorie malnutrition. Reappraisal of its diagnostic value. Lancet 1967;2:795-7.

33. Milewski PJ, Threlfall CJ, Heath DF, Holbrook IB, Wilford K, Irving MH. Intracellular free amino acids in undernourished patients with or without sepsis. Clin. Sci. 1982;62:83-91.

34. Vinnars E, Bergstom J, Furst $P$. Influence of the postoperative state on the intracellular free amino acids in human muscle tissue. Ann. Surg. 1975;182:665-71.

35. Askanazi J, Furst P, Michelsen $C B$, et al. Muscle and plasma amino acids after injury: hypocaloric glucose vs. amino acid infusion. Ann. Surg. 1980;191:465-72.

36. Fssen $P$, Wernerman $J$, Sonnenfeld T, Thunell S, Vinnars E. Free amino acids in plasma and muscle during 24 hours post-operatively - a descriptive study. Clin. Physiol, 1992;12:163-177.

37. Ruth E, Muhlbacher F, Rauhs R, Huk I, Soderland K, Funovics J. Free amino acids in plasma and muscle in fulminant hepatic coma during an extracorporeal liver perfusion. JPEN $J$. Parenter. Enteral Nutr. 1982;6:240-4.

38. Roth E, Zoch G, Schulz F, et al. Amino acid concentrations in plasma and skeletal muscle of paticnts with acute hemorrhagic necrotizing pancreatitis. Clin. Chem. 1985;31:1305-9.

39. Legaspi A, Roberts JP, Albert JD, Tracey KJ, Shires GT, Lowry SF. The effect of starvation and total parenteral nutrition on skeletal muscle amino acid content and membrane potential difference in normal man. Surg., Gynaecol. and Obstet. 1988;166:233-239.

40. Askanazi J, Elwyn DH, Kinney JM, et al. Muscle and plasma amino acids after injury: the role of inactivity. Ann. Surg. 1978;188:797-803.

41. Sandstedt $S$, Symreng T, Larsson J. Changes in muscle and plasma amino acid metabolism in severe malnutrition. The influence of total parenteral nutrition. Clin. Nutr. 1985;4:13-19.

42. Borghi L, Lugari R, Montanari A, et al. Plasma and skeletal muscle free amino acids in type $I$, insulin-treated diabetic subjects. Diabetes 1985;34:812-5.

43. Montanari A, Simoni I, Vallisa D, et al. Free amino acids in plasma and skeletal muscle of patients with liver cirrhosis. Hepatology 1988;8:1034-9. 
44. Bergstrom J, Alvestrand A, Furst P. Plasma and muscle free amino acids in maintenance hemodialysis patients without protein malnutrition. Kidney Int. 1990;38:108-14.

45. Wemerman J, Brandt R, Strandell T, Aligen LG, Vinnars E. The effect of stress hormones on the interorgan flux of amino acids and on the concentration of free amino acids in skeletal muscle. Clin. Nutr. 1985;4:217-224.

46. Baarends EM, Schols AMWJ, Akkermans MA, Wouters EFM. Decreased mechanical efficiency in clinically stable patients with chronic obstructive pulmonary disease. Thorax 1997;52:981986. 



\section{CHAPTER 8}

\section{Altered glutamate metabolism is associated with reduced muscle glutathione levels in patients with emphysema}

Mariëlle P.K.J. Engelen, Annemie M.W.J.

Schols, Joan D. Does', Nicolaas E.P. Deutz ${ }^{2}$ and Emiel F.M. Wouters

Depts. of Pulmonology and ${ }^{2}$ Surgery, University Hospital Maastricht, Maastricht, and 'Asthma Center Hornerheide, Horn, The Netherlands 


\section{ABSTRACT}

Chronic obstructive pulmonary disease (COPD) is often characterized by an impaired skeletal muscle energy metabolism, which is at least partly related to chronic hypoxia and a reduced diffusing capacity. We have found that muscle glutamate (GLU), which is negatively influenced by these conditions, was reduced in patients with severe COPD. The aim of this study was to investigate whether the reduced intracellular GLU level in patients with emphysema is associated with an increased muscle glycolytic metabolism. Since GLU is an important substrate in the synthesis of glutamine (GLN) and glutathione (GSH), the influence of GLU status on muscle GSH and GLN was also examined. In 13 patients with emphysema and 25 control patients, arterial blood and biopsies from the vastus lateralis muscle were obtained. Expressed as a percentage of the control values, the patients with emphysema had reduced values for muscle GLU $(64 \pm 12 \% ; \mathrm{p}<0.001)$, GSH $(76 \pm 23 \% ; p<0.01)$ and GLN $(93 \pm 5 \% ; p<0.01)$. and higher values for lactate $(p<0.05)$ and pyruvate $(p<0.05)$. No differences were found in plasma values. Muscle GLU was highly associated with GSH $\left(\mathrm{R}^{2}=0.61 ; \mathrm{p}<0.001\right)$, but not with $\mathrm{GLN}$. This study illustrates that reduced GLU levels in skeletal muscle of patients with emphysema are possibly related to an enhanced glycolytic activity and associated with decreased GSH levels.

\section{INTRODUCTION}

Several studies have emphasized the role of impaired muscle metabolism in the pathogenesis of the decreased exercise performance of patients with chronic obstructive pulmonary disease (COPD). A relative shift from oxidative to glycolytic capacity is the key finding in COPD, as reduced values were found for enzymes involved in the tricarboxylic acid (TCA) cycle and in $\beta$-oxidation of fatty acids $(1,2)$. In addition, increased cytochrome $c$ oxidase activity was found in patients with COPD, possibly to enhance muscle affinity for $\mathrm{O}_{2}$, since it was inversely related to arterial $\mathrm{pO}_{2}(1-3)$. Because the percentage of type $2 \mathrm{~b} / \mathrm{x}$ fibers was increased in quadriceps femoris muscle of patients with COPD with a reduced $\mathrm{Dl}_{\mathrm{co}}$ (diffusing capacity of the lung for $\mathrm{CO}$ ) (4), a decreased skeletal muscle oxidative metabolism is probably predominantly present in patients with emphysema. Also, functional consequences were found in this COPD subtype, as increased levels of inosine monophosphate (IMP) were observed (5).

Besides an altered energy metabolism, we have observed decreased glutamate (GLU) levels in the tibialis anterior muscle of a random severe COPD group (6). A decreased intracellular GLU level is not a unique feature in COPD since it has also been observed in metabolic stress-induced cachexia (i.e., cancer, sepsis, trauma), a catabolic condition that is also characterized by a relative shift from oxidative to glycolytic capacity in peripheral skeletal muscle (7). Cachexia and intermittent hypoxia are factors often observed in patients with emphysema $(8,9)$. 
Therefore, we hypothesize that the COPD subtype emphysema particularly is prone to intracellular GLU depletion, and that this depletion is related to enhanced muscle glycolytic metabolism.

Intracellular GLU has various important functions as it plays an important role in preserving high-energy phosphates in muscle through different metabolic mechanisms (i.e., substrate phosphorylation, replenishment of TCA intermediates). Moreover, intracellular GLU is known as an important precursor for antioxidant glutathione (GSH) and glutamine (GLN) synthesis in muscle. The antioxidant status in tissue is important since it determines its susceptibility to oxidative stress. Via free oxygen radicals, oxidative stress may contribute to muscle damage. Although there is evidence of an increased oxidative stress in the lungs of patients with COPD (10), it is still unknown whether the antioxidant / oxidant balance is altered in the peripheral skeletal muscles of patients with COPD. Glutamine has several important biochemical properties (i.e., provision of nitrogen for de novo synthesis of nucleotides, fuel for rapidly dividing cells, substrate for immune system, maintenance of acid/base balance (11)), which suggests that it plays an important role in health and disease. Thus, the clinical relevance of intracellular GLU depletion in COPD could be related to its negative effect on the GSH and GLN status in peripheral skeletal muscle.

The purpose of this study was to investigate whether the reduced GLU level in the peripheral skeletal muscle of patients with emphysema is associated with an increased muscle glycolytic metabolism. Furthermore, the influence of intracellular GLU depletion on skeletal muscle GSH and GLN status was examined in this COPD subtype.

\section{METHODS}

\section{Study population}

A group of 13 patients with emphysema ( 9 men and 4 women) and 25 healthy, agematched volunteers ( 19 men and 6 women) were studied. Patients were selected on the basis of the presence of severe emphysema, as determined by high-resolution computed tomography (12) (mean visual score: $82 \pm 24$ ), and COPD, according to American Thoracic Society guidelines (13). Chronic airflow limitation was defined as $\mathrm{FEV}$, less than $70 \%$ of the predicted value. All patients had irreversible obstructive airway disease ( $<10 \%$ improvement of $\mathrm{FEV}_{1}$ after inhalation of a bronchodilating agonist) and were clinically stable; they had not experienced a respiratory tract infection or an exacerbation of their disease at least $4 \mathrm{wk}$ before the study. Exclusion criteria included malignancies, cardiac failure, distal arteriopathy, recent surgery, use of anticoagulant medication, and severe endocrine, hepatic, or renal disorder. 
Written informed consent was obtained from all subjects and the study was approved by the medical ethics committee of the University Hospital Maastricht. (Maastricht, The Netherlands).

\section{Arterial blood sample collection and analysis}

After an overnight fast, arterial blood was obtained by puncture of the artery radialis while breathing ambient air. One sample was used for determination of blood gases $\left(\mathrm{pO}_{2}, \mathrm{pCO}_{2}\right), \mathrm{pH}$, and oxygen saturation (ABL 330; Radiometer, Copenhagen, Denmark). A second sample was put in a heparinized syringe, immediately placed on ice and subsequently centrifuged at $4^{\circ} \mathrm{C}$ for $10 \mathrm{~min}$ to obtain plasma. Arterial plasma was deproteinized with sulfosalicylic acid (SSA) for determination of GLU and GLN, and with trichloric acid for glucose, lactate, and pyruvate determination. Samples were frozen in liquid nitrogen and stored at $-80^{\circ} \mathrm{C}$ until analysis.

\section{Peripheral skeletal muscle biopsy collection and analysis}

Postabsorptive muscle biopsies of the lateral part of the quadriceps femoris muscle were obtained under local anesthesia by the needle biopsy technique (14). All biopsies were immediately frozen in liquid nitrogen and stored at $-80^{\circ} \mathrm{C}$ until analysis. Frozen muscle tissue was deproteinized with SSA for determination of GLU, GLN, and reduced GSH, and with trichloric acid for determination of lactate, pyruvate, and glucose. After adding glass beads $(1 \mathrm{~mm})$, the muscle tissue was homogenized with a Mini Beater (Biospec Products, Bartlesville,OK).

GLU, GLN, glucose, lactate, and pyruvate in muscle and arterial plasma, and GSH in muscle were analyzed by fully automated high-performance liquid chromatography (HPLC)(15).

\section{Assessment of body weight and composition}

Body weight was measured with an electronic beam scale with a digital readout to the nearest $0.1 \mathrm{~kg}$ (model 708, Seca, Hamburg, Germany), with subjects standing barefoot and wearing light indoor clothing. Body height was measured to the nearest $0.1 \mathrm{~cm}$ (model 220, Seca). All patients and healthy volunteers were scanned on a DPX-L bone densitometer (Lunar Radiation, Madison, WI). The amounts of bone mineral content and lean mass were derived from computer algorithms (Lunar software version 1.3) provided by the manufacturer. Fat-free mass (FFM) was computed as the sum of lean mass and bone mineral mass. Between-group comparisons were done by adjusting weight, FFM, and lean mass for differences in body surface. For this purpose, these parameters were divided by squared height $\left(\mathrm{kg} / \mathrm{m}^{2}\right)$, as suggested by Van Itallie (16) to obtain body mass index (BMI), FFM index, and lean mass index. 


\section{Pulmonary function tests}

All patients and healthy volunteers underwent spirometry with determination of $\mathrm{FEV}_{\mathrm{I}}$ and FVC with the highest value from at least three technically acceptable assessments being used. Static and dynamic lung volumes (total lung capacity (TLC), intrathoracic gas volume (ITGV), and airway resistance $\left(\mathrm{R}_{\mathrm{aw}}\right)$ ) were assessed by whole-body plethysmography (Masterlab; Jaeger, Wurzburg, Germany). $\mathrm{DL}_{\mathrm{co}}$ was measured using the single-breath method (Masterlab). All values obtained were related to a reference value and expressed as percentages of the predicted value (17).

\section{Statistical Analysis}

Results are expressed as means \pm standard deviations (SD). In Figures 1-3 GLU, GLN and GSH are presented as means \pm standard errors (SE) values. Analy sis of variance (ANOVA) was used to determine differences in pulmonary function, body composition, and muscle and plasma determinations between patients with emphysema and healthy volunteers. The relationships between muscle GLN, GSH and GLU were studied by calculating the Pearson correlation coefficients. A twotailed probability value of less than 0.05 was considered significant.

\section{RESULTS}

Thirteen patients with severe emphysema $\left(\mathrm{DL}_{\mathrm{co}} .37 \div 15 \%\right.$ pred) and airflow obstruction ( $\mathrm{FEV}_{\mathrm{l}}, 33 \pm 10 \%$ pred) and 25 healthy volunteers participated in the study. The mean age was $64 \mathrm{yr}$ in both groups.

Besides severely impaired pulmonary function (Table 1), the patients with emphysema had lower values for resting arterial $\mathrm{pO}_{2}(\mathrm{p}<0.01)$, oxygen saturation $(\mathrm{p}<0.01)$, and a higher value for $\mathrm{pH}(\mathrm{p}<0.01)$, than the healthy volunteers but no difference was found in $\mathrm{pCO}_{2}$. A negative relationship was found between arterial $\mathrm{pH}$ and $\mathrm{pCO}_{2}$, in the emphysema group ( $\mathrm{r}=-0.64 ; \mathrm{p}=0.01$ ), probably indicating an increased ventilatory $\mathrm{CO}_{2}$ washout. Furthermore, the patients with emphysema had lower values for BMI $\left(24.4 \pm 4.4\right.$ versus $\left.25.8 \pm 3.1 \mathrm{~kg} / \mathrm{m}^{2} ; \mathrm{p}<0.05\right), F F M$ index $(16.9$ \pm 2.4 versus $\left.18.9 \pm 2.3 \mathrm{~kg} / \mathrm{m}^{2} ; \mathrm{p}<0.05\right)$ and lean mass index $(16.2 \pm 2.3$ versus $18.0 \pm$ $\left.2.2 \mathrm{~kg} / \mathrm{m}^{2} ; \mathrm{p}<0.05\right)$.

The patients with emphysema had increased glycolytic activity in peripheral skeletal muscle relative to healthy volunteers, reflected by higher levels for pyruvate $(p<0.05)$ and lactate $(p<0.01)$ (Table 2$)$. Arterial plasma values for lactate and pyruvate were comparable between the groups. The lactate-to-pyruvate gradient was also not different in muscle or plasma between the groups. Lower values werc found for arterial plasma glucose in the patients with emphysema $(p<0.05)$ and comparable values were found for muscle glucose. 
Table 1. Pulmonary function and arterial blood gases, $p H$ and oxygen saturation of the emphysema patients and the healthy volunteers

$\begin{array}{cc}\text { Emphysema } & \text { Healthy volunteers } \\ \text { (9 men / } 4 \text { women }) & (19 \text { men } / 6 \text { women })\end{array}$

\begin{tabular}{lrll}
\hline Puimonary function & & \\
FEV $_{1}$ & \%pred. & $32.4 \pm$ & \pm .8 \\
FVC & \%pred. & $80.3 \pm$ & \pm 30.9 \\
DI $_{\mathrm{co}}$ & \%pred. & $36.8 \pm 14.8$ \\
TLC & \%pred. & $125.9 \pm 21.2$ \\
RV & \%pred. & $201.8 \pm 45.0$ \\
ITGV & \%pred. & $163.1 \pm$ & \pm 56.0 \\
$\mathrm{R}_{\mathrm{aw}}$ & \%pred. & $258.8 \pm 100.6$
\end{tabular}

$\begin{array}{rccc}105.1 & \pm & 15.5 & \ldots \\ 114.9 & \pm & 12.7 & \ldots \\ 116.8 & \pm & 17.4 & \ldots \\ 113.1 & \pm & 10.8 & \text { p.0.06 } \\ 114.4 & \pm & 19.9 & \ldots \\ 106.7 & \pm & 19.0 & \ldots \\ 92.5 & \pm & . & \\ & & & \end{array}$

Arterial bleod gases, $p H$ and oxygen saturation

\begin{tabular}{|c|c|c|c|c|c|c|c|}
\hline $\mathrm{pO}_{2}$ & $\mathrm{kPa}^{*}$ & 9.9 & \pm 1.8 & 11.8 & \pm & 1.7 & “ \\
\hline $\mathrm{pCO}_{2}$ & $\mathrm{kPa}^{\prime \prime}$ & 5.4 & \pm 0.6 & 5.5 & \pm & 0.4 & \\
\hline $\mathrm{pH}$ & & 7.42 & $\pm \quad 0.02$ & 7.41 & \pm & 0.01 & "• \\
\hline $\mathrm{SatO}_{2}$ & $\%$ & 94.5 & \pm 1.6 & 96.4 & \pm & 1.3 & \\
\hline
\end{tabular}

Values: means \pm SDs. Definition of abbreviations: $\mathrm{FEV}_{1}$ : forced expiratory volume in $1 \mathrm{~s} ; \mathrm{FVC}$ : forced vital capacity; TLC: total lung capacity; RV: residual volume; ITGV: intrathoracic gas volume: $\mathrm{R}_{\mathrm{aw}}$ : airway resistance; $\mathrm{SatO}_{2}$ : arterial oxygen saturation. " $\mathrm{l} \mathrm{kPa}=7.50 \mathrm{mmHg}$; ${ }^{*} \mathrm{P}<0.0 \mathrm{l}$; *** $P<0.001$, patients with emphysema versus healthy volunteers.

Table 2. Glycolysis related intermediates in peripheral muscle and arterial plasma of the emphysena patients and the healthy volunteers

Emphysema Healthy volunteers

\begin{tabular}{|c|c|c|c|c|c|c|}
\hline Glucose & & & & & & \\
\hline Muscle & $\mathrm{mmol} / \mathrm{kg}_{\mathrm{ww}}$ & 1.3 & \pm 0.3 & 1.3 & \pm 0.6 & \\
\hline Arterial plasma & $\mathrm{mM}^{\#}$ & 5.2 & \pm 0.8 & 5.8 & $\pm \quad 0.7$ & • \\
\hline Pyruvare & & & & & & \\
\hline Muscle & $\mu \mathrm{mol} / \mathrm{kg}_{\mathrm{ww}}$ & 116.9 & \pm 85.8 & 53.5 & \pm 29.6 & $\cdot$ \\
\hline Arterial plasma & $\mu \mathrm{M}$ & 39.1 & $\pm \quad 16.7$ & 48.9 & \pm 28.6 & \\
\hline Lactate & & & & & & \\
\hline Muscle & $\mathrm{mmol} / \mathrm{kg}_{\mathrm{ww}}$ & 3.7 & \pm 1.7 & 1.8 & \pm 0.5 & ・. \\
\hline Arterial plasma & $\mathrm{mM}$ & 0.8 & \pm 0.2 & 0.8 & $\pm \quad 0.2$ & \\
\hline Lactate/Pyruvat & & & & & & \\
\hline Muscle & & 41.9 & $\pm \quad 22.9$ & 35.5 & 11.7 & \\
\hline Arterial plasma & & 22.1 & \pm 5.2 & 20.4 & 8.3 & \\
\hline
\end{tabular}



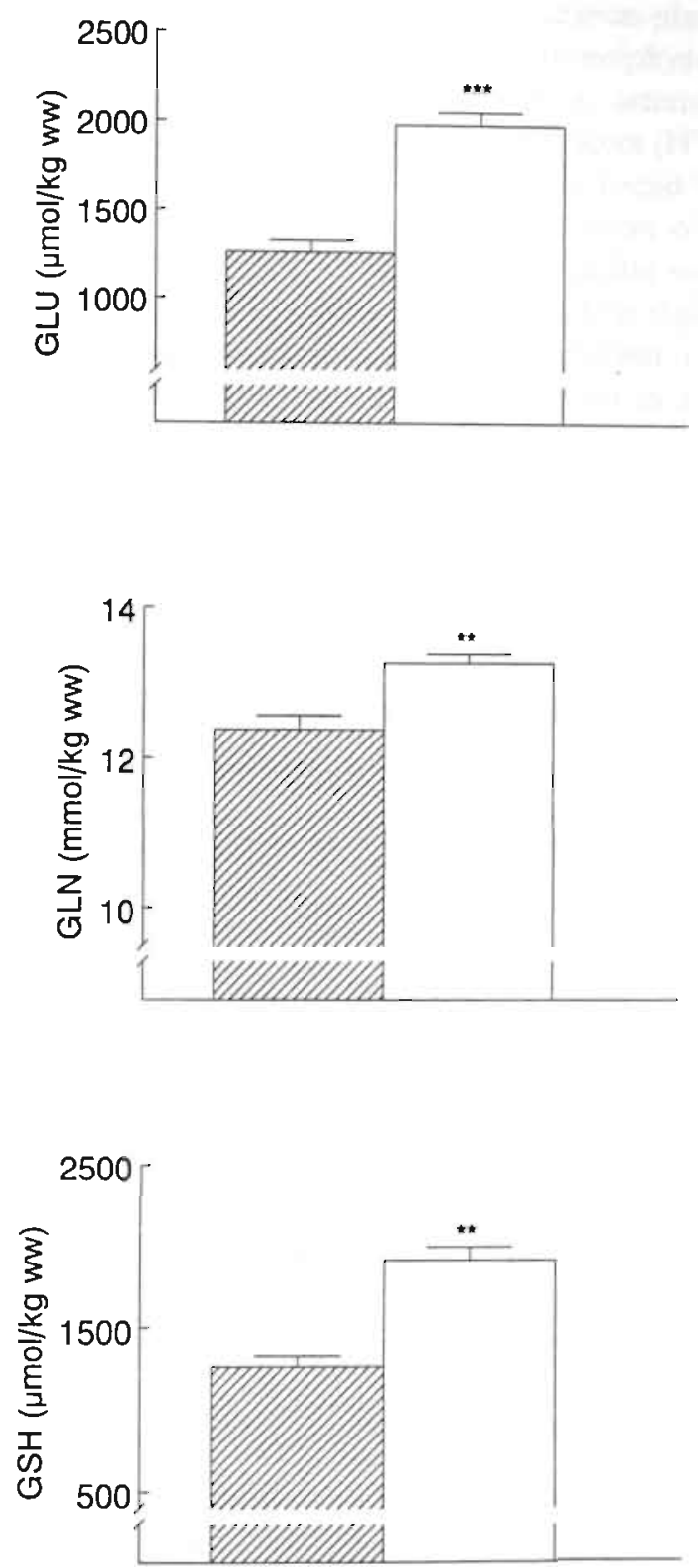

Figure 1. Bar diagram of levels of GLU (top panel), GLN (middle panel) and GSH (bottom panel) in peripheral skeletal muscle of 13 patients with emphysema (closed bars) and 25 healthy volunteers (control, open bars). Mean values $\pm 1 \mathrm{SE}$ are shown. Significance of differences was calculated as ${ }^{* * *} p<0.001$; $^{* *} p<0.01$. 

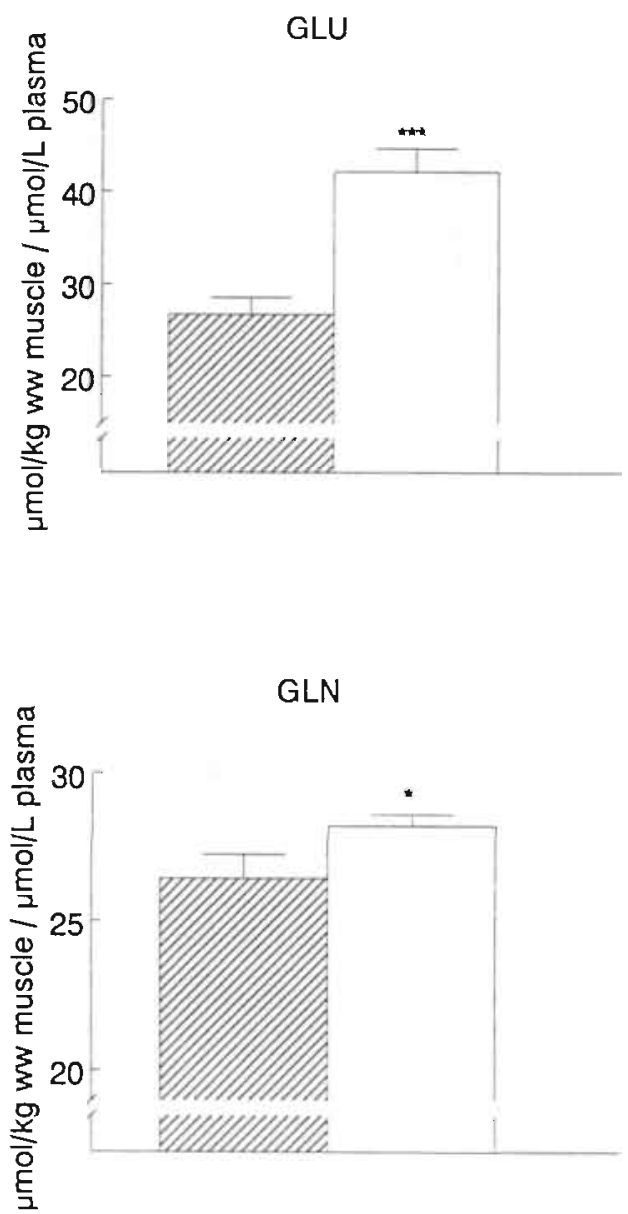

Figure 2. Bar diagram of muscle-to-arterial plasma gradient of GLU (top panel) and GLN (hottom panel) of 13 patients with emphysema (closed bars) and 25 healthy volunteers (open bars). Mean values $\pm 1 \mathrm{SE}$ are shown. Significance of differences was calculated as ${ }^{* * *} \mathrm{p}<0.001 ; * \mathrm{p}<0.05$. 
Muscle GLU concentration (Figure 1, top panel) and muscle-to-plasma gradient of GLU (Figure 2, top panel) were lower in the patients with emphysema than in the healthy volunteers $(\mathrm{p}<0.001)$. No difference was found in arterial plasma GLU (emphysema group (EMPH], $61.8 \pm 14.1 \mu \mathrm{M}$; healthy volunteers (HV), $63.3 \pm 13.6$ $\mu \mathrm{M})$. A similar trend was present for GLN: lower values were found for muscle GLN $(\mathrm{p}<0.01$; Figure 1, middle panel) and muscle-to-plasma gradient of GLN $(\mathrm{p}<0.05$; Figure 2, bottom panel) in the emphysema group and comparable values for plasma GLN (EMPH, $612.9 \pm 51.9 \mu \mathrm{M}$; HV, $603.0 \pm 57.6 \mu \mathrm{M}$ ). The significance of the lower values for muscle GLN and muscle-to-plasma gradient of GLN in the emphysema group remained after adjustment for the variation in nutritional status (FFM index and lean mass index) between the groups.

Furthermore, GSH (Figure 1, bottom panel) in peripheral skeletal muscle was significantly lower in the emphysema group than in the healthy volunteers $(p<0.01)$.

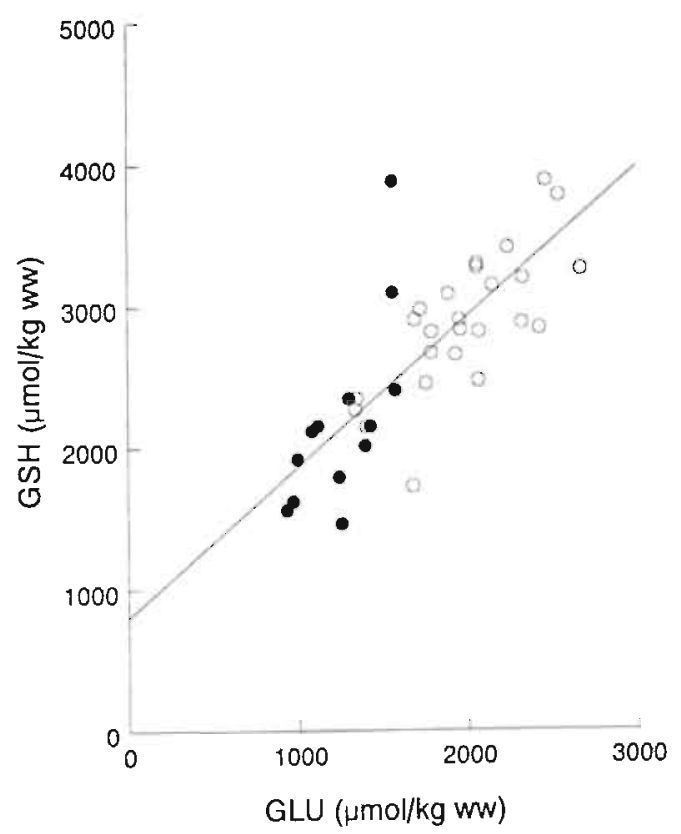

Figure 3. Scatter plot of muscle GLU and GSH of the patients with emphysema (closed circles) and the healthy volunteers (open circles). Regression line of the total study population is included $\left(\mathrm{R}^{2}=0.61, \mathrm{p}<0.001\right)$.

Despite the fact that GLU is known as an important precursor for GLN synthesis in muscle, no significant relation was found between muscle GLU and GLN (not shown, $\mathrm{R}^{2}=0.06$ ). However, a highly significant correlation was found between muscle GLU and GSH levels in the total study population $\left(\mathrm{R}^{2}=0.61, \mathrm{p}^{-0.001}\right.$; 
Figure 3), the emphysema group $\left(\mathrm{R}^{2}=0.50, \mathrm{p}<0.01\right)$ and in the healthy volunteer group $\left(R^{2}=0.56, p<0.001\right)$.

\section{DISCUSSION}

This study demonstrates that patients with emphysema have significantly lower values for GLU, GLN and GSH in peripheral skeletal muscle than do healthy volunteers. This reduced muscle GLU is highly associated with the decreased muscle GSH but not with the reduced muscle GLN. Furthermore, the patients are characterized by a lower skeletal muscle mass and an enhanced rate of muscle glycolytic activity, as shown by higher values for lactate and pyruvate.

In conditions and diseases commonly associated with progressive loss of skeletal muscle mass (i.e., cancer, human immunodeficiency virus (HIV)), decreased levels for peripheral muscle GLU and elevated levels for venous GLU were found $(7,18$, 19). In patients with cancer, this was explained by a decreased capacity of the peripheral skeletal muscle tissue to extract GLU from the circulation in the postabsorptive state (18). This was observed in cachectic as well as in well-nourished patients with cancer, suggesting that it is an early event in the development of cachexia. Although no direct correlation was found between GLU level and the stage of diseise (20), a significant association was observed with the rate of glycolytic activity $(21)$.

The similar values found for arterial plasma GLU between the patients with emphysema and the healthy volunteers suggest a comparable GLU supply to the muscle. However, muscle GLU and muscle-to-arterial plasma GLU gradient were lower in the emphysema group. On this basis, and because under normal conditions GLU is taken up by peripheral muscle but not released, we suggest that muscle GLU transport capacity is decreased in the patients with emphysema.

In general, GLU transport into peripheral muscle is partly $\mathrm{Na}^{+}$-dependent (22). A high rate of glycolytic activity, as observed in the study, could compromise the $\mathrm{Na}^{+}$dependent membrane transport of GLU into muscle by increasing the intracellular $\mathrm{Na}^{+}$concentration via the $\mathrm{Na}^{+} / \mathrm{H}^{+}$antiporter. Indeed, elevated $\mathrm{Na}^{+}$levels were found in peripheral skeletal muscle of patients with COPD (23), and these could negatively influence GLU transport capacity.

Besides GLU, most of the quantitatively important amino acids (e.g., GLN, Ala) use $\mathrm{Na}^{+}$-dependent transport systems in muscle. When GLU transport across the plasma membrane is indeed impaired in patients with emphysema, the peripheral muscles need to release more amino acids in order to increase the $\mathrm{Na}^{+}$gradient across the membrane. Therefore, increased muscle protein catabolism would facilitate GLU uptake into peripheral muscle. However, the reverse seems true. Protein degradation in skeletal muscle was not elevated in patients with emphysema (24) when compared with healthy controls. To find out whether relatively inadequate protein catabolism in patients with emphysema is actually contributing to the 
decreased intracellular GLU levels, more advanced metabolic techniques (e.g., use of stable isotopically labeled tracers) are needed.

Oxygen deprivation can also alter GLU metabolism. Ischemia and hypoxia lead to an increased degradation of intracellular GLU in heart tissue and mitochondria (25). Enhanced glycolysis and substrate phosphorylation are the sources of anaerobic ATP formation under these conditions; the latter is associated with increased succinate synthesis (26). Decreased oxygen saturation, which is a potential contributor of hypoxemia, frequently takes place during the daily life activities of patients with emphysema (9). Despite relatively well-preserved values for resting $\mathrm{paO}_{2}$, intermittent hypoxic episodes are probably present in the studied emphysema group, as indicated by the low mean values for transcutaneous $\mathrm{O}_{2}$ saturation $(88 \pm 3 \%)$ observed at peak incremental exercise. However, no information is available concerning the extent to which desaturation with sleep occurs in our emphysema group.

Therefore, it is possible that the occurrence of hypoxic episodes leads to decreased levels of GLU in peripheral skeletal muscle of patients with emphysema. However, one must be careful when extrapolating the GLU results obtained in cardiac muscle to peripheral skeletal muscle. GLN, for example, may act as a precursor for intramyocardial GLU, since there is substantial glutaminase activity in cardiac muscle (27), but not in skeletal muscle. To our knowledge, only a limited number of experimental studies have evaluated the effect of hypoxia on skeletal muscle GLU. In these studies, lower (28) as well as higher GLU levels (29) were found in rat gastrocnemius muscle after intermittent hypoxic-normoxic episodes. Therefore, more insight is needed in the specific effects of tissue hypoxia on GLU catabolism in the peripheral skeletal muscle.

An important biochemical function of skeletal musclc cells is to convert GLU into GLN. In this way, GLU depletion may generate an intracellular deficiency of GLN. GLN has several important functions, such as involvement as substrate and fuel in many physiological processes. In the present study, decreased levels of skeletil muscle GLN and decreased muscle-to-arterial GLN gradient were found in patients with emphysema. The intracellular GLN decrease in this selected group of patients is in conflict with the elevated GLN level found in a previous study of a random COPD group (6). However, we have observed striking differences in the intracellular amino acid profile (including GLN) between the COPD subtypes chronic bronchitis and emphysema (30). This indicates that careful stratification of the COPD population is necessary when studying amino acid metabolism in peripheral skeletal muscle of patients with COPD.

Decreased intracellular GLN concentrations were also found in a wide varicty of catabolic conditions or diseases (31). In these conditions, muscle GLN levels were decreased and GLN turnover was elevated, suggesting an accelerated muscle GLN efflux. One study assessed GLN turnover in patients with emphysema, and reported a decreased GLN efflux from skeletal muscle (24). This is quite remarkable since 
several factors with a stimulating effect on GLN efflux are present in patients with COPD (i.e., increased corticosteroids use, increased intracellular $\mathrm{Na}^{+}$concentration). In the present study, the lack of correlation between muscle GLU and GLN indicates that the reduced GLU level is not fully responsible for the decreased muscle GLN concentration in patients with emphysema. However, a highly significant association was found between muscle GLU and GSH.

Muscle GLU is also known as an important precursor for the first and rate-limiting step in the synthesis of the antioxidant GSH. GSH is the quantitatively most important intracellular antioxidant and serves multiple cellular and metabolic functions. Even a relatively moderate depletion of intracellular GSH causes oxidative damage and impairs the structural and functional integrity of mitochondria (32). In an animal model, decreased intracellular GSH levels were found to be correlated with a decrease in phosphocreatine, indicative of decreased mitochondrial energy metabolism (33).

Unless cysteine or glycine, or the corresponding enzymes, become limiting, the intracellular GSH level is determined by the intracellular GLU concentration. In the patients with emphysema, intracellular GLU as well as GSH were lower than in healthy volunteers. Furthermore, the decrease in GSH levels was highly associated with, and probably caused by, the decrease in GLU. These data confirm previous findings in weight-losing tumor-bearing mice, in which a relationship between muscle GSH and GLU was also found (34). Hypoxia-reoxygenation studies showed that an acute episode of intermittent hypoxia results in an increased production of free oxygen radicals (35). This suggests that the presence of intermittent hypoxic conditions in patients with emphysema, in combination with their reduced GLUrelated intracellular GSH levels, may result in an antioxidant / oxidant disbalance in their peripheral skeletal muscles. The reduced muscle oxidative capacity itself may also contribute to an enhanced oxidative stress in the peripheral skeletal muscles of patients with emphysema and particularly during exercise, when the increased oxygen flux toward the muscles cannot be efficiently metabolized. Increased oxidative stress in the peripheral skeletal muscles of patients with emphysema may result in muscle damage.

The results of the present study may therefore have important clinical implications, since it is hypothesized that avoidance of depletion of intracellular GLU may be important in the prevention of oxidative stress in the peripheral skeletal muscles of patients with emphysema. 


\section{References}

1. Maltais F, Simard AA, Simard C, Jobin J, Desgagnes P, LeBlanc P. Oxidative capacity of the skeletal muscle and lactic acid kinetics during exercise in normal subjects and in patients with COPD. Am. J. Respir. Crit. Care Med. 1996;153:288-293.

2. Jakobsson P, Jorfeldt L, Henriksson J. Metabolic enzyme activity in the quadriceps femoris muscle in patients with severe chronic obstructive pulmonary disease. Am. J. Respir. Crit. Care Med. 1995;151:374-377.

3. Sauleda J, Garcia-Palmer F, Wiesner RJ, Tarraga S, Harting I, Tomas P, Gomez C, Saus C, Palou A, Agusti AGN. Cytochrome oxidase activity and mitochondrial gene expression in skeletal muscle of patients with chronic obstructive pulmonary disease. Am. J. Respir. Crit. Care Med. 1998;157:1413-1417.

4. Satta A, Migliori GB, Spanevello A. Neri M, Bottinelli R, Canepari M, Pellegrino MA, Reggiani C. Fibre types in skeletal muscles of chronic obstructive pulmonary disease patients related to respiratory function and exercise tolerance. Eur. Respir. J. 1997;10:2853-2860.

5. Pouw EM, Schols AMWJ, Van der Vusse GJ, Wouters EFM. Elevated inosine monophosphate levels in resting muscle of patients with stable COPD. Am. J. Respir. Crit. Care Med. 1998; 157:453-457.

6. Pouw EM. Schols AMWJ, Deutz NEP, Wouters EFM. Arterial and muscle amino-acid levels in relation to resting energy expenditure and inflammation in stable COPD. Am. Rev. Respir. Crit. Care Med. 1998;158:1-5.

7. Tayek JA. A review of cancer cachexia and abnormal glucose metabolism in humans with cancer. J. Am. Col. Nutr. 1992;11:445-456.

8. Engelen MPKJ, Schols AMWJ, Lamers RJS, Wouters EFM. Different patterns of chronic tissue wasting among patients with chronic obstructive pulmonary disease. Clin. Nutr. 1991:18:275= 280.

9. Soguel Schenkel N, Burdet L. De Murait B, Fitting JW. Oxygen saturation during daily activities in chronic obstructive pulmonary disease. Eur. Respir. J. 1996;9:2584-2589.

10. Repine JE, Bast A, Lankhorst I. Oxidative stress in chronic obstructive pulmonary disease. Am. J. Respir. Crit. Care Med. 1997;156:341-357.

11. Lacey JM, Wilmore DW. Is glutamine a conditionally essential amino acid? Nutr. Rev. 1990;48:297-309.

12. Sakai F, Gamu G, Im JG, Ray CS. Pulmonary function abnormalities in patients with CTdetermined emphysema. J. Comput. Assist. Tomogr. 1987;11:963-968.

13. American Thoracic Society. Standards for the diagnosis and care of patients with chronic obstructive pulmonary disease (COPD) and asthma. Am. Rev. Respir. Dis. 1987;137:225-228.

14. Bergstrom L. Muscle electrolytes in man. Determination by neutron activation analysis on needle biopsy specimens. A study on normal subjects, kidney patients, and patients with chronic diarthea. Scand. J. Clin. Lab. Invest. 1962:68:7-110.

15. Van Eijk HMH, Rooyakkers DR, Deutz NEP. Rapid routine determination of amino acids in plasma by high-performance liquid chromatography with a 2-3 um Sperisorb ODS 2 column. J. Chromat. 1993;620:143-148.

16. VanItallie TB, Yan M, Heymsfield SB, Funk RC, Boileau RA. Height-normalized indices of body's fat-free mass and fat mass: potentially useful indicators of nutritional status. Am. J. Clin. Nutr. 1990;52:953-959.

17. Quanjer P, Tammeling GJ, Cotes JE, Pedersen OF, Peslin R, Yernault JC. Standardized lung function testing. Eur. Respir. J. 1993;6:5-40.

18. Hack V, Stutz O, Kinscherf R, Schykowski M, Kellerer M, Holm E, Droge W. Elevated venous glutamate levels in (pre)catabolic conditions result at least partly from a decreased glutamate transport activity. J. Mol. Med. 1996:337-343.

19. Holm E, Hack V, Tokus M, Breitkreutz R, Babylon A, Droge W. Linkage between postabsorptive amino acid release and glutamate uptake in skeletal muscle tissue of healthy young subjects, cancer patients, and the elderly. J. Mol. Med. 1997;75:454-461. 
20. Ollenschlager G, Karner J, Karner-Hanusch. J. Plasma glutamate: a prognostic marker of cancer and of other immunodeficiency syndromes. Scand. J. Clin. Lab. Invest. 1989;49:773-777.

21. Kinscherf R, Hack V, Fischbach T, Friedmann B, Weiss C, Edler L, Bartsch P, Droge W. Low plasma glutamine in combination with high glutamate levels indicate risk for loss of body cell mass in healthy individuals: the effect of $\mathrm{N}$-acetyl-cysteine. J. Mol. Med. 1996;74:393-400.

22. Hom LW. L-glutamate transport in internally dialyzed barnacle muscle fibers. Am. J. Physiol. 1989:257:C442-C450.

23. Fiaccedori E, Coffrini E, Ronda N, Gonzi G, Bonandrini L, Fracchia C, Rampulla C, Ambrosino N, Montagna T, Borghetti A. A preliminary report on the effects of malnutrition on skeletal muscle composition in chronic obstructive pulmonary disease. In: R.D. Ferranti, N. Ambrosino. editors. Nutrition and ventilatory function, Bi and Gi Publishers, Verona. 1992;77-85.

24. Morrison WL, Gibson JNA, Scrimgeour $C$, Rennie MJ. Muscle wasting in emphysema. Clin. Sci. 1988;75:415-420.

25. Wiesner RJ, Deussen A, Borst M, Schrader J, Grieshaber MK. Glutamate degradation in the ischemic dog heart: contribution to anaerobic energy production. J. Mol. Cell. Cardiol. 1989;21:49-59.

26. Pisarenko OI, Solomatina ES, Ivanov VE, Studneva IM, Kapelko VI, Smimov VN. On the mechanisms of enhanced ATP formation in hypoxic myocardium caused by glutamic acid. Basic Res. Cardiol. 1985;80:126-134.

27. Nelson D, Rumsey WL, Erecinska M. Glutamine catabolism by heart muscle. Biochem. J. 1992;282:559-564.

28. Pastoris O, Dossena M, Gorini A, Vercesi L, Benzi G. Adaptation of skeletal muscle energy metabolism to repeated hypoxic-normoxic exposures and drug treatment. Arch. Int. Pharmacodyn. 1985;274:145-158.

29. Pastoris O, Dossena M, Amaboldi R, Gorini A, Villa RF. Age-related alterations of skeletal muscle metabolism by intermittent hypoxia and trh-analoque treatment. Pharmacol. Res. 1994;30:171-185.

30. Engelen MPKJ, Schols AMWJ, Does JD, Deutz NEP, Wouters EFM. Differences in amino acid profile of peripheral skeletal muscle between patients with emphysema and chronic bronchitis. Am. J. Respir. Crit. Care Med. 1999;159:A475.

31. Rennie MJ, Babij P. Taylor PM, Hundal HS, MacLennan P, Watt PW. Characteristics of a glutamine carrier in skeletal muscle have important consequences for nitrogen loss in injury, infection, and chronic disease. Lancet 1986; 1:1008-1011.

32. Jain A, Martensson J, Stole E, Auld P, Meister A. Glutathione deficiency leads to mitochondrial damage in brain. Proc. Natl. Acad. Sci. USA 1991;88:1913-1917.

33. Hack V, Gross A, Bohme A, Stahl-Hennig C, Droge W. Decrease in phosphocreatine level in skeletal muscle of SIV-infected rhesus-macaques correlates with decrease in intracellular glutathione. Aids Res. Hum. Retrovinuses 1997;13:1089-1091.

34. Hack V, Gross A, Kinscherf K, Bocksette M, Fiers W. Berke G, Droge W. Abnormal glutathione and sulfate levels after interleukine 6 treatment and in tumor-induced cachexia. FASEB J, 1996;10:1219-1226.

35. Ferrari R, Ceconi C, Curello S, Alfieri O, Visioli O. Myocardial damage during ischaemia and reperfusion. Eur. Heart J. 1993;14:25-30. 


\section{CHAPTER 9}

\section{Exercise-induced lactate increase in relation to muscle substrates in patients with chronic obstructive pulmonary disease}

Mariëlle P.K.J. Engelen, Annemie M.W.J.

Schols, Joan D. Does', Harry R. Gosker, Nicolaas E.P. Deutz ${ }^{2}$ and Emiel F.M. Wouters

Depts. of Pulmonology and ${ }^{2}$ Surgery, University Hospital Maastricht, Maastricht, and 'Asthma Center Hornerheide, Horn, The Netherlands 


\section{ABSTRACT}

Early lactic acidosis has been suggested as negatively influence the exercise capacity of patients with chronic obstructive pulmonary disease (COPD). We conducted a study to investigate whether the early lactate ( $\mathrm{La}$ ) response to exercise in COPD is related to alterations in exercise-related substrate levels in resting muscle, associated with physical inactivity. Twenty-seven COPD patients and 22 controls (physically inactive (PI) subjects: $n=15$; physically active (PA) subjects: $n=7$ ) performed an incremental cycle test. Venous blood was sampled for La analyses, and the oxygen uptake at which the La began to rise (La threshold) was calculated. Vastus lateralis biopsy specimens were obtained at rest. In the PA group, muscle glutamate (GLU) and glycogen were higher, but muscle La, pyruvate, and glucose were not different than in the PI group. Moreover, the La threshold was higher in the PA group. The COPD group had lower values for La threshold and muscle GLU, and higher values for muscle La and pyruvate levels than did the PI group. Stratification of patients into those with and without macroscopic emphysema (EMPH+, EMPH-, respectively), with comparable physical activity levels on the basis of previous observations, revealed lower values for La threshold and GLU in EMPH+ patients. Diffusing capacity for carbon monoxide $\left(\mathrm{Dl}_{\mathrm{co}}\right)$ and arterial oxygen tension $\left(\mathrm{p}_{\mathrm{a}} \mathrm{O}_{2}\right)$ in the four study groups were positively related to GLU and La threshold. Morovver, La threshold was positively related to GLU. This study illustrates that the early lactic acidosis during exercise in patients with COPD is associated with the physical inactivity-related reduction in these patient's muscle GLU. However, other factors than physical inactivity, such as $\mathrm{pO}_{2}$ or $\mathrm{Dl}_{c o}$, play a role in the different La responses during exercise of subjects with different subtypes of COPD.

\section{INTRODUCTION}

It is generally known that a substantial portion of patients with chronic obstructive pulmonary disease (COPD) develop lactic acidosis early in exercise and at very low work rates $(1,2)$. Lactic acidosis is unfavorable, since it puts an additional stress on these patients' limited ventilatory system during exercise.

Recently, evidence has come available that a reduced oxidative capacity of skeletal muscle correlates with the accelerated lactate (La) response to exercise in COPD (3), as indicated by the inverse relationship between the steepness of the increase in $\mathrm{La}$ concentration and the activity of muscle oxidative enzymes. The significant correlation found between the decreased percentage of type 1 muscle fibers and diffusing capacity for carbon monoxide $\left(\mathrm{Dl}_{\mathrm{co}}\right)$ (4) suggests that emphysema patients in particular are prone to a reduced muscle oxidative capacity and thus to an increased lactate response to exercise.

Until now, no information has been available about the extent to which intrinsic changes in exercise-related substrate metabolism in COPD patients (i.e., previously reported increased levels of muscle $L a$ and reduced levels of glycogen $(5,6)$ ) are 
responsible for their patients' accelerated La response to exercise. Recently, we observed severely decreased glutamate (GLU) levels in two different muscle groups of COPD patients $(7,8)$. GLU is high in the free amino acid pool of human skeletal muscle, and takes part in numerous important metabolic processes at rest and during exercise. Studies have shown that in healthy human muscle, the GLU pool functions to generate tricarboxylic acid (TCA) intermediates during the first minutes of exercise $(9,10)$, which is achieved via the alanine aminotransferase reaction (pyruvate + GLU $\rightarrow$ alanine $+\alpha$-ketoglutarate) at the cost of GLU. Moreover, this reaction can shunt the pyruvate accumulated during exercise towards alanine instead of La, suggesting a possible role of the intracellular GLU level in the La response to exercise.

Physical inactivity is known to play a role in the early lactic acidosis in (.OPD (1), but the relative contribution of physical inactivity and disease-related muscle myopathy are still not clear. Recently, we studied the physical activity level of 20 COPD patients, recruited from a pulmonary rehabilitation center, who were able to participate in and finish the center's intense physical training program. The average physical activity score of the COPD group was lower than that of 10 healthy sedentary controls $(p<0.05)$, but no difference was found between COPD patients with and without macroscopic emphysema (EMPH- and EMPH+, respectively) (Voorrips score: controls: $19 \pm 6$; EMPH+: $11 \pm 5$; EMPH-: $7 \pm 1$ ). This indicates that patients with these COPD subtypes are comparable in their level of physical inactivity, and we therefore used this patient population to study the relative contribution of disease-related myopathy to possible differences in the La response to exercise. Additionally, in order to obtain greater insight into the effect of physical inactivity on muscle substrate metabolism, we used two control groups with a difference in their physical training status.

The first purpose of our study was to investigate whether the early La response to exercise in patients with COPD was associated with a reduced intramuscular GLU level and with intrinsic alterations in other exercise-related substrate levels (i.e., La, glucose, glycogen). The second purpose was to examine possible differences in the exercise-induced lactate increase in patients with the EMPH+ and EMPH- subtypes of COPD. The third purpose of our study was to investigate differences in intrinsic exercise related muscle substrate levels in a sedentary and a physically active control group.

\section{METHODS}

\section{Study population}

A group of 27 patients with moderate to severe airflow obstruction (males/females: 21/6; FEV : $45 \pm 14 \%$ (mean \pm SE) predicted) and 22 healthy, age-matched volunteers (males/females: 17/5) was studied. The control group was stratified by 
level of physical activity in daily life into a physically inactive group (PI; $n=15)$ and a physically active group (PA; $n=7$ ), using the modified Baecke questionnaire (11). Controls were defined as PA when they had a total Baecke index $>8.5$. All patients had COPD according to American Thoracic Society guidelines (12) and had chronic airflow limitation, defined as a measured forced expiratory volume in one second $\left(\mathrm{FEV}_{1}\right)$ less than $70 \%$ of reference $\mathrm{FEV}_{1}$. Furthermore, the patients had irreversible obstructive airway disease ( $<10 \%$ improvement of predicted baseline $\mathrm{FEV}_{1}$ after inhalation of $\beta_{2}$-agonist) and were in clinically stable condition and without respiratory tract infection or exacerbation of their disease at least four weeks before the study. Exclusion criteria were malignancy; cardiac failure, distal arteriopathy: recent surgery, severe endocrine, hepatic, or renal disorder; and use of anticoagulant medication. Written informed consent was obtained from all subjects, and the study was approved by the medical ethics committee of the University Hospital Maastricht.

\section{Exercise capacity}

Patients and healthy volunteers performed a symptom-limited incremental exercise test on an electronically braked cycle ergometer (Cornival 400, Lode, Groningen, The Netherlands). After a period of rest and two minutes of unloaded pedaling, a progressively increasing work rate test was started in order to determine each subject's peak work rate $\left(\mathrm{WR}_{\text {peak }}\right)$ and maximal oxygen uptake $\left(\mathrm{VO}_{2 \text { peak }}\right)$. The work rate increase was set at $10 \mathrm{Watts} / \mathrm{min}$ for each patient and $15-30 \mathrm{watts} / \mathrm{min}$ for the healthy volunteers, depending upon their training status. A pedaling frequency of 60 to $70 \mathrm{rpm}$ was selected by the subjects and held constant throughout the test. Breathby-breath gas exchange was measured throughout the test with a ventilated hood system (Oxycon- $\beta$, Jaeger, Bunnik, The Netherlands). An infrared electrode (Fasttrac, Sensor Medics Co., Anaheim. California) was placed on a finger to measure oxygen saturation. During rest, every minute during exercise and three minutes into the recovery period, blood samples were drawn from an antecubital vein, put into heparinized syringes, and subsequently centrifuged to obtain plasma for determination of La content using an enzymatic method (13) in an automated system (Cobas Mira, Roche, Bazel, Switzerland). Lactate threshold was determined according the method of Beaver and collegues (14). Plots of log La versus $\log \mathrm{VO}_{2}$ were constructed, and two straight-line segments were fitted to each plot. The point of intersection of these two line segments was defined as the La threshold.

\section{Collection and analysis of peripheral skeletal muscle biopsy and arterial blood samples}

In the early morning, a peripheral skeletal muscle biopsy specimen was collected from all subjects in the post-absorptive state and at rest.

The muscle biopsy specimen, from the lateral part of the quadriceps femoris, was obtained under local anesthesia, using the needle biopsy technique (15). The muscle tissue was immediately frozen in liquid nitrogen and stored at $-80^{\circ} \mathrm{C}$ until analysis. After the addition of glass beads $(1 \mathrm{~mm})$, the muscle tissue was homogenized with a 
Minibeater (Biospec Products, Bartlesville, OK). Muscle tissue was deproteinized with sulfosalicylic acid for determination of the citric acid cycle-related amino acids glutamate and alanine, and with trichloric acid for determination of the glycolytic substrates La, pyruvate, and glucose. One part of muscle was freeze-dried in order to determine glycogen. This muscle specimen was kept at $100{ }^{\circ} \mathrm{C}$ for 3 hours after addition of $1.0 \mathrm{ml}$ of $1 \mathrm{M} \mathrm{HCl}$ to hydrolyze glycogen, which was subsequently neutralized with TRIS $(0.12 \mathrm{M})-\mathrm{KOH}(2.1 \mathrm{M})$ saturated with $\mathrm{KCl}$. The glucose residues were measured fluorometrically as described elsewhere (16). The values obtained were corrected for the amount of free glucose already present at the time of tissue sampling.

Arterial blood was obtained by puncture of the radial artery while the subject breathed room air. One sample was used for determination of blood gases (ABL 330; Radiometer, Copenhagen, Denmark). A second sample was put in a heparinized syringe, immediately put on ice, and subsequently centrifuged at $4{ }^{\circ} \mathrm{C}$ for ten minutcs: to obtain plasma. The plasma was deproteinized with sulfosalicylic acid for determination of GLU and ALA, and with trichloric acid for determination of glucose, lactate, and pyruvate. The samples were frozen in liquid nitrogen and stored at $-80^{\circ} \mathrm{C}$ until analyses.

The glycolytic substrates and the TCA-related amino acids in muscle tissuc and arterial plasma were analyzed with a fully automated high-performance liquid chromatography (HPLC)(17), and muscle glycogen was analyzed by enzymatic techniques (18).

\section{Assessment of macroscopic emphysema}

In all patients, evaluation of the presence of parenchymal destruction, the hallmark of emphysema (19), was done by high-resolution computed tomography (HRCT), using a commercial scanner (Somatom Plus; Siemens, Erlangen, Germany) (voltage: 137 $\mathrm{kVp}$, current:220 mA, collimation: $1.0 \mathrm{~mm} ; 1.0 \mathrm{sec}$. scanning time). Five HRCT scans were obtained of each subject in supine position during breathholding at end-expiration: these consisted of two scans of the upper and two scans of the lower lung zones at three and six $\mathrm{cm}$ above and below the carina, respectively, and one scan at the carina. Images were made at a level of -800 Hounsfield Units (HU) and a window width of $1,600 \mathrm{HU}$, which is appropriate for lung detail. The severity and extent of emphysema in each scan were scored visually on a four-point scale by two independent observers according to the direct observational method developed by Sakai and colleagues (20). For each of the ten lung sections, the score for severity was multiplied by the score for extent of emphysema, and the resultant scores were subsequently summed to give the total HRCT score. Visual HRCT scores ranged from 0 (no macroscopic emphysema) to 120 (severe macroscopic emphyserna). Patients were stratified by HRCT score into two groups: HRCT score $<30$ : no or trivial macroscopic emphysema (EMPH-), HRCT score $\geq 30$ : macroscopic emphysema (EMPH +$)$. 


\section{Pulmonary function tests}

All patients and healthy volunteers underwent spirometry with determination of forced expiratory volume in one second $\left(\mathrm{FEV}_{1}\right)$ and forced vital capacity (FVC), with the highest value from at least three technically acceptable maneuvers being used. Static and dynamic lung volumes (total lung capacity (TLC), intrathoracic gas volume (ITGV) and airway resistance $\left(\mathrm{R}_{\mathrm{aw}}\right)$ ) were assessed through whole-body plethysmography (Masterlab, Jaeger, Wurzburg, Germany). Diffusing capacity for carbon monoxide $\left(\mathrm{Dl}_{\mathrm{co}}\right)$ was measured according to the single-breath method (Masterlab, Jaeger, Wurzburg, Germany). Subtracting estimated dead space from inspiratory volume gives an estimate of alveolar volume (VA) and the $\mathrm{Dl}$ co was then corrected for VA (transfer factor: $\mathrm{K}_{\mathrm{co}}$ ). All values obtained were related to a reference value and expressed as percentages of this predicted value (21).

\section{Statistical analysis}

Results for muscle and arterial plasma determinations are expressed as mean $t$ standard error (SE) and those for other characteristics as mean \pm standard deviation (SD). Analysis of covariance (ANCOVA), followed by Tukey's pairwise multiple comparison procedure, was used to determine differences between the EMPH+, EMPH-, PI and PA in pulmonary function, exercise capacity, and muscle and arterial plasma variables, with sex as the covariate. In addition, to adjust for the differences in FEV 1 between the EMPH+ and EMPH- groups, ANCOVA was used with FEV as the covariate. A two-tailed value of $\mathrm{p}<0.05$ was considered statistically significant.

\section{RESULTS}

\section{Physically inactive versus active healthy volunteers}

Twenty-two controls (15 PI and 7 PA) participated in the study (Table 1). All of these PA controls were men. Age, height, weight of the PI and PA groups were not significantly different. The pulmonary function of both groups was within the normal range. The PA group had higher values for $\mathrm{Dl}_{c 0}(p<0.01)$, arterial $\mathrm{pO}_{2}(\mathrm{p}<0.01)$ and $\mathrm{O}_{2}$ saturation $(\mathrm{p}<0.05)$, and lower values for $\mathrm{R}_{\mathrm{aw}}(\mathrm{p}<0.001)$ than did the PI group.

Exercise capacity (Figure 1), reflected by peak oxygen uptake $\left(\mathrm{VO}_{2 \text { peak }}\right)$ and work rate $\left(W R_{p e a k}\right)$, was higher in the PA than the PI group $(p<0.01)$. No significant difference between the two groups was found in venous lactate concentration at rest, peak exercise, or recovery (Table 2). La threshold (Table 2, Figure 2) was higher in the PA than in the PI group $(p<0.05)$.

In the PA group, higher values for muscle GLU $(\mathrm{p}<0.05)$ and glycogen $(p<0.01)$ than in the PI group (Table 3), but no significant differences were found in muscle glucose, pyruvate, La or ratio La to pyruvate. The observed differences 
between the PI and PA groups in lung function, exercise capacity, and muscle substrates remained after adjustment for the variation in sex.

Table 1. General characteristics and pulmonary function of patients with subtypes of COPD and physically inactive and active healthy volunteers.

EMPH+ EMPH- Phys inactive Phys. active healthy volunteers healthy volunteers

\begin{tabular}{|c|c|c|c|c|c|c|c|c|c|c|c|c|c|c|c|c|}
\hline \multicolumn{17}{|c|}{ General characteristics } \\
\hline Sex & $\mathrm{M} / \mathrm{F}$ & 10 & 1 & 2 & 11 & 1 & & & 10 & 1 & 5 & & 7 & 1 & 0 & \\
\hline Age & $\mathrm{Y}$ & 64 & \pm & 9 & 64 & \pm & 10 & & 67 & \pm & 3 & & 63 & \pm & 2 & \\
\hline Height & $\mathrm{Cm}$ & 170 & \pm & 10 & 170 & \pm & 8 & & 167 & \pm & 8 & & 172 & \pm & 9 & \\
\hline Weight & $\mathrm{Kg}$ & 66.2 & \pm & 11.4 & 76.5 & \pm & 10.1 & a & 73.3 & \pm & 11.2 & & 74.3 & \pm & 12.1 & \\
\hline PH & & 7.41 & \pm & 0.02 & 7.41 & \pm & 0.02 & & 7.41 & \pm & 0.01 & & 7.41 & \pm & 0.02 & \\
\hline $\mathrm{p}_{4} \mathrm{O}_{2}$ & $\mathrm{mmHg}$ & 70.8 & \pm & 6.8 & 78.5 & \pm & 9.0 & a & 81.3 & \pm & 9.5 & b & 97.5 & \pm & 10.0 & ceh \\
\hline $\mathrm{p}_{\mathrm{s}} \mathrm{CO}_{2}$ & $\mathrm{mmHg}$ & 42.4 & \pm & 6.6 & 40.9 & \pm & 3.4 & & 42.0 & \pm & 3.0 & & 40.3 & \pm & 2.2 & \\
\hline $\mathrm{HCO}_{3}$ & $\mathrm{mM}$ & 27.0 & \pm & 3.0 & 25.6 & \pm & 2.6 & & 26.0 & \pm & 1.2 & & 25.3 & \pm & 1.4 & \\
\hline $\mathrm{BE}$ & $\mathrm{mM}$ & 2.1 & \pm & 2.1 & 1.2 & \pm & 2.3 & & 1.3 & \pm & 0.8 & & 0.9 & \pm & 1.3 & \\
\hline $\mathrm{SatO}_{2}$ & $\%$ & 94.0 & \pm & 1.6 & 95.2 & \pm & 1.5 & a & 95.6 & \pm & 1.2 & 2 & 97.3 & \pm & 1.0 & $\operatorname{ceg}$ \\
\hline \multicolumn{17}{|c|}{ Pulmonary function } \\
\hline $\mathrm{FEV}_{\mathrm{I}}$ & $\%$ pred. & 34 & \pm & 8 & 54 & \pm & 12 & $\mathrm{r}$ & 111 & \pm & 21 & \& & 110 & \pm & 8 & of \\
\hline FVC & $\%$ pred. & 89 & \pm & 23 & 94 & \pm & 12 & & 118 & \pm & 18 & b? & 117 & \pm & 6 & bf \\
\hline $\mathrm{D} l_{\mathrm{co}}$ & $\%$ pred. & 43 & \pm & 8 & 79 & \pm & 15 & c & 107 & \pm & 11 & cf & 135 & \pm & 17 & efh \\
\hline $\mathrm{K}_{\mathrm{io}}$ & \%pred. & 48 & \pm & 9 & 87 & \pm & 21 & $\varepsilon$ & 107 & \pm & 18 & $\mathrm{~cd}$ & 128 & \pm & 19 & efg \\
\hline TLC & \%pred. & 125 & \pm & 13 & 111 & \pm & 11 & $b$ & 114 & \pm & 11 & $a$ & 113 & \pm & 4 & \\
\hline RV & $\%$ pred. & 144 & \pm & 31 & 186 & \pm & 43 & $a$ & 113 & \pm & 18 & ce & 107 & \pm & 13 & $\mathrm{ce}$ \\
\hline ITGV & \%pred. & 170 & \pm & 26 & 126 & \pm & 18 & $c$ & 104 & \pm & 19 & ce & 104 & \pm & 11 & $c d$. \\
\hline $\mathrm{R}_{\mathrm{aw}}$ & \%pred. & 249 & \pm & 99 & 222 & \pm & 111 & & 110 & \pm & 49 & ec & 65 & \pm & 13 & eff \\
\hline
\end{tabular}

Values are mean $\pm \mathrm{SD}$; EMPH+, EMPH-: COPD with and without emphysema, respectively; FEV forced expiratory volume in $1 \mathrm{~s}$; FVC: forced vital capacity; $\mathrm{Dl}_{\mathrm{ca}}$ : diffusing capacity for carbon monoxide; $\mathrm{K}_{\text {co }}$ : $\mathrm{Dl}_{c o}$ corrected for alveolar volume; TLC: total lung capacity; $\mathrm{RV}$ : residual volume; ITGV: intrathoracic gas volume; $\mathrm{R}_{\mathrm{aw}}$ : airway resistance. Significance of difference after correction for variation in sex: $a, b, c, p<0.05, p<0.01, p<0.001$ vs. EMPH $+; d, e, f, p<0.05, p<0.01, p<0.001$ vs. EMPH-; $g, h, i p<0.05, p<0.01, p<0.001$ vs. physically inactive healthy volunteers.

\section{Total COPD group stratified into EMPH+ and EMPH- subgroups, versus physically inactive healthy volunteers}

Twenty-seven COPD patients (12 EMPH+, 15 EMPH-) participated in the study (table 1). Age, height, and sex in the COPD and the PI groups did not differ significantly. Body weight of the total COPD group and the PI controls was not significantly different, but was lower in the EMPH+ group than in the EMPH- group $(\mathrm{p}<0.05)$. On average, the total COPD group was characterized by severe airflow obstruction ( $\mathrm{FEV}_{1}: 45 \pm 14 \%$ pred.), reduced $\mathrm{Dl}_{c o}(63 \pm 22 \%$ pred.), moderate 
hyperinflation (TLC: $117 \div 14 \%$ pred., RV: $163 \pm 42 \%$ pred.) and increased airways resistance $\left(\mathrm{R}_{\mathrm{s}}: 235 \pm 104 \%\right.$ pred.). The EMPH+ group (mean HRCT-score: $81.8 \pm$ $23.8)$ had more severe airflow obstruction and hyperinflation $(p<0.01)$, and lower values for arterial $\mathrm{pO}_{2}$ and $\mathrm{O}_{2}$ saturation $(\mathrm{p}<0.05$ ) than did the EMPH- group (mean HR('T-score: $3.3 \pm 6.6)$.

$V^{2 p e s k}$ and $W R_{p c a k}(p<0.01)$ (Figure 1) were lower in all COPD patients than in the controls, the lowest values being found in the EMPH+ group. The lower values for $V_{2 \text { peak }}$ and $W_{R_{\text {peak }}}$ in the EMPH+ than in the EMPH- group $(\mathrm{p}<0.01)$ remained after adjustment for the variation in $\mathrm{FEV}_{1}$. Moreover, the ratio of $\Delta \mathrm{VO}_{2}$ to $\mathrm{WR}_{\text {peak }}$ corrected for differences in work rate increase ( $\mathrm{VO}_{2 \text { (pcak-unloaded) }}$ )

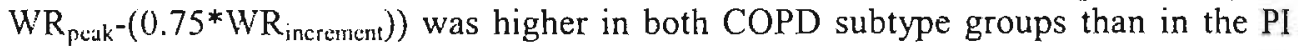
group ( $\mathrm{p}<0.05)$, but not significantly different between the EMPH+ and the EMPHgroups. Transcutaneous $\mathrm{O}_{2}$ saturation at peak exercise was lower in the EMPH+ group than in the EMPH- group $(89.4 \pm 2.5 \%$ vs. $93.8 \pm 2.1 \%$;p $<0.001)$.

At rest, venous La (Table 2) was higher in both COPD subtype groups than in the PI group $(\mathrm{p}<0.05)$, but no significant difference was found between the EMPH+ and EMPH- group. At peak exercise, no significant difference between the study groups was present in venous La. During recovery, venous La was lower in the total COPD group than in the PI controls $(p<0.01)$, being more reduced in the EMPH+ than in the EMPH- subgroup $(p<0.05)$. The La increase per maximal achieved workload $\left(\Delta l a c t a t e / W_{p e a k}\right)$ was higher in both COPD subtypes than in the PI group $(p<0.05)$ but not different between the EMPH+ and EMPH- groups. La threshold (Table 2, Figure 2) was lower in the EMPH+ subgroup than in the EMPH- subgroup $(p<0.01)$ or PI group $(p<0.001)$. Moreover, La threshold was lower in the EMPHsubgroup than in the PI group $(\mathrm{p}<0.01)$. 

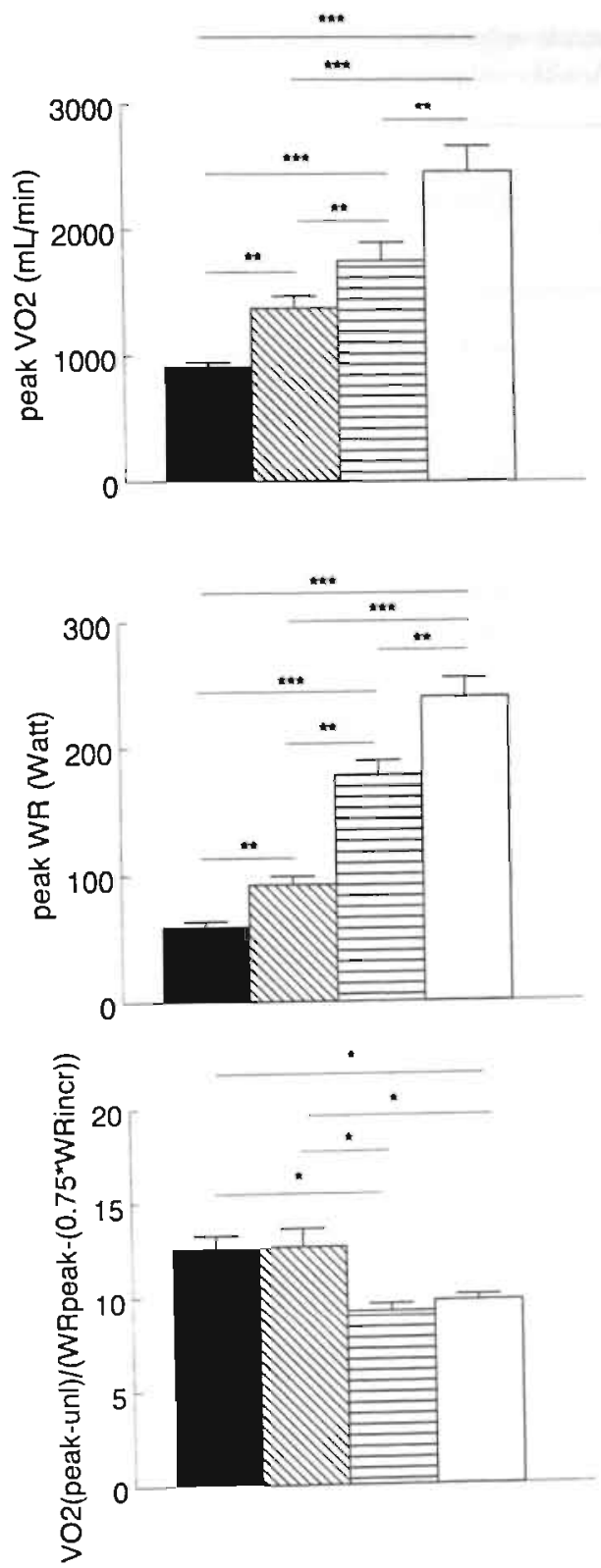

Figure 1. Bar diagram of the average values ( $\pm \mathrm{SEs}$ ) for peak $\mathrm{VO}_{2}$ (fig 1, top panei), peak work rate (fig l, middle panel) and ratio $\mathrm{VO}_{2 \text { (peak exercise-unloaded) }} /$ (peak work rate $-(0.75 *$ WR increment), where 0.75 is the (assumed) $\mathrm{VO}_{2}$ time constant (fig 1 , lower panel) of the EMPH+ group (closed bar), the EMPH- group (cross-striped bar), and the physically inactive healthy volunteers (horizontally-striped bar) and the physically active healthy volunteers (open bar). A portion of the difference in peak work rate between COPD patients and healthy controls is due to the different work rate increase. Significance of difference between the groups: ${ }^{*}: p<0.05 ;{ }^{* *}: \mathrm{p}<0.01 ;{ }^{* * *}: \mathrm{p}<0.001$ 
Table 2. Venous lactate response to exercise in patients with subtypes of COPD and physically inactive and active healthy volunteers

EMPH+ EMPH- Phys. inactive Phys. active healthy voluntecrs healthy volunteers

\begin{tabular}{|c|c|c|c|c|c|c|c|c|c|c|c|c|c|c|}
\hline Rest & $\mathrm{mM}$ & 1.6 & \pm 0.7 & 1.8 & \pm 0.7 & & 1.2 & \pm & 0.2 & $3 \sqrt{3}$ & 1.4 & \pm & 0.4 & d \\
\hline $\begin{array}{l}\text { Peak } \\
\text { exercise }\end{array}$ & $\mathrm{mM}$ & 4.0 & \pm 1.3 & 5.4 & \pm 2.1 & & 5.2 & \pm & 1.4 & & 6.4 & \pm & 3.0 & \\
\hline Recovery & $\mathrm{mM}$ & 4.6 & \pm 1.2 & 6.4 & \pm 2.3 & a & 8.1 & \pm & 2.3 & c & 8.9 & \pm & 2.5 & cd \\
\hline$\Delta \mathrm{La} / \mathrm{W}_{\text {peak }}$ & $\mathrm{mM} / \mathrm{w}$ & 0.03 & \pm 0.02 & 0.04 & \pm 0.02 & & 0.02 & \pm & 0.01 & ad & 0.02 & \pm & 0.01 & ad \\
\hline La threshold & $\mathrm{L} / \mathrm{min}$ & 0.56 & 0.04 & 0.76 & \pm 0.04 & b & 0.94 & \pm & 0.07 & c e & 1.49 & \pm & 0.16 & \\
\hline
\end{tabular}

Values are mean \pm SD. EMPH+: COPD with emphysema; EMPH-: COPD without emphysema; Significance of difference after correction for variation in sex: a, b, c p<0.05, p<0.01, $<<0.001$ vs. EMPH+; d, e $p<0.05 p<0.001$ vs. EMPH-; f $p<0.05$ vs. PI. La threshold is the $\mathrm{VO}_{2}$ at which blood lactate begins to increase.

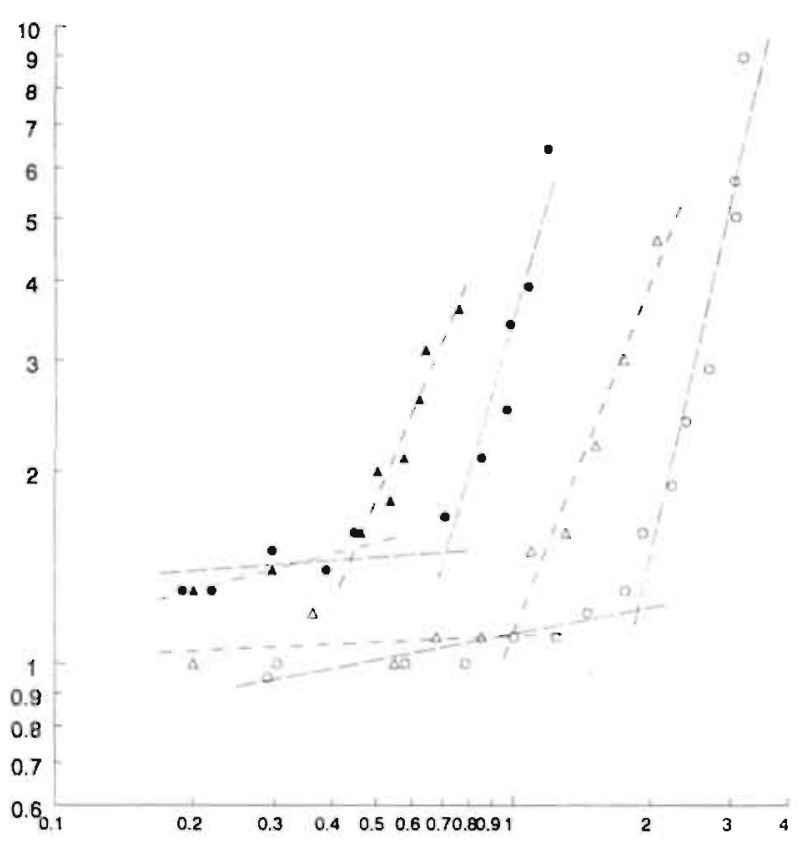

Figure 2. Effect of incremental exercise on venous lactate levels in one of the EMPH+ (closed triangles) and EMPH- (closed circles) patients, and in one of the physically inactive (open triangles) and physically active (open circles) volunteers. Venous lactate is plotted versus oxygen uptake on a log-log scale. The lactate threshold is the point of intersection of the two line segments. Use of anticubital venous blood will yield a significant delay in lactate increase as compared with arterial (or femoral venous) values. 
Table 3. Resting glutamate and glycolysis-related substrate levels of patients with subtypes of COPD and the physically inactive and active healthy volunteers

EMPH+ EMPH- Phys. inactive Phys. active healthy volunteers healthy volunteers

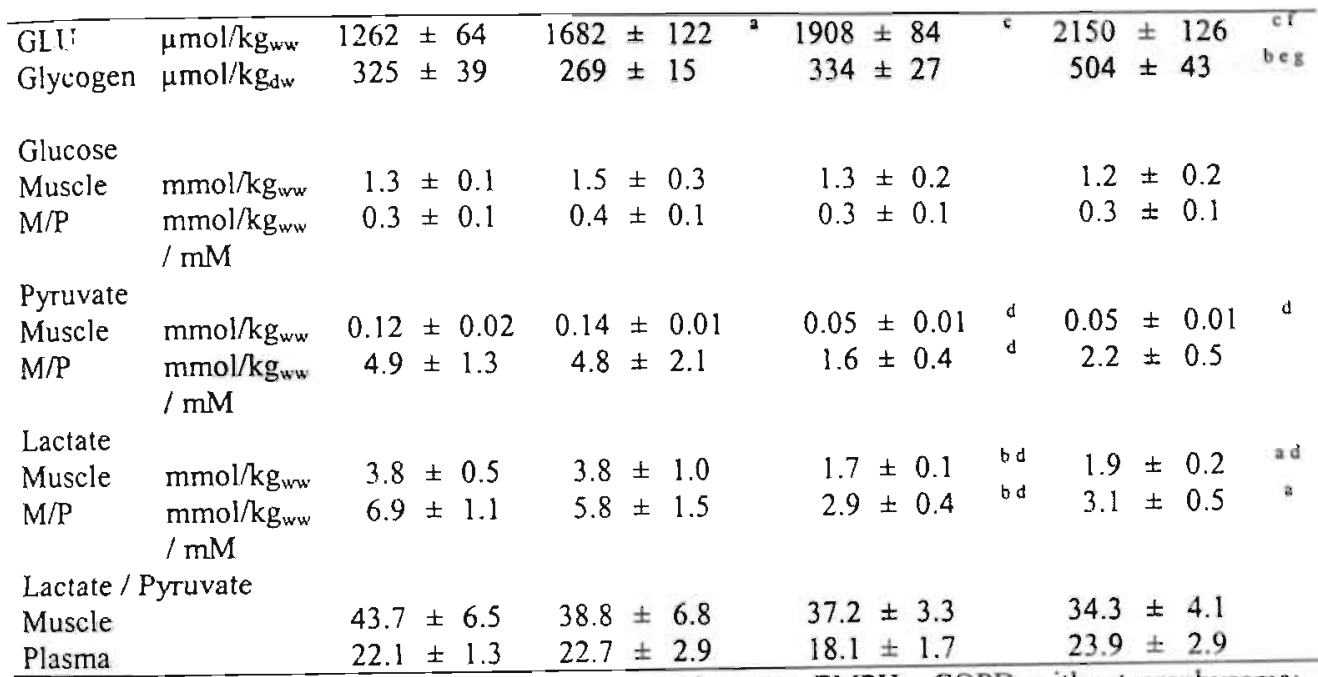

Values are mean $\pm \mathrm{SE}$; EMPH+: COPD with emphysema; EMPH-: COPD without emphysema; Significance of difference after correction for variation in sex: $a, b, c, p<0.05, p<0.01, p<0.001$ vs. EMPH+; d, e, $p<0.05, p<0.001$ vs. EMPH-; f,g $p<0.05, p<0.01$ vs. physically inactive healthy volunteers

Resting muscle GLU (table 3) was significantly lower in the total COPD group than in the PI group $(\mathrm{p}<0.01)$, whereas muscle pyruvate and La and muscle-to-plasma gradient for pyruvate and La were higher $(\mathrm{p}<0.05)$. Muscle GLU was significantly lower in the EMPH+ than in the EMPH- subgroup ( $\mathrm{p}<0.05)$, whereas the glycolysisrelated substrates in both peripheral skeletal muscle and arterial plasma (data not shown) were not significantly different in the two COPD subgroups. Muscle glycogen, glucose, and the La-to-pyruvate gradient, were not different among the total COPD group, EMPH+ and EMPH- subgroups, and PI group. The significance of the differences between the EMPH+ and EMPH- subgroups in body weight, exercise capacity, La threshold, venous La concentration at recovery from excrcise, and muscle GLU remained after adjustment for the subgroups' difference in $\mathrm{FEV}$.

In figure 3, mean $\mathrm{Dl}_{\text {co, }}$, muscle GLU, and La threshold during incremental exercise are plotted against each other for the four study groups (EMPH+, EMPH-, PI and PA). A positive relationship was visible between $\mathrm{Dl}_{\text {co }}$ and muscle GLU (Figure 3, top panel), and between $\mathrm{DI}_{\text {co }}$ and La threshold (Figure 3, middle panel). Moreover, a positive relationship was visible between muscle GLU and La threshold during exercise (Figure 3, lower panel). The relationships with muscle GLU and La 
threshold during exercise were also seen when using $\mathrm{p}_{2} \mathrm{O}_{2}$ instead of $\mathrm{Dl}_{\mathrm{CO}}$ (Figure 4). No relationship was found between La threshold during incremental exercise and muscle glycogen, glucose, pyruvate or La levels.

\section{DISCUSSION}

This study shows an early La response to incremental exercise in EMPH- patients, but to a greater extent in EMPH+ patients, as compared with control subjects. The La threshold during exercise was related to resting muscle GLU status, the latter being most severely depleted in EMPH+ patients. No association was found between lactate threshold and alterations in resting muscle glycogen, pynvate or La level.

Physical inactivity is often seen as (one of) the main cause(s) of the early lactic acidosis during exercise in COPD. In the present study, we compared two control groups with a different physical training status in order to gain greater insight into the effect of physical activity level on exercise related muscle substrate levels. The PA controls, characterized by higher values for $W_{R_{p e a k}}$ and $L a$ threshold during exercise than were the PI subjects, had higher resting values for the muscle GLU and glycogen, but showed no differences from the PI subjects in glucose, La or pyruvate. This indicates that the role of physical inactivity has to be taken into account when studying muscle glycogen and GLU metabolism in patients with COPD.

Since premature lactic acidosis represents a misbalance between lactate production and the body's ability to clear La, it is of importance to discern the factors that define both the rate of La production and La clearance in COPD. In this way, greater insight can be obtained about the potential causes of the different La responses to exercise in COPD patients and controls, and between the subtypes of COPD.

Under nomal conditions and in the presence of adequate $\mathrm{O}_{2}$ delivery, muscle La production may increase when the rate of pyruvate production by glycolysis exceeds the rate of pyruvate oxidation by the TCA cycle. Since it is unlikely that respiratory muscles contribute appreciably to the carly increase in La in COPD patients (22), an impaired oxidative muscle metabolism of the exercising peripheral skeletal muscles is likely to be an important source of this increase in La. Indeed, in a recent study by Maltais and coworkers (3), the enhanced increase in La in COPD patients was associated with decreased activities for the oxidative enzymes citrate synthase and 3- hydroxyacyl CoA. In accord with this is the observed increased proportion of type $2 \mathrm{~b} / \mathrm{x}$ fibers in quadriceps femoris of COPD patients $(4,23)$. Moreover, Satta and associates showed that increased levels of type $2 \mathrm{~b} / \mathrm{x}$ fibers were particularly present in COPD patients with a reduced $\mathrm{Dl}_{\mathrm{co}}$ (4), suggesting that patients with emphysema are particularly prone to a decreased muscle oxidative capacity. 

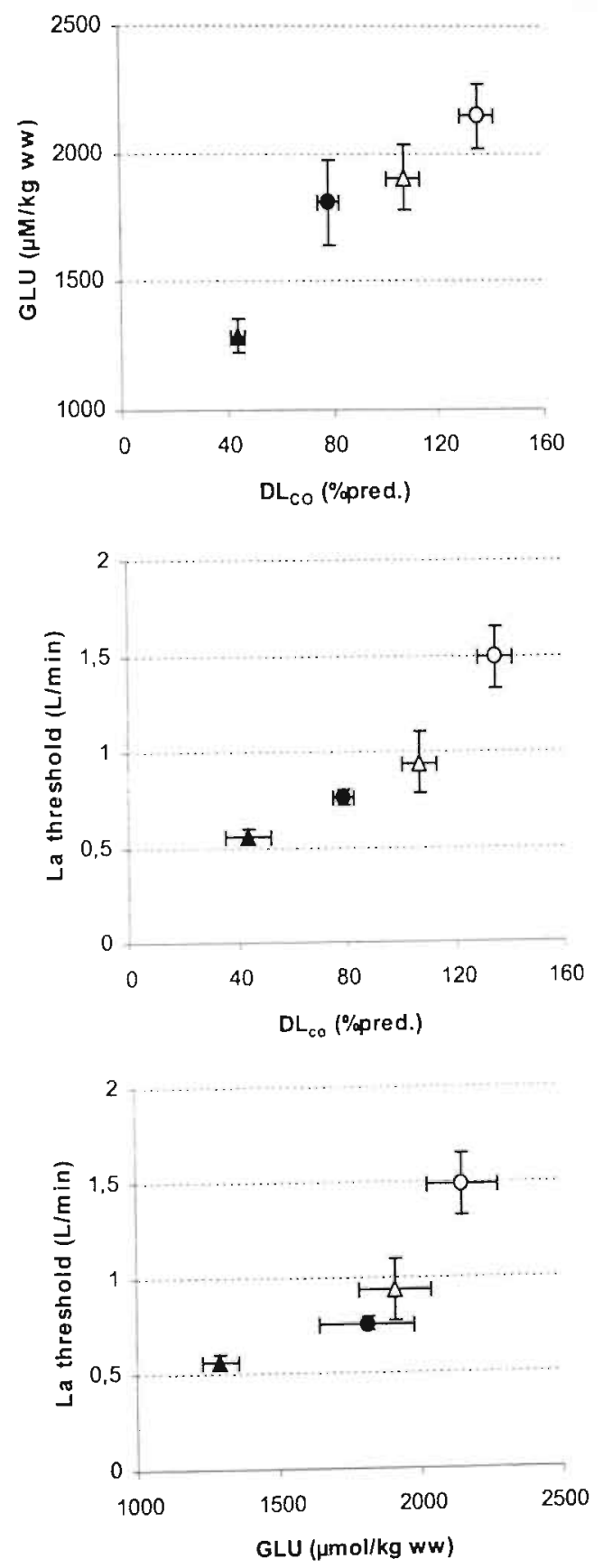

Figure 3. Scatter plot of the relationships between muscle glutamate vs. $\mathrm{Dl}_{\mathrm{co}}$ (fig 3 , top panel), lactate threshold vs. $\mathrm{Dl}_{\mathrm{co}}$ (fig 3, middle panel), and lactate threshold vs. muscle glutamate (fig 3, lower panel) for the EMPH+ group (closed triangles), the EMPHgroup (closed circles), the physically inactive volunteers (open triangles), and the physically active volunteers (open circles). Average values \pm SEs are shown. 

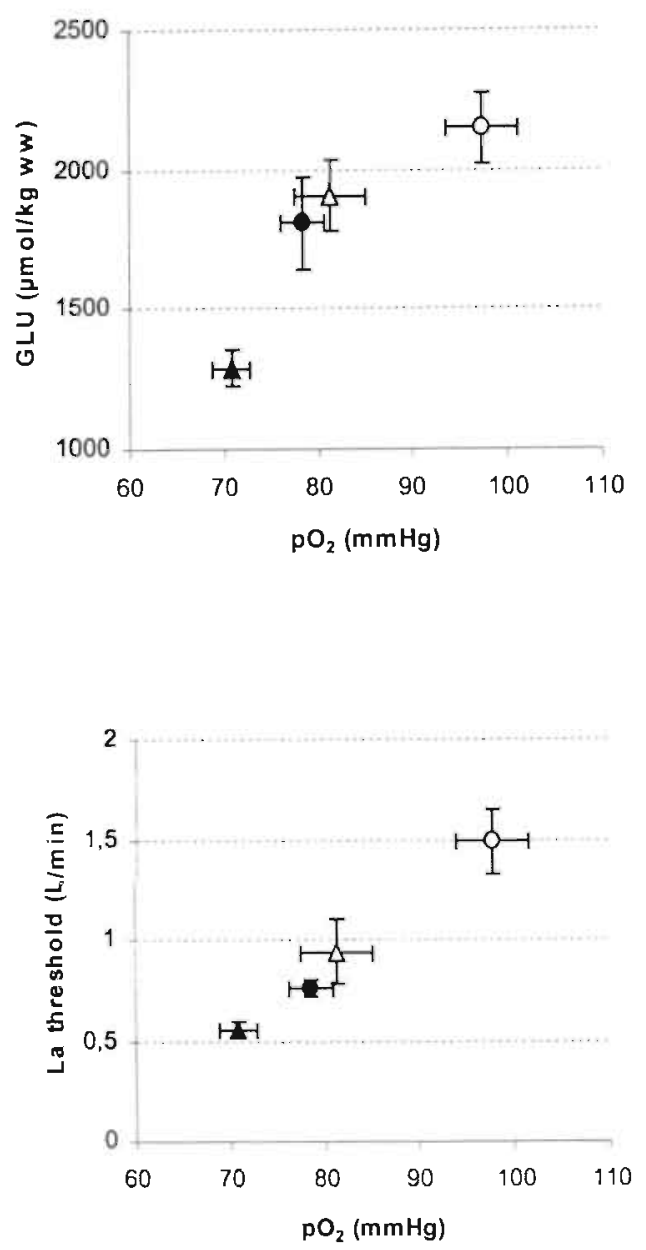

Figure 4. Scatter plot of the relationships between muscle glutamate vs. $\mathrm{p}_{2} \mathrm{O}_{2}$ (fig 4, top panel), and lactate threshold vs. $\mathrm{p}_{2} \mathrm{O}_{2}$ (fig 4, bottom panel) for the EMPH+ group (closed triangles), the EMPH- group (closed circles), the physically inactive volunteers (open triangles), and the physically active volunteers (open circles). Average values \pm SEs are shown.

The fiber type distribution in peripheral skeletal muscle is important, since the ratio of oxidative to glycolytic fibers may control the range over which lactic acidosis can shift during exercise. The metabolic profile of type $2 \mathrm{~b} / \mathrm{x}$ fibers, with a high concentration of glycolytic enzymes and La dehydrogenase-M isozyme and a low mitochondrial content, favors glycolytic energy production. These fibers produce La when stimulated. In contrast, the high mitochondrial density and enzyme activity of type 1 fibers favor oxidative energy production. Furthermore, type 1 fibers have a greater $\mathrm{La}$ and pyruvate oxidative capacity than do type $2 \mathrm{~b} / \mathrm{x}$ fibers during contraction, owing to a high La dehydrogenase-H isozyme concentration. Therefore, it is likely that the oxidative type 1 fibers play a role in the clearance of La produced 
by the glycolytic type $2 b / x$ fibers during exercise. Since COPD patients, and probably EMPH+ patients in particular, have a reduced percentage of type 1 fibers, the capacity of these patients to reduce the enhanced La levels produced by type $2 \mathrm{~b} / \mathrm{x}$ fibers during low-intensity exercise may be diminished.

In the present study, significantly lower values for transcutaneous $\mathrm{O}_{2}$ saturation were found at peak exercise in the EMPH+ group than in the EMPH- group ( $89 \%$ vs. $94 \%)$. In agreement with this is the finding that desaturation during exercise, a potential contributor of hypoxemia, occurred in $68 \%$ of the emphysema patients $\left(\mathrm{Dl}_{\mathrm{co}}\right.$ $<55 \%$ pred.). When $\mathrm{D}]_{\text {co }}$ fell below $55 \%$ pred., a further increase took place in both the percentage of COPD patients with desaturation during exercise and in the magnitude of desaturation. It is therefore very possible that a reduced $\mathrm{O}_{2}$ supply to the peripheries is present during exercise in the EMPH+ patients, contributing to these patients' early La response to exercise in these patients. However. Jespite normal resting $\mathrm{p}_{\mathrm{a}} \mathrm{O}_{2}$ values and the absence of oxygen desaturation during exercise in the EMPH- patients, it is also possible that $\mathrm{O}_{2}$ availability to the skeletal muscles is compromised during exercise in these patients as compared with controls. This may be due to more severe redistribution of blood flow toward the respiratory apparatus. Evidence for this is provided by a recent study which found that breathing of helium significantly increased values of $\mathrm{VO}_{2}$ max values in COPD patients, possibly because of a reduced work of breathing and increased skeletal muscle blood flow (24).

Hypoxic episodes are also suggested to have a detrimental effect on La clearance in the livers of patients with COPD. Recently, acute exposure to hypoxia in rats was found to inhibit liver gluconeogenesis through an abolishing effect on phosphoenolpyruvate carboxykinase activity and transcription, which was independent of food intake (25). Moreover, hypoxic episodes influence catecholamine levels in blood. Epinephrine is known to increase blood La by activating phosphorylase. During exercise, the concentration of epinephrine in the blood rises as $\mathrm{VO}_{2}$ exceeds $50 \%$ of $\mathrm{VO}_{2}$ max. This rise causes an increase in $\mathrm{La}_{\mathrm{a}}$ output of the working muscles, and it may stop the uptake of lactate (26).

Furthermore, the rising concentration of epinephrine may contribute to the rising La concentrations in other tissues by reducing the effective distribution volume of La from the La-producing tissues (i.e., working muscles). Earlier studies showed that patients with advanced emphysema (27) and patients with chronic respiratory failure (28) had higher values of plasma catecholamine nor-epinephrine than control did control subjects in the resting state. Although no difference was found in epinephrine levels at rest, it is still unknown whether exercise induces an alteration in the epinephrine response in those patients as compared with controls, thereby contributing to the difference in La response.

In the present study, the relationship between resting muscle GLU status and La threshold during exercise suggests that depleted GLU levels in resting peripheral skeletal muscle of COPD patients play a role in their early La response to exercise. We found no association between La threshold during exercise and other intrinsic changes in muscle substrates (i.e., La, pyruvate, glucose, or glycogen). Earlier reduced intracellular GLU levels are shown to negatively influence the alanine 
aminotransferase (AAT) reaction, since the muscle in which this occurs is less able to increase its capacity for resisting La production by shunting a smaller proportion of pyruvate for conversion into alanine than to La (29). Moreover, an adequate level of muscle GLU in peripheral skeletal muscle is necessary, since the AAT reaction occurs at the cost of GLU. The potential causes of the decreased intracellular GLU levels in COPD patients may be related to a decreased capacity for membrane transport of GLU into the muscle, and/or to increased intramuscular GLU degradation. The positive relationship between $\mathrm{p}_{\mathrm{a}} \mathrm{O}_{2}$ (and/or $\mathrm{Dl}_{\mathrm{co}}$ ) and muscle GLU in the present study indicates that a decrease in oxygen availability negatively influences muscle GLU metabolism, leading to a reduction in muscle GLU status.

This is in accord with several done in vivo and in vitro that have shown an accelerated GLU breakdown in muscle (mainly heart muscle) and mitochondria in situations in which oxygen deprivation is present (30-32). The myocardial tissue contents of GLU was depleted during hypoxia and by underperfusion of isolated heart preparations, and tended to decrease during cardioplegic arrest in humans. Together, these results indicate that ischemia as well as hypoxia causes an increased degradation and/or utilization of intracellular GLU. In patients with chronic heart failure, an augmented cardiac consumption of GLU was found even in the resting asymptomatic state, suggesting a specific metabolic adaptation induced by repetitive or chronic ischemia. Lower resting $\mathrm{pO}_{2}$ values and chronic intermittent hypoxia are often also present during daily living in COPD patients. However, it is not clear to what extent the lower resting $\mathrm{p}_{\mathrm{a}} \mathrm{O}_{2}$ levels and/or the presence of chronic intermittent hypoxia (possibly related to the reduced $\mathrm{Dl}_{\mathrm{co}}$ ) in the COPD group in our study contributed to their decreased muscle GLU status. The PA group in our study had significantly higher values for $\mathrm{Dl}_{c 0}, \mathrm{p}_{3} \mathrm{O}_{2}$, and arterial $\mathrm{O}_{2}$ saturation at rest than did the PI group. We are not aware of any studies indicating that physical training has a positive effect on $\mathrm{p}_{3} \mathrm{O}_{2}$. The exact reason for the higher arterial $\mathrm{p}_{2} \mathrm{O}_{2}$ in the PA group than in our PI group is not yet clear.

The increased levels of GLU in the PA as compared with the PI subjects in the present study are in accord with the increased GLU levels found in muscle of trained as compared with untrained men (33). It has also been shown that trained muscle is can increase its capacity for resisting La production by shunting a greater proportion of pyruvate to alanine than to La (29). Although we did not have physical activity scores for the COPD group in our study, the $50 \%$ higher $\mathrm{WR}_{\text {peak }}$ in the PI group than in the COPD group may suggest that we were not completely successful in recruiting controls with a comparably low physical activity level to that of our COPD patients. This indicates that physical inactivity may have been at least partly responsible for the decreased resting muscle GLU levels in our COPD group. However, the EMPHand $\mathrm{EMPH}+$ patients in the present study were able to participate in and complete the intensive training part of the pulmonary rehabilitation program, and had pulmonary function characteristics comparable to those of the group of COPD patients described at the beginning of this article, in whom we observed decreased GLU levels, indicating comparable physical activity levels in both subtypes of COPD patients. More evidence for the expectation of comparable physical activity levels in patients 
with the subtypes of COPD comes from a large database obtained from our pulmonary rehabilitation center $(n=61)$, in which we did not find a significant correlation between $\mathrm{Dl}_{\text {co }}$ (the indirect measure of emphysema) and physical activity score as scored by Voorrips and coworkers (34) or the Physical Activity Scale for the Elderly (35) questionnaire in COPD patients ( $r: 0.04$ and $r: 0.13$, respectively). This indicates that other factors, rather than physical inactivity, contributed to the lower resting GLU level found in the studied EMPH+ group as compared to the EMPHgroup in our study.

In conclusion, the present study indicates that the early La response in paticnts with COPD is associated with the reduction in muscle GLU related to physical inactivity in COPD. However, other factors, such as a reduced $\mathrm{pO}_{2}$ or $\mathrm{Dl}_{\text {co }}$ play a role in the early La response during exercise in the EMPH+ opposed to the EMPH- paticnts.

\section{References}

1. Casaburi R, Patessio A, Ioli F, Zanaboni S, Donner CF, Wasserman K. Reductions in exercise lactic acidosis and ventilation as a result of exercise training in patients with obstructive lung disease. Am. Rev. Respir. Dis. 1991;143:9-18.

2. Sue DY, Wasserman K, Moricca RB, Casaburi R. Metabolic acidosis during exercise in patients with chronic obstructive pulmonary disease. Chest 1988;94:931-938.

3. Maltais F, Simard AA, Simard C, Jobin J, Desgagnes P, LeBlane P. Oxidative capacity of the skeletal muscle and lactic acid kinetics during exercise in normal subjects and in patients with COPD. Am. J. Respir. Crit. Care Med. 1996;153:288-293.

4. Satta A, Migliori GB, Spanevello A, Neri M, Bottinelli R, Canepari M, et al. Fibre types in skeletal muscles of chronic obstructive pulmonary disease patients related to respiratory function and exercise tolerance. Eur. Respir. J. 1997;10:2853-2860.

5. Gertz I, Hedenstierna G, Hellers G, Wahren J. Muscle metabolism in patients with chronic lung. disease and acute respiratory failure. Clin. Sci. Mol. Med. 1977;52:395-403.

6. Jakobsson P, Jorfeldt $L$, Brundin A. Skeletal muscle metabolites and fibre types in patients with advanced chronic obstructive pulmonary disease (COPD), with and without chronic respiratory failure. Eur. Respir. J. 1990;3:192-196.

7. Pouw EM, Schols AMWJ, Deutz NEP, Wouters EFM. Plasma and muscle amino-acid levels in relation to resting energy expenditure and inflammation in stable COPD. Am. J. Respir. Crit. Care Med. 1998;158:797-801.

8. Engelen MPKJ, Schols AMWJ, Does JD, Deutz NEP, Wouters EFM. Altered glutamate metabolism is associated with reduced muscle glutathione levels in patients with emphysema. Am. J. Respir. Crit. Care Med. 2000;161:98-103.

9. Van Hall G. Saltin B, Vusse van der GJ, Soderlund K, Wagenmakers AJM. Deamination of amino acids as a source for ammonia production during prolonged exercise in man. J. Physiol. 1995;95:251-261.

10. Van Hall G, MacLean DA, Saltin B, Wagenmakers AJM. Mechanisms of activation of muscle branched-chain alpha-keto acid dehydrogenase during exercsie in man. J. Physiol. 1996;494:899-905.

11. Pols MA, Peeters PHM, Bueno-de-Mesquita HB, Ocke MC, Wentink CA, Kemper HCG, et al. Validity and repeatability of a modified Baecke questionnaire on physical activity. Int. J. Epidem. 1995;24:381-388.

12. American Thoracic Society. Standards for the diagnosis and care of patients with chronic obstructive pulmonary disease (COPD) and asthma. Am. Rev. Respir. Dis. 1995;152:s77-s120.

13. Noll F. L-(+)-lactate, determination with LDH, GTP and NAD. Bergmeyer, ed. New York; 1974:1475. 
14. Beaver $\mathrm{WL}_{3}$ Wasserman $\mathrm{K}$, Whipp BJ. Improved detection of lactate threshold during exercise using a log-log transformation. J. Appl. Physiol. 1985;59:1936-1940.

15. Bergstrom L. Muscle electrolytes in man. Determination by neutron activation analysis on needle biopsy specimens. A study on normal subjects, kidney patients, and patients with chronic diarrhea. Scand. J. Clin. Lab. Invest. 1962;68:7-110.

16. Van der Vusse GJ, Coumans WA, Van der Veen FH, Drake A, Flameng W, Suy R. ATP, creatine phosphate and glycogen content in human myocardial biopsies: markers for the efficacy of cardioprotection during aortocoronary bypass surgery. Vasc. Surg. 1984;18:127-134.

17. Van Eijk HMH, Rooyakkers DR, Deutz NEP. Rapid routine determination of amino acids in plasma by high-performance liquid chromatography with a 2-3 um Sperisorb ODS 2 column. J. Chromat. 1993;620:143-148.

18. Van der Vusse GJ, Janssen GME, Coumans WA, Kuipers H, Does RJMM, Hoor ten F. Effect of training and 15-,25-, and 42-km contests on the skeletal muscle content of adenine and guanine nucleotides, creatine phosphate, and glycogen. Int. J. Sports. Med. 1989;10:S146-S152.

19. American Thoracic Society. Chronic bronchitis, asthma, and pulmonary emphysema by the committee on diagnostic standards for nontuberculosis respiratory disease. Am. Rev. Respir. Dis. 1962;85:762-812.

20. Sakai F, Gamu G, Im JG, Ray CS. Pulmonary function abnormalities in patients with CTdetermined emphysema. J. Comput. Assist. Tomogr. 1987;11:963-968.

21. Quanjer P, Tammeling GJ, Cotes JE, Pedersen OF, Peslin R, Yernault JC. Standardized lung function testing. Eur. Respir. J. 1993;6:5-40.

22. Engelen MPK.J, Casaburi R, Rucker R, Carithers E. Contribution of the respiratory muscles to the lactic acidosis of heavy exercise in COPD. Chest 1995; 108:1246-1251.

23. Whittom F, Jobin J, Simard PM, Leblanc P, Simard C, Bernard S, et al. Histochemical and morphological characteristics of the vastus lateralis muscle in patients with chronic obstructive pulmonary disease. Med. Sci. Sports Exerc. 1998;30:1467-1474.

24. Richardson RS, Sheldon J, Poole DC, Hopkins SR, Ries AL, Wagner PD. Evidence of skeletal muscle metabolic reserve during whole body exercise in patients with chronic obstructive pulmonary disease. Am. J. Respir. Crit. Care Med. 1999;159:881-5.

25. Pison CM, Chauvin C, Perrault H, Schwebel C, Lafond JL, Boujet C, et al. In vivo hypoxic exposure impairs metabolic adaptations to a 48 hour fast in rats. Eur. Respir. J. 1998;12:658-65.

26. Stainsby WN, Sumners C, Eitzman PD. Effects of catecholamines on lactic acid output during progressive working contractions. J. Appl. Physiol. 1985;59:1809-1814.

27. Hofford JM, Milakofsky L, Vogel WH, Sacher RS, Savage GJ, Pell S. The nutritional status in advanced emphysema associated with chronic bronchitis. A study of amino acid and catecholamine levels. Am. Rev. Respir. Dis. 1990;141:902-908.

28. Keller R, Lohmann FW, Schuren KP. Catecholamines in chronic respiratory insufficiency. Respiration 1971:28:273-279.

29. Mole PA, Baldwin KM, Terjung RL, Holloszy JO. Enzymatic pathways of pyruvate metabolism in skeletal muscle: adaptations to exercise. Am. J. Physiol. 1973;224:50-4.

30. Pisarenko OI, Solomatina ES, Studneva IM, Ivanov VE, Kapelko VI, Smirnov VN. Effect of glutamic acid and aspartic acids on adenine nucleotides, nitrogenous compounds and contractile function during underperfusion of isolated rat heart. J. Molec. Cell. Cardiol. 1983;15:53-60.

31. Pisarenko OI, Studneva IM, Solomatina ES, Kapelko VI. Adenine nucleotides, glutamate and respiratory function of heart mitochondria during acute hypoxia. Biochem. J. 1986;13:5 I-58.

32. Wiesner RJ, Deussen A, Borst M, Schrader J, Grieshaber MK. Glutamate degradation in the ischemic dog heart: contribution to anaerobic energy production. J. Mol. Cell. Cardiol. 1989;21:49-59.

33. Henriksson J. Effect of exercise on amino acid concentrations in skeletal muscle and plasma. J. Exp. Biol. 1991;160:149-165.

34. Voorrips LE, Ravelli AC, Dongelmans PC, Deurenberg P, Van Staveren WA. A physical activity questionnaire for the elderly. Med. Sci. Sports Exerc. 1991;23:974-9.

35. Washburn RA, McAuley E. Katula J, Mihalko SL, Boileau RA. The physical activity scale for the elderly (PASE): evidence for validity. J. Clin. Epidemiol. 1999;52:643-51. 


\section{CHAPTER 10}

\section{Effects of exercise on amino acid metabolism in patients with chronic obstructive pulmonary disease}

Mariëlle P.K.J. Engelen, Emiel F.M. Wouters, Nicolaas E.P. Deutz', Joan D. Does' ${ }^{2}$, and Annemie M.W.J. Schols

Depts. of Pulmonology and 'Surgery, University Hospital Maastricht, Maastricht, and ${ }^{2}$ Asthma Center Hornerheide, Hom, The Netherlands 


\section{ABSTRACT}

Depletion of fat-free mass (FFM) significantly contributes to decreased skeletal muscle weakness and impaired exercise capacity in patients with COPD. Fat-free mass wasting suggests disturbances in intermediary metabolism which is recently confirmed by data showing profound alterations in the skeletal muscle amino acid (AA) status in COPD at rest. To unravel whether there is a role for AAs in the mechanisms for skeletal muscle dysfunction in COPD, basic knowledge on AA metabolism of the muscle during exercise is important. We examined the effects of twenty minutes of exercise on AA metabolism in 14 COPD patients and 8 controls. Arterialized-venous blood and a quadriceps femoris muscle biopsy was obtained before and immediately after exercise. FFM was not significantly different between the groups. In COPD, a significant reduction of most muscle AAs was present post-exercise, whereas several plasma AAs were increased $(p<0.05)$. Consequently, sum AAs was reduced in muscle $(20 \% ; \mathrm{p}<0.01)$ and increased in plasma $(16 \%, \mathrm{p}<0.05)$, suggesting an enhanced AA release from muscle in COPD during exercise. In the COPD group, the increase in plasma alanine and glutamine was even higher post-exercise $(61 \%, \mathrm{p}<0.01$ and $21 \%$, p $<0.01$,resp.), suggesting enhanced nitrogen efflux. This study shows that exercise alters amino acid (intermediary) metabolism in patients COPD and independent of the presence of FFM wasting.

\section{INTRODUCTION}

Depletion of fat-free mass (FFM) commonly occurs in COPD and is an important contributor to skeletal muscle weakness and impaired exercise capacity in these patients (1-3). Depletion of fat-free mass (FFM) suggests that alterations in intermediairy metabolism are present in COPD. Amino acids, the building blocks of proteins, play a pivotal role in intermediairy metabolism. There is increasing evidence available pointing towards disturbed amino acid metabolism in patients with chronic obstructive pulmonary disease (COPD) at rest, as reflected by pronounced alterations in several amino acid levels in skeletal muscle and plasma (4-7).

Skeletal muscle serves as an important reserve system which in conditions of storage and need maintains supplies of amino acids for protein synthesis and metabolism. During short-term exercise and at intensities between 30 and $70 \%$ of maximal work rate, skeletal muscle is shown to participate actively in metabolism of amino acids in healthy subjects (Fig 1). Six amino acids (glutamate (GLU), aspartate, asparagine, and the three branched-chain amino acids) are metabolized in muscle during exercise. As GLU has a central position in all aminotransferase reactions in muscle, the amino group of the six amino acids is interchangeable. In COPD, consistently reduced levels for glutamate (GLU) were found in two different peripheral skeletal muscle groups (quadriceps femoris and tibialis anterior muscle) $(6,7)$, independent of the severity of airflow obstruction. 
GLU has various important function during short-term exercise such as its role in the establishment and maintenance of a high concentration of tricarboxylic acid (TCA) cycle intermediates, thereby preserving high-energy phosphates during exercise. Moreover, GLU is involved in the synthesis of glutamine (GLN) and alanine (ALA), providing a mechanism for the elimination of amino groups from muscle in the form of non-toxic nitrogen carriers. Recently, evidence came available that the depleted resting GLU status in muscle of COPD patients plays a role in the early lactate response during maximal exercise in these patients (8).

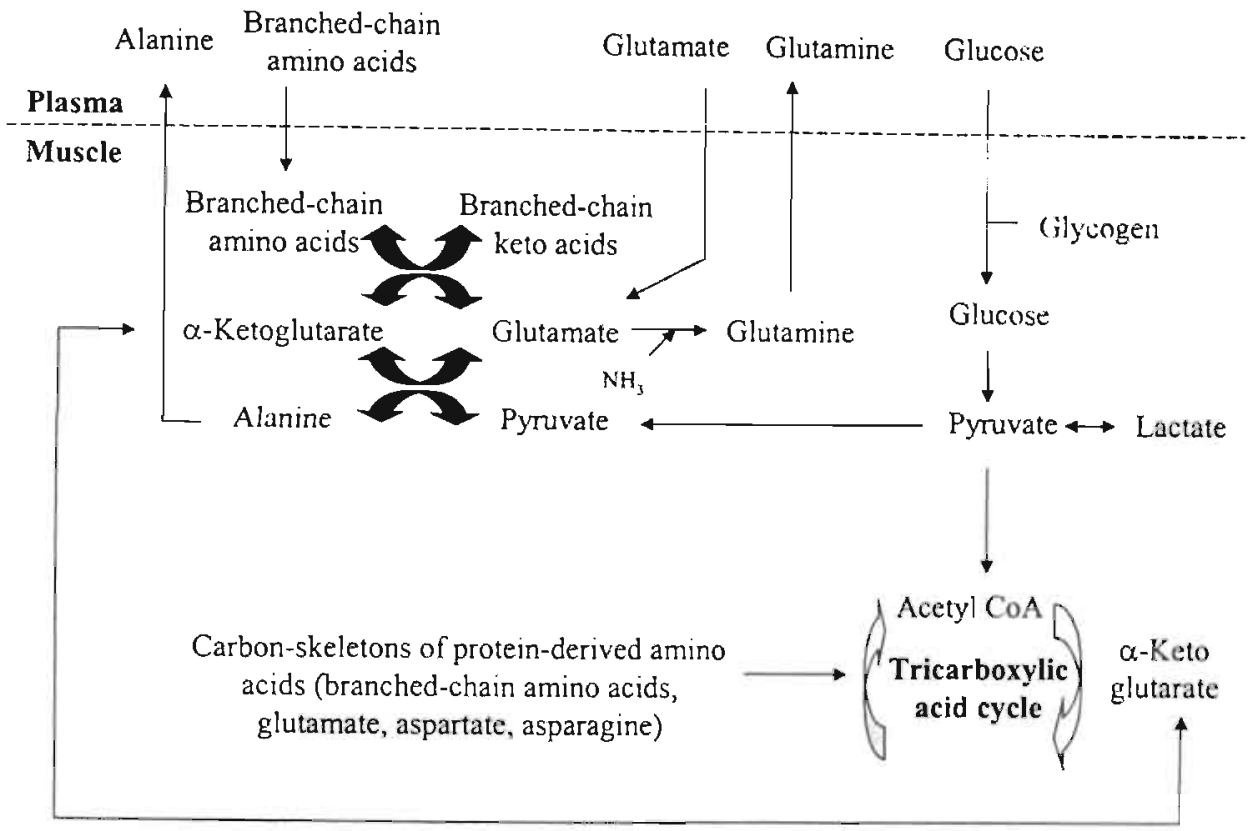

Figure 1. Schematic overview of normal muscle amino acid metabolism during short-term exercise.

Although substantial disturbances have been found in the amino acid status of the skeletal muscle at rest in COPD, it is unknown whether the amino acid response: to exercise is different as compared to healthy age-matched controls. Basic knowledge on amino acid metabolism of the skeletal muscle during exercise may particularly be important to unravel whether there is a potential role for amino acids in the mechanisms for skeletal muscle dysfunction and FFM wasting in patients with COPD. If this is the case, amino acid supplementation may become a potential treatment strategy in these patients.

Therefore, the purpose of the present study was to characterize the effect of submaximal constant work rate exercise on the (excrcise related) amino acid profile in peripheral skeletal muscle and plasma of patients with COPD compared with healthy age-matched controls. 


\section{METHODS}

\section{Study population}

Fourteen patients with severe airflow obstruction $\left(\mathrm{FEV}_{1}: 37 \pm 12 \%\right.$ pred.) and 8 healthy volunteers were studied. All subjects were men. All patients had COPD according to ATS guidelines (9) and chronic airflow limitation, defined as measured forced expiratory volume in one second $\left(\mathrm{FEV}_{1}\right)$ less than $70 \%$ of reference $\mathrm{FEV}_{1}$. Furthermore, the patients had irreversible obstructive airway disease $(<10 \%$ improvement of $F E V_{1}$ predicted baseline after inhalation of $\beta_{2}$-agonist) and were in clinically stable condition and not suffering from respiratory tract infection or exacerbation of their disease at least four weeks prior to the study. Exclusion criteria were malignancy, cardiac failure, distal arteriopathy, recent surgery, severe endocrine, hepatic or renal disorder, and use of anticoagulant medication. Written informed consent was obtained from all subjects and the study was approved by the medical ethical committee of the University Hospital Maastricht.

\section{Study protocol}

After an overnight fast, whole body FFM was measured by bioelectrical impedance analyses (BIA 101, RJL. Systems Detroit, USA). FFM was calculated in the COPD patients by using a patient specific regression equation (10), and in the control group by using a specific regression equation for elderly men as described by Lukaski (11). Subsequently, a catheter was placed in a dorsal vein of the hand, which was placed in a hot box $\left(60^{\circ} \mathrm{C}\right)$ in order to get arterialized venous blood. Arterialized venous blood was taken at 3 time points before exercise: 60 minutes, 30 minutes and immediately before exercise and the average value was taken as the baseline value. Just before the start of exercise, a biopsy of the lateral part of the quadriceps femoris muscle was obtained using the needle biopsy technique (12).

All subjects performed a submaximal constant work rate exercise test on an electronically braked cycle ergometer (Cornival 400, Lode, Groningen, The Netherlands) for 20 minutes. Work rate for each subject was calculated as $20 \%$ of the maximal predicted work rate, according to the equations of Jones (13). In COPD, this work rate would corresponded to a work rate intensity beyond $30 \%$ of maximal predicted which is necessary to trigger the metabolic changes in normals and which was tolerable for these patients for at least twenty minutes (corresponding to a single training session). Transcutaneous oxygen saturation and heart rate was measured throughout the test as described previously (8). Arterialized-venous blood was sampled at twenty minutes of exercise. Immediately after exercise, a second biopsy was taken from the quadriceps femoris muscle. 


\section{Analysis of skeletal muscle and arterialized venous blood}

Arterialized venous blood was put in a heparinized syringe, immediately put on ice and subsequently centrifuged at $4{ }^{\circ} \mathrm{C}$ for 10 minutes to obtain plasma. The muscle tissue was immediately frozen in liquid nitrogen. Analysis of both inuscle and plasma amino acids were performed as previously described (7). Another part of plasma and muscle was deproteinized with trichloric acid for determination of ammonia and the TCA-cycle intermediate succinate (only in muscle).

The concentrations of the amino acids in muscle and plasma, and muscle succinate were analyzed in the same batch run by fully automated High-Performance Liquid Chromatography (HPLC) system (14). The following amino acids were measured: glutamate (GLU), asparagine (ASN), serine (SER) glutamine (GLN), glycinc (GLY), threonine (THR), histidine (HIS), citrulline (CIT), alanine (ALA), taurine (TAU), arginine (ARG), $\alpha$-amino-butyric acid $(\alpha-A B)$, tyrosine (TYR), valine (VAL), methionine (MET), isoleucine (ILE), phenylalanine (PHE), tryptophan (TRP), leucine (LEU), ornithine (ORN), and lysine (LYS). Sum AAs is the sum of all measured amino acids. The ASP and MET peak at the HPLC chromatogram could not accurately be distinguished in muscle because of the complexity of the tissue matrix effects. The ILE peak in muscle was indistinguishable from an indefinable peak at the chromatogram, probably the result of contamination. Ammonia was determined spectrophotometrically on a COBAS Mira S (Roche Diagnostici, Hoffman-La Roche, Basel, Switserland) by standard enzymatic methods (15).

\section{Pulmonary function tests}

All patients and healthy volunteers underwent spirometry with determination of forced expiratory volume in one second $\left(\mathrm{FEV}_{1}\right)$. Diffusing capacity for carbon monoxide $\left(D_{c o}\right)$ was measured using the single-breath method (Masterlab, Jaeger, Wurzburg, Germany). All values obtained were related to a reference value and expressed as percentages of the predicted value (16).

\section{Statistical analysis}

Results are expressed or mean \pm standard error (SE) for muscle and arterializedvenous plasma determinations and mean \pm standard deviation (SD) for other characteristics. Because of the small group sizes, the non-parametric Mann-Whitney U test was used to determine differences in pulmonary function, exercise capacity, muscle and arterial plasma concentrations between the COPD patients and the healthy controls at rest and at the end of exercise. To study the effect of exercise, the difference between pre-exercise and post-exercise amino acid concentrations was measured for each subject. Subsequently, the Wilcoxon two-related samples T-test was used to examine whether the absolute change from baseline level was statistically different from zero. A two-tailed probability value of less than 0.05 was considered statistically significant. 


\section{RESULTS}

Fourteen COPD patients and 8 healthy volunteers participated in the study (table 1). All subjects were men. Age, height, body weight and FFM did not significantly differ between the groups. The COPD group was characterized by severe airflow obstruction, a moderately reduced diffusing capacity, and a lower arterial $\mathrm{pO}_{2}$ than the control subjects. In the control group, all lung function parameters were within the normal range.

Table 1. General characteristics of the study population

Controls

\begin{tabular}{|c|c|c|c|c|c|}
\hline Age & $Y$ & 66 & \pm 5 & 62 & \pm 9 \\
\hline Height & $\mathrm{Cm}$ & 172.4 & \pm 5.9 & 172.5 & \pm 7.4 \\
\hline Weight & $\mathrm{Kg}$ & 76.6 & \pm 11.9 & 76.1 & \pm 12.4 \\
\hline FFM & $\mathrm{Kg}$ & 55.9 & \pm 5.4 & 52.9 & \pm 7.3 \\
\hline $\mathrm{FEV}_{1}$ & \%pred. & 102 & \pm 19 & 37 & $12^{* * *}$ \\
\hline $\mathrm{DL}_{\mathrm{co}}$ & \%pred. & 112 & \pm 20 & 71 & $\pm 25^{* * * *}$ \\
\hline $\mathrm{PaO}_{2}$ & $\mathrm{kPa}$ & 11.3 & \pm 1.0 & 10.0 & $\pm 1.6^{*}$ \\
\hline $\mathrm{PaCO}_{2}$ & $\mathrm{kPa}$ & 5.1 & \pm 0.4 & 5.2 & \pm 0.6 \\
\hline $\mathrm{HCO}_{3}$ & MM & 25.2 & \pm 1.5 & 25.1 & \pm 1.7 \\
\hline $\mathrm{BE}$ & MM & 1.3 & \pm 1.2 & 0.9 & \pm 1.0 \\
\hline $\mathrm{SaO}_{2}$ & $\%$ & 96.4 & \pm 1.0 & 94.6 & \pm 2.2 \\
\hline
\end{tabular}

Values are mean $\pm \mathrm{SD}$; FFM: fat-free mass; $\mathrm{FEV}_{1}$ : forced expiratory volume in one second; $\mathrm{DL}_{\mathrm{co}}$ : diffusing capacity for carbon monoxide; $\mathrm{PaO}_{2}$ : arterial oxygen pressure; $\mathrm{PaCO}_{2}$ : arterial carbon dioxide pressure; $\mathrm{HCO}_{3}$ : bicarbonate; $\mathrm{BE}$ : base excess; $\mathrm{SaO}_{2}$ : arterial oxygen saturation. Significance of difference compared to the controls: ${ }^{*} p<0.05 ;{ }^{* *} p<0.01 ;{ }^{* * *} p<0.001$.

The average used absolute work rate (Table 2) was not different in the two study groups. Transcutaneous $\mathrm{O}_{2}$ saturation at rest and end-exercise was lower in the COPD group than in the controls $(\mathrm{p}<0.01)$. Heart rate was not different between the groups at rest and at end-exercise.

\section{Amino acid status in muscle and plasma}

The pre- and post-exercise amino acid profile as well as the exercise induced change in amino acids is presented in skeletal muscle and plasma in table 3 and 4, respectively. In the patients, lower levels for most muscle amino acids was found after exercise as compared to baseline values, including TAU $(24 \pm 3 \%, \mathrm{p}<0.01)$ (Table 3 ). 
Table 2. Exercise characteristics of the study population

Controls

$\begin{array}{ll}\text { Watt } & 33.5 \pm 2.8 \\ \% & 16.9 \pm 2.4 \\ \% & \\ & 95.6 \pm 0.7 \\ & 95.1 \pm 0.7\end{array}$

$\mathrm{B} / \mathrm{min}$

$73 \pm 6$
$92 \pm 3$

\section{COPD}

$35.1 \pm 6.3$
$44.0 \pm 15.0^{* * *}$
$93.5 \pm 1.3^{* *}$
$92.1 \pm 1.8^{* * *}$

$83 \pm 13$

$117 \pm 21$

End-exercise

Values are mean \pm SD; WR: work rate. Significance of difference compared to the controls: ** $p<0.01 ; * * * 0<0.001$.
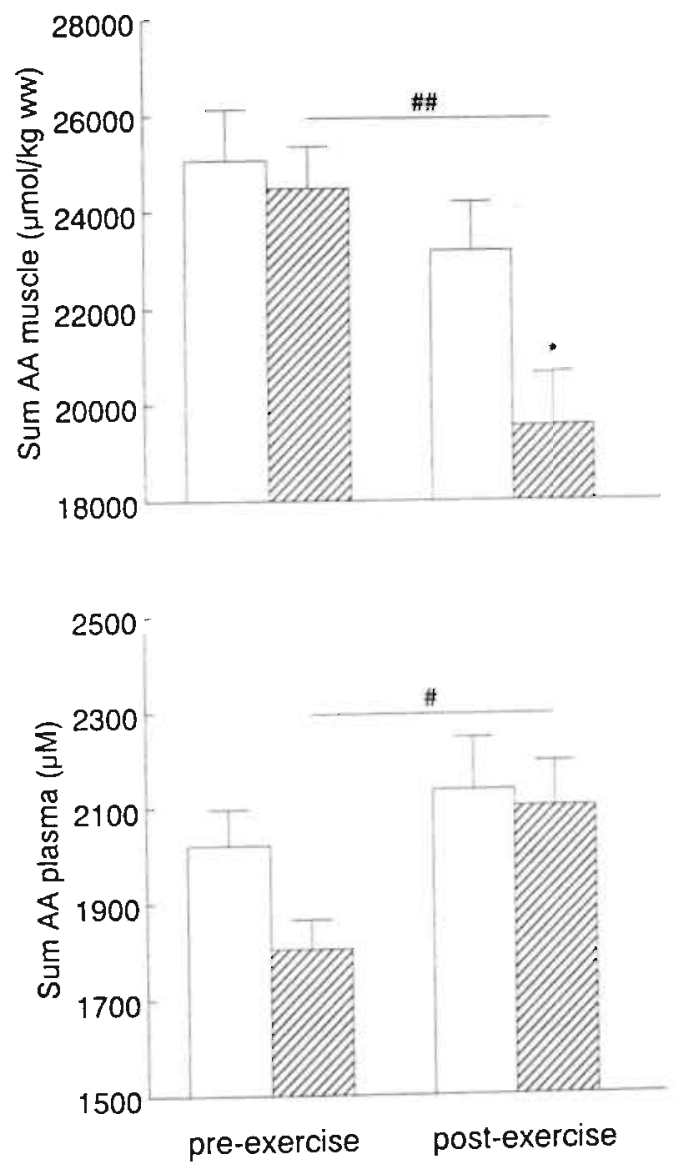

Figure 2. Bar diagram of sum amino acids in muscle (top panel) and plasma (bottom panel) of the healthy volunteers (open bar, $n=8$ ) and COPD group (horizontal-striped bar, $n-14$ ). Mean values \pm 1 SE are shown. Significance of differences between the COPD and control group: * $P<0.05$. Significance of the exercise induced changes in the COPD group: \#: $\mathrm{p}<0.01, \#: \mathrm{p}<0.05$. 
Table 3. Pre-and post-exercise amino acid profile in skeletal muscle, and the exercise induced change

$\left(\mu \mathrm{mol} / \mathrm{kg}_{w *}\right)$

Controls

COPD

Pre-exercise

Post-exercise

Pre-exercise

Post-exercise

$\Delta$

\begin{tabular}{|c|c|c|c|c|c|c|c|c|c|c|c|}
\hline GLU & 2229 & 199 & 1937 & \pm & 113 & -292 & \pm & 200 & 1817 & \pm & $102^{*}$ \\
\hline ASN & 163 & \pm 16 & 174 & \pm & 14 & 11 & \pm & 21 & 168 & \pm & 15 \\
\hline SER & 306 & \pm 28 & 265 & \pm & 36 & -40 & \pm & 40 & 261 & \pm & 13 \\
\hline GLN & 10417 & $\pm \quad 914$ & 9186 & \pm & 563 & -1230 & \pm & 986 & 11787 & \pm & 473 \\
\hline GLY & 756 & \pm 71 & 718 & \pm & 62 & -38 & \pm & 67 & 725 & \pm & 64 \\
\hline THR & 336 & \pm 33 & 327 & \pm & 28 & -9 & \pm & 44 & 302 & \pm & 22 \\
\hline HIS & 296 & \pm 18 & 299 & \pm & 25 & 3 & \pm & 35 & 310 & \pm & 27 \\
\hline CIT & 112 & \pm 21 & 105 & \pm & 10 & -6 & \pm & 19 & 121 & \pm & 31 \\
\hline AlA & 1343 & \pm 76 & 1485 & \pm & 127 & 142 & \pm & 77 & 1316 & \pm & 83 \\
\hline TAU & 7831 & \pm 560 & 7471 & \pm & 523 & -360 & \pm & 586 & 6685 & \pm & 578 \\
\hline $\mathrm{ARG}$ & 321 & \pm 45 & 325 & \pm & 76 & 4 & \pm & 66 & 410 & \pm & 39 \\
\hline$\alpha-A B$ & 36 & \pm 4 & 32 & \pm & 4 & -4 & \pm & 3 & 28 & \pm & 3 \\
\hline TYR & 75 & \pm 6 & 68 & \pm & 3 & -7 & \pm & 6 & 53 & \pm & $2^{* *}$ \\
\hline VAL & 183 & 19 & 194 & \pm & 14 & 11 & \pm & 8 & 154 & \pm & $6^{*}$ \\
\hline PHE & 563 & 69 & 474 & \pm & 78 & -88 & \pm & 64 & 619 & \pm & 47 \\
\hline TRP & 7 & 1 & 7 & \pm & 1 & -1 & \pm & 2 & 8 & \pm & 1 \\
\hline LEU & 214 & 16 & 197 & \pm & 14 & -16 & \pm & 10 & 148 & \pm & $7 * * *$ \\
\hline ORN & 151 & 26 & 131 & \pm & 14 & -20 & \pm & 17 & 186 & \pm & $7^{*}$ \\
\hline LYS & 461 & \pm 56 & 425 & \pm & 39 & -36 & \pm & 46 & 593 & \pm & 49 \\
\hline
\end{tabular}

$\begin{array}{rll}1258 & \pm & 78^{* * *} \\ 133 & \pm 13 \\ 224 & \pm 13 \\ 9085 & \pm 561 \\ 570 & \pm 59 \\ 276 & \pm 29 \\ 235 & \pm 15 \\ 103 & \pm 13 \\ 1239 & \pm 76^{*} \\ 5122 & \pm 496^{* *} \\ 380 & \pm 45 \\ 24 & \pm 2 \\ 63 & \pm 5 \\ 144 & \pm 11^{* *} \\ 399 & \pm 51 \\ 11 & \pm & 1^{*} \\ 130 & \pm 12^{* *} \\ 179 & \pm 12^{*} \\ 469 & \pm 45\end{array}$

$-559 \pm 75=$

$-34 \pm 18$

$-37 \pm 13^{\prime \prime}$

$-2702 \pm 602$ "n

$-154 \pm 46^{\mathrm{m}}$

$-26 \pm 30$

$-74 \pm 28$ "

$-17 \pm 24$

$-77 \pm 91$

$-1563 \pm 213^{n=1}$

$-30 \pm 44$

$-5 \pm 3^{\prime \prime}$

$9 \pm 4$ "

$-11 \pm 11$

$-220 \pm 57^{\text {hit }}$

$3 \pm 1^{\text {"tin }}$

$-17 \pm 13$

$-6 \pm 11$

$-123 \pm 33^{m}$

Values are mean \pm SE; GLU: glutamate; ASN: asparagine; SER: serine; GLN: glutamine; GLY: glycine; THR: threonine; HIS: histidine; CIT: citrulline; ALA: alanine; TAU: taurine; ARG: arginine; $\alpha$-AB: $\alpha$-amino-butyric acid; TYR: tyrosine ; VAL: valine ; PHE: phenylalanine ; TRP: tryptophan; LEU: leucine ; ORN: ornithine ; LYS: lysine. Significantly different compared to controls : ${ }^{* * *} p<0.001 ;{ }^{*} p<0.01 ;{ }^{*} p<0.05$. Significantly different compared to zero: ${ }^{n *} p<0.01 ;{ }^{*} p<0.05$. 


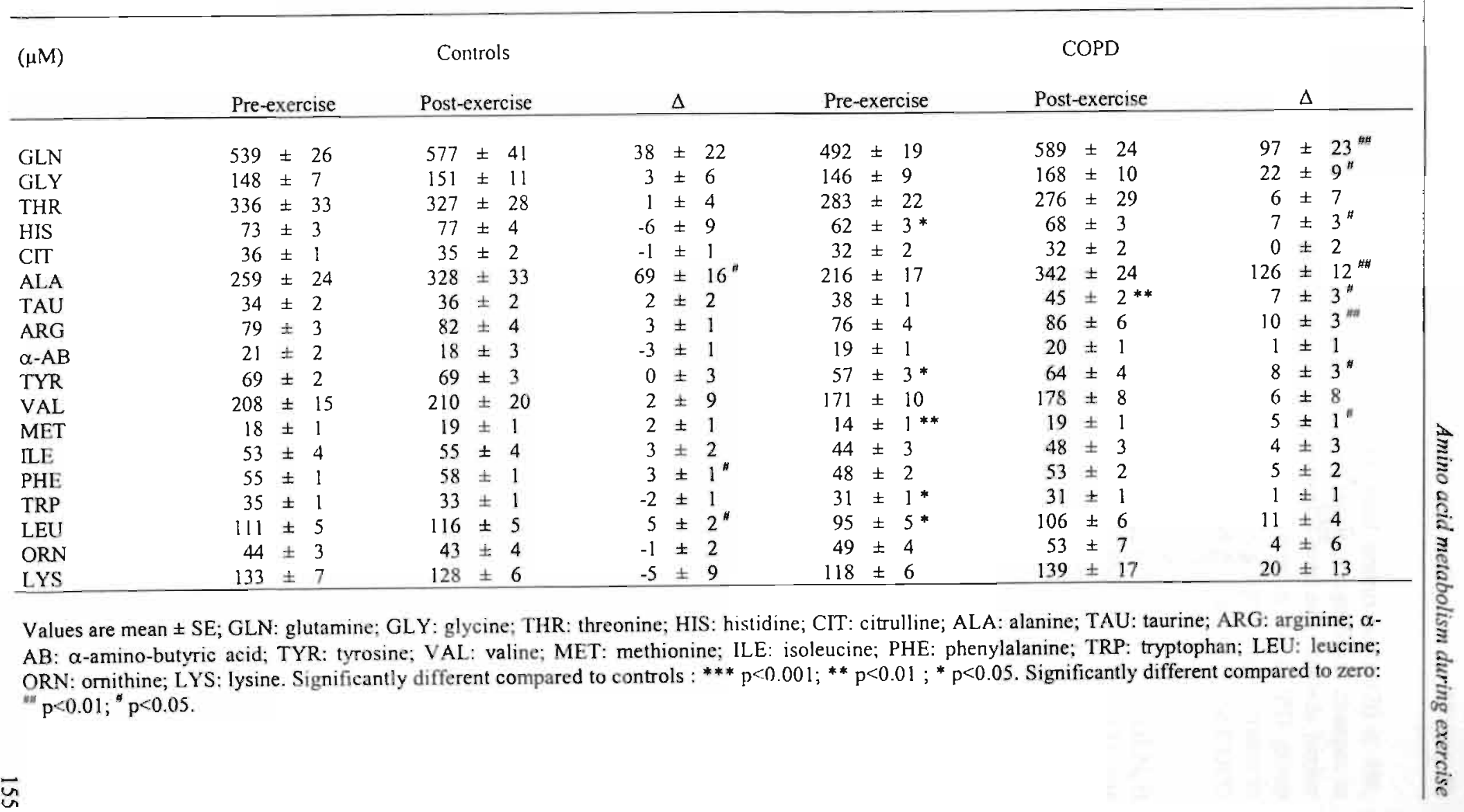



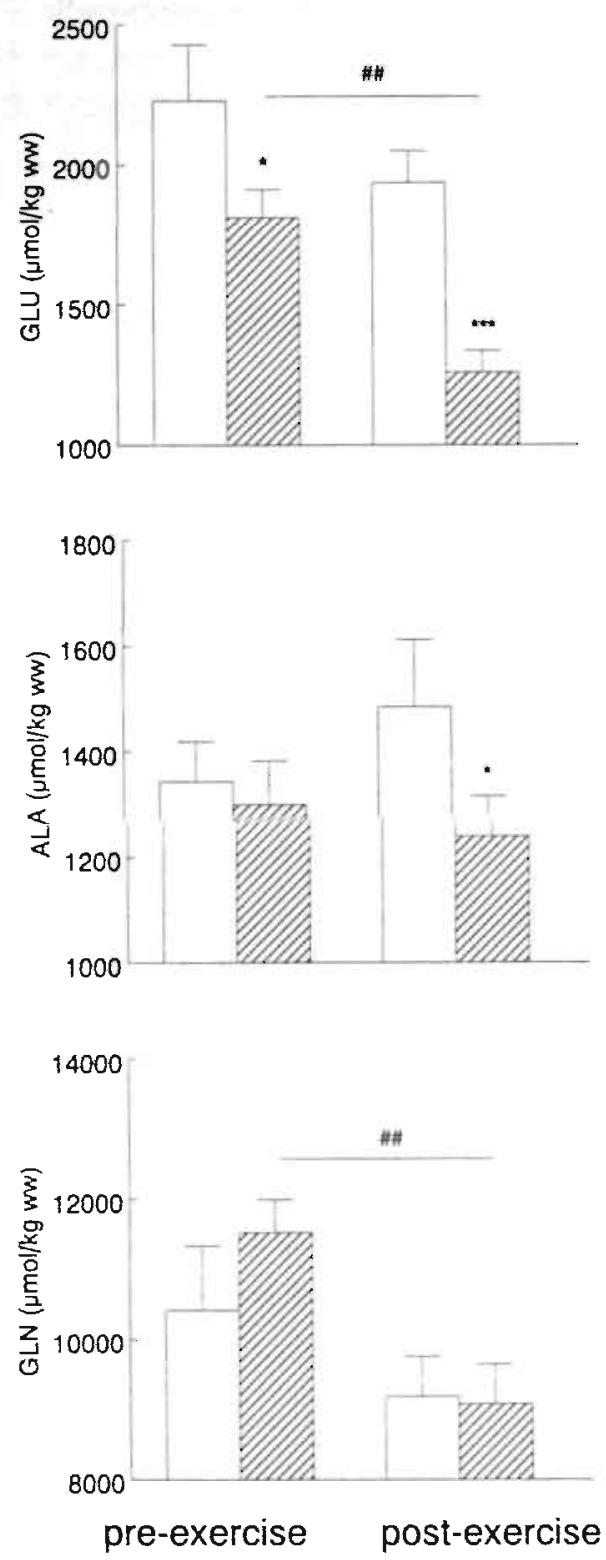

Figure 3. Bar diagram of glutamate (top panel), alanine (middle pancl) and glutamine (bottom pancl) in muscle of the healthy volunteers (open bar, $n=8$ ), and COPD group (horizontalstriped bar, $n=14$ ). Mean values \pm 1 SE are shown. Significance of difference between the COPD and the control group: *** $\mathrm{P}<0.001$; ${ }^{*} \mathrm{P}<0.05$; Significance of the exercise induced changes in the COPD group: $\#$ : $: 0.01$. 
The consequence was a significant decrease in sum total amino acids $(20 \pm 4 \%$, p $<0.01$ ) in COPD (Fig 2, upper panel). Exercise did not result in significant changes in muscle amino acid levels in the control group. There was a tendency towards higher values for several plasma amino acids at the end of exercise in the COPD group including TAU $(19 \pm 5, \mathrm{p}<0.01)$ (Table 4$)$. As a consequence, a significant increase in plasma sum total amino acids $(16 \pm 4 \%, \mathrm{p}<0.05)$ was found in plasma of the COPD group at the end of exercise (Fig 2, bottom panel).

When specifically examining the exercise related amino acids GLU, ALA and GLN, it appeared that in addition to the lower muscle GLU level at rest $(p<0.05)$, GLU was further decreased in the COPD group at the end of exercise $(31 \pm 4 \%, \mathrm{p}<0.01)$ (Fig 3, top panel). Muscle ALA (Fig 3, middle panel) and GLN (Fig 3, lower panel) were not significantly different at rest between the groups. Although at the end of exercise, muscle ALA was lower in the COPD than in the control group $(\mathrm{p}<0.05)$, ALA was not significantly different after exercise as compared to baseline values in the COPD group. Moreover, an exercise induced decrease in muscle GLN $(23 \pm 5 \%$, $\mathrm{p}<0.01$ ) was found in the COPD patients.

Plasma ALA (Table 4) was increased at the end of exercise in the control group $(27 \pm 6 \%, \mathrm{p}<0.05)$, but to a significantly higher extent in the COPD group ( $58 \pm 6 \%$, $\mathrm{p}<0.01)$. GLN in plasma was significantly increased after exercise in the COPD patients $(21 \pm 5 \% ; \mathrm{p}<0.01)$ but not in the controls. The pre- and post-exercise levels and absolute change of the remaining plasma and muscle amino acid levels are presented in table 3 and 4 , respectively.

No significant change in $\mathrm{NH}_{3}$ was found after exercise in muscle and plasma in the COPD patients or controls (mean change muscle: COPD: $73 \pm 65 \mu \mathrm{mol} / \mathrm{kg}_{w w}$; controls: $-38 \pm 79 \mu \mathrm{mol} / \mathrm{kg}_{\mathrm{u} w}$; mean change plasma COPD: $6 \pm 1 \mu \mathrm{M}$; controls: $7 \pm 1$ $\mu \mathrm{M})$. The TCA intermediate succinate at the end of exercise was not significantly changed in the controls as well as in the COPD group (mean change muscle: controls: $294 \pm 239 \mu \mathrm{mol} / \mathrm{kg}_{\mathrm{ww}}$; COPD: $30 \pm 151 \mu \mathrm{mol} / \mathrm{kg}_{\mathrm{ww}}$ ).

\section{DISCUSSION}

The present study is the first one examining amino acid metabolism in patients with COPD during exercise. In this patient population, a different response in amino acid status was found in skeletal muscle and plasma during twenty minutes of submaximal constant cycle exercise as compared with healthy age-matched controls.

The present study confirms that the reduced exercise capacity in COPD is associated with metabolic changes. During the last couple of years, evidence revealed that pronounced disturbances in muscle metabolism during exercise is present. Skeletal muscle energy metabolism is impaired in a substantial amount of COPD patients at rest and the situation becomes even worse during exercise. A greater increase in the inorganic phosphate-phosphocreatine ratio ( $\mathrm{Pi}-\mathrm{CrP}$ ratio) and a faster drop in $\mathrm{pH}$ were found in calf 
muscle and forearm muscle of COPD patients performing exercise than in healthy persons (17-20). Moreover, several studies revealed increased lactate levels early in exercise and at very low work rates in a substantial portion of patients with COPD $(8,21$, 22 ), which confirms enhanced anaerobic energy metabolism during exercise in these patients.

In the present study, a significant reduction was found in the levels of several amino acids in skeletal muscle of the studied COPD group at the end of exercise whereas several plasma amino acids were increased. This suggests an elevated release of amino acids from muscle during exercise in COPD. It is possible that this increased release of amino acids is related to a change in osmoregulation in muscle as taurine, an amino acid with the highest concentration in muscle and known as an effective osmolyte, was significantly reduced in muscle and increased in plasma after exercise. Although the relative work intensity was higher in the COPD group than in the controls ( $44 \%$ vs. $17 \%$, resp.), it is unlikely that this difference may explain the (unique) reduction in muscle amino acid status after exercise in the patient group. Several studies have been published examining muscle amino acid status in healthy subjects cycling at work intensities between 30 and $70 \%$ of maximal work rate. To our knowledge, none of these studies have observed this specific amino acid response to exercise.

In normal subjects during short-term exercise (10-20 minutes) at intensities between 30 and $70 \%$ of maximal work rate, muscle GLU decreases in concentration despite an increased GLU uptake from plasma, whereas ALA level in muscle and plasma increases (23-25). Muscle GLN increases after short-term exercise or remains constant like most of the other amino acids.

In addition to the reduced bascline values, muscle GLU was further decreased postexercise in the studied patients with COPD. The exercise induced decrease in GLU was even larger than the average decrease in sum amino acids in muscle of these patients and may theoretically be explained by two mechanisms: a reduced GLU uptake and/or an accelerated GLU breakdown. Conditions of $\mathrm{O}_{2}$ deprivation, often present in COPD, are known to decelerate GLU uptake as the energy-dependency of GLU carrier systems make them more inefficient. Moreover, tissue hypoxia is known to accelerate GLU degradation in muscle and mitochondria $(26,27)$. Transcutaneous $\mathrm{O}_{2}$ saturation was reduced in the COPD group post-exercise but was still above $90 \%$, indicating that it is speculative whether (regional) tissue hypoxia is playing a role in the explanation of the reduced muscle GLU after exercise in COPD. An enhanced anaerobic ATP production was observed particularly in the COPD group, as reflected by the higher venous lactate increase post-exercise ( $\triangle$ lactate: COPD: $1.5 \pm 0.3 \mathrm{mM}$; $p<0.01$ vs. controls: $0.5 \pm 0.2 \mathrm{mM} ; \mathrm{p}<0.05)$. GLU may contribute to this increased anaerobic ATP production via substrate phosphorylation to succinate (via the malateaspartate cycle) (28). 
In normal muscle, the main GLU breakdown pathway in the first minutes of exercise is the ALA aminotransferase reaction. In this reaction, GLU donates the amino group to pyruvate to form ALA and regenerate the TCA intermediate $\alpha$-ketoglutarate (Fig 1). In contrast to the other amino acids in muscle, ALA was not significantly reduced in the COPD group after exercise. Moreover, the increase in plasma ALA post-exercise in the COPD group was much higher than the average increase in plasma amino acid level, suggesting an additional ALA (de novo) production and release from muscle in COPD. Besides increased transamination to ALA, GLU may fall because of an increased GLN synthesis. A comparable increase was also observed for plasma GLN post-exercise. It is well possible that the enhanced ALA and GLN release from muscle during exercise provides an additional mechanism for the elimination of amino groups from muscle in the form of non-toxic nitrogen camiers. Moreover, it suggests that ALA and GLN are required in other processes such as gluconeogenesis.

Under normal conditions, the ALA aminotransferase reaction functions to establish and maintain high concentrations of TCA-cycle intermediates (including succinate) $(29,30)$ in muscle particularly during the first minutes of exercise, which help maximize oxidative use of fuels. In the present study, no increase was found in muscle succinate in the COPD group after exercise, suggesting that net synthesis of the TCA intermediates is not present in these patients during exercise despite an increased ALA aminotransferase reaction. Furthermore, this is remarkable when considering the relative higher work intensity in the COPD group than in the controls.

It is important to consider that the disturbed amino acid response during exercise was present in COPD patients who were characterized by relatively preserved baseline muscle amino acid status and "normal" values for FFM. This indicates that exercise is an important metabolic stressor even in COPD patients without evidence of FFM wasting. Protein depletion has been shown to impair skcletal muscle performance as reflected by reduced maximum handgrip and respiratory musele strength, and increased fatigability of in vivo electrically stimulated adductor pollicis muscle (31). This suggests that avoiding protein depletion seems to be important for achieving optimal physical performance in patients with COPD.

Recently, it has been observed that oral amino acid intake stimulates the transport of amino acids into muscle, and that there is a direct link between amino acid transport and muscle protein synthesis (32). Earlier studies in normal subjects showed that protein supplements taken immediately after exercise had a greater effect on muscle protein synthesis than when ingested before exercise or some time after exercise (33), which may be due to the fact that muscle is more efficiently utilizing amino acids after exercise. However, the optimal amount and amino acid composition of the supplement as well as the optimal timing of ingestion in relation to exercise has still to be determined.

More studies are needed to unravel whether there is a potential role for altered amino acid metabolism during exercise in the mechanisms for skeletal muscle dysfunction 
and muscle wasting in patients with COPD. If this is the case, amino acid supplementation may become a potential tool in improving functional performance and net muscle protein balance of these patients when incorporated in the rehabilitation and exercise training programs.

In conclusion, the present study illustrates that exercise alters amino acid (intermediary) metabolism in patients with COPD, independent of the presence of FFM wasting.

\section{References}

1. Bernard S, LeBlanc P, Whittom F, Carrier G, Jobin J, Belleau R, et al. Peripheral muscle weakness in patients with chronic obstructive pulmonary disease. Am. J. Respir. Crit. Care Med. 1998; 158:629-634.

2. Engelen MPKJ, Schols AMWJ, Does JD, Wouters EFM. Skeletal muscle weakness is associated with wasting of extremity fat-free mass loss but not with airflow obstruction in patients with chronic obstructive pulmonary disease. Am. J. Clin. Nutr. 2000;71:733-738.

3. Baarends EM, Schols AMWJ, Mostert R, Wouters EFM. Peak exercise response in relation to tissue depletion in patients with chronic obstructive pulmonary disease. Eur. Respir. J. 1997; 10:2807-2813.

4. Hofford JM, Milakofsky L, Vogel WH, Sacher RS, Savage GJ, Pell S. The nutritional status in advanced emphysema associated with chronic bronchitis. A study of amino acid and catecholamine levels. Am. Rev. Respir. Dis. 1990;141:902-908.

5. Schols AMWJ, Deutz NEP, Mostert R, Wouters EFM. Plasma amino acid levels in patients with chronic obstructive pulmonary discase. Monaidi Arch. Chest Med. 1993;48:546-548.

6. Pouw EM, Schols AMWJ, Deutz NEP. Wouters EFM. Plasma and muscle amino-acid levels in relation to resting energy expenditure and inflammation in stable COPD. Am. J. Respir. Crit. Care Med. 1998;158:797-801.

7. Engelen MPKJ, Schols AMWJ, Does JD, Deutz NEP, Wouters EFM. Altered glutamate metabolism is associated with reduced muscle glutathione levels in patients with emphysema. Am. J. Respir. Crit. Care Med. 2000;161:98-103.

8. Engelen MPKJ, Schols AMWJ, Does ID, Gosker HR, Deutz NEP, Wouters EFM. Exercise induced lactate increase in relation to muscle substrates in patients with COPD. Am. J. Respir. Crit. Care Med. 2000; In press.

9. American Thoracic Society. Standards for the diagnosis and care of patients with chronic obstructive pulmonary disease (COPD) and asthma. Am. Rev. Respir. Dis. 1995; 152:s77-s120.

10. Schols AMWJ, Wouters EF, Soeters PB, Westerterp KR. Body composition by bioelectricalimpedance analysis compared with deuterium dilution and skinfold anthropometry in patients with chronic obstructive pulmonary disease. Am. J. Clin. Nutr. 1991;53:421-4.

11. Lukaski HC, Bolonchuk WW, Hall CB, Siders WA. Validation of tetrapolar bioelectrical impedance method to assess human body composition. J. Appl. Physiol. 1986;60:1327-32.

12. Bergstrom L. Muscle electrolytes in man. Determination by neutron activation analysis on needle biopsy specimens. A study on normal subjects, kidney patients, and patients with chronic diarrhea. Scand. J. Clin. Lab. Invest. 1962;68:7-110.

13. Jones NL. Clinical exercise testing. 3rd ed. ed. Philadelphia: Saunders; 1988.

14. Van Eijk HMH, Rooyakkers DR, Deutz NEP. Rapid routine determination of amino acids in plasma by high-performance liquid chromatography with a 2-3 um Sperisorb ODS 2 column. J. Chromat. 1993;620:143-148.

15. Neeley Wl: Phillipson J. Automated enzymatic method for determining ammonia in plasma, with 14- day reagent stability. Clin. Chem. 1988;34:1868-9.

16. Quanjer P, Tammeling GJ, Cotes JE, Pedersen OF, Peslin R, Yemault JC. Standardized lung function testing. Eur. Respir. J. 1993;6:5-40. 
17. Payen JF, Wuyam B, Levy P, Reutenauer H, Stieglitz P, Paramelle B, et al. Muscular metabolism during oxygen supplementation in patients with chronic hypoxemia. Am. Rev. Respir. Dis. 1993; 147:592-598.

18. Thompson CH, Davies RJO, Kemp GJ, Taylor DJ, Radda GK, Rajagopalan B. Skeletal muscle metabolism during exercise and recovery in patients with respiratory failure. Thorax 1993;48:486490.

19. Kutsuzawa T, Shioya S, Kurita D, Haida M, Ohta Y, Yamabayashi H. 31P-NMR study of skeletal muscle metabolism in patients with chronic respiratory impairment. Am. Rev. Respir. Dis. 1992;146:1019-1024.

20. Tada H, Kato H, Misawa $T$, Sasaki S, Hayashi S, Takahashi H, et al. 31P-Nuclear magnetic resonance evidence of abnormal skeletal muscle metabolism in patients with chronic lung disease and congestive heart failure. Eur. Respir. J. 1992;5:163-169.

21. Casaburi R, Patessio A, loli F, Zanaboni S, Donner CF, Wasserman K. Reductions in exercise lactic acidosis and ventilation as a result of exercise training in patients with obstructive lung disease. Am. Rev. Respir. Dis. 1991;143:9-18.

22. Sue DY, Wasserman K, Moricca RB, Casaburi R. Metabolic acidosis during exercise in patients with chronic obstructive pulmonary disease. Chest 1988;94:931-938.

23. Wagenmakers AJ. Protein and amino acid metabolism in human muscle. Adv. Exp. Med. Biol. 1998;441:307-19.

24. Katz A, Broberg S, Sahlin K, Wahren J. Muscle ammonia and amino acid metabolism during dynamic exercise in man. Clin. Physiol. 1986;6:365-379.

25. Henriksson J. Effect of exercise on amino acid concentrations in skeletal muscle and plasma. J. Exp. Biol. 1991;160:149-165.

26. Pisarenko OI, Studneva IM, Solomatina ES, Kapelko VI. Adenine nucleotides, glutamate and respiratory function of heart mitochondria during acute hypoxia. Biochem. J. 1986;13:51-58.

27. Wiesner RJ, Deussen A, Borst M, Schrader J, Grieshaber MK. Glutamate degradation in the ischemic dog heart: contribution to anaerobic energy production. J. Mol. Cell. Cardiol. 1989:21:49-59.

28. Pisarenko OI, Solomatina ES, Ivanov VE, Studneva IM, Kapelko VI, Smimov VN. On the mechanisms of enhanced ATP formation in hypoxic myocardium caused by glutamic acid. Basic Res. Cardiol. 1985;80:126-134.

29. Gibala MJ, Tamopolsky MA, Graham TE. Tricarboxylic acid cycle intermediates in human muscle at rest and during prolonged cycling. Am. J. Physiol. 1997;272:E239-E244.

30. Sahlin K, Katz A, Broberg S. Tricarboxylic acid cycle intermediates in human muscle during prolonged exercise. Am. J. Physiol. 1990;259:C834-C841.

31. Hill GL. Jonathan E. Rhoads Lecture. Body composition research: implications for the practice of clinical nutrition. J. Parenter. Enteral Nutr. 1992;16:197-218.

32. Biolo G, Fleming RY, Maggi SP, Wolfe RR. Transmembrane transport and intracellular kineties of amino acids in human skeletal muscle. Am. J. Physiol. 1995;268:E75-84.

33. Biolo G, Tipton KD, Klein S, Wolfe RR. An abundant supply of amino acids enhances the metabolic effect of exercise on muscle protein. Am. J. Physiol. 1997;273:E122-E129. 



\section{CHAPTER 11}

General discussion 


\section{INTRODUCTION}

The studies described in this thesis were designed to provide a metabolic and functional perspective of muscle wasting in patients with COPD. The specific aims were to characterize muscle wasting in COPD and to evaluate its effect on peripheral skeletal muscle function (part 1). In addition, underlying metabolic changes with respect to alterations in protein metabolism (part 2) and changes in muscle and plasma amino acid status (part 3) were examined at rest and during exercise. COPD patients were investigated as a group and stratified into subgroups according to the presence or absence of radiologically diagnosed emphysema. The current literature on the subject, as described in part 1 , reveals several inconsistencies and no or only very limited data are available on amino acid and protein metabolism in COPD. In this chapter, the results of the studies presented in this thesis will be considered in the context of available literature. The new data regarding the underlying metabolic changes at rest and during exercise, as well as future lines of investigation, will be discussed.

\section{PART 1}

\section{Muscle wasting in relation to skeletal muscle function}

Many patients with COPD are limited in their daily functioning. It has become clear that, besides the primary lung disorder, secondary factors contribute to limited physical functioning in the daily life of these patients such as impaired exercise capacity and muscle dysfunction. Muscle dysfunction is not limited to the peripheral skeletal muscles, but also affects the diaphragm and other respiratory muscles. Muscle mass is an important determinant of muscle function and can be assessed indirectly in clinically stable COPD patients by measurement of fat-free mass.

In chapter 2, dual-energy X-ray absorptiometry (DXA) appeared to be an informative and alternative method to deuterium dilution for assessing body composition, the amount of fat-free mass and fat mass, in COPD. Moreover, DXA, being applicable in clinical practice, appeared to be of value in identifying the relative high percentage of COPD patients with bone mineral loss. Multiple factors may contribute to this high prevalence of bone mineral loss in COPD such as decreased mechanical loading due to a sedentary lifestyle, and duration and dose of specific medication ie. inhaled or oral glucocorticosteroids. However, it was not possible to conclude which factor was mainly responsible for this high prevalence since no association was found with lung function or body composition. No information was available about the history of duration and dose of corticosteroid intake. Therefore, the exact cause of this high prevalence of bone mineral loss in COPD is still open for discussion.

Striking differences in body composition were found between COPD patients and healthy volunteers despite comparable values for body mass index (chapter 3 ). 
Moreover, different patterns of chronic tissue wasting could be distinguished among COPD patients with and without the presence of macroscopic emphysema. In the late $19^{\text {th }}$ century, Fowler and Godlee described the association between weight loss and emphysema. A few decades ago, the classical description of the pink puffer (emphysematous type) and the blue bloater (bronchitic type) was introduced (1). This classification is still being used today but is limited by the fact that only anthropometric measures were used to identify the thin 'pink puffer' as opposed to the more obese 'blue bloater'. Nowadays, advanced body composition techniques can be used to supplement the anthropometric measures. As a result, we were able to provide more insight into the different patterns of chronic tissue wasting between the COPD subtypes. Many of the COPD patients with emphysema manifested weight loss and were underweight (chapter 3). However, depletion of fat-free mass, even with preservation of fat mass, also occurs in COPD patients without emphysema.

In order to provide a rationale for specific treatment, insight is needed into the underlying regulatory mechanisms and contributory factors of weight loss and tissue wasting in COPD. Weight loss, and particularly loss of fat mass, occurs if energy expenditure exceeds dietary intake. After adjustment for the metabolically active fatfree mass, resting energy expenditure was found to be elevated in COPD (2). Factors, often considered to contribute to these elevated levels are an increased work of breathing, medication, inflammation and changes in hormone levels. Perhaps surprisingly, resting energy expenditure was lower in the fat losing emphysema group as compared to those without emphysema who had relative preservation of their fat mass (chapter 7). However, resting energy expenditure does not always reflect the total amount of energy expended during the day. Recently, total daily energy expenditure was found to be elevated in patients with COPD and this was mainly the consequence of an increase in the non-resting component (3). Moreover, this activity-related energy expenditure was particularly elevated in those patients with emphysema. Part of the increased oxygen consumption during exercise could be due to inefficient ventilation as a result of increased ventilatory demand.

Especially under conditions of dynamic hyperinflation, the oxygen cost of breathing of COPD patients will increase due to more air trapping (4). Although no measure of dynamic hyperinflation was made in chapter 3 , the marked static hyperinflation in the emphysema patients indicates that these patients are likely to have dynamic hyperinflation during activity. Besides this mechanical inefficiency during exercise, metabolic inefficiency of the pcripheral skeletal muscle may also be a factor contributing to the increased activity related energy expenditure in COPD. Impaired oxidative phosphorylation was found during exercise in patients with COPD $(5,6)$. Moreover, exercise was accompanied by increased anaerobic metabolism, which is less efficient than aerobic metabolism (5). Evidence for functional disturbances in skeletal muscle energy metabolism have been found particularly in COPD patients with a low diffusing capacity (emphysematous type). Elevated inosine monophospate levels in resting tibialis anterior muscle were found, reflecting an imbalance between resynthesis and utilization of ATP (7). Thus, due to their augmented work of 
breathing and inefficient muscle contraction during exercise (mechanical and metabolic inefficiency), emphysema patients increase their total daily energy expenditure. When this increased energy requirement is not balanced by dietary energy intake, loss of weight and fat mass occurs.

Reduced fat-free mass was present in both COPD subtypes, suggesting that, besides energy imbalance, additional factors have to be considered. Evidence exists that in COPD alterations are present in several anabolic and catabolic mediators which regulate muscle mass. COPD is often accompanied by a systemic inflammatory response manifested by elevated levels for acute phase proteins and cytokines in plasma (8). Recently, systemic inflammation has been suggested to affect appetite and dietary intake, mediated by leptin, a hormone with appetiteregulating properties (9). A significant relationship has been found between systemic inflammation in COPD and increased values for resting energy expenditure (8), and changes in plasma amino acid metabolism, as a global marker of altered protein metabolism (10). Evidence for an association between inflammation and muscle protein catabolism has been demonstrated in vitro. Low concentrations of tumor necrosis factor alpha were found to induce skeletal muscle protein loss (11). Further studies investigating this relationship in human muscle biopsies are necessary.

In this thesis, preserved fat mass levels despite reduced values for fat-free mass were found in the COPD patients without emphysema. The observation of relatively elevated fat mass is not only confined to this COPD subgroup since comparable data were recently found in emphysema patients with a moderate degree of airflow obstruction (12). Besides a role for physical inactivity, this latter study provided evidence that disturbances in intermediary metabolism may also contribute to the relatively increased fat levels in COPD. Thus, reduced levels of lipolysis were noted after $\beta$-adrenergic stimulation (12). More studies are necessary to understand further the mechanisms behind the selective preservation of fat mass in COPD.

The observed differences in wasting patterns among the COPD subtypes need to be considered when studying the functional consequences of muscle wasting. Respiratory and peripheral skeletal muscle weakness are commonly present in COPD and appear to be important determinants of the symptoms of dyspnea and exercise intolerance $(13,14)$. To study the precise contribution of FFM loss on muscle function, quantification of the physically active muscle mass during activities of daily living is important. Earlier studies revealed that the cross-sectional areas of calf muscle (5) and of thigh muscle (15) were significantly smaller in patients with severe COPD than healthy controls. However, a drawback of this nuclear magnetic resonance imaging technique is that it is not easily applicable in clinical practice.

Therefore, we measured FFM of the extremities by dual-energy X-ray absorptiometry and related this to peripheral skeletal function (chapter 4). Both measures were lower in COPD patients than in healthy controls. Extremity FFM was not different between COPD patients with and without emphysema. However, significantly lower values were found for whole body FFM in those with emphysema, suggesting that whole body FFM is not a good reflection of extremity 
FFM in COPD. This dissociation needs to be considered when peripheral skeletal muscle function is evaluated in these patients. Skeletal muscle function expressed per kilogram of extremity FFM was not significantly different among the COPD subtype groups and healthy controls. Moreover, skeletal muscle weakness was not associated with the severity of airflow obstruction, which is in contrast to a previous study by Bernard et al (15). These findings suggest that, independent of the presence of emphysema and the severity of airflow obstruction, peripheral skeletal muscle weakness in COPD is determined by the loss of skeletal muscle mass. It also suggests that the contractile properties of the peripheral skeletal muscles of COPD patients are preserved, despite the fact that intrinsic changes in muscle metabolism are likely to be present.

Besides effects on peripheral skeletal muscle strength, several studies have shown that FFM is a significant determinant of exercise capacity in COPD as lower values were found for peak workload in the COPD patients who had FFM depletion than those with normal FFM values (16). Moreover, the FFM depleted patients had higher levels for ratio lactate increase to maximally obtained workload, indicating that muscle wasting increases glycolytic metabolism in the skeletal muscle of these patients. This is in line with previous observations in anorexia nervosa. Clearly more research has to be performed to determine the exact effect of FFM wasting on intrinsic alterations in skeletal muscle e.g. enzyme activities, fiber type distribution. However, it seems that tissue depletion increases even further the disease-related oxidative to glycolytic shift in muscle metabolism in COPD. Therefore, it can be concluded that wasting of muscle mass has a direct negative effect on skeletal muscle function and exercise capacity in COPD. In addition, muscle wasting indirectly contributes to the impaired exercise capacity and altered metabolic response in these patients by inducing intrinsic alterations in muscle oxidative metabolism.

\section{PART 2}

\section{Protein metabolism}

Protein turnover refers to a dynamic flux in protein metabolism whereby proteins are being degraded and synthesized simultaneously. Protein turnover rates may differ considerably depending on function and specific need. Muscle wasting is the consequence of a negative protein balance, indicating an imbalance between protein synthesis and breakdown. In critical acute illness, net protein catabolism can be markedly stimulated, resulting in a rapid decrease in FFM.

In order to study protein synthesis and breakdown in ambulant patients with COPD, mechanistic studies are needed such as the use of amino acid labeled tracers. It is unknown to what extent chronic and acute unstable conditions in COPD, which are associated with FFM wasting e.g. acute exacerbations of COPD symptoms and periods of progressive weight loss alter protein synthesis and breakdown in these 
patients. However, one of the difficulties when measuring whole body protein turnover in these unstable conditions is their association with alterations in hormone levels e.g. insulin, glucagon, medication e.g. use of fluorinated glucocorticosteroids, presence of acute inflammation, and/or changes in physical activity level. All these factors among others may influence protein metabolism.

To investigate the effect of the underlying lung disease on whole body protein metabolism more specifically, we studied a homogeneous group of severe COPD patients who were clinically and weight stable, and did not have any signs of FFM depletion. It is of value to study these patients during daily life situations e.g. fasting and physical exercise as these are known to alter whole body protein synthesis and breakdown even in people who are not in negative protein balance. In chapter 5, we observed substantial changes in whole body protein metabolism after overnight fasting in a group of clinically stable COPD patients as reflected by significantly elevated levels of whole body protein synthesis and breakdown. This indicates that overnight fasting in COPD is associated with a disease-related increase in whole body protein turnover, without inducing net protein catabolism. Also previous studies in other chronic wasting diseases, like stable chronic liver failure and human immunodeficiency virus, observed elevated levels of whole body protein tumover $(17,18)$. The elevated protein turnover could be mostly explained by the presence of an enhanced systemic inflammatory response as indicated by an increased production of acute phase proteins. Previously, we have also observed an inverse relationship between the acute phase protein level and the total sum of plasma amino acid levels in patients with COPD (10), confirming a relationship between inflammation and alterations in protein metabolism. Whether the presence of systemic inflammation is the only mechanism responsible for the increased whole body protein tumover in COPD patients is unclear at present.

Besides overnight fasting, physical exercise is an everyday condition, which, in particular at high intensities, is known to change protein turnover considerably (19, 20). Low intensity constant exercise was observed to induce considerable alterations in whole body protein turnover in the COPD group (chapter 6). Specifically in those patients with emphysema, a suppressed response in whole body protein turnover was present not only during exercise but for at least one hour post-exercise. Nevertheless, neither low intensity exercise nor overnight fasting induced net protein catabolism in these clinically and weight stable COPD patients, suggesting that whole body protein balance was preserved. Furthermore, this suggests that no extra daily dietary protein sources are needed in this patient population as long as they remain weight stable.

It is unclear whether the whole body protein turnover data obtained in these COPD pationts accurately reflect what is going on in the skeletal muscle compartment. Based on previous studies, it is likely that these clinically and weight stable COPD patients with no evidence of an acute infection, are still experiencing low-grade inflammation. Therefore, it is possible that a combination of the enhanced net splanchnic (acute phase) protein synthesis, associated with low-grade inflammation, and (the directly or indirectly related) increased net skeletal muscle protein 
breakdown results in increased whole body protein turnover without increased net whole body protein breakdown. This is of considerable importance since skeletal muscle mass generally makes up about $40-45 \%$ of body weight and contributes approximately $25 \%$ to whole body protein turnover in normal man at rest (21). Whether the latter percentage is the same in pathophysiological conditions such as COPD and changes differently under various circumstances (like overnight fasting and physical exercise) is not clear. Despite the fact that clinical studies in unstable conditions in COPD have several difficulties, it is important to elucidate the extent and directions of the changes in protein synthesis and breakdown on a whole body level as well as in skeletal muscle under these conditions. When this information is available, it may be possible to determine whether and to what extent daily dietary protein requirements should be adjusted to diminish the negative impact of chronic and acute unstable conditions on short term muscle mass loss, as well as on longterm morbidity and mortality.

\section{PART 3}

\section{Amino acid status in peripheral skeletal muscle and plasma at rest and during exercise}

\section{Altered muscle amino acid profile in COPD}

Amino acids, the building blocks of proteins, are derived from an active metabolic pool. $40 \%$ of the pool originates from endogenous protein breakdown with the remainder being derived from dietary protein sources. Therefore, skeletal muscle serves as an important reserve system, which, in conditions of need, maintains supplies of amino acids for protein synthesis and metabolism.

In the past, extensive studies have been carried out in acute catabolic diseases and other conditions associated with muscle wasting resulting from metabolic stress e.g. sepsis, injury, surgical trauma. Similar patterns of amino acid changes in skeletal muscle have been found in several conditions related to metabolic stress namely a rise in the branched-chain amino acids and aromatic amino acids and a fall in glutamine (22-24). These conditions are in general characterized by an inability to suppress amino acid release from muscle despite nutritional supplementation. Most of the nitrogen lost during acute stress derives from skeletal muscle sources and, in particular, contractile proteins $(25,26)$. The fate of mobilized amino acids includes substrates for gluconeogenesis, oxidation and synthesis of essential and acute phase proteins.

To date, little information has been available regarding the amino acid profile of skeletal muscle in chronic diseases associated with muscle wasting such as COPD. In COPD several other metabolic factors may be present in addition to the frequently occurring periods of acute metabolic stress, related to infective exacerbations. In addition, COPD is often accompanied by chronic metabolic stress related to factors like systemic inflammation, hypoxia etc. These factors among others may influence 
amino acid metabolism, independent of each other. Although only small changes were present in muscle amino acid levels in the clinically stable total COPD group compared with the healthy age-matched controls, striking differences were seen after stratification of the patients with COPD into those with and without radiologically proven emphysema (chapter 7). Elevated values for most amino acids were present in the patients without emphysema compared with the healthy controls. In contrast, nearly all muscle amino acid levels were reduced in the COPD patients with emphysema. This discrepancy in muscle amino acid profile between the COPD subtypes needs further exploration. It is unclear whether there is a relationship between the different muscle amino acid profiles and the distinct wasting patterns in COPD. The contribution of chronic starvation to the muscle amino acid profile of emphysema patients is also unclear. To our knowledge, no human studies have been performed examining muscle amino acid profile in other chronic, non-metabolic stress related conditions associated with muscle wasting such as anorexia nervosa.

A marked response in muscle amino acid profile was present not only at rest but also during constant work rate exercise in COPD (chapter 10). Exercise resulted in a significant reduction in the levels of most amino acids in muscle, whereas at the same time an increase was found in several plasma amino acids. This suggests an elevated release of amino acids from muscle during exercise.

Although distinctive, both patterns of muscle amino acid status in the two COPD subgroups observed in this thesis during rest and exercise indicate pronounced alterations in amino acid metabolism. More mechanistic studies are necessary in order to unravel the exact mechanisms behind these observations, e.g. the use of arterial-venous amino acid (exchange) measurements across skeletal muscle in combination with measurements of changes in the intramuscular amino acid concentrations.

\section{Mechanisms and possible consequences of altered glutamate status in muscle of COPD patients}

One consistent finding among the few available studies investigating muscle amino acid profile in COPD is the decreased glutamate level at rest (GLU) (chapter 7, 9, 10). Depleted GLU levels have been found in different muscle groups (quadriceps femoris muscle vs. tibialis anterior muscle) of severe COPD patients $(10,27)$. Moreover, depleted muscle GLU levels were present in all COPD patients, independent of the severity of airflow obstruction, but to the greatest extent in those with radiologically proven emphysema. The decreased GLU concentration in the muscle of COPD patients may be the consequence of increased GLU degradation, decreased GLU production in the splanchnic area and/or reduced uptake of GLU in skeletal muscle.

GLU, which comprises $\sim 20 \%$ of all amino acids in natural proteins, is one of the amino acids in highest concentration in the free amino acid pool in human skeletal muscle. GLU is present at a low concentration in plasma. GLU is one of the most 
important non-essential amino acids and takes part in numerous important metabolic processes at rest and during exercise.

First of all, GLU is an important precursor for the first and rate-limiting step in the synthesis of the antioxidant glutathione (GSH). Unless cysteine, glycine or the corresponding enzymes become limiting, GSH level is determined by GLU concentration. GSH is one of the most important antioxidants. The antioxidant status in tissue determines its susceptibility to oxidative stress, which may induce muscle damage via the formation of free oxygen radicals. Even a relatively moderate depletion of GSH has negative consequences as it causes oxidative damage and impairs the structural and functional integrity of mitochondria $(28,29)$. Furthermore, an association has been found between reduced intracellular GSH levels and a decrease in phosphocreatine, which is indicative of decreased mitochondrial energy metabolism (30).

In patients with emphysema, muscle GLU as well as GSH levels were lower than in healthy age-matched controls (27) (chapter 8). Moreover, the decrease in GSH was highly associated with the decrease in GLU, suggesting that muscle GLU in emphysema patients may be rate-limiting in the synthesis of GSH. Previously, a relationship has been observed between muscle GSH and GLU in weight-losing tumor-bearing mice (31). Reduced GLU levels were also shown in other catabolic conditions (ie cancer, sepsis), which are characterized by an oxidative to glycolytic shift in metabolism of peripheral skeletal muscle. This suggests that the presence of tissue wasting in emphysema patients at least partly explains the reduced muscle GLU levels.

Oxygen desaturation is frequently present during activities of daily living in these patients (e.g. meals, exercise (32-34). Since this implies that hypoxia-reoxygenation in tissues may be present in these conditions, an adequate level of antioxidants is of particular importance. Hypoxia-reoxygenation studies have shown that an acute episode of intermittent hypoxia results in increased oxidative stress (35). Moreover, the reduced oxidative capacity in muscle of these patients may also contribute to increased oxidative stress particularly during exercise when the increased oxygen flux towards the muscles cannot be efficiently metabolized. This suggests that the presence of increased oxidative stress in combination with reduced muscle GSH levels may result in an antioxidant to oxidant imbalance and in this way induce muscle damage in patients with emphysema. In this thesis, we observed that the physically active controls had higher values for muscle glutamate than the physically inactive controls (chapter 9). It is therefore possible that exercise training is able to elevate GLU in skeletal muscle. Further studies are needed to investigate the role of nutritional supplementation and exercise training as stimuli to increase the glycolytic to oxidative shift in metabolism. This might result in possible treatments to increase muscle GSH level in these patients. Moreover, it is possible that incorporation of a GLU enriched supplement may be of benefit in these patients but further investigation is necessary. 
It has also been suggested that in hypoxic conditions, GLU may be able to shunt glycolytic pyruvate to alanine, via the alanine aminotransferase reaction, instead of lactate. In this way, it could diminish lactate accumulation. Lactic acidosis early in exercise has been shown to occur in a substantial proportion of COPD patients (36, 37). Lactic acidosis is detrimental to these patients, since it puts an additional stress on their limited ventilatory system during exercise. Recently, evidence has become available that a reduced oxidative capacity is associated with an early lactate response to exercise in COPD. An inverse relationship was found between the activity of muscle oxidative enzymes and the steepness of lactate increase during exercise (38). It has not previously been shown however, whether changes in substrate levels within the skeletal muscle at rest contribute to the altered lactate response during exercise in COPD. In this thesis, we found that the reduced resting muscle GLU levels in the emphysema patients were associated with a reduced lactate threshold during incremental exercise (chapter 9), whereas no relationship was found with changes in the resting levels of other substrates such as glycogen, lactate or glucose. This suggests that a reduced resting muscle GLU level may contribute to the early lactate response to exercise in these patients probably because of reduced shunting of pyruvate towards alanine instead of lactate. Exercise training may be important in this situation, since the trained muscle is able to increase its capacity for resisting lactate production by shunting a greater proportion of pyruvate to alanine than to lactate (39). Further studies are necessary to determine whether GLU supplementation in COPD might delay the lactate threshold during incremental exercise.

GLU plays a role in preserving high-energy phosphates in muscle through different metabolic mechanisms at rest and during exercise. GLU is involved in anaerobic ATP formation by enhancing substrate phosphorylation during ischemic and hypoxic conditions (40). These conditions have been shown to increase intracellular GLU degradation in heart tissue and mitochondria. However, enhanced substrate phosphorylation is at the cost of intracellular GLU (41). Other studies in healthy human muscle have shown that the GLU pool functions to generate TCA-intermediates during the first minutes of exercise $(42,43)$. This increase in TCA cycle intermediates is achieved via the alanine aminotransferase reaction (pyruvate + GLU $\rightarrow$ alanine $+\alpha$-ketoglutarate) and is needed to meet the increased energy demand of exercise. In this thesis, we did not observe any change in the TCA cycle intermediate succinate in the COPD group despite a large reduction in muscle GLU after 20 minutes of low intensity exercise (chapter 10 ).

In summary, the clinical relevance of muscle GLU depletion in patients with emphysema may be related to its negative effect on GSH status in the skeletal muscle. Moreover, it is likely that muscle GLU depletion negatively influences aerobic and anaerobic exercise capacity of emphysema patients by altering exerciserelated substrate metabolism, contributing to early lactic acidosis, and by negatively influencing muscle energy status. Therefore, it can be hypothesized that avoidance of depletion of intracellular GLU may be important in the prevention of oxidative stress 
in the peripheral skeletal muscles, in enhancing the energy generating capacity during exercise, and in delaying the occurrence of the lactate threshold in COPD patients and in particular in those with emphysema.

\section{Mechanisms of altered branched-chain amino acid profile in COPD}

In plasma of COPD patients, consistently reduced levels have been found for the branched-chain amino acids (BCAAs) compared with those in healthy age-matched controls (44-46). In this thesis (chapter 7), we found that the reduced BCAA level in plasma of COPD patients was due to reduced levels of leucine (LEU), whereas no changes were found in valine or isoleucine. Moreover, the ratio of muscle to plasma LEU was increased, indicating that specific disturbances in LEU metabolism are present in these patients. The alterations in LEU metabolism may possibly by mediated by changes in insulin and associated with loss of FFM. Increased levels of insulin, an anabolic hormone, were present in the COPD group. Insulin is generally known to influence amino acid metabolism and in particular that of the BCAAs. We found that the increased insulin levels were associated with elevated values of muscle to plasma LEU gradient, suggesting possible abnormalities in the transmembrane LEU transport system. A deprived nutritional state may further contribute to the reduced plasma LEU levels in the COPD group. This is in line with reduced BCAA levels reported in subjects suffering from anorexia nervosa (47) and protein-calorie malnutrition (48). However, it remains unknown to what extent hyperinsulinemia contributes to the reduced plasma LEU levels in COPD. Other studies examining the relationship between insulin and LEU metabolism indicate that hyperinsulinemia may negatively influence LEU metabolism by suppressing LEU flux. Until now, the exact cause of the observed increased insulin level and the decreased glucose to insulin ratio, suggesting insulin resistance, remains unknown. COPD patients with an acute phase response and elevated levels of soluble tumour necrosis factor receptors have been found to have a significantly lower fat-free mass and thus a higher fat mass than healthy controls and COPD patients without evidence of systemic inflammation (8). Therefore, one of the factors contributing to insulin resistance may be the inflammation related abnormalities in body composition i.e. a decreased fat-free mass and relative preservation of fat mass, observed in a substantial part of COPD patients. Besides the effect on amino acid metabolism, hyperinsulinemia may also directly affect muscle fiber type composition by increasing the type $2 \mathrm{x}$ myosin heavy chain mRNA (49). More investigation is needed to elucidate the underlying mechanisms of increased insulin levels in COPD (changes in fat metabolism, increased inflammatory response) and the consequences for muscle wasting and alterations in muscle morphology and amino acid (ie. LEU) metabolism.

Under normal conditions, the metabolism of LEU is considered to reflect accurately the metabolism of all amino acids. However, if a specific disturbance in LEU metabolism is indeed present in COPD, this may indicate that LEU turnover does not provide a good reflection of protein tumover in general. Indeed, in chapter 5 , a discrepancy was observed when measuring the whole body protein flux as assessed 
by infusion of the stable isotope of LEU in comparison to that of phenylalanine. The only study that measured whole body protein tumover in severely FFM depleted COPD patients (44), found unaltered whole body protein breakdown and reduced whole body protein synthesis using the LEU tracer. Our work suggests that this study needs to be reevaluated using a different amino acid labeled tracer.

\section{CONCLUSIONS}

By definition COPD is characterized by irreversible airflow obstruction showing little or no improvement despite optimal medical treatment. During the last decade the systemic consequences accompanying COPD, such as muscle wasting, have gained more and more attention. It is becoming increasingly clear that these systemic factors exert a negative impact on morbidity and mortality and on quality of life.

The research presented in this thesis was directed towards the consequences and underlying metabolic mechanisms of muscle wasting in COPD. Accurate assessment of fat-free mass was performed in order to characterize the presence and severity of muscle wasting in COPD and specifically to evaluate the functional consequences. In this way, we were able to distinguish different patterns of tissue wasting between COPD patients with and without emphysema. In addition, it was possible to assess the major role of selective extremity muscle wasting in skeletal muscle weakness in COPD. The distinctive wasting patterns between the COPD subtypes suggest that different underlying mechanisms may be present and responsible for muscle wasting in COPD. Several factors may play a role: a negative energy balance mainly due to increased activity-related metabolic and mechanical inefficiency, hypoxia, a systemic inflammatory response, physical inactivity and disturbances in intermediary metabolism. The precise contribution of each of these factors is not yet clear and deserves further investigation.

To achieve a better understanding of the role of metabolic determinants of muscle wasting, we examined protein and related amino acid metabolism in skeletal muscle in detiil. A novel insight was obtained in the underlying metabolic alterations in protein and amino acid metabolism, at a whole body level, and in skeletal muscle in COPD. We found alterations in protein tumover and muscle amino acid status observed during everyday conditions such as overnight fasting and exercise. This suggests that pronounced metabolic alterations are present throughout the day even in COPD patients who are clinically and weight-stable. The metabolic response during acute or chronic unstable conditions is unknown and merits further investigation as these conditions are often present and may contribute to a vicious circle of chronic invalidity. Also more data are needed regarding substrate metabolism and molecular mechanisms in well defined sub-groups of COPD. Examples might be the pattern and degree of FFM depletion, the presence of emphysema and quantitation of tissue hypoxia. This information is important in improving the efficacy of current treatment of muscle wasting and to provide a rationale for innovative treatments in COPD. 


\section{References}

1. Filley GF, Beckwitt HJ, Reever JT, Mitchelli RS. Chronic obstructive bronchopulmonary disease. 2. oxygen transport in two clinical types. Am. J. Med. 1968;44:26-38.

2. Creutzberg EC, Schols AMWJ, Bothmer-Quaedvlieg FC, Wouters EFM. Prevalence of an elevated resting energy expenditure in patients with chronic obstructive pulmonary disease in relation to body composition and lung function. Eur. J. Clin. Nutr. 1998;52(6):396-401.

3. Baarends EM, Schols AMWJ, Pannemans DLE, Westerterp KR, Wouters EFM. Total free living energy expenditure in patients with severe chronic obstructive pulmonary disease. Am. J. Respir. Crit. Care Med. 1997;155:549-554.

4. Baarends EM, Schols AMWJ, Westerterp KR, Wouters EFM. Total daily energy expenditure relative to resting energy expenditure in clinically stable patients with chronic obstructive pulmonary disease. Thorax 1997;52:780-785.

5. Wuyam B, Payen JF, Levy P, Bensaidane H, Reutenauer H, Le Bas JF, et al. Metabolism and aerobic capacity of skeletal muscle in chronic respiratory failure related to chronic obstructive pulmonary disease. Eur. Respir. J. 1992:5:157-162.

6. Tada H, Kato H, Misawa $\mathrm{T}$, Sasaki S, Hayashi S, Takahashi H, et al. 31P-Nuclear magnetic resonance evidence of abnormal skeletal muscle metabolism in patients with chronic lung disease and congestive heart failure. Eur. Respir. J. 1992;5:163-169.

7. Pouw EM, Schols AMWJ, Van der Vusse GJ, Wouters EFM. Elevated iosine monophosphate levels in resting muscle of patients with stable COPD. Am. J. Respir. Crit. Care Med. 1998;157:453-457.

8. Schols AMWJ, Buurman WA, Staal-Van den Brekel AJ, Dentener MA, Wouters EFM. Evidence for a relation between metabolic derangements and increased levels of inflammatory mediators in a subgroup of patients with chronic obstructive pulmonary disease. Thorax 1996;51:819-824.

9. Schols AMWJ, Creutzberg EC, Campfield A, Buurman WA, Saris WHM, Wouters LiFM. A role for leptin in emphysema related tissue wasting? Am. J. Respir. Crit. Care Med. 1997;155:A901.

10. Pouw EM, Schols AMWJ, Deutz NEP, Wouters EFM. Plasma and muscle amino-acid levels in relation to resting energy expenditure and inflammation in stable COPD. Am. J. Respir. ('rit. Care Med. 1998;158:797-801.

11. Li YP, Schwartz RJ, Waddell ID, Holloway BR, Reid MB. Skeletal muscle myocytes undergo protein loss and reactive oxygen-mediated NF-kappaB activation in response to tumor necrosis factor alpha. Faseb J. 1998;12:871-80.

12. Schiffelers S, Blaak E, Baarends E, Van Baak M, Wouters EFM, Schols AMWJ. Betaadrenoceptor mediated thermogenesis in patients with emphysema. Am. J. Respir. Crit. Care Med. 2000:A92.

13. Hamilton AL, Killian KJ, Summers E, Jones NL. Muscle strength, symptom intensity, and exercise capacity in patients with cardiorespiratory disorders. Am. J. Respir. Crit. Care Med. 1995; 152:2021-2031.

14. Gosselink R, Troosters T, Decramer M. Peripheral skeletal muscle weakness contributes to exercise limitation in COPD. Am. J. Respir. Crit. Care Med. 1996;153:976-980.

15. Bernard S, LeBlanc P, Whittom F, Carrier G, Jobin J, Belleau R, et al. Peripheral muscle weakness in patients with chronic obstructive pulmonary disease. Am. J. Respir. Crit. Care Med. 1998; 158:629-634.

16. Baarends EM, Schols AMWJ, Mostert R, Wouters EFM. Peak exercise response in relation to tissue depletion in patients with chronic obstructive pulmonary disease. Eur. Respir. J. 1997; 10:2807-2813.

17. Macallan DC, McNurlan MA, Milne E, Calder AG, Garlick PJ, Griffin GE. Whole-body protein turnover from leucine kinetics and the response to nutrition in human immunodeficiency virus infection. Am. J. Clin. Nutr. 1995;61(4):818-26.

18. Jeevanandam M, Horowitz GD, Lowry SF, Brennan MF. Cancer cachexia and protein metabolism. Lancet 1984;1:1423-6. 
19. Rennie MJ, Edwards RH, Krywawych S, Davies CT, Halliday D, Waterlow JC, et al. Effect of exercise on protein turnover in man. Clin. Sci. 1981;61:627-39.

20. Phillips SM, Atkinson SA, Tarnopolsky MA, MacDougall JD. Gender differences in leucine kinetics and nitrogen balance in endurance athletes. J. Appl. Physiol. 1993;75:2134-41.

21. Deutz NEP, Wagenmakers AJ, Soeters PB. Discrepancy between muscle and whole body protein turnover. Curr. Opin. Clin. Nutr. Metab. Care 1999;2:29-32.

22. Roth E, Zoch G, Schulz F, Karner J, Muhlbacher F, Hamilton $G$, et al. Amino acid concentrations in plasma and skeletal muscle of patients with acute hemorrhagic necrotizing pancreatitis. Clin. Chem. 1985;31:1305-9.

23. Milewski PJ, Threlfall CJ, Heath DF, Holbrook IB, Wilford K, Irving MH. Intracellular free amino acids in undernourished patients with or without sepsis. Clin. Sci. 1982;62:83-91.

24. Vinnars E, Bergstom J, Furst P. Influence of the postoperative state on the intracellular free amino acids in human muscle tissue. Ann. Surg. 1975;182:665-71.

25. Biolo G, Toigo G, Ciocchi B, Situlin R, Iscra F, Gullo A, et al. Metabolic response to injury and sepsis: changes in protein metabolism. Nutrition 1997;13:52S-57S.

26. Rennie MJ, Millward DJ. 3-Methylhistidine excretion and the urinary 3methylhistidine/creatinine ratio are poor indicators of skeletal muscle protein breakdown. Clin. Sci. 1983;65:217-25.

27. Engelen MPKJ, Schols AMWJ, Does JD, Deutz NEP, Wouters EFM. Altered glutamate metabolism is associated with reduced muscle glutathione levels in patients with emphysema. Am.J..Respir..Crit..Care Med. 2000;161:98-103.

28. Traber J, Suter $M$, Walter P, Richter C. In vivo modulation of total and mitochondrial glutathione in rat liver. Biochem. Pharmacol. 1992;43:961-964.

29. Jain A, Martensson J, Stole E, Auld P, Meister A. Glutathione deficiency leads to mitochondrial damage in brain. Proc. Natl. Acad. Sci. USA 1991;88:1913-1917.

30. Hack V, Gross A, Bohme A, Stahl-Hennig C, Droge W. Decrease in phosphocreatine level in skeletal muscle of SIV-infected rhesus-macaques correlates with decrease in intracellular glutathione. Aids Res. Hum. Retroviruses 1997;13:1089-1091.

31. Hack V, Gross A, Kinscherf K, Bocksette M, Fiers W, Berke G, et al. Abnormal glutathione and sulfate levels after interleukine 6 treatment and in tumor-induced cachexia. FASEB J. 1996; 10:1219-1226.

32. Soguel Schenkel N, Burdet L, de Murait B, Fitting JW. Oxygen saturation during daily activities in chronic obstructive pulmonary disease. Eur. Respir. J. 1996;9:2584-2589.

33. Schols AMWJ, Mostert R, Cobben N, Soeters PB, Wouters EFM. Transcutaneous oxygen saturation and carbon dioxide tension during meals in patients with chronic obstructive pulmonary disease. Chest 1991;100:1287-1292.

34. Owens GR, Rogers RM, Pennock BE, Levin D. The diffusing capacity as a predictor of arterial oxygen desaturation during exercise in patients with chronic obstructive pulmonary disease. $\mathrm{N}$. Engl. J. Med. 1984;310:1218-1221.

35. Ferrari R, Ceconi C, Curello S, Alfieri O, Visioli O. Myocardial damage during ischaemia and reperfusion. Eur. Heart J. 1993;14 Suppl G:25-30.

36. Casaburi R, Patessio A, Ioli F, Zanaboni S, Donner CF, Wasserman K. Reductions in exercise lactic acidosis and ventilation as a result of exercise training in patients with obstructive lung disease. Am. Rev. Respir. Dis. 1991;143:9-18.

37. Sue DY, Wasserman K, Moricca RB, Casaburi R. Metabolic acidosis during exercise in patients with chronic obstructive pulmonary disease. Chest 1988;94:931-938.

38. Maltais F, Simard AA, Simard C, Jobin J, Desgagnes P, LeBlanc P. Oxidative capacity of the skeletal muscle and lactic acid kinetics during exercise in normal subjects and in patients with COPD. Am. J. Respir. Crit. Care Med. 1996;153:288-293.

39. Mole PA. Baldwin KM. Terjung RL, Holloszy JO. Enzymatic pathways of pyruvate metabolism in skeletal muscle: adaptations to exercise. Am. J. Physiol. 1973;224(1):50-4.

40. Wiesner RJ, Deussen A, Borst M, Schrader J, Grieshaber MK. Glutamate degradation in the ischemic dog heart: contribution to anaerobic energy production. J. Mol. Cell. Cardiol. 1989;21:49-59. 
41. Pisarenko OI, Solomatina ES, Ivanov VE, Studneva IM, Kapelko VI, Smimov VN. On the mechanisms of enhanced ATP formation in hypoxic myocardium caused by glutamic acid. Basic Res. Cardiol. 1985;80:126-134.

42. Van Hall G, Saltin B, Van der Vusse GJ, Soderlund K, Wagenmakers AJM. Deamination of amino acids as a source for ammonia production during prolonged exercise in man. J. Physiol. 1995;1995:251-261.

43. Van Hall G, MacLean DA, Saltin B, Wagenmakers AJM. Mechanisms of activation of muscle branched-chain alpha-keto acid dehydrogenase during exercsie in man. J. Physiol. 1996;494:899-905.

44. Morrison WL, Gibson JNA, Scrimgeour C, Rennie MJ. Muscle wasting in emphysema. Clin. Sci. 1988;75:415-420.

45. Schols AMWJ, Deutz NEP, Mostert R, Wouters EFM. Plasma amino acid levels in patients with chronic obstructive pulmonary disease. Monaldi Arch. Chest Med. 1993;48:546-548.

46. Hofford JM, Milakofsky L, Vogel WH, Sacher RS, Savage GJ, Pell S. The nutritional status in advanced emphysema associated with chronic bronchitis. A study of amino acid and catecholamine levels. Am. Rev. Respir. Dis. 1990;141:902-908.

47. Halmi KA, Struss AL, Owen WP, Stegink LD. Plasma and erythrocyte amino acid concentrations in anorexia nervosa. J. Parenter. Enteral Nutr. 1987;11:458-64.

48. Saunders SJ, Truswell AS, Barbezat GO, Wittman W, Hansen JD. Plasma free aminoacid pattem in protein-calorie malnutrition. Reappraisal of its diagnostic value. Lancet 1967;2:795-7.

49. Houmard JA, O'Neill DS, Zheng D, Hickey MS, Dohm GL. Impact of hyperinsulinemia on myosin heavy chain gene regulation. J. Appl. Physiol. 1999;86:1828-32. 


\section{CHAPTER 12}

Summary / Samenvatting 


\section{SUMMARY}

This thesis describes the role of muscle wasting in patients with chronic obstructive pulmonary disease (COPD) from a metabolic and functional perspective. Three main topics were addressed in this patient population: characterization of muscle wasting in relation to skeletal muscle function (part 1); analysis of whole body protein metabolism at rest and during exercise (part 2); analysis of the specific disturbances in amino acid status of the peripheral skeletal muscle at rest and during exercise (part 3 ).

\section{PART 1: Muscle wasting in relation to skeletal muscle function}

In chapter 2, we determined whether dual-energy X-ray absorptiometry (DXA) is an applicable method in the clinical evaluation of body composition in COPD with special emphasis on fat-free mass (FFM) and bone mineral density. We compared FFM measured by DXA with values obtained by deuterium dilution in a group of stable patients with severe COPD. A high level of agreement was found between DXA and deuterium dilution in the estimation of FFM, although systematically higher values were given by DXA. This indicates that DXA appears to be a suitable alternative method to deuterium dilution for assessing FFM. Bone mineral density values as assessed by DXA were lower in the COPD group than in the healthy volunteers. The present data illustrate that DXA is an informative, convenient, non-invasive method to evaluate body composition clinically in COPD and also to identify the relatively high percentage of COPD patients with bone mineral loss.

In chapter 3, the results of a study on body composition in two groups of COPD patients were presented: COPD patients with and without radiologically diagnosed emphysema (EMPH+ and EMPH-, respectively). Differences in body composition were found between COPD patients and healthy controls despite comparable values for body mass index. Moreover, striking differences were found in body composition between the COPD subtypes. A relatively high proportion of the EMPH+ patients had weight loss and were underweight. Moreover, the $\mathrm{EMPH}+$ patients had lower values for body mass index than the EMPH- patients, due to a lower fat mass, lean mass and bone mineral mass. However, a reduced lean mass and bone mineral mass were also found in EMPHpatients when compared to healthy controls, despite a relatively elevated fat mass. Although the precise factors responsible for the differences in body composition between the COPD subtypes are as yet unknown, the presence of marked static hyperinflation in the $\mathrm{EMPH}+$ patients may play a role. The present data illustrate that different patterns of chronic tissue wasting can be distinguished in COPD patients with and without emphysema. This suggests that different regulatory mechanisms for disturbances in intermediary metabolism occur in COPD.

The functional consequences of FFM loss in COPD were studied in chapter 4. Besides whole body FFM, FFM of the extremity compartment was examined as it has been suggested to give a more detailed reflection of physically active muscle mass in daily 
living. Whole body and extremity FFM were significantly lower in all COPD patients than in healthy controls, but trunk FFM was lower only in the EMPH+ patients. Extremity FFM was not different between the COPD subtype groups, despite significantly lower values for whole body and trunk FFM in the EMPH+ patients. This suggests that whole body FFM is not a good reflection of extremity FFM in the COPD groups. Skeletal muscle function in absolute terms and per kilogram of whole body FFM was significantly lower in the COPD patients than in the healthy volunteers. However, skeletal muscle function expressed per kilogram of extremity FFM was not significantly different between the COPD and control group. Skeletal muscle function was not different between the COPD subtypes EMPH+ and EMPH-, and no association was found between skeletal muscle function and airflow obstruction. The data in the present study suggest that the contractile properties of the peripheral skeletal muscles in COPD are independent of the presence of emphysema and the severity of airflow obstruction. Furthermore, extremity FFM assessment is informative when peripheral skeletal muscle function is evaluated in COPD.

\section{PART 2: Protein metabolism}

In general, muscle wasting is the consequence of a negative protein balance, indicating an imbalance between the rate of protein synthesis and protein breakdown.

In chapter 5, we examined the effects of COPD on specific processes in whole body protein metabolism eg. protein synthesis, protein breakdown and net protein breakdown. Infusion of stable isotopes of the amino acids phenylalanine and tyrosine was performed in clinically and weight-stable patients with severe COPD without FFM depletion, and in age-matched controls. To exclude the potential influence of gender and systemic corticosteroid use on protein metabolism, all subjects studied were men and were free of systemic corticosteroids as maintenance medication. We obscrved substantial changes in whole body protein metabolism in the COPD patients in the postabsorptive state. Whole body protein synthesis as well as protein breakdown were higher in the COPD patients than in the age-matched controls, reflecting an elevated protein turnover. However, no enhanced net protein breakdown was found in these patients.

Besides overnight fasting, physical exercise is an everyday occurrence which may theoretically influence whole body protein metabolism. In chapter 6 , we assessed the effect of 20 minutes of constant low intensity exercise on whole body protein synthesis and breakdown during exercise and recovery in stable severe COPD patients and healthy age-matched controls. Specifically in those COPD patients with emphysema, whole body protein turnover was suppressed both during exercise and for at least one hour post-exercise. No net protein breakdown was found in the COPD patients during exercise or recovery. The studies reported in part 2 showed that daily life conditions such as overnight fasting and low intensity exercise are able to induce considerable alterations in whole body protein turnover in clinically and weight- 
stable COPD patients without FFM depletion. The precise mechanisms behind these alterations are as yet unknown and deserve further investigation.

\section{PART 3: Amino acid status of the peripheral skeletal muscle at rest and during exercise}

Skeletal muscle serves as an important reserve system which in conditions of need maintains supplies of amino acids for metabolism and protein synthesis. Accordingly, we focused on amino acid status in peripheral skeletal muscle of COPD patients.

In chapter 7, we studied the amino acid profile of skeletal muscle in patients with COPD. Only small differences were present in skeletal muscle amino acid profile in the COPD group as a whole compared to healthy age-matched controls. However, striking differences were found between COPD patients with and without emphysema. Elevated values for most amino acids were present in the EMPH- patients compared to age-matched controls. In contrast, nearly all skeletal muscle amino acid levels were reduced in the EMPH+ patients. This implies that careful stratification and characterization of the COPD group is of importance when studying differences in muscle amino acid levels. The exact reasons for the observed discrepancy in muscle amino acid profile need further exploration. In plasma, we were specifically interested in the branched-chain amino acids since consistently reduced values have previously been reported in COPD. Factors possibly contributing to the alterations in plasma branched-chain amino acid profile namely hyperinsulinemia and lung function impairment, were examined. Leucine (LEU) was the only branched-chain amino acid which was decreased in the plasma of the COPD patients, whereas muscle to plasma LEU gradient was elevated. This suggests that specific alterations in LEU metabolism, eg. transmembrane amino acid transport system, are likely to be present in COPD. Increased insulin levels were found in the COPD patients. These increased insulin levels were associated with elevated values of muscle to plasma LEU gradient. This suggests that altered insulin regulation among other factors (eg. deprived nutritional state and systemic inflammation) may be involved in disturbances in LEU metabolism in COPD.

In chapter 8, particular attention was paid to the amino acid glutamate (GLU) which in normal conditions is present in high concentration in skeletal muscle. Intracellular GLU is known to be an important precursor for antioxidant (glutathione) and glutamine synthesis in muscle. In the present study, alterations in the concentration of GLU as substrate for glutamine and glutathione synthesis were studied in the skeletal muscle of COPD patients with emphysema. We observed reduced values for GLU, glutamine and glutathione in skeletal muscle of EMPH+ patients as compared to age-matched controls. Muscle GLU was strongly associated with glutathione but not with GLN in the COPD patients as well as in the controls. This suggests that avoiding depletion of intracellular GLU may be important in the prevention of oxidative stress in the skeletal muscle of COPD patients. 
Lactic acidosis early in exercise commonly occurs in COPD and is detrimental to these patients since it puts an additional stress on their limited ventilatory system. In chapter 9 , we studied the relationship between the venous lactate response to incremental exercise and glutamate levels in the skeletal muscle of COPD patients. We observed lower levels of muscle GLU at rest and lower values for lactate threshold during incremental exercise in patients with COPD than in agc-matched controls. GLU as well as lactate threshold during exercise were even more severely reduced in those with emphysema. Elevated levels for muscle GLU and lactate threshold during exercise were found in physically active controls as compared to those who were physically inactive. This suggests that physical inactivity besides factors related to the presence of emphysema (eg. reduced diffusing capacity, reduced $\mathrm{pO}_{2}$ ) may contribute to the reduced GLU level in skeletal muscle at rest. A reduced muscle GLU level may contribute to the early lactate response during exercise in COPD patients because of a reduced shunting of pyruvate towards alanine instead of lactate.

Exercise is known to influence amino acid metabolism in healthy subjects. In chapter 10, the response of the total amino acid profile in skeletal muscle and plasma after 20 minutes of submaximal constant workrate cycle exercise was examined in COPD patients and healthy age-matched controls. In this study, exercise resulted in a reduction in the levels of most amino acids in muscle, whereas an increase was found in several plasma amino acids compared to normal. This suggests an elevated release of amino acids from muscle during exercise in COPD. The precise mechanisms behind this increased exercise-induced amino acid efflux remain to be elucidated.

In summary, in this thesis muscle wasting was studied in patients with COPD from a metabolic and functional perspective. Remarkably different patterns of tissue wasting were found among patients with COPD. It was shown that skeletal muscle weakness in COPD is associated with wasting of fat-free mass in the extremities. Furthermore, pronounced alterations were found in whole body protein metabolism in clinically and weight-stable COPD patients during everyday conditions i.e. after an overnight fast and during submaximal exercise. However, no net protein catabolism was found with fasting or exercise in these COPD patients. Disturbances in the amino acid profile of the skeletal muscle were found in COPD at rest as well as during exercise. Specific attention was paid to the reduced levels for the amino acid GLU as GLU is involved in many metabolic pathways at rest as well as during exercise.

In addition to the remarkable differences in body composition, pronounced changes were observed in protein metabolism and muscle amino acid status at rest and during exercise between COPD patients with and without emphysema. In order to explain the metabolic alterations underlying muscle wasting in COPD, more insight is needed into the role of specific mediators associated with emphysema. This information is likely to be important in the treatment of muscle wasting and in providing a rationale for more specific innovative treatments in COPD patients with and without emphysema. 


\section{SAMENVATTING}

Dit proefschrift beschrijft de rol van spiermassaverlies bij patiënten met chronisch obstructief longlijden (COPD) vanuit een metabool en functioneel perspectief. Drie aandachtsgebieden werden onderscheiden: karakterisering van spiermassaverlies in relatie tot skeletspierfunctie (deel 1); analyse van het eiwitmetabolisme op geheel lichaamsniveau in rust en tijdens inspanning (deel 2); analyse van de stoornissen aanwezig in de aminozuurstatus van de perifere skeletspier in rust en na inspanning (deel 3).

\section{DEEL 1: Spiermassaverlies in relatie tot skeletspierfunctie}

In hoofdstuk 2 werd bestudeerd in hoeverre dual-energy X-ray absorptiometry (DXA) een toepasbare methode is voor de klinische beoordeling van de lichaamssamenstelling in patiënten met COPD. De nadruk werd hierbij gelegd op de hoeveelheid vet-vrije massa (VVM), aangezien deze vaak verlaagd is in deze patiënten, en de botdichtheid. In een groep stabiele patiënten met ernstig COPD werd de hoeveelheid VVM (welke hoofdzakelijk uit spiermassa bestaat) gemeten met behulp van DXA en vergeleken met waarden verkregen met behulp van deuteriumdilutie als referentiemethode. Een hoge mate van overeenstemming werd gevonden voor VVM gemeten met beide methoden, ondanks het feit dat de VVM waarden gemeten met behulp van DXA systematisch hoger waren. Verder was de botdichtheid significant lager in de COPD groep dan in de gezonde op leeftijd gematchte controlegroep. De huidige studie geeft dus aan dat DXA een informatieve, gemakkelijk toepasbare en niet-invasieve methode is in de klinische evaluatie van lichaamssamenstelling bij COPD patiënten en dat DXA tevens in staat is het relatief hoge percentage $C O P D$ patiënten met botmassaverlies te identificeren.

In hoofdstuk 3 werd de lichaamssamenstelling van twee COPD subgroepen gekarakteriseerd. De VVM, botmassa en vetmassa van COPD patiënten met en zonder radiologisch gediagnostiseerd emfyseem werden vergeleken met die van gezonde controlepersonen. Verschillen in lichaamssamenstelling werden waargenomen tussen alle COPD patiënten en gezonde controles ondanks vergelijkbare waarden voor de quetelet-index (gewicht/lengte ${ }^{2}$ ). Daamaast werden opmerkelijke verschillen in lichaamssamenstelling gevonden tussen de COPD subgroepen. Een relatief hoog percentage van de emfyseempatiënten werd gekenmerkt door recent gewichtsverlies. Bovendien hadden de emfyseempatiënten lagere waarden voor de quetelet-index dan de patiënten zonder emfy'seem wat, naast een lagere VVM, voomamelijk het gevolg was van een lagere vetmassa. Ook in de COPD groep zonder emfyseem werden lagere waarden gevonden voor de 'lean' massa (=VVM-botmassa) en botmassa dan in de gezonde controlegroep, terwijl hun vetmassa behouden was. De data in deze studie laten zien dat verschillende patronen van chronische weefselverlies onderscheiden kunnen worden tussen COPD patiënten met en zonder emfyseem. Dit suggereert dat meerdere regulatiemechanismen ten grondslag liggen aan de gevonden stoomissen in het intermediairmetabolisme van COPD patiënten. 
De functionele consequentie van VVM verlies in COPD werd onderzocht in hoofdstuk 4. Behalve het meten van de hoeveelheid VVM van het gehele lichaam werd de VVM van de extremiteiten bepaald aangezien in het algemeen verondersteld wordt dat de laatste maat een meer gedetailleerde weergave geeft van de fysiek actieve spiermassa. In beide COPD subgroepen was de VVM van het gehele lichaam evenals van de extremiteiten significant lager dan in de gezonde controlegroep. De VVM in de romp was daarentegen alleen verlaagd in de emfyseemgroep. VVM van de extremiteiten was niet verschillend tussen de COPD patiënten met en zonder emfyseem. Deze resultaten suggereren dat het meten van de VVM van het gehele lichaam van COPD patiënten een niet geheel correcte afspiegeling geeft van hun extremiteiten VVM. Absolute skeletspierfunctie evenals skeletspierfunctie uitgedrukt per kilogram VVM van het gehele lichaam waren significant lager in de COPD patiënten dan in de gezonde controlepersonen. Echter skeletspierfunctie uitgedrukt per kilogram extremiteiten VVM was niet significant verschillend tussen de COPD en controlegroep, en tussen de COPD patiënten met en zonder emfyseem. Verder was geen significante relatie aanwezig tussen de skeletspierfunctie en de mate van luchtwegobstructie in de COPD groep. De data zoals weergegeven in de huidige studie suggereren dat de contractiele eigenschappen van de perifere skeletspieren van COPD patiënten onafhankelijk zijn van de mate van luchtwegobstructie. Verder is de bepaling van extremiteiten VVM informatief bij de evaluatie van perifere skeletspierfunctie in patiënten met COPD.

\section{DEEL 2: Eiwitmetabolisme}

In het algemeen kan gesteld worden dat spiermassaverlies het directe gevolg is van een negatieve eiwitbalans, wat impliceert dat de snelheid van eiwitsynthese verhoogd is ten opzichte van de snelheid van eiwitafbraak.

In hoofdstuk 5 werd op geheel lichaamsniveau de effecten van COPD onderzocht op specifieke metabole processen zoals eiwitsynthese, eiwitafbraak en netto eiwitafbraak. In klinisch en gewicht stabiele patiënten met ernstig COPD zonder depletie van VVM werden de stabiele isotopen van de aminozuren phenylalanine en tyrosine geïnfundeerd. Om de mogelijke invloed van bekende verstorende invloeden als geslacht en systemisch medicijngebruik op het eiwitmetabolisme uit te sluiten werden mannelijke patiënten geïncludeerd die gedurende de laatste 6 maanden voor de meting geen orale corticosteroïden als onderhoudsmedicatie hadden gebruikt. Aanzienlijke verstoringen in het eiwitmetabolisme werden aangetroffen in de COPD patiënten in de nuchtere toestand. Zowel eiwitsynthese evenals eiwitafbraak waren verhoogd in de COPD groep in vergelijking met die van leeftijd-gematchte controles, wat duidt op een verhoogde eiwitturnover. Zoals verwacht resulteerde overnacht vasten in netto eiwitafbraak (= eiwitsynthese-afbraak) in beide groepen. Echter netto eiwitafbraak was niet hoger in de COPD groep dan in de controlegroep. Deze studie laat dus zien dat het eiwitstofwisseling reeds verstoord is in klinisch en gewicht stabiele COPD patiënten met behoud van VVM. Een mogelijke factor die hierbij een rol speelt is de verhoogde chronische systemische inflammatoire status in deze patiënten. Meer onderzoek is 
noodzakelijk naar het effect van overnachtvasten op de eiwitturnover (synthese en afbraak) van COPD patiënten, die in een niet-stabiele situatie verkeren zoals tijdens een exacerbatie en tijdens een periode van onvrijwillig gewichtsverlies.

Naast vasten gedurende de nacht is lichamelijke inspanning een dagelijkse omstandigheid, die de eiwitstofwisseling ook kan beïnvloeden. In hoofdstuk $\mathbf{6}$ is het effect van 20 minuten fietsinspanning op een lage intensiteit bestudeerd op de eiwitsynthese en eiwitafbraak van stabiele patiënten met ernstige COPD en gezonde gematchte controlepersonen. Zowel de eiwitafbraak als eiwitsynthese steeg tijdens inspanning in de controlegroep en in de COPD groep zonder emfyseem. In de herstelfase normaliseerde de eiwitafbraak en synthese zich onmiddellijk in beide groepen. In de emfyseemgroep, daarentegen, bleef de eiwitsynthese en afbraak (turnover) onveranderd tijdens inspanning, maar daalde in de herstelfase tot waarden beneden de beginwaarden. Deze verlangde eiwitturnover bleef bestaan gedurende (tenminste) 1 uur in de herstelfase van inspanning. Inspanning leidde echter in geen van de groepen tot netto eiwitafbraak.

De studies in deel 2 laten zien dat dagelijkse omstandigheden, zoals het vasten gedurende de nacht en het leveren van lichamelijke inspanning op een lage intensiteit, in staat zijn aanzienlijke veranderingen in de eiwittumover op geheel lichaamsniveau te induceren in klinisch en gewichtstabiele COPD patiënten zonder verlies van VVM. De exacte mechanismen, die leiden tot deze veranderingen in de eiwitstofwisseling, zijn tot dusverre onbekend en vergen nader onderzoek.

\section{DEEL 3: Aminozuurstatus van de perifere skeletspier in rust en gedurende inspanning}

De skeletspier is een belangrijk reservesysteem. In tijden van vraag reageert ze onmiddellijk op de verhoogde behoefte aan aminozuren voor stofwisseling en eiwitsynthese.

In hoofdstuk 7 werd het aminozuurprofiel van de skeletspier bestudeerd bij patiënten met COPD. Alhoewel slechts kleine verschillen werden gevonden in het aminozuurprofiel van de totale COPD groep in vergelijking met die van gematchte controlepersonen, waren opmerkelijke verschillen aanwezig in het spieraminozuurprofiel tussen de COPD subgroepen (met en zonder emfyseem). Een hogere concentratie werd gevonden voor de meeste spieraminozuren in de COPD patiënten zonder emfyseem in vergelijking met die van gematchte controlepersonen. Daarentegen waren de meeste aminozuurspiegels juist lager in de COPD groep met emfyseem dan in de controlegroep. Om inzicht te verkrijgen in de exacte factoren die bijdragen aan de gevonden verschillen in het aminozuurprofiel van de skeletspier van de twee COPD subgroepen is verder onderzoek noodzakelijk. De gevonden resultaten in deze studie tonen echter aan dat stratificatie en karakterisering van de COPD groep 
naar de twee subgroepen van belang is wanneer verder onderzoek gedaan wordt naar de aminozuurstofwisseling van de perifere skeletspier in COPD.

In eerder onderzoek werden consistent verlaagde vertakte-keten aminozuurspiegels gevonden in plasma van patiënten met COPD. In hoofdstuk 7 werd nagegaan in hoeverre het onderliggend longlijden en de aanwezigheid van hyperinsulinemie geassocieerd zijn met de verstoringen in het vertakte-keten aminozuurprofiel in het plasma van deze patiënten. Leucine (LEU) bleek het enige vertakte-keten aminozuur te zijn welke verlaagd was in plasma van COPD patiënten. Verder waren de insulinespiegels hoger in deze patiënten dan in controlepersonen. De verhoogde insulinespiegels waren geassocieerd met verhoogde waarden voor de spier-plasma LEU gradiënt. Deze bevinding suggereert dat een specifieke verandering in het vertakte-keten (LEU) metabolisme mogelijk aanwezig is in COPD. Een gestoord membraantransport systeem van LEU tussen spier en plasma zou hierbij een rol kunnen spelen.

In hoofdstuk 8 werd aandacht besteed aan het aminozuur glutamaat (GLU). Deze is in normale situaties in hoge mate aanwezig in de skcletspier. Intracellulair GLU is bekend als een belangrijke substraat voor de synthese van glutamine en de antioxidant glutathione in de spier. In de huidige studie werden de gevolgen van veranderingen in de GLU concentratie voor de glutamine en glutathione status in de skeletspier bestudeerd in COPD patiënten met emfyseem. We vonden verlaagde concentraties voor GLU, glutamine en glutathione in de skeletspier van emfyseempatiënten in vergelijking tot die van leeftijd-gematchte gezonde controlepersonen. In zowel de COPD- als de controlegroep was de GLU concentratie significant geassocieerd met de glutathione concentratie maar niet met de glutaminestatus. De data in deze studie suggereren, dat het vermijden van verlaagde GLU spiegels van belang kan zijn in de preventie van oxidatieve stress in de perifere skeletspier van patiënten met COPD.

Verzuring treedt veelvuldig en vroegtijdig op tijdens lichamelijke inspanning in patiënten met COPD. Verzuring kan ongunstig zijn voor deze patiënten aangezien het een extra belasting legt op hun toch al beperkte ventilatoire capaciteit. In hoofdstuk 9 is de relatie bestudeerd tussen de veneuze lactaatstijging tijdens een maximale fietsergometertest en de GLU spiegel in rust in de skeletspier van COPD patiënten, aangezien het bekend is dat GLU als substraat betrokken is in meerdere metabole routes tijdens inspanning. Verlaagde spiegels voor spier GLU in rust en gereduceerde waarden voor lactaatdrempel tijdens inspanning werden gevonden in patiënten met COPD in vergelijking met die van een gematchte controlegroep. GLU spiegel evenals de lactaatdrempel waren verlaagd met name in de COPD patiënten met emfyseem.Verhoogde waarden voor spier GLU en lactaatdrempel werden daarentegen gevonden in lichamelijke actieve controles in vergelijking met lichamelijk inactieve controlepersonen. Dit duidt erop dat lichamelijke inactiviteit, naast factoren die gerelateerd zijn aan de aanwezigheid van emfyseem (zoals een verlaagde diffusiecapaciteit en arteriele $\mathrm{pO}_{2}$ ), mogelijk een rol speelt bij de totstandkoming van de verlaagde GLU spiegel in de skeletspier van COPD patiënten. Via een verminderde 
omzetting van pyruvaat naar alanine in plaats van lactaat draagt een gereduceerde GLU spiegel waarschijnlijk bij aan de vroegtijdige lactaatstijging tijdens inspanning in patiënten met COPD.

Het is bekend, dat inspanning de aminozuurstofwisseling van gezonde personen beïnvloedt. In hoofdstuk 10 werd het aminozuurprofiel van de skeletspier en van het plasma van COPD patiënten na 20 minuten submaximale constante inspanning vergeleken met die van gezonde controles. Inspanning resulteerde in een verlaging van de meeste aminozuurspiegels in de spier, terwijl een stijging werd gevonden in de spiegels van verschillende plasma aminozuren in vergelijking met beginwaarden. Dit duidt op een verhoogde afgifte van aminozuren uit de spier gedurende inspanning bij patiënten met COPD. De exacte mechanismen, die leiden tot deze gestegen inspanningsgeïnduceerde aminozuurafgifte van skeletspier aan plasma, zijn nog onduidelijk.

Samenvattend werd in dit proefschrift spiermassaverlies bestudeerd in patiënten met COPD vanuit een metabool en functioneel perspectief. Aanzienlijke verschillen werden gevonden in de patronen van weefselverlies tussen COPD patiënten met en zonder emfyseem. Er werd aangetoond dat skeletspierzwakte aanwezig is in COPD patiënten en dat deze geassocieerd is met verlies van VVM met name van de extremiteiten. Aanzienlijke veranderingen werden gevonden in de eiwitstofwisseling van klinisch- en gewichtstabicle COPD patiënten gedurende dagelijkse omstandigheden zoals na overnacht vasten en gedurende submaximale lichamelijke inspanning. Echter geen netto eiwitafbraak was aanwezig in beide omstandigheden in de COPD groep. Specifieke verstoringen in het aminozuurprofiel van de skeletspier werden gevonden in de COPD patiënten in rust, evenals na inspanning.

Specifieke aandacht werd besteed aan het aminozuur glutamaat aangezien glutamaat als substraat een rol speelt in meerdere metabole routes in rust evenals tijdens inspanning.

Naast de opmerkelijke verschillen in lichaamssamenstelling tussen de COPD groep met en zonder aanwezigheid van emfyseem, werden aanzienlijke veranderingen in de eiwitstofwisseling op geheel lichaamsniveau en in de aminozuurstatus van de perifere skeletspier gevonden in rust en gedurende inspanning. Om de metabole veranderingen, die ten grondslag liggen aan het spiermassaverlies in COPD te verklaren, is meer inzicht nodig in de rol van mediatoren, die geassocieerd zijn met de aanwezigheid van emfyseem. Deze informatie is van belang bij de behandeling van spiermassaverlies en dient als rationale voor meer specifieke en innovatieve behandelingen in COPD patiënten met en zonder emfyseem. 
Abbreviations 


\section{ABBREVIATIONS}

\begin{tabular}{|c|c|c|c|}
\hline $\mathrm{AA}$ & Amino acid & $K_{c o}$ & Diffusing capacity for \\
\hline ALA & Alanine & & carbon monoxide corrected \\
\hline ATP & Adenosine tri-phosphate & & for alveolar space \\
\hline \multirow[t]{2}{*}{ BCAA } & Branched-chain amino & $\mathrm{La}$ & Lactate \\
\hline & acids & LEU & Leucine \\
\hline \multirow[t]{2}{*}{ BIA } & Bio-electrical impedance & LeanI & Lean index \\
\hline & analysis & $\mathrm{NaBr}$ & Sodium-bromide \\
\hline $\mathrm{BMC}$ & Bone mineral content & NEAA & Non-essential amino acids \\
\hline BMD & Bone mineral density & Net PB & PB-PS \\
\hline BMI & Body mass index & $\mathrm{NH}_{3}$ & Ammonia \\
\hline $\mathrm{Br}$ & Bromide & PA & Physically active healthy \\
\hline \multirow[t]{2}{*}{ COPD } & : Chronic obstructive & & volunteers \\
\hline & pulmonary disease & $\mathrm{PaCO}_{2}$ & Arterial pressure of carbon \\
\hline DEU & Deuterium dilution & & dioxide \\
\hline $\mathrm{Dl}_{c o}$ & $\begin{array}{l}\text { Diffusing capacity for } \\
\text { carbon monoxide }\end{array}$ & $\begin{array}{l}\mathrm{PaO}_{2} \\
\mathrm{~PB}\end{array}$ & $\begin{array}{l}\text { Arterial pressure of oxygen } \\
\text { Protein breakdown }\end{array}$ \\
\hline $\mathrm{D}_{2} \mathrm{O}$ & Deuterium labeled water & PI & Physically inactive healthy \\
\hline \multirow[t]{2}{*}{ DXA } & Dual-energy X-ray & & volunteers \\
\hline & $\begin{array}{l}\text { absorptiometry } \\
\text { Essential amino acids }\end{array}$ & Pimax & $\begin{array}{l}\text { Maximal inspiratory mouth } \\
\text { pressure }\end{array}$ \\
\hline EMPH+ & $\begin{array}{l}\text { COPD with macroscopic } \\
\text { emphysema }\end{array}$ & Pemax & $\begin{array}{l}\text { Maximal expiratory mouth } \\
\text { pressure }\end{array}$ \\
\hline \multirow[t]{2}{*}{ EMPH- } & COPD without & PHE & Phenylalanine \\
\hline & macroscopic emphysema & PS & Protein synthesis \\
\hline \multirow[t]{2}{*}{$\mathrm{FEV}_{1}$} & Forced expiratory volume & PYR & Pyruvate \\
\hline & in 1 second & $\mathrm{R}_{\mathrm{a}}$ & Rate of appearance \\
\hline FFM & Fat-free mass & $\mathrm{R}_{3 \mathrm{w}}$ & Airways resistance \\
\hline FFMI & Fat-free mass index & REE & Resting energy expenditure \\
\hline FM & Fat mass & RV & Residual volume \\
\hline FMl & Fat mass index & $\mathrm{SaO}_{2}$ & Arterial oxygen saturation \\
\hline FVC & Forced vital capacity & $\mathrm{SD}$ & Standard deviation \\
\hline GLU & Glutamate & SE & Standard error \\
\hline GLN & Glutamine & TBW & Total body water \\
\hline GSH & Glutathione & TLC & Total lung capacity \\
\hline \multirow[t]{2}{*}{ HRCT } & High-resolution computed & TYR & Tyrosine \\
\hline & tomography & $\mathrm{VO}_{2 \mathrm{peak}}$ & Peak oxygen uptake \\
\hline \multirow[t]{2}{*}{ ITGV } & Intrathoracic gas volume & $\mathrm{VCO}_{2}$ & Carbon dioxide production \\
\hline & & $W R_{\text {peak }}$ & Peak work rate \\
\hline
\end{tabular}


Dankwoord 


\section{DANKWOORD}

Ik ben blij de gelegenheid te hebben, al die mensen te bedanken, die op een of andere manier hun steentje hebben bijgedragen aan de totstandkoming van dit proefschrift. Dit onderzoek zou niet mogelijk zijn geweest zonder de COPD patiënten. Ondanks de bcperkingen als gevolg van hun aandoening en zonder zelf direct profijt te hebben van de uitkomsten van het onderzoek, heb ik bewondering voor de enorme bereidwilligheid tot deelname aan het onderzoek. Verder wil ik de groep gezonde controles bedanken, die belangeloos en vaak met veel 'enthousiasme' niet één maar meerdere spierbiopten wilden ondergaan. Dit alles om een steentje bij te kunnen dragen aan het vergroten van de inzichten in en de consequenties van spiermassaverlies in patiënten met COPD.

Professor Wouters, mijn promotor, wil ik danken voor de waardevolle kritische blik op de verkregen onderzoekresultaten en het geven van vrijheid en vertrouwen in het ontwikkelen en uitwerken van onderzoeksideeën.

Wanneer ik denk aan het koppelen en in perspectief brengen van alle onderzoeksresultaten, dan denk ik aan Annemie Schols, mijn co-promotor. Annemie, ik kijk emaar uit het 'metabole' onderzoeksterrein samen met jou verder te verkennen en te verdiepen.

Rob Lamers, je stond elke dinsdagochtend weer enthousiast klaar om de HRCT scans van COPD patiënten met en zonder 'de bommen' te maken. Ik heb de fijne samenwerking met je erg gewaardeerd! Lia en Sandra van de afdeling Nucleaire Geneeskunde wil ik bedanken voor hun hulp bij het aanleren van de DEXA scans. Gabrie, Hans en Jean van het metabole lab van de vakgroep Algemene Heelkunde wil $i k$ bcdanken voor al hun inspanningen bij het opzetten en uitvoeren van de bepalingen. Die aminozuurconcentraties en tracerverrijkingen van jullie zijn goud waard! Mick Deutz, je metabool inzicht en je beheersing van complexe tracermodellen is bijzonder! Dat belooft veel goeds voor de toekomst!

Het onderzoek beschreven in dit proefschrift was niet mogelijk geweest zonder het astmacentrum Hornerheide, een plek waar ik altijd met veel plezier naar toe ben gegaan. De bereidwilligheid en flexibiliteit van de medewerkers om steeds weer het beste voor patient en onderzoeker eruit te halen, is bijzonder. Belangrijke schakel hierin is Rob Mostert. Naast zijn enthousiast meedenken ter verbetering van het onderzoeksprotocol, heeft hij belangrijke stappen ondernomen om het onderzoek zo goed mogelijk te laten verlopen.

Joan Does is van onmisbare waarde geweest in mijn onderzoek. Joan, wat moest ik zonder jou beginnen! Het aantal spierbiopten, die je in de afgelopen jaren genomen hebt, zijn talrijk. Ik wil je hartelijk bedanken voor de bereidwilligheid om steeds klaar te staan voor mijn onderzoek, ondanks dat je daarnaast vaak druk bezet was met klinische taken. 
De dames van het laboratorium, Peggy, Monique, Gonnie onder leiding van Annelies wil ik bedanken voor de gezelligheid en belangstelling, en de intentie om een handje te helpen met het verwerken van de bloedmonsters wanneer het erg druk was.

De voedingsassistenten, in het bijzonder Truus en Alda, wil ik bedanken voor het steeds zorgdragen, dat de 'gezonde' controlepersonen na het onderzoek met een goed gevulde maag naar huis konden terugkeren.

Marianne en Kitty van de longfunctie wil ik bedanken voor het geduld dat zij hebben opgebracht bij het steeds maar opnieuw uitleggen aan de ongeoefende blazers (de controlepersonen) wat het verschil tussen in- en uitademen is. De bewegingsagogen Marco en Jerôme zijn onmisbaar geweest bij de uitvoering van de inspanningstesten en Paul Jansen nam de zorg op zich dat dit altijd organisatorisch gesmeerd verliep. Wanneer ik aan Clarie denk, dan denk ik aan de gezellige ritjes naar en van het astmacentrum. De verpleging, onder leiding van Jos, Coby en Leneke wil ik bedanken voor al hun inzet. Ondanks de verschillende onderzoeksprotocollen hebben jullie het overzicht kunnen behouden. Verder wil ik de secretaresses Annemiek en Gerry, de longartsen Jean en Herman-Jan, en de afdeling fysiotherapie (in het bijzonder Pauline) bedanken voor hun interesse en hun bijdrage aan het onderzoek.

Van de vakgroep Longziekten / capaciteitsgroep Pulmonologie wil ik bedanken de secretaresses en de longartsen (in opleiding) en de fijne samenwerking met de collega's, die in en rond het wetenschappelijk onderzoek betrokken waren in deze periode: Francine, Harry, Solange, Juanita, Mehmet, Ramon, Mieke, Roelinka, Esther, Tim, Esther, Eva, Diederik, Frits, Erica, Karin, Marja en André.

De leden van de beoordelingscommissie: Prof. Saris, Prof. Bast, Prof. Romijn en Prof. van der Vusse wil ik bedanken voor het beoordelen van het manuscript. In particular, I would like to thank Prof. Wasserman. I value the opportunity you provided me to enter the world of science. It is a great pleasure and honour to have you in the Referee Committee. I would like to thank Marshall Riley for his kind willingness to review a few sections of this thesis.

Gabriëlla Cleuren -de kunstenares in de familie- het mooie ontwerp op de omslag van het proefschrift komt van jouw hand. Hartelijke dank hiervoor!

Een klankbord heb ik altijd gevonden bij mijn familie. Ma, Pa en Peter-Paul, jullie liefde en niet aflatende belangstelling is bijzonder. Mijn maatje, door dik en dun, heb ik gevonden in Mick. 

Publicaties 
- Engelen MPKJ, Schols AMWJ, Baken WC, Wesseling GJ, Wouters EFM. Nutritional depletion in relation to peripheral skeletal and respiratory muscle function in out-patients with COPD. Eur. Resp. J. 1994;7:1793-1797

- Engelen MPKJ, Casaburi R, Rucker R, Carithers E. Contribution of the respiratory muscles to the lactic acidosis during heavy exercise in chronic obstructive pulmonary disease. Chest 1995;108;5:1246-1251

- Engelen MPKJ, Pórszász J, Riley MS, Maehara K, Wasserman K, Barstow TJ. Effects of hypoxic hypoxia on $\mathrm{O}_{2}$ uptake and heart rate kinetics during heavy exercise. J. Appl. Physiol. 1996;82:2500-2508

- Riley MS, Maehara K, Pórszász J, Engelen MPKJ, Barstow TJ, Tanaka H, Wasserman K. Association between the anaerobic threshold and the break-point in the double product / work rate relationship. Eur. J. Appl. Physiol. $1997 ; 75: 14-21$

- Riley MS, Pórszász J, Miranda J, Engelen MPKJ, Brundage BH, Wasserman K. Exhaled nitric oxide during exercise in primary pulmonary hypertension and pulmonary fibrosis. Chest. 1997; 111:44-50

- Engelen MPKJ, Schols AMWJ, Heidendal GAK, Wouters EFM. Dual-energy $\mathrm{X}$-ray absorptiometry in the clinical evaluation of body composition and bone mineral density in patients with chronic obstructive pulmonary disease. Am. J. Clin. Nutr. 1998;68:1298-1303

- Engelen MPKJ, Schols AMWJ, Lamers RJS, Wouters EFM. Different patterns of chronic tissue wasting among patients with chronic obstructive pulmonary disease. Clin. Nutr. 1999;18:275-280

- Engelen MPKJ, Schols AMWJ, Does JD, Deutz NEP, Wouters EFM. Altered glutamate metabolism is associated with reduced muscle glutathione levels in patients with emphysema. Am. J. Respir. Crit. Care Med. 2000;161:98-103

- Engelen MPKJ, Schols AMWJ, Does JD, Wouters EFM. Skeletal muscle weakness is associated with extremity fat-free mass wasting but not with airflow obstruction in patients with COPD. Am. J. Clin. Nutr. 2000;71:733-738

- Engelen MPKJ, Deutz NEP, Wouters EFM, Schols AMWJ. Enhanced whole body protein turnover in patients with chronic obstructive pulmonary disease. Am. J. Respir. Crit. Care Med. 2000;162:1488-1492 
- Riley MS, Pórszász J, Engelen MPKJ, Shapiro SM, Brundage BH, Wasserman $\mathrm{K}$. Responses to constant work rate bicycle ergometry exercise in primary pulmonary hypertension: the effect of inhaled nitric oxide. J. Am. Coll. Cardiol. 2000;36:547-556

- Riley MS, Pórszász J, Engelen MPKJ, Brundage BK, Wasserman K. Gas exchange responses to continuous incremental cycle ergometry exercise in primary pulmonary hypertension in humans. Eur. J. Appl. Physiol. 2000;83:6370

- Engelen MPKJ, Schols AMWJ, Does JD, Deutz NEP, Wouters EFM. Factors contributing to alterations in skeletal muscle and plasma amino acid profiles in patients with chronic obstructive pulmonary disease. Am. J. Clin. Nutr. 2000;72: In press

- Engelen MPKJ, Schols AMWJ, Does JD, Deutz NEP, Wouters EFM. Excrciseinduced lactate increase in relation to muscle substrates in patients with chronic obstructive pulmonary disease. Am. J. Respir. Crit. Care Med. 2000;162; In press

- Engelen MPKJ, Wouters EFM, Deutz NEP, Does JD, Schols AMWJ. Effects of excrcise on amino acid metabolism in patients with chronic obstructive pulmonary disease. Am. J. Respir. Crit. Care Med. 2000; In press

- Engelen MPKJ, Deutz NEP, Wouters EFM, Mostert R, Schols AMWJ. Suppressed response in whole body protein turnover to exercise in patients with chronic obstructive pulmonary disease. Submitted

- Gosker HR, van Mameren H, van Dijk P, Engelen MPKJ, van der Vusse GJ, Wouters EFM, Schols AMWJ. Fiber type redistribution and altered oxidative capacity in the vastus lateralis of patients with COPD. Submitted 

Curriculum Vitae 


\section{CURRICULUM VITAE}

Mariëlle P.K.J. Engelen werd geboren op 6 september 1969 te Weert. In 1988 behaalde zij het VWO- $\beta$ diploma aan het Bisschoppelijk College te Weert. In datzelfde jaar startte zij met de studie Gezondheidswetenschappen aan de Universiteit Maastricht, met als afstudeerrichting Bewegingswetenschappen. Zij behaalde het doctoraal examen in 1992. Vervolgens heeft zij gedurende 9 maanden als 'research associate' gewerkt bij de Division of Respiratory and Critical Care Medicine van Harbor U.C.L.A. Medical Center te Torrance, U.S.A., onder leiding van Prof. dr. K. Wasserman, Dr. T. Barstow en Prof. dr. R. Casaburi. In 1994 werd ze onderzoeksassistent en vervolgens in 1995 assistent in opleiding (A.I.O.) bij de capaciteitsgroep Pulmonologie, Universiteit Maastricht, onder leiding van Prof. dr. E. Wouters en Dr. A. Schols. In 1997 kreeg ze een research fellowship van de European Society of Parenteral and Enteral Nutrition. In 2000 kreeg zij een projectsubsidie van het Nederlands Astmafonds. Het onderzoek beschreven in het proefschrift werd uitgevoerd in nauwe samenwerking met het astmacentrum Hornerheide te Horn. Momenteel is ze werkzaam als post-doc bij de capaciteitsgroep Pulmonologie van de Universiteit Maastricht. 

